\title{
Isolation and characterisation of antibodies against colorectal cancer antigens by phage antibody display
}

Citation for published version (APA):

Roovers, R. C. (2000). Isolation and characterisation of antibodies against colorectal cancer antigens by phage antibody display. [Doctoral Thesis, Maastricht University]. Universiteit Maastricht. https://doi.org/10.26481/dis.20001214rr

Document status and date:

Published: 01/01/2000

DOI:

10.26481/dis.20001214rr

Document Version:

Publisher's PDF, also known as Version of record

\section{Please check the document version of this publication:}

- A submitted manuscript is the version of the article upon submission and before peer-review. There can be important differences between the submitted version and the official published version of record.

People interested in the research are advised to contact the author for the final version of the publication, or visit the DOI to the publisher's website.

- The final author version and the galley proof are versions of the publication after peer review.

- The final published version features the final layout of the paper including the volume, issue and page numbers.

Link to publication

\footnotetext{
General rights rights.

- You may freely distribute the URL identifying the publication in the public portal. please follow below link for the End User Agreement:

www.umlib.nl/taverne-license

Take down policy

If you believe that this document breaches copyright please contact us at:

repository@maastrichtuniversity.nl

providing details and we will investigate your claim.
}

Copyright and moral rights for the publications made accessible in the public portal are retained by the authors and/or other copyright owners and it is a condition of accessing publications that users recognise and abide by the legal requirements associated with these

- Users may download and print one copy of any publication from the public portal for the purpose of private study or research.

- You may not further distribute the material or use it for any profit-making activity or commercial gain

If the publication is distributed under the terms of Article $25 \mathrm{fa}$ of the Dutch Copyright Act, indicated by the "Taverne" license above, 
Isolation and characterisation of antibodies against colorectal cancer antigens by phage antibody display 


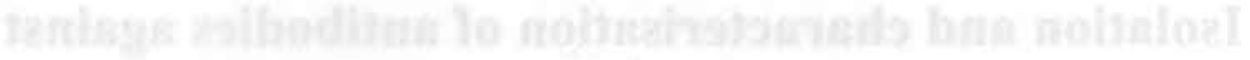

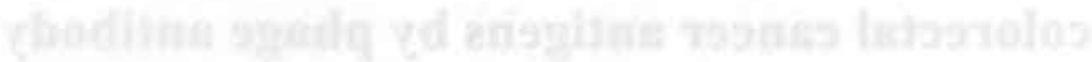
valchib 


\section{Isolation and characterisation of antibodies against colorectal cancer antigens by phage antibody display}

\section{PROEFSCHRIFT}

ter verkrijging van de graad van doctor aan de Universiteit Maastricht, op gezag van de Rector Magnificus,

Prof. dr. A.C. Nieuwenhuijzen Kruseman, volgens het bes!uit van het College van Decanen, in het openbaar te verdedigen op donderdag 14 december 2000 om 14.00 uur

door

Robertus Comelis Roovers

Geboren op S September 1971 te Tilburg: 


\section{Promotor}

Prof. dr. J.W. Arends

\section{Co-promotores}

Dr. ir. H.R. Hoogenboom

Dr. A.P. de Bruïne

\section{Beoordelingscommissie}

Prof. dr. J. Wagstaff (voorzitter)

Prof. dr. J.W. Cohen Tervaert

Prof. dr. G.A. Heidendal

Prof. dr. L.F. de Leij (Rijksuniversiteit Groningen)

Prof. dr. D. Neri (ETH Zürich, Zwitserland)

The publication of this thesis was financially supported by:

Target Quest' BY (Maastricht, the Netherlands), a wholly owned subsidiary of Dyax Corp. (USA) and

Biotechnology Application Centre BV (BAC, Naarden, the Netherlands). 


\section{Voor's-pap}

Alors sans avoir rien

que la force d'aimer.

Nous aurons dans nos mains, ami le monde entier!

J. Brel 


\section{Table of Contents}

$\begin{array}{lll}\text { Chapter } 1 & \text { Introduction } & 9\end{array}$

$\begin{array}{lr}\text { 1. Colorectal carcinoma } & 10\end{array}$

2. The first generation of cancer targeting antibodies 11

2.1 The use of murine antibodies 11

2.2 Improving the effector functions of "naked" antibodies 13

3. Improving anti-cancer antibodies by molecular engineering 14

4. Recombinant antibodies in cancer targeting 15

5. Tumour antigens for antibody-mediated cancer targeting 16

5.I Identification of tumour antigens $\quad 16$

5.2 Tumour antigens in colorectal carcinoma $\quad 17$

5.3 The Epithelial Cell Adhesion Molecule (Ep-CAM) 17

6. Display technology based antibodies and tumour antigens for cancer 19 targeting

6.1 Phage display technology 19

6.2 Antibody phage display for target identification 19

7. Aim and outline of this thesis 20

Chapter 2 Antibody phage display technology and its applications 31

Chapter 3 High affinity recombinant phage antibodies to the pan-carcinoma marker epithelial glycoprotein-2 for tumour targeting

Chapter 4 Design and application of Diabodies, Triabodies and Tetrabodies for 81 cancer targeting

Chapter 5 Guided Selection of a Pan Carcinoma Specific Antibody Reveals

Similar Binding Characteristics yet Structural Divergence Between the Original Murine Antibody and its Human Equivalent

Chapter 6 In vitro characterisation of a monovalent and bivalent form of a fully human anti Ep-CAM phage antibody

Chapter 7 Model systems to study the parameters determining the success of phage antibody selections on complex antigens

Chapter 8 Identification of colon tumour-associated antigens by phage antibody selections on primary colorectal carcinoma

Chapter 9 Evidence for a bias towards intracellular antigens in the local humoral anti-tumour immune response in a colorectal cancer patient revealed by phage display 
Chapter 10 Epilogue

Summary

Samenvatting

Dankwoord

228

Curriculum Vitae

230

List of publications

231 


\section{Abbreviations used in the text}

Ag: antigen

AMP: ampicillin

APTS: 3-aminopropyl-tri ethoxy silane

CHI: first constant domain of the heavy chain of antibody molecules

CDR: complementarity determining region

cfu: colony forming unit

CRC: colorectal carcinoma

DAB: di-aminobenzidin

DMSO: dimethylsulfoxide

EC: Endothelial cell

E.coli: Escherichia coli

EGP-2: epithelial glycoprotein-2

ELISA: enzyme linked immunosorbent assay

Fab: antigen-binding fragment of antibody molecules

FACS: fluorescence activated cell sorting

FR: framework

Fv: variable fragment (of $\mathrm{Ig}$ )

gIII: bacteriophage gene III

HEL: hen egg lysozyme

HLA: human leukocyte antigen

hrs.: hours

HRP: horse raddish peroxydase

HUVEC: Human Umbilical Vein Endothelial Cell

Ig: immunoglobulin

IMAC: immobilised metal ion affinity chromatography

i.v.: intravenously

kDa: kiloDalton

$\mathbf{k}_{\text {or }}$ kinetic off-rate constant

$\mathbf{k}_{\mathrm{on}}$ : kinetic on-rate constant

mAb: monoclonal antibody

min: minutes

$\mathrm{MW}$ : molecular weight

NP-40: Nonidet P40

pIII: bacteriophage protein III, product of the gene III

PBS: phosphate buffered saline

PCR: polymerase chain reaction

PEG: polyethylene glycol

PMSF: phenylmethylsulfonyl fluoride ( $\alpha$-toluenesulfonyl fluoride)

psp: phage shock promoter

rt: room temperature

s: seconds

seFv: single-chain Fv

SCLC: small cell lung cancer

SDS: sodium duodecyl sulphate

SPR: surface plasmon resonance

$\mathrm{V}$ : variable

$\mathrm{V}_{\mathrm{H}}$ : variable domain of the heavy chain of Ig molecules

$V_{1}$ : variable domain of the light chain of Ig molecules

TET: tetracyclin

TIL: tumor infiltrating lymphocyte

TU: transforming units

$\Phi$ : phage 


\section{Chapter 1}

\section{Introduction}

Rob C. Roovers 


\section{Colorectal carcinoma}

Colorectal carcinoma (CRC) is the third most common cancer in the Western World, only preceded by lung cancer, breast cancer among women and prostate cancer among men. The mortality due to this type of cancer has not declined over the last years [1]. Surgery is the only curative treatment option for patients with low stage CRC. Other treatment modalities, such as chemotherapy and radiotherapy, are mostly given in an adjuvant setting to reduce the risk of recurrences after surgical removal of the primary tumour. Staging of CRC is based on the depth of invasion of the primary tumour $(\mathrm{T})$, the extent of lymph node involvement $(\mathrm{N})$ and the presence of distant metastases, (M), called the "TNM-classification" [2,3]. Also frequently used is the Dukes' classification: Table 1. Adjuvant treatment is mandatory for patients with stage III colon cancer. At present, 6 months of fluorouracil (5-FU) plus leucovorin (folinic acid) can be considered standard therapy. Recently, the dose of folinic acid given and the possible combination of this treatment with levamisole were investigated and shown not to have any beneficial effect [4]. Despite debulking surgery and adjuvant treatment, the prognosis for advanced stages of the disease remains relatively poor (Table 1).

Table $\mathbf{1}^{*}$

Dukes' staging system for colorectal cancer

\begin{tabular}{|c|c|c|}
\hline Stage & Description & 5-year survival: \\
\hline$A$ & $\begin{array}{l}\text { Confined to bowel wall, i.e. mucosa and } \\
\text { submucosa, or early muscular invasion }\end{array}$ & $>90 \%$ \\
\hline B & $\begin{array}{l}\text { Invasion through the muscle wall but no lymph } \\
\text { node involvement }\end{array}$ & $70-85 \%$ \\
\hline $\mathrm{Cl}$ & $\begin{array}{l}\text { Lymph node involvement, but not up to } \\
\text { highest point of vascular ligation }\end{array}$ & \multirow[t]{2}{*}{$25-65 \%$} \\
\hline $\mathrm{C} 2$ & $\begin{array}{l}\text { Nodes involved up to highest nodes at the } \\
\text { point of ligation }\end{array}$ & \\
\hline $\mathrm{D}$ & Distant metastases to other organs & $<5 \%$ \\
\hline
\end{tabular}

* adapted from [5] 
The relatively low percentage of patients having Dukes' C CRC that survives 5 years indicates that despite surgery and adjuvant chemo- and radiotherapy, residual tumour cells frequently survive that eventually grow out to local recurrences or give rise to distant metastases after a variable period of dormancy. The selective killing of tumour cells by conventional therapeutic strategies usually depends on differential vulnerability of tumour cells versus normal cells for cytotoxic drugs. This limited specificity leads to systemic toxicity in patients, thereby limiting the dose that can safely be given to patients and restricting the available "therapeutic window". Therefore, alternative therapies are needed to further reduce the mortality of the discase.

\section{The first generation of cancer targeting antibodies}

Paul Ehrlich already envisioned at the beginning of last century that antibodies may be used as highly specific targeting molecules to deliver anti-tumour agents to the tumour site, thereby postulating the idea of the "magic bullet". However, efforts to use polyclonal antibody preparations, for example from horses immunised with cancer cells [6] (reviewed in [7]) were largely unsuccessful.

The historic report of the immortalisation of B-cells of a single specificity using the hybridoma technology [8] opened a route to obtain monoclonal antibodies. This technology initiated a search for antibodies reactive with cancer, involving the immunisation of mice with cancer cells, cell lines or cell-extracts and the subsequent screening of hybridomas for antibodies that bind the target cell [9-1 i]. A whole range of anti-tumour antibodies has been generated by this technique $[12,13]$, the specificity of which was not always known. In many cases, the antigens these antibodies recognised have later been identified as tumour associated antigens (i.e. structures that distinguish normal from malignant cells: see section 5) and cloned [14,15]. Ever since, antibodies have extensively been used as vehicles to specifically target and eradicate tumours (for review, see $[16,17]$ ).

\subsection{The use of murine antibodies}

The most obvious way to employ antibodies in the treatment of cancer is passive immunotherapy using antibodies directed to tumour antigens. The idea behind this treatment regime is that the specific homing of the therapeutic antibody to the tumour will recruit the natural effector mechanisms of antibodies to the tumour site, resulting in destruction of tumour cells. Dependent on their isotype, antibodies possess several natura! effector functions that may be effective in tumour eradication. These include complement mediated lysis (CML), opsonisation, the formation of immune complexes (if the antigen is shed into the circulation) and antibody-dependant cell-mediated cytotoxicity (ADCC). The latter is thought to be one of the 
major effector mechanisms by which 'naked' antibodies directed to tumour-associated antigens exert their therapeutic effect. An important enhancement of this effect may be achieved by increasing the affinity of the antibody used [18], or by using combinations of non-competing antibodies directed to the same antigen [19].

Since it is known that murine antibodies of several isotypes can interact with human $\mathrm{Fc}$ receptors, these monoclonal antibodies could mediate an anti-tumour effect. Indeed, this strategy of using intact murine IgG for cancer treatment has met with a few successes, notably in the cancer field. In an adjuvant setting, treating patients with resected Dukes' C CRC, the "Panorex" antibody, targeting the Ep-CAM antigen (see section 5.3) increased the overall 5-year survival rate with approximately $30 \%[20,21]$. However, overall response rates in patients were generally low. This can be attributed to several reasons, some of which involve the immunogenicity of murine antibodies in humans, the pharmacokinetic behaviour of antibodies in man and characteristics of solid tumours. In addition, a major problem has been the lack of tumourspecific targets. Only in the case of lymphoma, the B-cell receptor (BCR) or antibody specificity provides a tumour antigen that is truly tumour-specific and that constitutes an excellent target for antibody treatment [22]. In addition, the target antigen on the malignant cell is freely accessible from the blood. In solid tumours, however, the high molecular weight of antibodies (between 150 and $180 \mathrm{kDa}$ for $\mathrm{lgG}$, much larger for $\mathrm{IgA}$ or $\operatorname{lgM}$ ) causes their poor penetration into the tumour. In addition, the physiology of solid tumours disfavours accretion of antibody at the tumour site [23]; e.g. solid tumours frequently lack draining lymphatic vessels, which causes high interstitial fluid pressure in the tumour micro-environment, thereby further decreasing the depth of penetration of antibodies. Even more important reasons for failure of antibody treatment may be the fact that most tumour antigens are heterogeneously expressed in tumours [24] and that antigen-loss variants occur [25] that are resistant to antibody treatment [26]. The use of murine antibodies in man is further hampered by the induction of an immune response to the foreign protein, resulting in a HAMA (human anti mouse antibody) response [27], which causes toxicity in patients and frequently prevents repeated administration of antibody. In theory, however, this HAMA response could also have beneficial effects for the patient, since it may result in an antiidiotype antibody cascade.

The induction of such an anti-idiotype antibody response upon immunisation with an antibody is relatively poorly understood and its contribution to any therapeutic effect of antibody treatment is still under debate. Immunisation may induce a humoral immune response directed to the antigen-binding site of that antibody, resulting in anti-idiotype antibodies (Ab2). This in turn may cause a response to the antigen-combining site of the anti-idiotype antibody, giving rise to an anti-anti-idiotype response ( $\mathrm{Ab} 3$ or $\mathrm{Abl}^{\prime}$ ) that may partially be directed to the same epitope as the original antibody used for immunisation. The induction of this anti-idiotypic antibody 
network is generally believed to have a beneficial effect for the patient. Recently, however, it was shown that the presence of such anti-idiotype antibodies did not correlate with the clinical response of patients treated with the 17-1A anti-Ep-CAM antibody [28]. On the other hand, therapeutic strategies using anti-idiotype antibodies, designed to induce an anti-idiotype network have been shown to yield clinical responses in cancer patients [29-31], thereby proving that the anti-idiotype network may contribute to tumour eradication.

\subsection{Improving the effector functions of "naked" antibodies}

In an attempt to endow antibodies with a different, potentially more potent effector function, several new types of antibodies have been generated. Bispecific antibodies are bivalent molecules in which the two antigen-binding sites of the antibody are directed to two different antigens. Antibodies of this format were initially synthesised by fusion of two hybridomas, called tetradomas or quadromas [32], by chemical cross-linking [33,34] and later by recombinant DNA technology (see section 3). Bispecific antibodies have been used in immunotherapy of cancer to retarget important immune effector cells to tumours, e.g. by cross-linking T-cells to tumour cells [35,36], by cross-linking monocytes/macrophages to tumour cells [37] or by recruiting natural killer cells for tumour eradication $[38,39]$. A few of these molecules have now entered clinical trials with some promising results $[38,40]$. Another approach to augment the cytotoxic effect of whole antibodies is radio-immuno targeting. In radio-immuno targeting, antibodies are used as targeting vehicles to deliver radio isotopes to the tumour site. By using $\gamma$-emitting radionuclides, this strategy can be used to visualise tumours (radio-immuno-imaging) $[41,42]$ or as radioimmuno guided surgery [43] and through the use of $\beta$-emitting radionuclides, the approach can be used as therapy (radio-immuno-therapy: RIT) [44,45]. However, although many reports have emerged that describe the successful use of antibodies for radio-immuno-imaging (diagnosis) of cancer, successful RIT has been mostly limited to haematological malignancies. Again, this lack of success is partly due to unfavourable pharmacokinetic properties of antibodies and partly to tumour type. For review, see [46]. However, by means of antibody engineering and recombinant DNA technology, the format of antibodies may be optimised for this particular application (see section 3). To improve on existing protocols for RIT, bispecific antibodies have been used in two-phase radio immunotherapy (RIT). This alters and improves the uptake of radiolabel in the tumour [47]. Although promising results have been obtained in murine models for solid tumours, e.g. using bivalent chelates carrying the radio-isotope [48], clinical trials based on this targeting approach have been scarce $[49,50]$. 


\section{Improving anti-cancer antibodies by molecular engineering}

Antibody molecules are proteins consisting of four polypeptide chains: two heavy chains and two light chains. Every chain is composed of a number of discrete domains having a similar overall structure consisting of several $\boldsymbol{\beta}$ sheets forming a barrel-like structure [51]. Since the advent of the hybridoma technology [8], monoclonal antibodies of a single specificity could be generated against a broad range of target antigens. However, this technology still requires immunisation of rodents with the antigen of interest, which limits the scala of antigens that can be used to those that are immunogenic and non-toxic in vivo. As discussed, the antibodies obtained are of murine origin, which limits their usefulness as tumour targeting vehicles in man through the induction of a HAMA (human anti mouse antibody) response [27]. These limitations were partially overcome by the synthesis of chimeric molecules consisting of human Fc regions fused to murine variable regions [52-56], which substantially reduces the amount of foreign sequence in an antibody. Antibodies were even further "humanised" by grafting the antigenbinding loops (complementarity-determining regions: CDR's) of a murine antibody with known specificity onto a fully human framework [57]. Fully human antibodies have been obtained through EBV-immortalisation [58] of human B-cells, although this technique mostly yields hybridomas of poor stability (reviewed in [59]). Recently, recombinant DNA technology has permitted the cloning of genes encoding antibodies [60] and the subsequent expression of functional antibody molecules in E.coli [61-63]. Together with the development of the display of proteins on filamentous bacteriophage, this has led to the development of the phage antibody display technology [64]. The latter has permitted the isolation of a broad scala of fully human antibodies to a wide range of antigens. Finally, an even more recent development is the use of transgenic mice to generate "human" hybridomas. By endowing mice deficient in immunoglobulin production with large portions of the human immunoglobulin loci, "conventional" hybridoma technology can be used to produce fully human antibodies [65].

The cloning of the genes encoding (human) antibodies also permits the manipulation of their format to better fit the envisaged application. As smallest antigen-binding molecules. Fv and scFv have been described [61-63]. In a seFv, the variable domains of heavy- and light chain (VH and VL) are joined by a flexible peptide sequence keeping them together. By shortening this linker between VH and VL, multimeric molecules are synthesised, i.e. diabodies [66], triabodies [67] and tetrabodies [68] containing two, three and four binding sites respectively. In addition, by fusing the $\mathrm{VH}$ of antibody $\mathrm{A}$ to the $\mathrm{VL}$ of antibody $\mathrm{B}$ and vica versa, bispecific molecules can be created [66]. Minibodies are composed of two scFv moieties that are fused via a $\mathrm{CH} 3$ domain, thereby creating a bivalent antibody format [69]. This format has been shown to be well suited for cancer imaging purposes using short-lived radio-isotopes, since it combines bivalency 
with a lower molecular weight compared with whole $\operatorname{lgG}[70,71]$. Multivalent molecules have also been designed on the basis of an amphipathic helix, which causes tetramerisation of scFv moieties [72] or by linking diabodies together with a flexible linker [73]. For review, see [74]. The availability of the genes encoding anti-tumour antibodies permits their fusion with a range of molecules, limited only by the imagination-including enzymes, toxins, viruses, liposomes, cationic tails and many more (see section 4 ).

\section{Recombinant antibodies in cancer targeting}

The availability of the genes encoding antibodies opens up a range of possibilities to manipulate their format, size and valency to meet the specific requirements of the application (for review, see [75]). The development of monoclonal- and recombinant antibodies for cancer therapy has recently' culminated in the FDA approval of the first recombinant antibodies "Rituxan" (Rituximab), targeting CD20 for the treatment of non-Hodgkin's lymphoma [76,77], "Herceptin" (Trastuzumab) for therapy of metastasised breast cancer [78] and Mylotarg (Gentuzumab zogamicin) for the treatment of acute myeloid leukaemia (AML). These antibodies are either chimeric (Rituximab) or humanised (Herceptin and Mylotarg) versions of murine monoclonal antibodies. Indeed, most of the antibodies which are currently being tested in clinical trials are humanised antibodies, the technology for which was developed towards the end of the eighties. However, Mylotarg is the first antibody-targeted chemotherapy for cancer treatment. This illustrates the time needed to develop a promising research candidate antibody into a clinical grade product and explains why the novel engineering methods described have not yet been translated into clinically better products. As discussed, antibody engineering has made it possible to adapt and optimise the format (i.e. valency, size, charge, flexibility,....) of antibodies to meet the requirements of the application, being either visualisation or treatment of the tumour. An illustrative example of the use of a recombinant antibody in the diagnosis of cancer is given by the development and application of the anti-CEA scFy MFE-23. First, immunisation of mice and antibody phage display was used to obtain a high affinity scFv fragment against CEA [79]. This antibody fragment was subsequently engineered to incorporate a C-terminal peptide tag to directly label the protein with the commonly used ${ }^{99} \mathrm{~m} \mathrm{Cc}$ radionuclide [80] for tumour imaging. Finally, this recombinant MFE-23 scFv was shown to be a valuable tool for radio-immuno imaging of cancer patients [81] and for radio-immuno guided surgery [82]. In adidition, fusion molecules are being made between the scFv and carboxypeptidase G2 $[83,84]$ to further improve on antibody-dependent enzyme prodrug therapy (ADEPT). For excellent reviews on the use of recombinant antibodies in cancer targeting and therapy, see $[85,86]$. 


\section{Tumour antigens for antibody-mediated cancer targeting}

Although these novel engineering strategies may lead to large improvements in the design and generation of antibodies for cancer targeting and therapy, the success of the use of these recombinant antibodies heavily depends on the availability of suitable tumour antigens. Tumour specific epitopes (i.e. proteins, part of proteins, post translational modifications of proteins, lipid or carbohydrate structures) that distinguish malignant cancer cells from their normal counterparts, may arise through a number of mechanisms: de novo expression of an antigen on otherwise antigen-negative tissue [87], through mutation of the gene coding for the protein [88], through the expression of different splice variants of a protein [89], through demethylation of the promolor region of the gene [90] or through aberrant post-translational modification [91]. In addition, overexpression of normal proteins can give rise to tumour-associated antigens $[92,93]$. The latter are not tumour specific in the strict sense, but distinguish tumour from normal tissue by the amount of antigen expressed in the tissue.

Ideally and theoretically, the perfect mmour antigen for antibody-based targeting should have a number of characteristics. Some of the most important ones are: it should be homogeneously and strongly expressed on the cell surface in malignant, but not in non-malignant tissues. In addition, it should not be shed from the cell surface, since this would cause the forming of unwanted antibody-antigen complexes in the circulation. For antibody-based targeting of toxins, the antigen should be internalised upon antibody binding. Finally, the protein should possess a biological role that is indispensable for the survival of the tumour cell, e.g. a growth factor receptor. Such a phenomenon would cause antigen-loss variants of the tumour not to survive, thereby augmenting the therapeutic effect of antibody targeting.

\section{S.I Identification of tumour antigens}

The hybridoma technology described earlier (see section 2) has also been extensively used in the search for new target antigens expressed in cancer. Again, this has involved the immunization of mice and the subsequent screening of hybridomas for antibodies with the desired specificity [9-11]. In addition, tumour antigens have been identified by the cloning of T-cells that recognise MHC-I restricted peptides derived from the antigen [94-96]. Phage display of antibody fragments [64] (see chapter $\mathbb{l}$ of this thesis) has also been used as a tool for the identification of antigens expressed in tumours. This has involved the selection of phage antibody repertoires on tumour material and the subsequent screening for antibodies with reactivity towards the fumour $[97,98]$. More recently, genetic approaches are increasingly being used to define genes that are associated with malignant transformation [99-103] or to define distinct genetic subtypes of a malignancy [104] at the transcriptional level. Although this approach will 
certainly identify a number of new genes that are useful tumour targets, it does not directly provide information on the in vivo immunogenicity of the expressed protein.

\subsection{Tumour antigens in colorectal carcinoma}

A number of antigens has been described as tumour-antigen in CRC. Among these are a number of intracellular proteins functioning as transcription factors (P53, c-myc) or as signal transduction molecules (Ras), but also cell-surface expressed molecules which could be used as target for immunotargeting: CEA, Ep-CAM, blood group related antigens (e.g. Le(x), Le(y).... [105]), several mucin-like molecules and carbohydrate epitopes (e.g. Tn, sTn) and an antigen related to the annexin family of proteins (28A32-32K). In addition, several growth factor receptors have been described to be over expressed in CRC, notably the c-ERB-2 gene product. The GA733-2 antigen or Ep-CAM (epithelial cell adhesion molecule) is discussed in more detail, since part of the work described in this thesis focuses on this protein.

\subsection{The Epithelial Cell Adhesion Molecule (Ep-CAM)}

The Epithelial Cell Adhesion Molecule (Ep-CAM; also known as Epithelial Glycoprotein-2 (EGP-2), 17-1A antigen or GA733-2 antigen) is a member of the class of furnourassociated antigens. The antigen is a glycosylated type I transmembrane protein, originally described as a cluster of reactivity of murine antibodies directed to lung cancer cell lines $[15,106]$. The cDNA encoding the antigen was independantly cloned by four different groups [107-110]. It has homology to nidogen, a basement membrane protein [110] and comprises a cysteine-rich $\mathrm{N}$-terminal part containing two Epidermal-Growth-Factor (EGF)-like repeats, a 23 amino acid transmembrane domain and a 26 amino acid C-terminal cytoplasmic tail (Fig. 1). The function of the antigen is still only partially known. Ep-CAM has been shown to act as a homophilic cell adhesion molecule $[113,114]$ and to influence the cadherin-based intercellular junctions $[115,116]$. The $\mathrm{C}$-terminal cytoplasmic tail has been shown to regulate the intercellular adhesion functions and to contain two actinin binding sites [117] via which it is linked to the actin-based cytoskeleton. However, its role in colorectal carcinogenisis and in particular metastatic spread of the disease, is somewhat contradictory. The antigen is upregulated on carcinomas of different origin [ 92,118$]$, but when transfected into antigen negative-cells, it increases cellular adhesion and decreases their metastatic potential $[119,120]$. On the other hand, Ep-CAM has been shown to modulate cadherin-based intercellular junctions, causing a redistribution of $\mathrm{E}$-cadherin and catenins and a downregulation of $\alpha$-catenin in transfected $\mathrm{L}$-cells and epithelial cells [115]. This suggests that increased expression of Ep-CAM may lead to a decrease of the number of cadherin-based junctions, thereby possibly destabilising intercellular contacts and promoting metastasis. The murine homologue of Ep-CAM has been shown to be 
expressed by developing thymocytes and thymic dendritic cells, suggesting a role in lymphostromal interactions during thymocyte development [121]. For an excellent review of the biology of the antigen, see Balzar et al. [111].

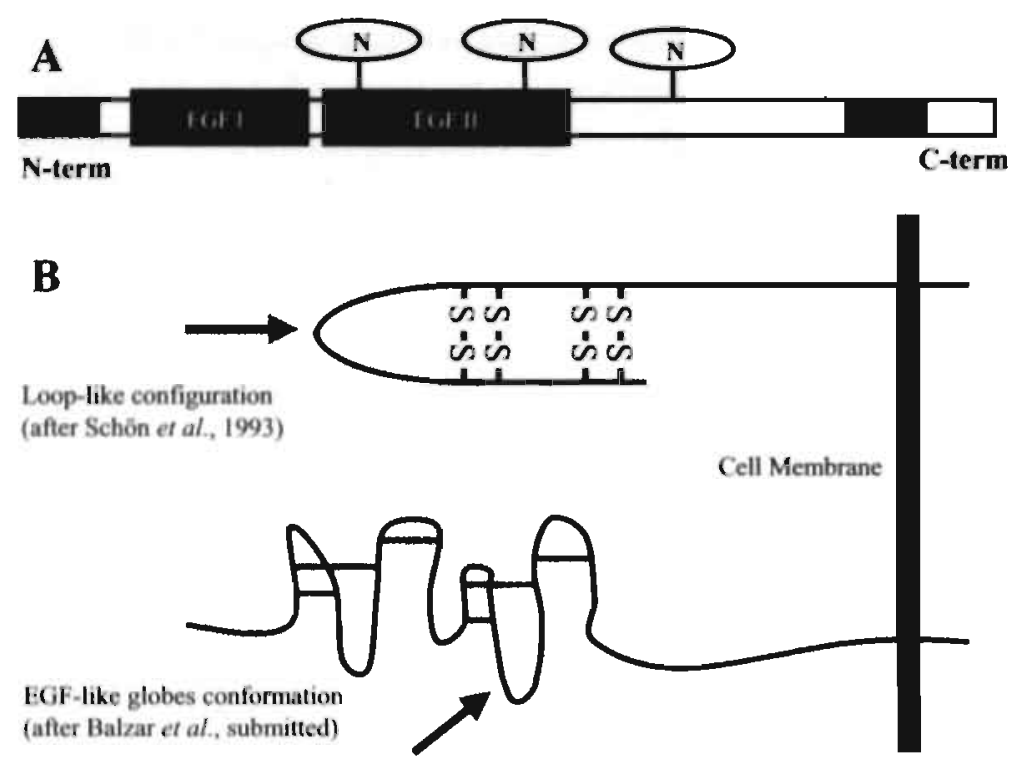

\section{Figure 1}

Structure of the Ep-CAM antigen (reprinted from [111]).

A: schematic representation of the Ep-CAM polypeptidebackbone showing the $\mathrm{N}$-terminai signal peptide (sp), the EGF-like repeats in the extracellular domain (EGFI and EGFII) and transmembrane domain (TM). Oval circls containing an " $\mathrm{N}$ " indicate sites for $\mathrm{N}$-glycosylation.

B: Conformation of the Ep-CAM molecule. The disulphide bridges formed between cysteine residues in the $\mathrm{N}$ terminai half of the extracellular domain may result in two conformational models for the molecule: a foop-like conformation, as postulated by [112] and a model based on correct folding of the EGF-like repeats. The black arras indicates the potential proteolytic cleavage site at the position of Arg80.

Although Ep-CAM has extensively and successfully been used as tumour target (see section 2), the problems encountered in clinical trials using high affinity antibodies [122] to this antigen emphasise its limitations as tumour target. Therefore, an urgent need exists for the identification and validation of new and ideally more specific tumour targets. 


\section{Display technology based antibodies and tumour antigens for cancer targeting}

\subsection{Phage display technology}

The display of foreign molecules on the surface of filamentous bacteriophage was first described in 1985 by George Smith, who showed that short peptides could be expressed on the surface of phage by fusion to one of the minor coat proteins [123]. The genes encoding peptides were genetically fused to the gene of one of the coat proteins of the bacteriophage, which, after infection into E.coli, caused these peptides to be displayed on the tip of the phage. Since one particular phage only expresses one peptide, genotype and phenotype are linked. This linkage permits the selection of rare phage carrying a peptide of interest by means of the characteristics of the peptide and the simultaneous co-selection of the encoding gene. In 1990 it was shown that the antigen-binding moiety of an antibody (as scFv) could also be expressed in this system [64] while retaining the epitope specificity of that antibody. The synthesis of phage antibody libraries was reported in 1991 with the successful selection of antibody specificities from large collections of randomly paired heavy- and light chain genes [124]. This then led to the development of large, non-immunised 'single pot' human phage antibody repertoires [125], from which antibodies with specificities to a wide range of epitopes could be obtained, including non-immunogenic and "self"-antigens [126]. In addition, it provides the genes encoding the selected antibodies for the subsequent engineering of the format for any envisaged application.

\subsection{Antibody phage display for target identification}

To date, only a limited number of antigens expressed by tumours that are useful for tumour targeting have been described. Novel tumour antigens may possibly be identified by differential selection using large 'single pot' phage antibody repertoires. And since phage display works outside the immune system [125], these repertoires will also contain antibodies to nonimmunogenic and self-antigens [126], thereby avoiding possible restrictions induced by in viva tolerance mechanisms. Thus, by using a powerful selection procedure for phage library selection on cell surfaces, it may be possible to identify novel tumour antigens by virtue of the antibodies that recognise them. Therefore, this technology may be an ideal tool to use in the identification of possibly novel antigens expressed in CRC. 


\section{Aim and outline of this thesis}

The work presented in this thesis focuses on two goals in the tumour immunology $/$ immunotherapy of colorectal carcinoma: 1) the selection and development/engineering of fully human antibodies to known colon tumour antigens and 2) the identification of possibly novel antigens expressed in CRC.

Chapter one gives a detailed description of the phage antibody display technology and of its possible applications. It highlights the many possibilities, but also the limitations of the technique and extensively describes the possible applications.

The tumour antigen Ep-CAM has been shown to be a promising target antigen, especially for the visualisation of solid tumours $[41,127]$, but also for treatment of minimal residual disease $[20,21]$. Since it is known that the affinity of an antibody (and especially the off-rate) is an important parameter for efficient tumour targeting, we first conducted a systematic analysis of the kinetics of binding of several well-characterised murine anti-Ep-CAM antibodies. In chapter two we then aimed at the isolation of the V-genes of the highest affinity antibody to obtain building blocks for the rational design and engineering of antibodies.

Using antibody engineering, the format of antibodies may be adapted and optimised for almost any given application. It has been shown that the apparent affinity of an antibody may be increased through avidity, i.e. multiple binding sites being present in the same molecule. To further increase the affinity of the anti-Ep-CAM antibody through avidity, multivalent forms of this antibody were designed and synthesised. Chapter three describes the design and applications of these multivalent molecules for cancer targeting.

The use of murine antibodies in humans is limited by the induction of an immune response to the foreign molecule, called HAMA response [27]. Therefore, to improve the applicability of the murine anti-Ep-CAM antibody described in chapter two for tumour targeting, we aimed at the humanisation of this antibody. Chapter four reports this humanisation through a phage display procedure termed "guided selection".

The influence of the exact epitope specificity of anti-Ep-CAM antibodies on their tumour targeting properties is not known. Thus, a human antibody recognising an epitope on the antigen different from that of the well-characterised murine hybridomas may offer advantages in tumour targeting. In chapter six, therefore, in parallel to the studies described in chapters two and four, we aimed at the isolation of such antibodies by performing selections on recombinant, purified Ep-CAM using a large, human, non-immunised phage antibody repertoire. To obtain an antibody format that is well-suited for the imaging of solid tumours, we additionally engineered and reformatted the genes of the selected antibody into the minibody format [69].

When the phage antibody display technology is used to search for antigenic (and possibly 
novel) antigens on CRC, the target antigen is unknown and phage antibody selections have to be performed on complex mixtures of antigens (e.g. cell surfaces or tissue sections of patient material). To determine whether phage antibody selections on these complex antigen sources are feasible and to compare their relative efficiency in the selection of binding phage, we have set up model systems to study these selections. These models and the conclusions that can be drawn from them are described in chapter six.

Large, "non-immunised" phage antibody repertoires [125,128-130] are not biased by any tolerance mechanisms of the in vivo immune system and are therefore suitable for the selection of anti-tumour antibodies, since the latter may consist of (mutated) "self"-antigens. In chapter seven, we aimed at the identification of novel cell surface-expressed antigens in CRC. To this aim, a large, non-immunised human phage antibody repertoire was used to select antibodies that recognise $\mathrm{CRC}$-associated antigens.

On the other hand, the in vivo immunogenicity of a number of tumour antigens has clearly been demonstrated by serum IgG titers to that antigen [13 -134]. Thus, lymphoid tissue of cancer patients may also be a valuable source of V-genes encoding anti tumour antibodies. In addition, the identification of these antigens causing an immune response in patients will lead to a better understanding of this response and could eventually provide handles for vaccine development. Therefore, we synthesised phage antibody repertoires made from different, CRC patient-derived lymhoid tissues and compared these repertoires with a large, non-immunised repertoire for the selection of antibodies reactive with patient tumours.

\section{References}

1. Bailar JC 3rd, Gomik HL (1997) Cancer undefeated. N. Engl. J. Med. 336: 1569-1574

2. Wood DA (1970) The TNM system of classification for gastrointestinal cancer. Proc. Natl. Cancer Conf. 6: 403-415

3. Wood DA (1971) Clinical staging and end results classification: TNM system of clinical classification as applicable to carcinoma of the colon and rectum. Cancer. 28: 109-114

4. QUASAR Collaborative Group (2000) Comparison of flourouracil with additional levamisole, higher-dose folinic acid, or both, as adjuvant chemotherapy for colorectal cancer: a randomised trial. QUASAR Collaborative Group. The Lancel 355: 1588-1596

5. Souhami R, Tobias J (1995) Cancer and its management. Blackwell Science Lid., London, p309

6. Scherer E, Van Dijk WF, Emmelot P (1976) The effect of antilymphocytic and nomal horse serum on growth of precancerous foci and development of tumours induced by diethylnitrosamine in rat liver, Eur. J. Cancer 12: 25-31

7. Heyworth MF (1982) Clinical experience with antilymphocyte serum. Immunol. Rev: 65 : 79-97

8. Kohler G, Milstein C (1975) Continuous cultures of fused cells secreting antibody of 
predefined specificity. Nature 256: 495-497

9. Carrel S, Accolla RS, Carmagnola AL, Mach JP (1980) Common human melanomaassociated antigen(s) detected by monoclonal antibodies. Cancer Res. 40: 2523-2528

10. Morgan AC Jr, Woodhouse CS, Knost JA, Abrams PG, Clarke GC, Arthur LO, McIntyre R, Ochs JJ, Foon KA, Oldham RK (1984) Monoclonal antibodies to human colorectal tumor-associated antigens: improved elicitation and subclass restriction. Hybridoma $\mathbf{3}$ : 233-245

I1. Verstijnen CP, Arends JW, Moerkerk PT, Pijls M, Kuypers-Engelen B, Bosman FT (1989) Colonic epithelium reactive monoclonal antibodies. Identification and immunohistochemical localization of the target epitopes. Histochemistry 92: 397

12. Herlyn M, Steplewski Z, Herlyn D, Koprowski H (1979) Colorectal carcinoma-specific antigen: Detection by means of monoclonal antibodies. Proc. Natl. Acad. Sci. U.S. A. 76: 1438-1442.

13. Edwards DP, Grzyb KT, Dressler LG, Mansel RE, Zava DT, Sledge GW Jr, McGuire WL (1986) Monoclonal antibody identification and characterization of a $\mathrm{Mr} 43,000$ membrane glycoprotein associated with human breast cancer. Cancer Res. 46: 1306-1317

14. Ligtenberg MJ, Vos HL, Gennissen AM, Hilkens J (1990) Episialin, a carcinomaassociated mucin, is generated by a polymorphic gene encoding splice variants with alternative amino termini. $\boldsymbol{J}$. Biol. Chem. 265: 5573-5578

15. De Leij L, Helfrich W, Stein R, Jules Mattes M (1994) SCLC-cluster-2 antibodies detect the pancarcinoma/epithelial glycoprotein EGP=2. Int. J. Cancer Supplement 8: 60-63

16. Waldmann TA (1991) Monoclonal antibodies in diagnosis and therapy. Science 252: $1657-1662$

17. Welt S, Ritter G (1999) Antibodies in the therapy of colon cancer. Semin. Oncol. 26: 683690

18. Velders MP, van Rhijn CM, Oskam E, Fleuren GJ, Warnaar SO, Litvinov SV (1998) The impact of antigen density and antibody affinity on antibody-dependent cellular cytotoxicity: relevance for immunotherapy of carcinomas. Br. J. Cancer 78: 478-483

19. Fogler WE, Klinger MR, Abraham KG, Gottlinger HG, Riethmuller G, Daddona PE (1988) Enhanced cytotoxicity against colon carcinoma by combinations of noncompeting monoclonal antibodies to the 17-1A antigen. Cancer Res. 48: 6303-6308

20. Riethmüller G, Schneider-Gädicke E, Schlimok G, Schmiegel G, Raab R, Höffken K, Gruber R, Pichlmaier H, Hirche H, Pichlmayer R, Buggisch P, Witte J (1994) Randomized trial of monoclonal antibody for adjuvant therapy of resected Dukes' $\mathrm{C}$ colorectal carcinoma. The Lancet 343: 1177-1183

21. Riethmüller G, Holz E, Schlimok G, Schmiegel W, Raab R, Hoffken K, Gruber R, Funke I. Pichlmaier H, Hirche H, Buggisch P, Witte J, Pichlmayr R (1998) Monoclonal antibody therapy for resected Dukes' $\mathrm{C}$ colorectal cancer: seven-year outcome of a multicenter randomized trial. J. Clin. Oncol. 16: 1788-1794

22. Meeker TC, Lowder J, Maloney DG, Miller RA, Thielemans K, Warnke R, Levy R (1985) A clinical trial of anti-idiotype therapy for B cell malignancy. Blood 65: 1349 1363

23. Kievit E, Pinedo HM, Schluper HM, Haisma HJ, Boven E (1997) Determination of tumor-related factors of influence on the uptake of the monoclonal antibody 323/A3 in experimental human ovarian cancer. Int. J. Cancer 71: 237-245 
24. Fleuren GJ, Gorter A, Kuppen PJ, Litvinov S, Warnaar SO (1995) Tumor heterogeneity and immunotherapy of cancer. Immunol. Rev. 145: 91-122

25. Uyttenhove C, Maryanski J, Boon T (1983) Escape of mouse mastocytoma P815 after nearly complete rejection is due to antigen-loss variants rather than immunosuppression. J. Exp. Med. 157: 1040-1052

26. Davis TA, Czerwinski DK, Levy R (1999) Therapy of B-cell lymphoma with anti-CD20 antibodies can result in the loss of CD20 antigen expression [see comments]. Clin. Cancer Res. 5: 611-615

27. Khazaeli MB, Conry RM, LoBuglio AF (1994) Human immune response to monoclonal antibodies. J. Immunother. 15: 42-52

28. Gruber R, van Haarlem LJ, Warnaar SO, Holz E, Riethmuller G (2000) The human antimouse immunoglobulin response and the anti-idiotypic network have no influence on clinical outcome in patients with minimal residual colorectal cancer treated with monoclonal antibody CO17-1A. Cancer Res. 60: 1921-1926

29. Robins RA, Denton GW, Hardcastle JD, Austin EB, Baldwin RW, Durrant LG (1991) Antitumor immune response and interleukin 2 production induced in colorectal cancer patients by immunization with human monoclonal anti-idiotypic antibody. Cancer Res. 51: $5425-5429$

30. Samonigg H, Wilders-Truschnig M, Loibner H, Plot R, Rot A, Kuss I, Werner G, Stoger H, Wrann M, Herlyn D, et al. (1992) Immune response to tumor antigens in a patient with colorectal cancer after immunization with anti-idiotype antibody. Clin. Immunol. Immunopathol. 65: 271-277

31. Fagerberg J, Steinitz M, Wigzell H, Askelöf P, Mellstedt H (1995) Human anti-idiotypic antibodies induced a humoral and cellular immune response against a colorectal carcinoma-associated antigen in patients. Proc. Natl. Acad. Sci. U. S. A. 92: 4773-4777

32. Xiang J, Pan Z, Attah-Poku S, Babiuk L, Zhang Y, Liu E (1992) Production of hybrid bispecific antibody recognizing human colorectal carcinoma and CD3 antigen. Mol. Biother. 4: 15-23

33. Nitta T, Yagita H, Azuma T, Sato K, Okumura K (1989) Bispecific F (ab')2 monomer prepared with anti-CD3 and anti-tumor monoclonal antibodies is most potent in induction of cytolysis of human T cells. Eur. J. Immunol. 19: 1437-1441

34. Ball ED, Guyre PM, Mills L, Fisher J, Dinces NB, Fanger MW (1992) Initial trial of bispecific antibody-mediated immunotherapy of CD15-bearing tumors: cytotoxicity of human tumor cells using a bispecific antibody comprised of anti-CD15 (MoAb PM81) and anti-CD64/Fc gamma RI (MoAb 32). J. Hematother. 1: 85-94

35. Kroesen BJ, Buter J, Sleijfer DT, Janssen RAJ, Van der Graaf WTA, Hauw The T, De Leij L, Mulder NH (1994) Phase I study of intraveneously applied bispecific antibody in renal cell cancer patients recieving subcutaneous interleukin 2. Br. J. Cancer 70: 652-661

36. Canevari S, Stoter G, Arienti F, Bolis G, Colnaghi MI, Di Re EM, Eggermont AM, Goey SH, Gratama JW, Lamers CH, et al. (1995) Regression of advanced ovarian carcinoma by intraperitoneal treatment with autologous $\mathrm{T}$ lymphocytes retargeted by a bispecific monoclonal antibody. J. Natl. Cancer Inst. 87: 1463-1469

37. Repp R, Valerius T, Wieland G, Becker W, Steininger H, Deo Y, Helm G, Gramatzki M, Van de Winkel JG, Lang N, et al. (1995) G-CSF-stimulated PMN in immunotherapy of breast cancer with a bispecific antibody to Fc gamma RI and to HER-2/neu (MDX-210). 


\section{J. Hematother, 4: 415-421}

38. Weiner LM, Clark JI, Davey M, Li WS, Garcia de Palazzo I, Ring DB, Alpaugh RK (1995) Phase I trial of 2B1, a bispecific monoclonal antibody targeting c-erbB-2 and Fc gamma RIII. Cancer Res. 55: 4586-4593

39. Renner C, Hartmann F, Jung W, Deisting C, Juwana M, Pfreundschuh M (2000) Initiation of humoral and cellular immune responses in patients with refractory Hodgkin's disease by treatment with an anti-CDI6/CD30 bispecific antibody [In Process Citation]. Cancer Immunol. Immunother 49: 173-180

40. Bauer S, Renner C, Juwana JP, Held G, Ohnesorge S, Gerlach K, Pfreundschuh M (1999) Immunotherapy of human tumors with $\mathrm{T}$-cell-activating bispecific antibodies: stimulation of cytotoxic pathways in vivo. Cancer Res. 59: 1961-1965

41. Kosterink JG, de-Jonge MW, Smit EF, Piers DA, Kengen RA, Postmus PE, Shochat D, Groen HJ, The HT, de-Leij L (1995) Pharmacokinetics and scintigraphy of indium-111DTPA-MOC-31 in small-cell lung carcinoma. J. Nucl. Med. 36: 2356-2362

42. Wong JY, Chu DZ, Yamauchi D, Odom-Maryon TL, Williams LE, Liu A, Esteban JM, Wu AM, Primus FJ, Beatty JD, Shively JE, Raubitschek AA (1998) Dose escalation trial of indium-111-labeled anti-carcinoembryonic antigen chimeric monoclonal antibody (chimeric T84.66) in presurgical colorectal cancer patients. J. Nucl. Med. 39: 2097-2104

43. Aftab F, Stoldt HS, Testori A, Imperatori A, Chinol M, Paganelli G, Geraghty J (1996) Radioimmunoguided surgery and colorectal cancer. Eur. J. Surg. Oncol. 22: 381-388

44. DeNardo GL, DeNardo SJ, O'Grady LF, Levy NB, Adams GP, Mills SL (1990) Fractionated radioimmunotherapy of B-cell malignancies with 131I-Lym-1. Cancer Res. 50: $1014 \mathrm{~s}-1016 \mathrm{~s}$

45. Juweid M, Sharkey RM, Behr T, Swayne LC, Rubin AD, Hanley D, Herskovic T, Markowitz A, Siegel J, Goldenberg DM (1995) Targeting and initial radioimmunotherapy of medullary thyroid carcinoma with 1311-labeled monoclonal antibodies to carcinoembryonic antigen. Cancer Res. 55: $5946 \mathrm{~s}-5951 \mathrm{~s}$

46. Verhaar-Langereis MJ, Zonnenberg BA, de Klerk JM, Blijham GH (2000) Radioimmunodiagnosis and therapy. Cancer Treat. Rev. 26: 3-10

47. Kranenborg MH, Boeman OC, Oosterwijk-Wakka JC, de Weijert MC, Corstens FH, Oosterwijk E (1995) Development and characterization of anti-renal cell carcinoma $x$ antichelate bispecific monoclonal antibodies for two-phase targeting of renal cell carcinoma. Cancer Res. 55: $5864 \mathrm{~s}-5867 \mathrm{~s}$

48. Boerman OC, Kranenborg MH, Oosterwijk E, Griffiths GL, McBride WJ, Oyen WJ, de Weijert M, Oosterwijk-Wakka J, Hansen HJ, Corstens FH (1999) Pretargeting of renal cell carcinoma: improved tumor targeting with a bivalent chelate. Cancer Res. 59: 44004405

49. Vuillez JP, Kraeber-Bodere F, Moro D, Bardies M, Douillard JY, Gautherot E, Rouvier E, Barbet J, Garban F, Moreau P, Chatal JF (1999) Radioimmunotherapy of small cell lung carcinoma with the two-step method using a bispecific anti-carcinoembryonic antigen/anti-diethylenetriaminepentaacetic acid (DTPA) antibody and iodine-131 DiDTPA hapten: results of a phase I/II trial. Clin. Cancer Res. 5: 3259s-3267s

50. Kraeber-Bodere F, Bardet S, Hoefnagel CA, Vieira MR, Vuillez JP, Murat A, Ferreira TC, Bardies M, Ferrer L, Resche I, Gautherot E, Rouvier E, Barbet J, Chatal JF (1999) Radioimmunotherapy in medullary thyroid cancer using bispecific antibody and iodine 
131-labeled bivalent hapten: preliminary results of a phase I/I clinical trial. Clin. Cancer Res. 5: $3190 \mathrm{~s}-3198 \mathrm{~s}$

51. Huber R, Deisenhofer J, Colman PM, Matsushima M, Palm W (1976) Crystallographic structure studies of an IgG molecule and an Fc fragment. Nature 264: 415-420

52. Morrison SL, Johnson MJ, Herzenberg LA, Oi VT (1984) Chimeric human antibody molecules: mouse antigen-binding domains with human constant region domains. Proc. Natl. Acad. Sci. U. S. A. 81: 6851-6855

53. Boulianne GL, Hozumi N, Shulman MJ (1984) Production of functional chimacric mouse/human antibody. Nature 312: 643-646

54. Shaw DR, Khazaeli MB, LoBuglio AF (1988) Mouse/human chimeric antibodies to a tumor-associated antigen: biologic activity of the four human IgG subclasses. $J$. Natl. Cancer Inst. 80: 1553-1559

55. Beidler CB, Ludwig JR, Cardenas J, Phelps J, Papworth CG, Melcher E, Sierzega M, Myers LJ, Unger BW, Fisher M, et al. (1988) Cloning and high level expression of a chimeric antibody with specificity for human carcinoembryonic antigen. I. Immunol. 141: 4053-4060

56. Velders MP, Litvinov SV, Warnaar SO, Gorter A, Fleuren GJ, Zurawski VR Jr, Coney LR (1994) New chimeric anti-pancarcinoma monoclonal antibody with superior cytotoxicity-mediating potency. Cancer Res. 54: 1753-1759

57. Jones PT, Dear PH, Foote J, Neuberger MS, Winter G (1986) Replacing the complementarity-determining regions in a human antibody with those from a mouse. Nature 321: $522-525$

58. Roder JC, Cole SP, Kozbor D (1986) The EBV-hybridoma technique. Methods Enzymol. 121: $140-167$

59. James K, Bell GT (1987) Human monoclonal antibody production. Current status and future prospects. J. Immunol. Methods 100: 5-40

60. Orlandi R, Gussow DH, Jones PT, Winter G (1989) Cloning immunoglobulin variable domains for expression by the polymerase chain reaction. Proc. Natl. Acad. Sci. U.S. A. 86: $3833-3837$

61. Skerra A, Pluckthun A (1988) Assembly of a functional immunoglobulin Fv fragment in Escherichia coli. Science 240: 1038-1041

62. Better M, Chang CP, Robinson RR, Horwitz AH (1988) Escherichia coli secretion of an active chimeric antibody fragment. Science 240: 1041-1043

63. Huston JS, Levinson D, Mudgett-Hunter M. Tai MS, Novotny J, Margolies MN, Ridge RJ, Bruccoleri RE, Haber E, Crea R, et al. (1988) Protein engineering of antibody binding sites: recovery of specific activity in an anti-digoxin single-chain $\mathrm{Fv}$ analogue produced in Escherichia coli. Proc. Natl. Acad. Sci. U. S. A. 85: 5879-5883

64. MeCafferty J, Griffiths AD, Winter G, Chiswell DJ (1990) Phage antibodies: filamentous phage displaying antibody variable domains. Nature 348: 552-554

65. Green LL (1999) Antibody engineering via genetic engineering of the mouse: XenoMouse strains are a vehicle for the facile generation of therapeutic human monoclonal antibodies. J. Immunol. Methods 231: i 1.23

66. Holliger P, Prospero T, Winter G (1993) "Diabodies": small bivalent and bispecific: antibody fragments. Proc. Natl. Acad. Sci. U. S. A. 90: 6444-6448 
67. Kortt AA, Lah M, Oddie GW, Gruen CL, Burns JE, Parce LA, Atwell JL, McCoy AJ, Howlett GJ, Metzger DW, Webster RG, Hudson PJ (1997) Single-chain Fv fragments of anti-neuraminidase antibody NC10 containing five and ten-residue linkers form dimers and with zero-residue linker a trimer. Protein Eng. 10: 423-433

68. Le Gall F, Kipriyanov SM, Moldenhauer G, Little M (1999) Di-, tri- and tetrameric single chain Fv antibody fragments against human CD19: effect of valency on cell binding [In Process Citation]. FEBS Lett. 453: 164-168

69. Hu S, Shively L, Raubitschek A, Sherman M, Williams LE, Wong JY, Shively JE, Wu AM (1996) Minibody: A novel engineered anti-carcinoembryonic antigen antibody fragment (single-chain Fv-CH3) which exhibits rapid, high-level targeting of xenografts. Cancer Res. 56: 3055-3061

70. Williams LE, Liu A, Wu AM, Odom-Maryon T, Chai A, Raubitschek AA, Wong JY (1995) Figures of merit (FOMs) for imaging and therapy using monoclonal antibodies. Med. Phys. 22: 2025-2027

71. Wu AM, Yazaki PJ, Tsai Sw, Nguyen K, Anderson A-L, McCarthy DW, Welch MJ, Shively JE, Williams LE, Raubitschek AA, Wong JYC, Toyokuni T, Phelps ME, Gambhir SS (2000) High-resolution microPET imaging of carcinoembryonic antigenpositive xenografts by using a copper-64-labeled engineered antibody fragment. Proc. Natl. Acad. Sci. U. S. A. 97: 8495-8500

72. Pack P, Muller K, Zahn R, Pluckthun A (1995) Tetravalent miniantibodies with high avidity assembling in Escherichia coli. J. Mol. Biol. 246: 28-34

73. Kipriyanov SM, Moldenhauer G, Schuhmacher J, Cochlovius B, Von der Lieth CW, Matys ER, Little M (1999) Bispecific tandem diabody for tumor therapy with improved antigen binding and pharmacokinetics. J. Mol. Biol. 293: 41-56

74. Pluckthun A, Pack P (1997) New protein engineering approaches to multivalent and bispecific antibody fragments. Immunotechnology 3: 83-105

75. Hudson PJ (1998) Recombinant antibody fragments. Curr. Opin. Biotechnol. 9: 395-402

76. Maloney DG, Liles TM, Czerwinski DK, Waldichuk C, Rosenberg J, Grillo-Lopez A, Levy R (1994) Phase I clinical trial using escalating single-dose infusion of chimeric antiCD20 monoclonal antibody (IDEC-C2B8) in patients with recurrent B-cell lymphoma. Blood 84: 2457-2466

77. Leget GA, Czuczman MS (1998) Use of rituximab, the new FDA-approved antibody. Curr. Opin. Oncol. 10: 548-551

78. Goldenberg MM (1999) Trastuzumab, a recombinant DNA-derived humanized monoclonal antibody, a novel agent for the treatment of metastatic breast cancer. Clin. Ther: 21: 309-318

79. Chester KA, Begent RH, Robson L, Keep P, Pedley RB, Boden JA, Boxer G, Green A, Winter G, Cochet O, et al. (1994) Phage libraries for generation of clinically useful antibodies. The Lancer 343: 455-456

80. Verhaar MJ, Keep PA, Hawkins RE, Robson L, Casey JL, Pedley B, Boden JA, Begent RH. Chester KA (1996) Technetium-99m radiolabeling using a phage-derived singlechain Fv with a C-terminal cysteine. J. Nucl. Med. 37: 868-872

81. Begent RHJ, Verhaar MJ, Chester KA, Casey JL, Green AJ, Napier MP, Hope-Stone LD, Cushen N, Keep PA. Johnson CJ, Hawkins RE, Hilson AJW, Robson L (1996) Clinical evidence of efficient tumor targeting based on single-chain $\mathrm{Fv}$ antibody selected from a 
combinatorial library. Nat. Med. 2: 979-984

82. Mayer A, Tsiompanou E, O'Malley D, Boxer GM, Bhatia J, Flynn AA, Chester KA, Davidson BR, Lewis AA, Winslet MC, Dhillon AP, Hilson AJ, Begent RH (2000) Radioimmunoguided surgery in colorectal cancer using a genetically engineered antiCEA single-chain Fv antibody [In Process Citation]. Clin. Cancer Res. 6: 1711-1719

83. Michael NP, Chester KA, Melton RG, Robson L, Nicholas W, Boden JA, Pedley RB, Begent RH, Sherwood RF, Minton NP (1996) In vitro and in vivo characterisation of a recombinant carboxypeptidase G2::anti-CEA scFv fusion protein. Immunotechnology.

2: $47-57$

84. Bhatia J, Sharma SK, Chester KA, Pedley RB, Boden RW, Read DA, Boxer GM, Michael NP, Begent RH (2000) Catalytic activity of an in vivo tumor targeted anti-CEA scFv::carboxypeptidase G2 fusion protein. Int. J. Cancer 85: 571-577

85. Farah RA, Clinchy B, Herrera L, Vitetta ES (1998) The development of monoclonal antibodies for the therapy of cancer. Crit. Rev. Eukaryot. Gene Expr. 8: 321-356

86. Hudson PJ (1999) Recombinant antibody constructs in cancer therapy, Curr. Opin. Immunol. 11: 548-557

87. Grabmaier K, Vissers JL, De Weijert MC, Oosterwijk-Wakka JC, Van Bokhoven A, Brakenhoff RH, Noessner E, Mulders PA, Merkx G, Figdor CG, Adema GJ, Oosterwijk E (2000) Molecular cloning and immunogenicity of renal cell carcinoma-associated antigen G250. Int. J. Cancer 85: 865-870

88. Hollstein M, Sidransky D, Vogelstein B, Harris CC (1991) p53 mutations in human cancers. Science 253: 49-53

89. Herrlich P, Pals S, Ponta H (1995) CD44 in colon cancer. Eur. J. Cancer 31 A: I1 101112

90. De Smet C, De Backer O, Faraoni I, Lurquin C, Brasseur F, Boon T (1996) The activation of human gene MAGE-1 in tumor cells is correlated with genome-wide demethylation. Proc. Natl. Acad. Sci. U. S. A. 93: 7149-7153

91. Apostolopoulos V. McKenzie IF (1994) Cellular mucins: targets for immunotherapy. Crit. Rev. Immunol. 14: 293-309

92. Gottlinger HG, Funke I, Johnson JP, Gokel JM, Riethmulter G (1986) The epithelial celi surface antigen 17-IA, a target for antibody-rnediated tumor therapy: its biochemical nature, tissue distribution and recognition by different monoclonal antibodies. Int. .j. Cancer 38: 47-53

93. Kapitanovic S, Radosevic S, Kapitanovic M, Andelinovic S, Ferencic Z, Tavassoli M, Primorac D, Sonicki Z, Spaventi S, Pavelic K, Spaventi R (1997), The expression of p185(HER-2/neu) correlates with the stage of disease and survival in colorectal cancer. Gastroenterology 112: 1103-1113

94. van der Bruggen P. Traversari C, Chomez P, Lurquin C, de Plaen E, van den Eynde B, Knuth A, Boon T (1991) A gene encoding an antigen recognized by cytolytic T lymphocytes on a human melanoma. Science 254: 1643-1647

95. Kawakami Y, Eliyahu S, Delgado CH, Robbins PF, Rivoltini L, Topalian SL, Miki T, Rosenberg SA (1994) Cloning of the gene coding for a shared human melanoma antigen recognized by autologous T cells infiltrating into tumor. Proc. Natl. Acad. Sci. U. S. A. 91: $3515-3519$

96. Boon T, van-der-Bruggen $\mathrm{P}$ (1996) Human tumor antigens recognized by $\mathrm{T}$ lymphocytes. 
J. Exp. Med. 183: 725-729

97. Cai X, Garen A (1995) Anti-melanoma antibodies from melanoma patients immunized with genetically modified autologous tumor cells: Selection of specific antibodies from single-chain Fv fusion phage libraries. Proc. Natl. Acad. Sci. U. S. A. 92: 6537-6541

98. Kupsch JM, Tidman NH, Kang NV, Truman H, Hamilton S, Patel N, Newton Bishop JA, Leigh IM, Crowe JS (1999) Isolation of human tumor-specific antibodies by selection of an antibody phage library on melanoma cells [In Process Citation]. Clin. Cancer Res. 5: 925-931

99. Velculescu VE, Zhang L, Vogelstein B, Kinzier KW (1995) Serial analysis of gene expression [see comments]. Science 270: 484-487

100. Zhang L, Zhou W, Velculescu VE, Kern SE, Hruban RH, Hamilton SR, Vogelstein B, Kinzler KW (1997) Gene expression profiles in normal and cancer cells. Science 276: 1268-1272

101. Lal A, Lash AE, Altschul SF, Velculescu V, Zhang L, McLendon RE, Marra MA, Prange C, Morin PJ, Polyak K, Papadopoulos N, Vogelstein B, Kinzler KW, Strausberg RL, Riggins GJ (1999) A public database for gene expression in human cancers. Cancer Res. 59: $5403-5407$

102. Hufton SE, Moerkerk PT, Brandwijk R, de Bruïne AP, Arends JW, Hoogenboom HR (1999) A profile of differentially expressed genes in primary colorectal cancer using suppression subtractive hybridization. FEBS Letl. 463: 77-82

103. Yang GP, Ross DT, Kuang WW, Brown PO, Weigel RJ (1999) Combining SSH and cDNA microarrays for rapid identification of differentially expressed genes. Nucleic Acids Res. 27: 1517-1523

104. Alizadeh AA, Eisen MB, Davis RE, Ma C, Lossos IS, Rosenwald A, Boldrick JC, Sabet H, Tran T, Yu X, Powell Jl, Yang L, Marti GE, Moore T, Hudson J Jr, Lu L, Lewis DB, Tibshirani R, Sherlock G, Chan WC, Greiner TC, Weisenburger DD, Armitage JO, Warnke R, Staudt LM, et al. (2000) Distinct types of diffuse large B-cell lymphoma identified by gene expression profiling [see comments]. Nature 403: 503-511

105. Itzkowitz SH (1992) Blood group-related carbohydrate antigen expression in malignant

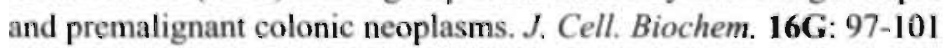

106. Souhami RL, Beverley PC, Bobrow LG (1987) Antigens of small-cell lung cancer. First International Workshop. The Lancet 2: 325-326

107. Sirnad J, Hamilton AE, Beavers LS, Gamboa GC, Apelgren LD, Taber LD, Sportsman JR, Bumol TF, Sharp JD, Gadski RA ( 1989) Molecular cloning and characterization of a human adenocarcinoma/epithelial cell surface antigen complementary DNA. Cancer Res. 49: $314-317$

108. Perez MS, Walker LE (1989) Isolation and characterization of a cDNA encoding the $\mathrm{KSI} / 4$ epithelial carcinoma marker. J. Immunol. 142: 3662-3667

109. Szala S, Froehlich M, Scollon M, Kasai Y, Steplewski Z, Koprowski H, Linnenbach AJ (1990) Molecular cloning of cDNA for the carcinoma-associated antigen GA733-2. Proc. Natl. Acad. Sci. U. S. A. 87: 3542-3546

110. Simon B, Podolsky DK, Moldenhauer G, Isselbacher KJ, Gattoni-Celli S, Brand SJ (1990) Epithelial glycoprotein is a member of a family of epithelial cell surface antigens homologous to nidogen, a matrix adhesion protein. Proc. Natl. Acad. Sci. U. S. A. 87: 2755-2759 
111. Balzar M, Winter MJ, de Boer CJ, Litvinov SV (1999) The biology of the 17-1A antigen (Ep-CAM). J. Mol. Med. 77: 699-712

112. Schon MP, Schon M, Mattes MJ, Stein R, Weber L, Alberti S, Klein CE (1993) Biochemical and immunological characterization of the human carcinoma-associated antigen MH 99/KS 1/4. Int. J. Cancer 55: 988-995

113. Litvinov SV, Bakker HA, Gourevitch MM, Velders MP, Warnaar SO (1994) Evidence for a role of the epithelial glycoprotein 40 (Ep-CAM) in epithelial cell-cell adhesion. Cell. Adhes. Commun. 2: 417-428

114. Litvinov SV, Velders MP, Bakker HA, Fleuren GJ, Wamaar SO (1994) Ep-CAM: a human epithelial antigen is a homophilic cell-cell adhesion molecule. J. Cell Biol. 125: 437-446

115. Litvinov SV, Balzar M, Winter MJ, Bakker HA, Briaire-de Bruijn IH, Prins F, Fleuren GJ, Warnaar SO (1997) Epithelial cell adhesion molecule (Ep-CAM) modulates cell-cell interactions mediated by classic cadherins. J. Cell Biol. 139: 1337-1348

116. Balzar M, Prins FA, Bakker HA, Fleuren GJ, Warnaar SO, Litvinov SV (1999) The structural analysis of adhesions mediated by Ep-CAM. Exp. Cell Res. 246: 108-121

117. Balzar M, Bakker HA, Briaire-de-Bruijn IH, Fleuren GJ, Warnaar SO, Litvinov SV (1998) Cytoplasmic tail regulates the intercellular adhesion function of the epithelial cell adhesion molecule. Mol. Cell. Biol. 18: 4833-4843

118. Herlyn M, Steplewski Z, Herlyn D, Koprowski H (1986) CO 17-IA and related monoclonal antibodies: their production and characterization. Hybridoma 5: S3-10

119. Basak S, Speicher D, Eck S, Wunner W, Maul G, Simmons MS, Herlyn D (1998) Colorectal carcinoma invasion inhibition by CO17-1A/GA733 antigen and its murine homologue. J. Natl. Cancer Inst. 90: 691-697

120. Zutter MM (1998) Gastrointestinal carcinoma antigen GA733: target for immunodestruction and potential modifier of invasiveness and chemoresponsiveness . J. Natl. Cancer inst. 90: 642-644

121. Nelson AJ, Dunn RJ, Peach R, Aruffo A, Farr AG (1996) The murine homolog of human Ep-CAM, a homotypic adhesion molecule, is expressed by thymocytes and thymic epithelial cells. Eur. J. Immunol. 26: 401-408.

122. Knox SJ, Goris ML, Tempero M, Weiden PL, Gentner L, Breitz H, Adams GP, Axworthy D, Gaffigan S, Bryan K, Fisher DR, Colcher D, Horak ID, Weiner LM (2000) Phase II trial of yttrium-90-DOTA-biotin pretargeted by NR-LU-10 antibody/streptavidin in patients with metastatic colon cancer [In Process Citation]. Clin. Cancer Res. 6: 406414

123. Smith GP (1985) Filamentous fusion phage: novel expression vectors that display cloned antigens on the virion surface. Science 228: 1315-1317

124. Clackson T, Hoogenboom HR, Griffiths AD, Winter G (1991) Making antibody fragments using phage display libraries. Nature 352: 624-628

125. Marks JD, Hoogenboom HR, Bonnert TP, McCafferty J, Griffiths AD, Winter G (1991) By-passing Immunization; Human Antibodies, from V-gene Libraries Displayed on Phage. J. Mol. Biol. 222: 581-597

126. Griffiths AD, Malmqvist M, Marks JD, Bye JM, Embleton MJ, McCafferty J, Baier M, Holliger KP, Gorick BD, Hughes-Jones NC, Hoogenboom HR, Winter G (1993) Human anti-self antibodies with high specificity from phage display libraries. EMBO J. 12: 725- 
734

127. Balaban EP, Walker BS, Cox JV, Sein AA, Abrams PG, Salk D, Sheehan RG, Frenkel EP (1991) Radionuclide imaging of bone marrow metastases with a Tc-99m labeled monoclonal antibody to small cell lung carcinoma. Clin. Nucl. Med. 16: 732-736

128. Vaughan TJ, Williams AJ, Pritchard K, Osbourn JK, Pope AR, Earnshaw JC, McCafferty J, Hodits RA, Wilton J, Johnson KS (1996) Human Antibodies with Sub-nanomolar Affinities Isolated from a Large Non-immunized Phage Display Library. Nat. Biotechnol. 14: $309-314$

129. Sheets MD, Amersdorfer P. Finnern R, Sargent P, Lindqvist E, Schier R, Hemingsen G, Wong C, Gerhart JC, Marks JD (1998) Efficient construction of a large nonimmune phage antibody library: the production of high-affinity human single-chain antibodies to protein antigens. Proc. Natl. Acad. Sci. U. S. A. 95: 6157-6162

130. de Haard HJ, van Neer N, Reurs A, Hufon SE, Roovers RC, Henderikx. P, de Bruïne AP, Arends J-W, Hoogenboom HR (1999) A large non-immunized human Fab fragment phage library that permits rapid isolation and kinetic analysis of high aftinity antibodies. J. Biol. Chem. 274: 18218-18230

131. Lubin R, Schlichtholz B, Bengoufa D, Zalcman G, Tredaniel J, Hirsch A, de Fromentel CC, Preudhomme C, Fenaux P, Foumier G, et al. (1993) Analysis of p53 antibodies in patients with various cancers define B-cell epitopes of human p53: distribution on primary structure and exposure on protein surface. Cancer Res. 53: 5872-5876

132. Hammel P, Boissier B, Chaumette MT, Piedbois P, Rotman N, Kouyoumdjian JC, Lubin R, Delchier JC, Soussi T (1997) Detection and monitoring of serum p53 antibodies in patients with colorectal cancer. Gut 40: 356-361

133. Disis ML, Pupa SM, Gralow JR, Dittadi R, Menard S, Cheever MA (1997) High-titer HER-2/neu protein-specific antibody can be detected in patients with early-stage breast cancer. J. Clin. Oncol. 15: 3363-3367

134. Mosolits S, Harmenberg U, Ruden U, Ohman L, Nilsson B, Wahren B, Fagerberg J, Mellstedt H (1999) A.utoantibodies against the tumour-associated antigen GA733-2 in patients with colorectal carcinoma. Cancer Immunol. Immunother 47: 315-320 


\section{Chapter 2}

\section{Antibody phage display technology and its applications}

Hennie R. Hoogenboom, Adriaan P. de Bruïne, Simon E. Hufton, René M. Hoet, Jan-Willem Arends and Rob C. Roovers

Immunotechnology 4(1), 1-20 (1998) 


\begin{abstract}
In recent years, the use of display vectors and in vitro selection technologies has transformed the way in which we generate ligands, such as antibodies and peptides, for a given target. Using this technology, we are now able to design repertoires of ligands from scratch and use the power of phage selection to select those ligands having the desired (biological) properties. With phage display, tailor-made antibodies may be synthesized and selected to retain the desired affinity of binding and specificity for in vitro and in vivo diagnosis, or for immunotherapy of human disease. This review addresses recent progress in the construction of, and selection from phage antibody libraries, together with novel approaches for screening phage antibodies. As the quality of large naïve and synthetic antibody repertoires improves and libraries becomes more generally available, new and exciting applications are pioneered such as the identification of novel antigens using differential selection and the generation of receptor a(nta)gonists. Combining the design and generation of millions to billions of different ligands, together with phage display for the isolation of binding ligands and with functional assays for identifying (and possibly selecting) bio-active ligands, will open even more challenging applications of this inspiring technology, and provide a powerful tool for drug and target discovery well into the next decade.
\end{abstract}

\title{
1. Introduction
}

The generation of new drugs has long involved the search amongst hundreds of thousands of components using well defined in vitro screening tests, the output of which was chosen to mimic as closely as possible the desired in vivo activity of the new drug. Now new library methodologies offer many alternative and at least as powerful routes, by combining the creation of billions of components with a fast screening or selection procedure to identify the most interesting lead candidates. One of the most widely used library methodologies is based on the use of filamentous phage [1], a bacteriophage that lives on Escherichia coli. Phage-display has proven to be a very powerful technique to display libraries containing millions or even billions of different peptides or proteins. One of the most successful applications of phage display has been the isolation of monoclonal antibodies using large phage antibody libraries [2]. Indeed, in the last few years, very efficient techniques have been developed to design and build large libraries of antibody fragments, and ingenious selection procedures have been established to derive antibodies with the desired characteristics. Here, we review the progress made in this rapidly developing field, and discuss a broad range of applications, including the use of large 
phage antibody libraries to discover novel targets on cells and methods for selection of biologically active ligands. Finally, we address the potential of combining phage display with complementary technologies, to increase the scope and range of applications of this technology.

\section{Antibody Phage display}

\section{I. The phage display principle}

The power of the phage display system is illustrated in Fig. 1. DNA encoding millions of variants of a certain ligands (e.g. peptides, proteins or fragments thereof) is batch-cloned into the phage genome as a fusion to the gene encoding one of the phage coat proteins (pill. pVI or pVIII). Upon expression of the ligands, the coat protein fusion wili be incorporated into new phage particles that are assembled in the bacterium. Expression of the fusion product and its subsequent incorporation into the mature phage coat results in the ligand being presented on the phage surface, while its genetic material resides within the phage particle. This linkage between ligand genotype and phenotype allows the enrichment of antigen-specific phage, e.g. using selection on immobilised antigen. Phage that display a relevant ligand will be retained on a surface coated with antigen, while non-adherent phages will be washed away. Bound phages can be recovered from the surface, reinfected into bacteria and re-grown for further enrichment, and

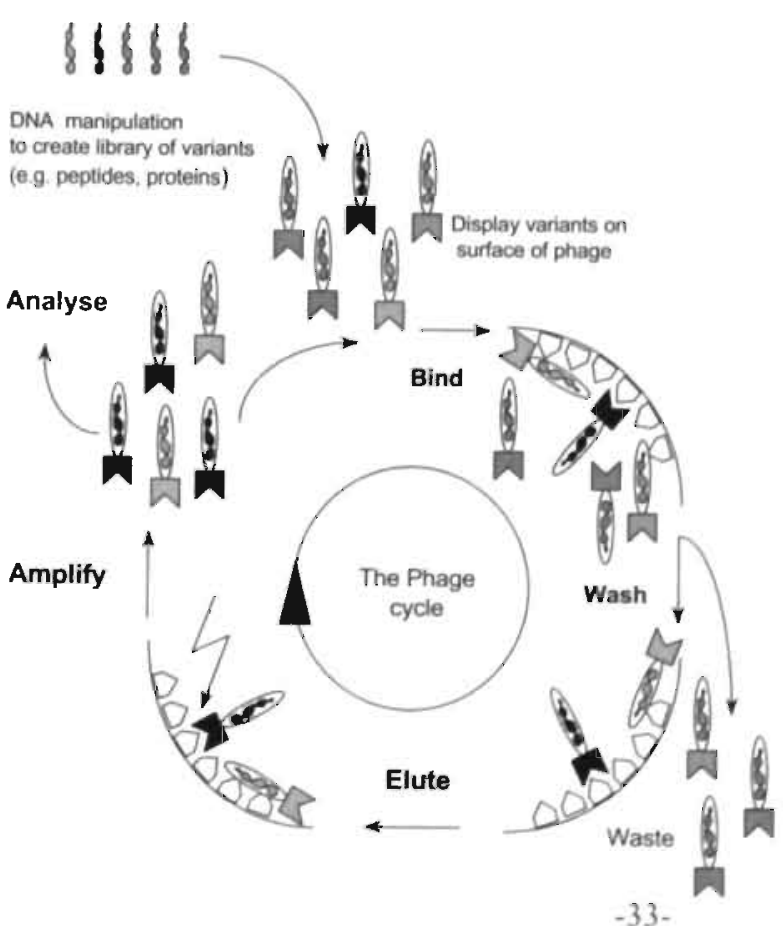
eventually for analysis of binding. The success of ligand phage display hinges on the combination of this display and enrichment method, with the creation of large combinatorial repertoires on phage.

\section{Figure 1}

The phage display cycle

DNA encoding for milions of variants of certain ligands (e.g. peptides, proteins or fragments thereof) is batch-cloned into the phage genome as part of one of the phage coat proteins (pIII, pVI or pVIII), Large libraries containing millions of different: ligands can be obtained by force cloning in E.coli. From these repertoires phage carrying specific binding ligands can be isolated by a series of recursive cycies of selection on antigen, each of which involves binding, washing elution and amplification. 


\subsection{Filamenious phage biology and display}

By far the most popular phage that has been used for display is the filamentous bacteriophage. The non-lytic filamentous phage fd or M13 infect strains of $E$. coli containing the $\mathrm{F}$ conjugative plasmid. Phage particles attach to the tip of the $\mathrm{F}$ pilus that is encoded by genes on this plasmid, and the phage genome, a circular single-stranded DNA molecule, is translocated into the cytoplasm. The genome is replicated involving both phage and host derived proteins, and packaged by the infected cell into a rod-shaped particle, which is released into the media. All virion proteins will undergo transport to the cell periplasm prior to assembly and extrusion. Several filamentous phage coat proteins have been used for display of ligands (for review, see an excellent issue of Methods in Enzymology [3] and a book on phage biology and display applications [4]). By far the most extensively used is the pIII phage protein, which is involved in bacterial infection and is present in three to five copies per phage particle.

\subsection{Basic display methodology}

Antibodies were the first proteins to be displayed successfully on the surface of phage [5]. This was achieved by fusing the coding sequence of the antibody variable (V) regions encoding a single-chain Fv (scFv) fragment to the amino terminus of the phage minor coat protein pllI. The antibody was displayed using a phage vector, based on phage fd-tet [6] and its gene III as fusion pariner. In this vector, the genes encoding an antibody scFv fragment were cloned in frame with gene III and downstream of the gene III signal sequence, which normally directs the adsorption protein to the periplasm. Here, the VH and VL domains will fold correctly, both stabilised by a intramolecular disulphide-bridge, and pair to form a functional scFv [7, 8]. Initially, phage vectors that earry all the genetic information required for the phage life cycle were used [5, 9]. Now, phagemids, have become a more popular type of vector for display. Phagemids are small plasmid vectors that carry gene III with appropriate cloning sites and a phage packaging signal [10-12]. In phagemids, the scFv may be fused at the N-terminus of the mature gene III protein $[5,11]$ or at the $\mathrm{N}$-terminus of a truncated plll lacking the first two $\mathrm{N}$-terminal domains $[10,13]$. Phagemids have high transformation efficiencies and are therefore ideally suited for generating very large repertoires, as well as providing a format for direct secretion of the unfused antibody fragment, without subcloning [11].

Many phagemids utilize the lacZ promoter to dirive expression of the antibody-plII fusion [1], 13-15]. For display of the antibody-pIII product, either the catabolic repressor (glucose) of the lac $\mathrm{Z}$ promoter is removed or depleted, leading to expression of sufficient fusion product to derive 'monovalent' phage particles. Whenever expression-mediated toxicity is an issue (which is the case for some, mostly hybridoma-derived, antibody fragments [16]), it may be required to 
regulate the expression more tightly. The use of a lacZ promoter with an additional transcriptional terminator [17] or of the phage shock promoter (psp) [18] may allow display of relatively toxic products and reduce expression-mediated library bias.

The phagemid DNA encoding the antibody-pIII fusion will be preferentially packaged into phage particles using a helper phage such as M13KO7 or VCS-M13, which supplies all structural proteins. Since helper phage also encode wild-type pIII, typically over $90 \%$ of rescued phage display no antibody at all and the vast majority of the rescued phage particles that do display the fusion product will only contain a single copy. Ideally, more efficient, even multivalent display would therefore be preferable when selecting very large antibody libraries to guarantee selection with a limited number of phage particles per clone. Monovalent display, on the other hand, may be essential when selecting antibodies of higher affinity. Therefore the use of inducible promoters [19] or the use of a helper phage with gene III deleted [20, 21], which may be produced efficiently in cells containing gIII under control of psp [18], may in the future allow the modulation of the valency of displayed antibodies.

\subsection{Formats for antibody display}

Effective display formats for antibodies are scFv [5, 9, 22], Fab fragments [10, 11, 13, 23], Fv's with an engineered intermolecular disulphide bond to stabilize the $V_{1}{ }_{1} V_{L}$ pair ('dsFv's: [24]), and diabody fragments $[25,26]$. The smaller size of the scFv format makes these libraries genetically more stable than Fab libraries. However, many scFv's can form higher molecular weight species including dimers and trimers, which can complicate selection and characterisation (see [25]). Fab fragments, on the other hand, lack this tendency to dimerise, which facilitates for example assays to screen the kinetics of binding (see 5.2). To display Fab fragments on phage, either the light or heavy (Fd) chain is fused via its C-terminus to $\mathrm{pIII}$ and the partner chain is expressed unfused and secreted into the periplasmic space, where it can associate to form an intact Fab fragment, as illustrated in Fig. 2. A similar method is used to express bispecific diabodies [26]. Such bispecific dimers of scFv's were displayed on phage by expression from a bicistronic cassette containing two VH-VL fusion products, one of which is also fused to gIII. The advantage of the diabody format is that either bivalent antibodies may be isolated, a feature that could be used for 'functional' screening (see 5.4) or that large panels of bispecific molecules may be generated, avoiding extensive recloning after selection [26]. 


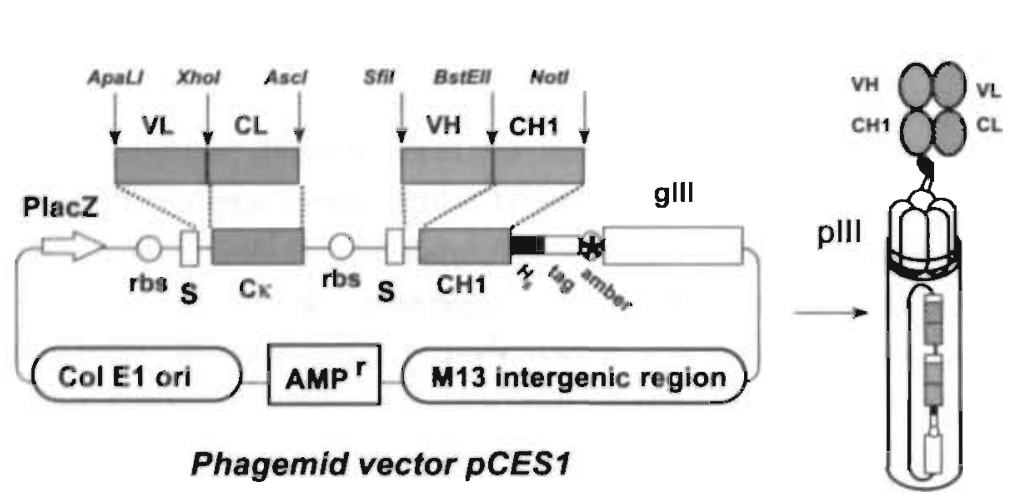

Figure 2

Display of Fab

fragments on

filamentous phage

Fab fragments may

be displayed on

phage using

phagemids (pCESI

is shown as an

example) that

express the heavy chain (Fd) fragment containing the variable domain and the first constant domain fused to a coat protein gene, gene III, of filamentous phage $\mathrm{fd}$, in combination

with separate expression of the partner (light) chain. Bacteria harbouring this phagemid vector are superinfected. with helper phage to drive production of phage particles carrying the Fab fragment, asa fusion product with the phage coat protein p!II, on the surface, and the DNA encoding the immunoglobulins inside the particle Abbreviatirons : rbs, ribosome binding site; AMPr, ampicillingresistance, $\mathrm{H}_{6}$ and tag. Histidine stretch and peptide lag respectively, for purification and detection purposes; amber codon (TAG) that allows expression of solubt antibody fragment in non-suppressor strains; gIII, gene III for phage fd; S, signal sequence directing the expressd protein to the bacterial periplasm.

\section{Antibody libraries}

One of the most suceessful applications of phage display has been the isolation of monoclonal antibodies from large phage antibody libraries (Fig. 3). We will discuss the three types of such phage libraries, immune, naïve and synthetic antibody libraries.

\subsection{Antibody libraries from immunized animals or immune donors}

Repertoires may be created from the $\operatorname{lgG}$ genes of spleen B-cells of mice immunised with antigen [9] or from immune donors. An immune phage antibody repertoire will be enriched in antigen-specific antibodies, some of which will also have been affinity matured by the immune system $[9,27]$. This method gives access to more and sometimes antibodies with higher affinity than obtained from hybridomas, as was reported for an anti-CEA antibody [28]. Other advantages of this procedure are that, compared to the hybridoma technology, many more antibodies may be accessed from the material of a single immunised donor, and selected antibodies can be rapidly derived or further manipulated. 


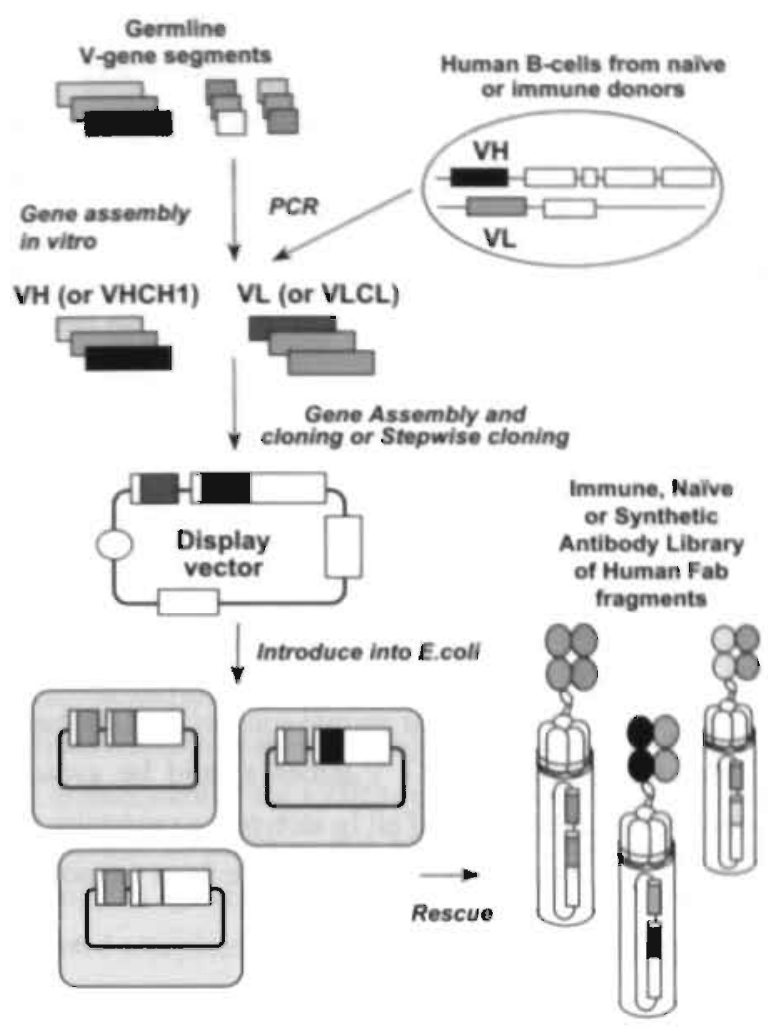

Figure 3

Construction of a human antibody library diplayed on phage.

cDNA fragments encoding for the heavy and the light variable regions of antibodies $\left(\mathrm{V}_{\mathrm{H}}, \mathrm{V}_{\mathrm{L}}\right)$ are amplified from human B-cells by PCR and assembled. The assembled genes are inserted in a phagemid vector in frame with the gene encoding the coat protein $\mathrm{pIII}$. The vector is introduced into $E$. coli. After rescue with helper phage, the random combinatorial library of antibodies is displayed on phage, and selection performed.

The construction of immune libraries from a variety of species has been reported, including mouse $[9,28,29]$.

human [30, 31], chicken [32, 33], rabbit [34], and camel [35]. Active immunization is, however, not always possible due to ethical constraints, neither always effective due to tolerance mechanisms towards or toxicity of the antigen involved. Tolerance mechanisms may be put to use in some cases, for example to deplete antibodies to certain antigens in vivo before immunization and selection of the new phage library on antigen in vitro [31]. Provided suitable sources of antibody producing B-cells or plasma cells are accessible, immune phage libraries are useful in analyzing natural humoral responses, for example in patients with autoimmune disease [36-38], viral infection (for review see [39]) or neoplastic diseases [31, 40, 41] (R.C.R. et al., in preparation), or to study in vitro immunisation procedures [42]. In addition, when studying specific (e.g. mucosal) humoral responses, mRNA coding for specific Ig isotypes (e.g. IgA) may be selectively used for library synthesis [43].

\subsection{Single pot repertoires}

From immune libraries, antibodies can be obtained only against the set of antigens to which an immune response was induced, which necessitates repeated immunization and library 
construction. ideally, universal, antigen-unbiased libraries would be available, from which very high affinity antibodies to any chosen antigen may directly be selected, independent of the immune history. At present, several of such 'single-pot' libraries have been described (reviewed in $[2,44])$, which are particularly useful for the selection of human antibodies since these are very difficult to establish with more traditional techniques. We discriminate 'naïve' and 'synthetic' antibody libraries, depending on the source of immunoglobulin genes. For most applications, the availability of large pre-made collections of non-immune repertoires has thus superseded the use of immune repertoires.

\subsubsection{Antibody libraries from non-immunised donors}

The primary (unselected) antibody repertoire contains a large array of IgM antibodies that recognize a variety of antigens. This array can be cloned as a 'naïve' repertoire of rearranged genes, by harvesting the $\mathrm{V}$-genes from the IgM mRNA of B-cells of unimmunized human. donors, isolated from peripheral blood lymphocytes [22], spleen (de Haard, H.R.H., et al, unpublished), bone marrow or tonsil B-cells [45], or from similar animal sources [46]. In theory, the use of possibly heavily mutated and antigen-biased $\operatorname{IgG} \mathrm{V}$-genes should be avoided. However, even when using random priming to include mRNA of all Ig isotypes, a repertoire with excellent, nerformance hac heen sunthesized [45] I ibrariec could alon he made fom thęnocsib]v more "naïve" pool of IgD mRNA.

The V-genes are amplified from the cDNA using family-based oligonucleotides [47], and heavy and light chains are randomly combined and cloned to encode a combinatotial library of scFv or Fab antibody fragments. This procedure generates access to antibodies that have not yet encountered antigen, although the frequency of those genuine 'germline antibodies' will depend heavily on the source of B-cells [48]. A single 'naïve' library, if sufficiently large and diverse, can indeed be used to generate antibodies for a large panel of antigens, including self, nonimmunogenic and relatively toxic antigens $[20,22,45]$.

The affinity of antibodies selected from a naïve library is proportional to the size of the library, ranging from $10^{6-7} \mathrm{M}^{-1}$ for a small library, with $3 \times 10^{7}$ clones $[20,22]$, to $10^{8-10} \mathrm{M}^{1}$ for a very large repertoire with $10^{10}$ clones made by brute force cloning [45], a finding which is in line with theoretical considerations [49]. Other large naïve human scFv libraries $\left(6.7 \times 10^{9}\right.$ clones) (J.D. Marks, unpublished) and a very large Fab library $\left(4.1 \times 10^{10}\right.$ clones) (de Haard, H.R.H., et al., unpublished), made via an efficient 2 -step restriction fragment cloning procedure, also seem to perform very well. 


\subsubsection{Synthetic antibody libraries}

In the second type of 'single pot' repertoires, the antibodies are built artificially, by in vitro assembly of V-gene segments and D/J segments. V-genes may be assembled by introducing a predetermined level of randomization of CDR regions (and possibly also of bordering framework-regions) into germline V-gene segments [50], or rearranged V-genes [51]. The regions and degree of diversity may be chosen to correspond to areas of highest natural diversity of the antibody repertoire. Most natural structural and sequence diversity is found in the loop most central to the antigen combining site, the CDR3 of the heavy chain, while the five other CDRs have limited variation [52]. This has therefore been the target for introduction of diversity in the first synthetic libraries.

In the first synthetic antibody library constructed according to these principles [50], a set of 49 human VH-segments was assembled via PCR with a short CDR3 region (encoding either 5 or 8 amino acids) and a J-region, and cloned for display as a scFv with a human lambda light chain. From this repertoire many antibodies to haptens and one against a protein antigen, were isolated [50]. Subsequently, the CDR3-regions were enlarged (ranging from 4 to 12 residues) to supply more length diversity in this loop [53]. Other original designs have used only one (cloned) rearranged V-gene pair with a single-size randomized CDR3 region in the heavy chain [51], or have used complete randomization of all 3 CDR-loops in one antibody V-domain $[54,55]$. Some of these libraries have yielded antibodies against many different antigens, including haptens [50, 51], proteins [53], and cell-surface markers [56], but their affinities are typically in the micromolar range.

Antibodies with nanomolar affinity were eventually isolated from a synthetic antibody library which combined a novel synthesis method to construct combinatorial libraries, in vivo recombination, with an effort to maximally mimic natural antibody diversity (i.e. to optimaily use 'sequence space'). In the largest synthetic library made to date [57], the 49 human heavy chain segments that were used earlier [50] were combined with a collection of 47 human kappa and lambda light chain segments with partially randomised CDR3 regions. The heavy and light chain V-gene repertoires were combined on a phage vector in bacteria using the lox-Cre sitespecific recombination system to create a large $6.5 \times 10^{10}$ clone repertoire of Fab fragments displayed on phage. The library yielded antibodies with in some cases nanomolar affinity against numerous different antigens $[36,57]$. This phage library proved to be difficult to re-propagate without significant loss of diversity. However, a more stable, large $1.2 \times 10^{9}$ clone scFv phagemid library made by standard cloning methods and using the same synthetic V-genes was recently shown to be equally effective (Heather Griffin, personal communication). 
It would seem desirable to synthesize even larger collections of antibodies. However, there are physical limitations to the enrichment that may be achieved in the selection procedure, which limits the size of accessible genetic diversity. With enrichment factors for a single selection round never reported to be higher than $10^{5}$ per round and a typical phage titre of $10^{6}$ clones eluted in the first, critical, round of selection, the total genetic diversity accessed by the selection procedure would be at the most $10^{11}$ clones. If selection conditions are so stringent that very few phage particles are recovered in the first round (typical for, for example, panning on cells followed by sorting via flow cytometry [56]), chances are that different subsets of antibodies will be selected every time the selection is repeated. It therefore appears that it becomes more crucial to optimise the quality of the displayed antibodies (with regard to display and expression level), and the selection procedure itself. This is where synthetic antibody libraries will have a major advantage over naïve libraries using naturally rearranged V-genes. For example: the choice of $\mathrm{V}$-gene segments for the construction of synthetic antibody repertoires may be guided by factors that will increase the overall performance of the library, such as good expression and folding and low toxicity in E.coli; this will increase the functional library size. Large differences in V-gene usage both in vivo and in phage repertoires [57] also suggest that some scaffolds may be better suited to form antigen-binders than others. Such a promising second generation synthetic antibody library is being built by MorphSys, using V-gene segments based on 'master' frameworks representing each of the Kabat subclasses, incorporating in principle only well expressed scaffolds. To overcome the problem of introducing stop-codons within the area of diversity, which would also decrease the functional library size, they assembled V-genes with oligonuceotides made from trinucleotides instead of from single bases [58] (MorhoSys, unpublished).

It is likely that further thoughtful design will continue to improve the performance of these libraries. For example, pre-selection of amplified and displayed synthetic V-domains on Igdomain binding proteins (protein $A$ for $V_{H}$ protein $L$ for $V_{\kappa}$ etc. [59]) would remove clones with stop codons and frameshifts, as well as select for functional expression (Tomlinson, unpublished). Finally, an exciting idea is to combine the complementary diversity of the primary (germline) and secundary (somatic hypermutation) antibody libraries in one single phage antibody library. This may be feasible, since only a few residues are known to be hotspots for the hypermutation machinery. These developments may well eventually establish a 'super' library, which may contain antibodies of a superior affinity than what nature-made B-cells have on offer $[44,60]$. 


\subsection{Secondary phage libraries for affinity maturation}

Although the antibodies selected from many of the immune and even the large single pot repertoires may be extremely useful for the researcher for ELISA, Western blot, immunofluorescence etc., their affinity is often not sufficiently high for therapeutic applications as immunotherapy, viral neutralization, or for use in sensitive diagnosis. Sufficient gain in apparent affinity may be achieved by simply constructing multivalent molecules, as reviewed in $[61,62]$; however there will be situations in which in vitro affinity maturation of the selected antibodies is required.

The process essentially involves three steps, ( 1 ) introduction of diversity in the V-genes of the anibody (or antibodies) chosen to mature, creating a 'secondary' library, (2) selection of the higher affinity from the low affinity variants, and (3) screening to allow discrimination of antibody variants with differences in affinity or kinetics of binding. Diversity in the antibody genes may be introduced using a variety of methods, either more or less random using mutator strains $[63,64]$, error-prone PCR [65], chain shuffling $[9,66]$, and DNA shuffling $[67]$, or directed to defined residues or regions of the V-genes using codon based mutagenesis, oligonucleotide-directed mutagenesis and PCR techniques [58, 68-71]. The non-directed approaches have been used to mature some antibodies with relatively low starting affinity [63, $66,70,72]$. Once antibodies with nanomolar affinities are used as starting leads, it appears that CDR-directed approaches are more successful. For example, residues that modulate affinity may be randomised, ideally 4-6 residues at a time to allow efficient sampling of the sequence space. Such residues that contact the antigen or influence other residues contacting the antigen may be defined experimentally by chain shuffling [16], by alanine-scanning of the CDR-regions [73], by parsimonious mutagenesis [74, 75], or by modeling [73]. Targeting CDRs in parallel has been carried out [71], but additive effects of mutants are frequently unpredictable. The most successful approaches report improvements of affinity to below $100 \mathrm{pM}$, by saturation mutagenesis and affinity selection of CDR3 of heavy and light chain which form the centre of the antibody combining site $[70,71]$. A detailed study of the sequence diversity of human antibodies created in the primary and secondary immune responses also suggests other key residues for targeting in affinity maturation studies [60,76]. Several chapters in [77] give detailed protocols for creating secondary phage libraries; the selection and screening for clones with affinity differences is discussed below:

\subsection{Beyond phage display libraries}

Before we discuss selection and screening procedures in detail, we report on a very recent development that may well allow even larger repertoires of biomolecules to be made, as well as 
facilitate antibody affinity maturation. A display method has been described in which proteins are entirely in vitro translated by, displayed- and selected on ribosomes [78, 79]. The polysome complex containing the encoding mRNA and translated amino acid sequence are utilized for selection with a ligand. The mRNA from selected polysomes is converted into CDNA and used for the next transcription, translation and selection round. Antibody fragments, and in particular scFv's, may form functional molecules in several cell-free translation systems ([80] and ref. in [79]). This approach has therefore recently been used for the display [79, 81] and evolution of a scFv antibody in vitro [79]. This system has the major advantage that the diversity of any repertoire of proteins will not be limited by the host cell/phage life cycle. The size of repertoire that can be sampled is potentially unlimited, and its generation would be very fast and greatly simplified. It remains to be seen whether these in vitro methods will compete with the rather robust in vivo display technologies, but the fact that they are more amenable to automation will definitely favour a swift development.

\section{Phage antibody selection procedures and applications}

\subsection{Diversity in selection methods}

Phage antibody selections involve the sequential enrichment of specific binding phage from a large excess of non-binding clones. This is achieved by multiple rounds of phage binding to the target, washing to remove non-specific phage and elution to retrieve specific binding phage (a schematic outline is depicted in Fig. 1). Any method that separates clones that bind from those that do not, can be used as a selection method, and as such, many different selection methods have been used. In Fig. 4, top panel, the most popular procedures are listed. These include biopanning on immobilised antigen coated onto plastic plates, columns or BIAcore sensorchips [9, 22, 57, 82], selection using biotinylated antigen [65], panning on fixed prokayotic cells [83] and on mammalian cells $[31,56]$. subtractive selection using sorting procedures [56], enrichment on tissue sections or pieces of tissue [84], and, in principle selections using living animals, as was reporied for peptide phage libraires [85]. The selection methods described in Fig. 4, panel A.F, have been extensively described and were reviewed elsewhere $[2,44,77]$.

Phage antibodies bound to antigen can be eluted in different ways: with (one step or gradients of acidic solutions such as $\mathrm{HCl}$ or glycine buffers [86, 87], with basic solutions like triethylamine [22], with DTT when biotin was linked to antigen by a disulphide bridge [20], by enzymatic cleavage of a protease site engineered between the antibody and gene III [88], or by competition with excess antigen [9] or antibodies to the antigen [89]. 

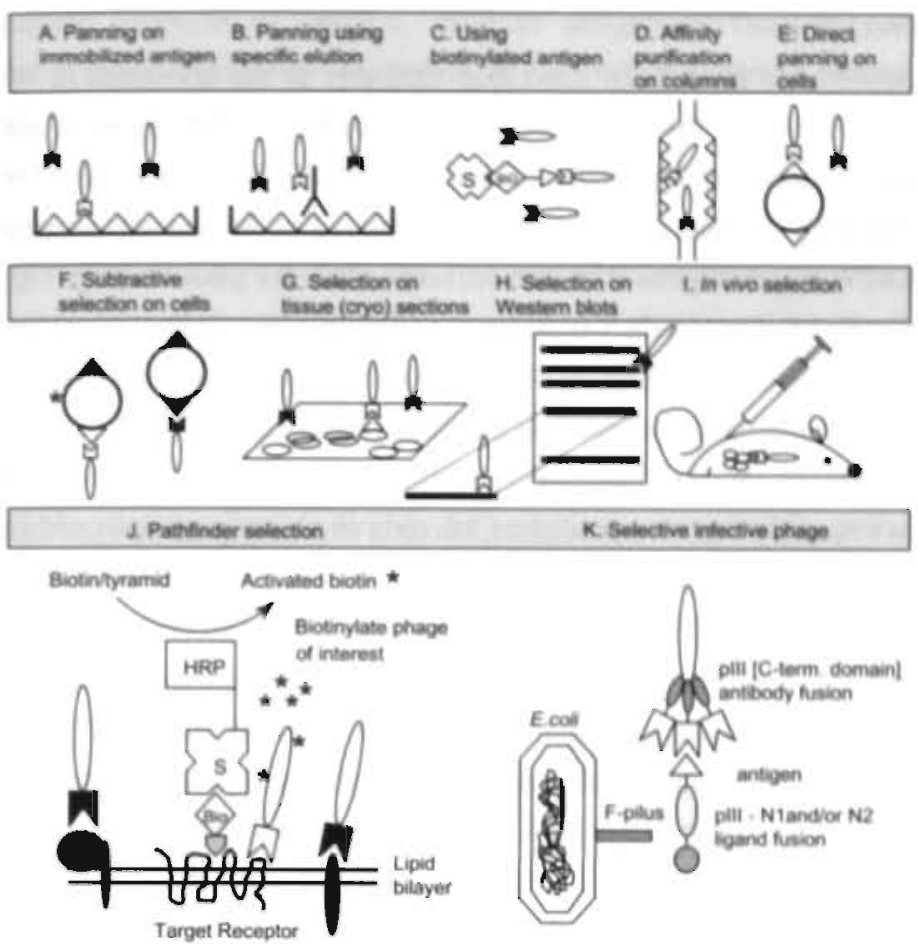

Figure 4

Selection strategies for obtaining specific phage ligands.

Affinity selection of phage (antibody) libraries by (a) panning on antigen adsorbal onto a solid support. After washing. specific phage is eluted with acid or basic solutions: (b) altematively elution with antibody or an excess of the antigen is possible. (c) To avoid conformational changes during coating, selection of specific antibodies to biotinylated antigen in solution is more favoured. Bound and unbound phage antibodies are separated using streptavidin-coated magnetic beads. (d) Antigen can be immobilized onto a column for affinity selection. (e) Selection on cells can be done directly by panning on cell monolayers or cells in suspension. (f) Subtraction via

FACS: the cells of interest are fluorescently labeled and separated from theothers by cell sorting. (g) Tissue and organ specific phage antibodies might be obtained by selection on tissue slides. (h) Non-purifiable or unknow antigens may be separated on SDS-PAGE and blotted onto membranes for selection. (i) In vivo selection. (j) The procedure of 'Pathfinder' selection, and $(\mathrm{k})$ infection-mediated selection. Specific phage carry a white ligand irrelevant phage a black one.

Phage background binding to the matrix or antigen itself inevitably necessitates the repetition of the selection procedure. Background problems may diminish when repeated selections of phage libraries are carried out without amplification step, by reusing the eluted and neutralized polyclonal phage ligands directly for selection, as reported for protease inhibitors [90]. Some recent evidence indicates that anti-hapten antibodies may also by isolated by 3 rounds of panning without re-amplification, using a very large naïve Fab library (de Haard, H.R.H., et al., unpublished). If in vivo re-amplification steps could be by-passed, it might be possible to fully automate the isolation of antibody fragments from very large libraries. During affinity maturation studies direct selection without re-amplification may speed up the procedure. and reduce selection of aberrant clones with a growth but no affinity advantage $[16,65]$. 


\subsection{Infection-based selection methods}

Alternative selection methods have been described that aim at the co-selection of antibodies and their cognate antigens. In the 'selectively infective phage' (SIP) method, an antibody library is made using non-infective phage particles, by deleting part of the gene III protein. Infection will be restored by binding a fusion protein consisting of the cognate antigen and the two first amino terminal domains of gene III which are responsible for pilus binding (Fig. 5) [91-93], reviewed in [94]. The fusion product may be supplied in vitro; infection of the antibody-displaying phage will be mediated in a small concentration window. In the alternative, in vivo, system, both antibody and antigen are encoded on the same phage genome. Both affinity and folding properties have been shown to influence the selection of antibodies with the SIP methodology [95]. Finally, in a recently reported procedure, bacteria expressing epitopes within the context of the F pilus were proven to be infected by phage only when they displayed an antibody recognising the epitope [96]. It still remains to be seen whether these selection systems will be more efficient than standard procedures in isolating antibodies from very large naïve or synthetic antibody libraries. A better understanding of the infection process itself [97] may eventually lead to more generic application of these procedures in isolating interacting proteinligand pairs.

\subsection{Selection for affinity}

In a similar fashion to what happens in vivo during B-celi selection, phage antibodies with higher affinity may be enriched during successive rounds of selection by decreasing the concentration of antigen used for selection. The selection may be chosen to favour affinity or kinetic parameters such as off-rate; this hinges on the use of limited and decreasing amounts of antigen and on performing the selections in solution rather than by avidity-prone panning on coated antigen [65]. When selecting from a secondary phage library (see section 3.3), the antigen concentration is typically reduced below the $\mathrm{K}_{\mathrm{d}}$ of the parent clone to allow preferential selection of higher affinity mutants [65]. In one of the most thorough studies on antibody affinity maturation carried out to date [73], it was necessary to empirically determine the antigen concentration to be used for selection, as well as the elution condition for phage retrieval, using BIAcore [98]. The SIP procedure may also be used to enrich antibodies for certain kinetic parameters $[95,99]$.

\subsection{Selection on complex antigens}

Most successes with selections have been reported using purified antigen. Selections on impure antigens are significantly more difficult, due to the problem of limited amount of target antigen present in the mixture, and of enrichment of phage antibodies specific for non-relevant 
antigens. Examples of complex, "difficult" antigens are those that cannot easily be purified from contaminants with similar properties, or cell surface receptors that are only functionally retained in lipid bilayers. Depletion and/or subtraction methods, competitive elution with an antibody or the antigen itself [89], or selection by alternating between different sources of antigen [100] may be used. Theoretical, as well as experimental studies may help to understand the extent to which different parameters govern the outcome of subtractive selection processes [101-103]. The enrichment of phage antibodies specific for the target antigen is also influenced by the background binding of non-specific phage particles, which necessitates reiteration of the selection procedure. Background problems may diminish when repeated selections of phage libraries are carried out without amplification step, by reusing the eluted and neutralized polyclonal phage ligands directly for selection, as reported for protease inhibitors [90]. During affinity maturation studies, direct selection without re-amplification may speed up the procedure and reduce selection of abberant clones with growth advantages [65]. Some recent evidence indicates that anti-hapten antibodies may also by isolated by 3 rounds of panning without reamplification, using a very large naïve Fab library (de Haard, H.R.H., et al., unpublished). If in vivo re-amplification steps could be by-passed, it might be possible to fully automate the isolation of antibody fragments from very large libraries. Background binding of phage has also been a major obstacle to carry out selection on antigens blotted onto nitrocellulose or other membranes. Such a procedure could be applied to batch-select phage antibodies to very large collections of (denatured) antigens, and possibly to isolate antibodies to small quantities of partially purified proteins. Using combinations of detergents, we have recently succeeded in obtaining a 10-50-fold enrichment on Westem blots using a low affinity phage antibody $\left(10^{7} \mathrm{M}^{1}\right)$ to the UIA protein (Fig. 4H; R.M.H. et al., in preparation).

\subsection{Selection on cells}

A special case form the antigens present on cell surfaces. Direct panning on cell surfaces carrying the antigen may be carried out on adherent cells grown in monolayers, or on intact cells in suspension (Fig. 4E) [31, 104, 105]. This may fortuitously select for antigen-specific phage antibodies, in particular when using immune libraries in which the frequency of irrelevant phage antibodies will be lower [31, 104]. Depletion and/or subtraction methods, cell sorting (Fig. 4F) using flow cytometry [56] or magnetic bead systems [106], competitive elution with an antigenspecific ligand or antibody, or selection by alternating between different cell types all carrying the antigen, are possible, at least in theory. However, it should be noted that in many cases, antigens will be present at very low densities on the cell surface, and antigen concentrations during selections will reach values much lower than the $\mathrm{K}_{\mathrm{d}}$ of any antibody in the library. Even when antigen concentration is sufficient for antibody binding and retrieval, antigen inaccessibility 
through steric hindrance caused by the presence of other proteins or glycosylation may prevent the selection of antibodies specific for the target antigen. This may be illustrated by an example of a naivve library selection [45] that we carried out on cell transfectants, which expressed relatively high levels (200.000 copies per cell) of one of two very different membrane antigens. Strikingly different results were obtained, depending on the structure and nature of the transmembrane protein. Selections on $\mathrm{CHO}$ cells one of the $\mathrm{G}$-protein coupled seven-helix transmembrane receptors for somatostatin were unsuccessful, despite extensive pre-absorption of phage with receptor-negative cells. On the other hand, direct panning (without depletion) on cells carrying the transmembrane glycoproteins CD36 at similar surface density; generated a large collection of antigen-specific antibodies to a selection-dominant epitope on the antigen (Lutgerink, H.R.H., et al., in preparation). It is therefore difficult to assess the value of subtractive methods, i.e. cell sorting by flow cytometry [56] or magnetic activated cell separation [106], without a direct comparison with cell panning. Nevertheless, for most applications, it is likely that more refined subtraction methods will be required to home in on antigen-specific phage antibodies.

The feasibility of selecting antibodies to "difficult" complex antigens and in particular to cell surface molecules would expand the utility of phage antibody libraries tremendously. However, for such antigens the selection conditions including pre-treatment of the samples, incubation conditions, washing procedure and phage retrieval, need to be established empirically. We have developed a model that can compare and determine the relative efficacies of the various enrichment procedures on complex sources of antigen. Phage canying a scFv specific for the tumor-associated antigen epithelial glycoprotein-2 (EGP-2) were mixed with an excess of irrelevant phage and the enrichment factor and recovery of specific phage were determined after a single round of selection. As antigen source we ưsed a tumour cell line, a tissue cryosection of prinary colon carcinoma and (subcutaneous) in vivo grown solid tumours in mice (Fig. 4E, G and I). Our results, summarised in Table 1, show that there are major differences with regards to selection efficacy; however, antibody-displaying phage were enriched in all but one selection method.

The efficacy of the procedure depends on the antigen amount and concentration (Table 1; estimated to decline from top to bottom) and on antigen accessibility. The most efficient procedure, recovery of phage using panning on cells in suspension (2-5\% recovery of the input phage), reaches an enrichment factor similar to what has been reported for purified antigens [102]. For the in vivo selection, antibody-displaying phage are enriched over non-binding phage only when phage are directly injected into the tumour interstitium, but not when injected 
intravenously. Efficient in vivo selection may thus be suited only for antigens that are in direct contact with the blood stream i.e. endothelial cell antigens [107]. Such model selections help in defining the optimal experimental parameters for selections on complex antigens.

\section{Table 1}

Enrichment factors and phage recovery after a single round of selection on different complex antigens

\begin{tabular}{|c|c|c|}
\hline $\begin{array}{l}\text { Colon cancer } \\
\text { cell line }\end{array}$ & $\begin{array}{l}\text { Panning on cells in sus- } \\
\text { pension }\end{array}$ & 10,000 \\
\hline
\end{tabular}

\begin{tabular}{llll}
$\begin{array}{l}\text { Tissue } \\
\text { cryosection }\end{array}$ & $\begin{array}{l}\text { Panning on glass slide- } \\
\text { mounted cryosections }\end{array}$ & 80 & 0.02 \\
\hline
\end{tabular}

\begin{tabular}{llcc}
$\begin{array}{l}\text { In vivo grown } \\
\text { tumour }\end{array}$ & $\begin{array}{l}\text { Injection of phage into } \\
\text { tumour interstitium }\end{array}$ & 10 & 0.005 \\
\hline
\end{tabular}

\begin{tabular}{lll}
$\begin{array}{l}\text { In vivo grown } \\
\text { tumour }\end{array}$ & $\begin{array}{l}\text { Injection of phage into the none } \\
\text { tail vein }\end{array}$ & 0.001 \\
\hline
\end{tabular}

' Phage mixtures of an excess of control phage over specific (anti EGP-2) phage were selected on a number $\delta$ different antigen sources. Since antigen-specific and control phage confer a different antibiotic resistance to tie bacterial host upon infection (ampicillin (AMP) and tetracyclin (TET) respectively), arichment and recovery of binding phage can easily be determined by titration and parallel selection on both antibiotics. Recovery of specife phage was calculated as the amount (percentage) of AMP-resistant colonies (cfu), recovered after one round $\boldsymbol{\sigma}$ selection. Enrichment factors were calculated as the product of ntios of AMP and TET-resistant colonies before and after selection, according to the formula (in = input titer; out = output titer): enrichment factor $=\left(\mathrm{Ccfu}_{\text {ia }}\right)$

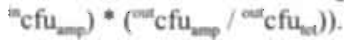

\subsection{Finding new antigens with large phage libraries}

Selection from phage antibody libraries provides a new tool for the isolation of novel self antigens, such as disease- (e.g. tumour-) associated antigens. Both the de novo combined Vdomain pairs in naïve and synthetic antibody libraries (but particularly the latter) are not shaped by the constraints of the immune system, and avoid library bias caused by in vivo tolerance mechanisms. Therefore, antibodies to unique self-epitopes can be isolated, provided powerful cell depletion or subtraction methods are available. To date, this application has been used for probing lymphocyte [56] and tumor [31] cell surfaces, yielding antibodies to known antigens and a number of promising but as yet uncloned new cell-type specific antigens. We have recently 
generated panels of anti-epithelial cell antibodies by panning a large naïve antibody library on tumour cell lines, but also with libraries derived from the B-cells of a tumour draining lymph node of a patient with colorectal cancer (R.C.R. et al., in preparation). These studies will help to study the natural humoral immune response of cancer patients to the autologous tumour and will possibly identify alternative targets for active or passive immunotherapy.

A recently described method, called 'Pathfinder' selection, might be suitable to overcome several difficulties associated with phage antibody selections, i.e, the use of complex antigens like cell surfaces for selection and the preferential selection of antibodies to dominant epitopes on a given antigen [108]; the procedure is schematically depicted in Fig. 4K. The method uses a peroxidaseconjugated ligand ("lead") to deposit biotin-tyramine free radicals in a local area around the binding site of the lead. If phage are bound within this radius (of approximately $25 \mathrm{~nm}$ ), they will be biotinylated and therefore retrievable on streptavidin-coated beads. The target antigen in this procedure can be anything from a purified protein to a receptor on a cell surface, or an antigen fixed on tissue sections. The procedure was examplified by selecting antibodies to TGF- $\beta \mathrm{i}, \mathrm{CEA}$ and a cell surface receptor, CC-CKR5. The method may overcome problems of 'selectiondominant' epitopes, as well as provide a means to select phage antibodies to rare cell surface receptors of orphan ligands.

\section{Phage antibody screening procedures and applications}

\subsection{Basic screening assays}

The outcome of any selection procedure is a mixture of binding ligands with differing properties. It may be necessary to screen large numbers of antibodies to identify those variants with the most optimal characteristics. The best screening assays are fast, robusi, amenable to automation (96-well format), and use unpurified phage antibodies, or the soluble antibody fragments from the bacterial supematant. The screening assay should also be linked as closely as possible to the ultimate (functional) requirements of the ligand. Binding of poly- or monoclonal phage antibodies to the antigen has been tested with diverse assays, ranging from a simple ELISA with coated antigen [22], to bioassays that screen for direct neutralization upon binding [109], and whole cell ELISA or flow cytometry. Typically, for a first screen ELISAbased assays are used, in combination with restriction-fingerprinting of the antibody-DNA to identify different clones [22]. Further, specificity of antibodies may be tested using immunoprecipitation [36] or immunocyto- or histochemistry [84, 110]. 
To speed up screening procedures, phagemid vectors that incorporate a dual purpose have been developed. These allow both monovalent display of antibody fragments and the production of soluble antibody fragments for screening without the necessity to subclone the antibody V-genes. In such systems, an amber codon is positioned between the antibody and pIII genes; in $E$. coli suppressor strains, expression of the fusion product for incorporation into the phage coat is possible; in non-suppressor strains, this amber serves as a stop codon yielding soluble antibody fragments [11] (due to incomplete suppression, this will also happen to some extend in suppressor strains). A variety of tags have been described that are appended to the antibody fragment for detection, including the myc-derived tag recognised by the antibody $9 \mathrm{E} 10$ [22], and the Flag sequence [111, 112]. This set-up will allow the use of unpurified phage antibodies or antibody fragments, present in crude supernatant or periplasmic extracts, for screening assays. Finally, it is possible to fuse, for example in between the antibody and gII, a Histidine-encoding tag, for purification of soluble antibodies using Immobilised Metal Affinity Chromatography $[113,114]$ and detection with antibodies.

\subsection{Screening for affinity or kinetics of binding}

After selection of the higher affinity from the low affinity variants, the screening assay will need to differentiate between antibody variants with differences in affinity or kinetics of binding. ELISA-based methods have been described as well as screening using BIAcore [71, 73]; for extensive discussion see [115] and various chapters in [77]). Affinity and dissociation rate screening on the BIAcore is particularly straight forward when using antibody Fab fragments. These lack the problem of the multimerisation behaviour inherent to many scFv formats [61], which complicates measurement of the kinetics of antigen binding of unpurified scFv fragments. We have developed on- and off-rate screening assays for panels of unpurified Fab fragments using periplasmic extracts (A. Reurs, H.R.H., in preparation; an example of an off-rate screen is shown in Fig. 5A). In combination with BIAcore-based methods to determine the amount of Fab in these crude preparations (necessary for accurate determination of the association rate constants [116]), the affinity of large panels of antibodies may be determined. A routine, reliable determination of affinity constants is very important in deciding which molecules to use in further analysis and affinity maturation steps. It should be kept in mind that it will be necessary to test biological potency, cross-reactivity and expression level to further assess the potential of the affinity matured candidates, as these parameters may change with changing affinity [117, [18]. 

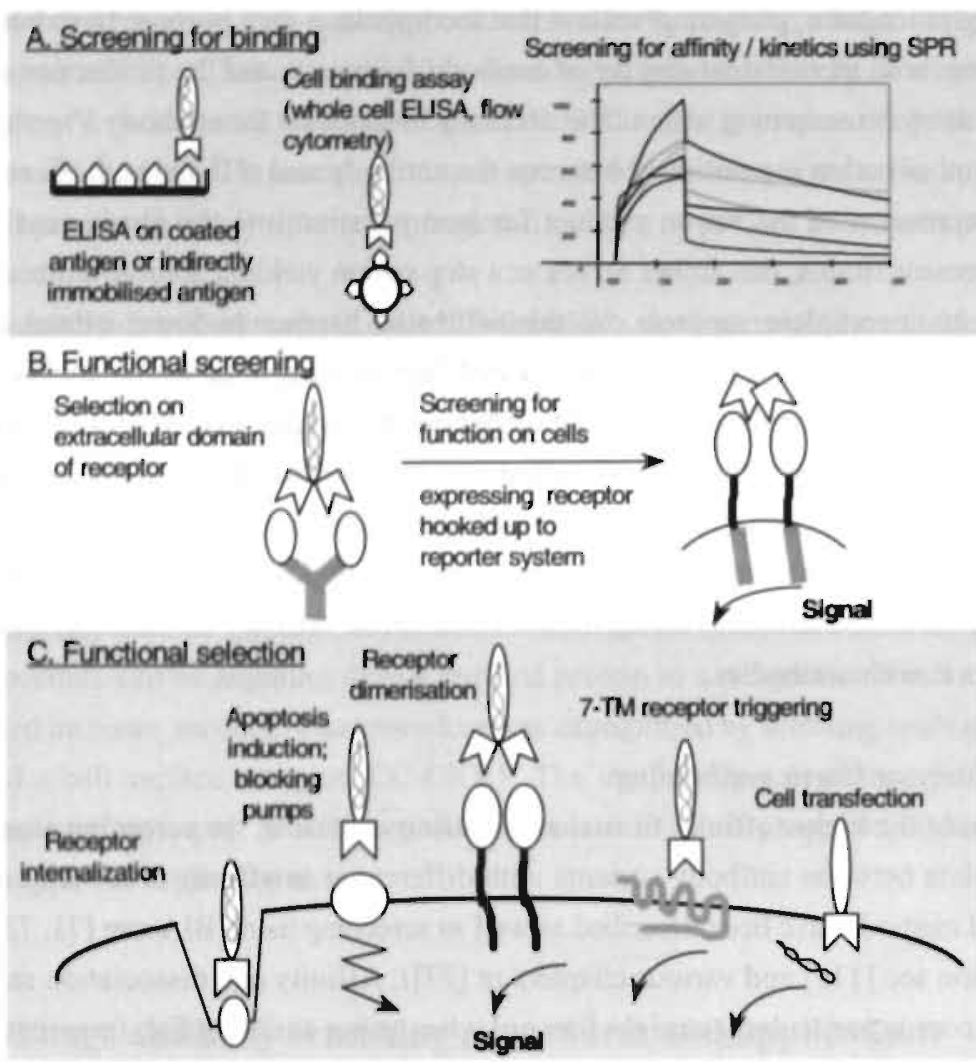

\section{Combininglprocedures}

\section{Selection of phage}

for binding

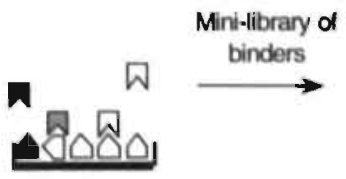

Transfection into eukaryotic cells followed by selection for survival

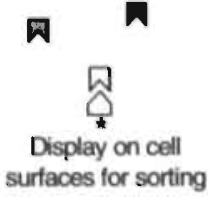

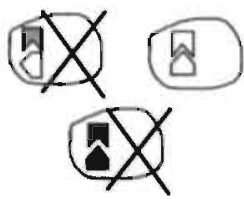

\section{Figure 5}

Multiple strategies for selecting and screening phage ligands.

(a) Primary screens of selected phage ligands frequently involve tests to measure binding, including ELISA, cell binding methods and BIAcore screening. (b) Alternatively, selected phage ligands may be tested for bioactivity, for example by selecting on a receptorimmunoadhesin, and screening for receptor triggering on cells. (c) Direct selection of phage ligands for a particular function may be envisaged using a variety of methods; depicted here are cellrelated methods only. (d) Example of a combined procedure, involving selection of antigen-binding phage ligands, and a secundary selection in an alternative system, i.e. using a prokayotic or eukaryotic cell system, either for affinity sorting, or for selection based on cell survival (see text for details).

\subsection{Recloning selected phage antibodies for expression in other hosts.}

One drawback for analysis after the first screen is that antibody expression levels in E.coli are dependent on the primary sequence of the individual antibody, and can be extremely variable (from $10 \mu \mathrm{g}$ to $100 \mathrm{mg} / \mathrm{L}$ ). Unless expression is at sufficiently high levels, consideration should be given to re-cloning the antibody into another expression system (for review see [61]). To reformat selected antibodies, however, fast recloning methods are needed in those cases where 
large numbers of clones need to be screened. Recently a eukaryotic expression vector was described that may be used for one-step re-cloning of V-genes derived from any phage repertoire, and cloned for expression as Fab fragments or whole antibody, or for targeting to different intracellular compartments [119, 120]. This permits facile and rapid, one-step cloning of antibody genes for either transient or stable expression in mammalian cells. By carefully choosing restriction sites that are rare in human $\mathrm{V}$ genes, the immunoglobulin genes of selected populations may be batch-cloned into these expression vectors. All the important elements in the vectors -promoter, leader sequence, constant domains and selectable markers- are flanked by unique restriction sites, allowing simple substitution of elements, and further engineering. By design of the correct promoter cassette, ribosome binding site, 'consensus' signal sequences and by using 'intron space' appropriately, it should be possible to create vectors that mediate both phage display of antibody fragments in prokaryotic hosts, as well as expression of antibody fragments or whole antibodies from eukaryotic hosts (A. Bradbury and H.R.H., unpublished). Such shuttle vectors would be suitable for linking selection of panels of binding antibodies, with a screening assay based on a particular format of the antibody, to be expressed in cukaryotic cells. In addition, it would allow the combination of different methods of display or combinatorial library screening. For example, a pre-selection for binding from a very large bacteriophage display library, followed by a fine-tuned affinity selection by means of flow cytometry of the medium-sized library using yeast or bacterial surface display (Fig. 5D) can be envisaged. In a milestone study which is further discussed in section 5.5, Gargano and Cattaneo [121] demonstrate the power of such combined methods for retrieving biologically active anti-viral agents.

\subsection{Bioactivity assays with phage antibodies and peptides}

Fast read-out is particularly required for screening methods where the influence of affinity or kinetic behaviour is unclear or less important than the functional result of binding, e.g. virus or cytokine neutralization and receptor blocking or triggering. In such assays many different factors besides epitope recognition or antibody affinity will determine antibody. Methods have been reported to quickly test phage derived Fab or scFv fragments for their blocking or enhancing effect on the activity of a growth factor [109], or for their direct receptor triggering effects based on receptor dimerisation [122]. In the latter case, high affinity anti-MuSK antibodies were selected from a large naïve antibody library by selection on an MuSK-Fc immuno-adhesin, and scFv-agonists were identified by screening on cells expressing a chimeric MuSK-Mpl receptor (Fig. 5B). An elegant study with Epidermal Growth Factor displayed on phage demonstrates that phage particles themselves may also induce receptor triggering [123]. The applicability of this screening method for phage antibodies has to be proven still, and will depend on the mechanism 
of receptor triggering and receptor accessibility.

In the example of MuSK, receptor dimerization is required for signal transduction, thus the ligand needs to be dimeric, either by multivalent display on phage or via natural dimerisation, like has been noted for scFv fragments [122]. The use of repertoires of bivalent ligands, such as 'diabody' libraries [26], would be preferable for these applications. Phage-mediated receptor triggering is, however, also feasible for receptors that do not require dimerisation for activation, in particular for phage that recognise G-protein coupled receptors with multiple membrane spanning regions, which are normally triggered directly via ligand interaction. Such receptors have a wide range of activities and have therefore been used as target for ligand screening using chemical peptide and other libraries. We have recently obtained evidence that peptide liganddisplaying phage themselves may act as receptor agonists (Rousch, H.R.H. et al., submitted), a feature which will dramatically simplify screening for phage-based ligands in search of a(nta)gonistic lead compounds. Phage carrying somatostatin, a 14-mer cyclic peptide, were shown to be enriched via panning on cells expressing one of its receptors, and also scored positive in flow cytometry, whole cell ELISA and ELISA using anti-ligand sera. Upon cell binding, this phage lowered intracellular cAMP concentration and reduced adenylyi cyclase activity, providing evidence for specific triggering of this G-protein coupled 7-TM receptor. To date only one other study has addressed phage-mediated triggering of 7-TM receptors [124]: in this study the melanocortin receptor was triggered using one of the receptor's natural ligands displayed on phage. It should thus be feasible to isolate receptor-specific ligands from phage libraries, using panning on cells that overexpress the target receptor, and screen the selected phage directly for activity. After selection for binding, individual phage clones may be screened for receptor triggering, effects, to differentiate agonists from antagonists from irrelevant binders.

\section{New avenues for phage libraries}

\subsection{Selection for function}

With large libraries at hand, we may go beyond the in vitro binding interaction itself, and select for a particular function. For example, provided reporter systems with sufficient sensitivity' are used, it may eventually be possible to sort ce!!s which have been triggered by a phage partic!e displaying an a(nta)gonistic ligand. Such sorting procedures could allow the direct selection of phage particles with agonist or antagonist activity for a given receptor directly from the phage library. With new reporter genes and sensitive fluorescent read-out methods under development (for review, see Ref. [125]), we envisage that such 'functional selection' schemes will be useful tools for drug discovery. Such methods may be used to identify peptide ligands for orphan 
receptors (such as the many related opioid receptors), for which a function but not a natural ligand is known. Examples of already demonstrated functional selection methods are found in retrieving catalytic antibodies [126]; as yet underexplored routes are selection for cell internalization [127], cell survival or killing (induction of apoptosis) upon ligand binding, cell transfection, specific inhibition of certain cell surface molecules such as drug pumps, (inhibition of) viral entry, and, finally, receptor cross-linking or triggering. The list of these novel applications, some of which are depicted in Fig. 5C, will keep growing as access to the technology widens.

\subsection{Combining phage display with other procedures}

Functional selection may also be carried out, after preselection of antigen-specific phage antibodies, using selection schemes in other cellular systems. In Fig. X two of such possible procedures are described. The first hypothetical application is to display the selected library on the surface of particles which are large enough to allow affinity sorting (bacteria, yeast or mammalian cells [128], reviewed in [129]). This could possibly provide a rapid method for antibody affinity maturation. The other application involves a selection step for bioactivity, which allows to select for a subset of phage library-derived ligands from a mini-library of ligands that interact with the target antigen. An elegant example of this, using intracellular selection, was described by Gargano and Cattaneo [121]. They developed a model system showing that intracellularly (cytosolic) expressed antibody fragments that block the activity of reverse transcriptase (RT), can inhibit integration of a retrovirus containing the Herpes Simplex Thymidine Kinase gene, resulting in the selective survival of transfected cells through protection against the cytotoxic action of Gancyclovir. Using pools of antibody fragments, cloned in expression vectors that mediate cytosolic expression of the antibodies, it was possible to select the antibody with neutralizing activity for reverse transcriptase from a polyclonal population of antibodies that just bound (but not blocked) RT. This suggests that it may be possible to combine the power of the large phage libraries, to select pools of antigen-specific phage antibodies together with their genetic material, with a subsequent selection of the population using a mammalian host cell [121], or other cell systems [130]. This combination of technologies may indeed optimally utilize the advantages of each system and also by-pass some of the disadvantages of individual methods.

\section{Beyond antibodies}

The ideas on functional selections and screening procedures may be expanded to the use of alternative proteins or protein domains for constructing binding molecules (reviewed in [131]). 
Scaffolds different from antibodies have been reported to form suitable binding ligands for many types of antigens. There are ample examples of 'host scaffolds' that contain sufficient permissive regions to accomodate a reasonable numbers of substitutions, which may be used to generate a library of localised variability. Alternative scaffolds reported to date include $\beta$-sheet proteins $[132,133], \alpha$-helical bundle proteins [134-138], combinations of these two [139, 140], a separate group of highly constrained protease inhibitors [141-143], and, most recently, Green Fluorescent Protein (GFP) [144]. Since secreted as well as cytoplasmic and nuclear proteins have been displayed on phage (for review see [3]), display on phage is often the first strategy to define permissive sites for randomization and to generate ligand-binding variants [145]. Alternatively, the use of lambda [146], bacterial [129] or eukaryotic cell display methods has been reported. In regards of 'functional selection' methods, choosing other types of molecule besides antibodies is validated by the fact that antibody expression and folding may be impaired in the subcellular location where the desired functional activity is required. It would be advantageous to engineer the antibody for intracellular expression, for example by building stable disulphide free antibodies [147], or to use libraries of scaffolds that are naturally produced in the targeted cell organelle, provided that effective structural diversity may be obtained.

\section{Perspectives}

This review highlights the advantages and possible applications of phage display for the development of antibodies. With this technology, antibody engineering for the first time may be used to design antibodies from scratch, with an option to choose its building blocks, its affunity (up to the picomolar range), its format (size and valency) and its effector function (natural (IgG) or novel (enzymes etc.) [148]. Tailor-made reagents may thus be generated, for in vitro or in vivo diagnosis and for therapy. We expect that the number and quality of naive and synthetic phageantibody libraries will increase over the next few years. The extent of the use of phage antibody libraries in academic research will benefit from a virtual unrestricted availability of such very large and stable phage libraries. The libraries may be used for the search for new drug targets, cell receptors and their ligands, which will interface with the human genome project and functional genomics. Combining the design and generation of millions to billions of different ligands, with a function-based selection procedure rather than mere selection for binding, will open even more challenging applications of this inspiring technology, and provide a powerful tool for drug and target discovery well into the next decade. 


\section{Acknowledgements}

This work has been supported by grants from the Profileringsfonds of the University Hospital Maastricht (grant PF37), the European Community, Biotechnology Programme 5.1 (PL950252), and receives financial support from the Netherlands Technology Foundation (STW) in a project coordinated by the Life Sciences Foundation (SLW) (project 805.17.753).

\section{References}

1. Smith, G.P. (1985) Science 228, 1315-1317.

2. Winter, G., Griffiths, A.D., Hawkins, R.E. and Hoogenboom, H.R. (1994) Ann. Rev. Immunol. 12, 433-455.

3. Abelson, J., . Methods in Enzymology, ed. J. Abelson and M. Simon. Vol. 267. 1996, San Diego: Academic Press, INC. 493.

4. Kay, B.K., Winter, J. and McCafferty, J., . 1996, San Diego: Academic Press İnc.

5. McCafferty, J., Griffiths, A.D., Winter, G. and Chiswell, D.J. (1990) Nature 348, 552-554.

6. Zacher, A.N., Stock, C.A., Golden, J.W. and Smith, G.P. (1980) Gene 9, 127-140.

7. Skerra, A. and Pluckthun, A. (1988) Science 240, 1038-1041.

8. Better, M., Chang, C.P., Robinson, R.R. and Horwitz, A.H. (1988) Science 240, 1041-1043. 9. Clackson, T., Hoogenboom, H.R., Griffiths, A.D. and Winter, G. (1991) Nature 352, 624628.

10. Garrard, L.J., Yang, M., O'Connell, M.P., Kelley, R.F. and Henner, D.J. (1991) BioTechnology 9, 1373-1377.

11. Hoogenboom, H.R., Griffiths, A.D., Johnson, K.S., Chiswell, D.J., Hudson, P. and Winter, G. (1991) Nucleic Acids Res 19, 4133-4137.

12. Bass, S., Greene, R. and Wells, J.A. (1990) Proteins 8, 309-314.

13. Barbas, C., Kang, A.S., Lerner, R.A. and Benkovic, S.J. (1991) Proc Natl Acad Sci USA 88, 7978-7982.

14. Orum, H., Andersen, P.S., Oster, A., Johansen, L.K., Riise, E., Bjornvad, M., Svendsen, I. and Engberg, J. (1993) Nucleic Acids Res 21, 4491-4498.

15. Breitling, F., Dubel, S., Seehaus, T., Klewinghaus, I. and Little, M. (1991) Gene 104, 147153.

16. Thompson, J., Pope, T., Tung, J.S., Chan, C., Hollis, G., Mark, G. and Johnson, K.S. (1996) $J$ Mol Biol 256, 77-88.

17. Krebber, A., Burmester, J. and Pluckthun, A. (1996) Gene 178, 71-74.

18. Rakonjac, J., Jovanovic, G. and Model, P. (1997) Gene 198, 99-103.

19. Lutz, R. and Bujard, H. (1997) Nucleic Acids Res 25, 1203-12I0.

20. Griffiths, A.D., Malmqvist, M., Marks, J.D., Bye, J.M., Embleton, M.J., McCafferty, J., Baier, M., Holliger, K.P., Gorick, B.D., Hughes, J.N., Hoogenboom, H.R. and Winter, G. (1993) EMBO J 12, 725-734.

21. Duenas, M. and Borrebaeck, C.A. (1995) FEMS Microbiol Lett 125, 317-321.

22. Marks, J.D., Hoogenboom, H.R., Bonnert, T.P., McCafferty, J., Griffiths, A.D. and Winter, G. (1991) J Mol Biol 222, 581-597.

23. Chang, C.N., Landolfi, N.F and Queen, C. (1991) J. Immunology 147, 3610-3614. 
24. Brinkmann, U., Chowdhury, P.S., Roscoe, D.M. and Pastan, I. (1995) J Immunol Methods 182, $41-50$.

25. Holliger, P., Prospero, T. and Winter, G. (1993) Proc Natl Acad Sci U S A 90, 6444-6448. 26. McGuinness, B.T., Walter, G., FitzGerald, K., Schuler, P., Mahoney, W., Duncan, A.R. and Hoogenboom, H.R. (1996) Nature Biotechnol. 14, 1149-I154.

27. Burton, D.R., Barbas, C.F., Persson, M.A.A., Koenig, S., Chanock, R.M. and Lerner, R.A. (1991) Proc. Natl. Acad. Sci. USA 88, 10134-10137.

28. Chester, K.A., Begent, R.H., Robson, L., Keep, P., Pedley, R.B., Boden, J.A., Boxer, G., Green, A., Winter, G., Cochet, O. and et, a. (1994) Lancet 343, 455-456.

29. Kettleborough, C.A., Ansell, K.H., Allen, R.W., Rosell-Vives, E., Gussow, D.H. and Bendig, M.M. (1994) Eur J Immunol 24, 952-958.

30. Barbas, C.F., Collet, T.A., Amberg, W., Roben, P., Binley, J.M., Hoelstra, D., Cababa, D., Jones, T.M., Williamson, A., Piklinlgton, G.R., Haigwood, N.L., Cabezas, E., Satterhwait, A.C., Sanz, I. and Burton, D.R. (1993) J. Mol. Biol. 230, 812-823.

31. Cai, X. and Garen, A. (1995) Proc. Natl. Acad. Sci USA 92, 6537-6541.

32. Davies, E.L., Smith, J.S., Birkett, C.R., Manser, J.M., Anderson, D.D. and Young, I.R. (1995) J Immunol Methods 186, 125-135.

33. Yamanaka, H.I., Inoue, T. and Ikeda, T.O. (1996) J Immunol 157, 1156-1162.

34. Lang, I.M., Barbas, C.r. and Schleef, R.R. (1996) Gene 172, 295-298.

35. Arbabi Ghahroudi, M., Desmyter, A., Wyns, L., Hamers, R. and Muyldermans, S. (1997) FEBS Lett 414, 521-526.

36. de Wildt, R.M., Finnern, R., Ouwehand, W.H., Griffiths, A.D., van Venrooij, W.J. and Hoet, R.M. (1996) Eur J Immunol 26, 629-639.

37. Finnern, R., Pedrollo, E., Fisch, I., Wieslander, J., Marks, J.D., Lockwood, C.M. and Ouwehand, W.H. (1997) Clin Exp Immunol 107, 269-281.

38. Graus, Y.F., de Baets, M.H., Parren, P.W., Berrih-Aknin, S., Wokke, J., van Breda Vriesman, P.J. and Burton, D.R. (1997) J Immunol 158, 1919-1929.

39. Barbas, C.F. and Burton, D.R. (1996) Trends Biotechnol 14, 230-234.

40. Pereira, S., Van Belle, P., Elder, D., Maruyama, H., Jacob, L., Sivanandham, M., Wallack, M., Siegel, D. and Herlyn, D. (1997) Hybridoma 16, 11-16.

41. Clark, M.A., Hawkins, N.J., Papaioannou, A., Fiddes, R.J. and Ward, R.L. (1997) Clin Exp Immunol 109, 166-174.

42. Duenas, M., Chin, L.T., Malmborg. A.C. Casalvilla, R., Ohlin, M. and Borrebaeck, C.A. (1996), Immunology 89, 1-7.

43. Moreno de Alboran, 1., Martinez-alonso, C., Barbas, C.F., 3rd, Burton, D.R. and Ditzel, H.J. (1995) Immunotechnology 1, 2!-28:

44. Hoogenboom, H.R. (1997) Trends Biotechnol 15, 62-70.

45. Vaughan, T.P., Williams A.W., Pritchard, K., Osbourn, J.K., Pope, A.R., J.C., E., McCafferty, J., Hodits, R.A., Wilton, J. and Johnson, K.S. (1996) Nat Biotechnol 14, 309-31.4. 46. Gram, H., Marconi, L., Barbas, C.F., Collet, T.A., Lerner, R.A. and Kang, A.S. (1992) Proc. Natl. Acad. Sci. USA 89, 3576-3580.

47. Marks, J.D., Tristem, M., Karpas, A. and Winter, G. (1991) Eur J'Immunol 21, 985-991.

48. Klein, U., Kuppers, R. and Rajewsky, K. (1997) Blood 89, 1288-1298.

49. Perelson, A.S. and Oster, G.F. (1979) J. Theor. Biol. 81, 645-670.

50. Hoogenboom. H.R. and Winter, G. (1992) J Mol Biol 227, 381-388. 
51. Barbas, C.F., Bain, J.D., Hoekstra, D.M. and Lemer, R. (1992) Proc. Natl. Acad. Sci. US.A 89, 4457-4461.

52. Chothia, C., Lesk, A.M., Tramontano, A., Levitt, M., Smith-Gill, S.J., Air, G., Sheriff, S., Padlan, E.A., Davies, D., Tulip, W.R. and et, a. (1989) Nature 342, 877-883.

53. Nissim, A., Hoogenboom, H.R., Tomlinson, L.M., Flynn, G., Midgley, C., Lane, D. and Winter, G. (1994) EMBO J 13, $692-698$.

54. Garrard, L.J. and Henner, D.J. (1993) Gene 128, 103-109.

55. Soderlind, E., Vergeles, M. and Borrebaeck, C.A. (1995) Gene 160, 269-272.

56. de Kruif, J., Terstappen, L., Boel, E. and Logtenberg, T. (1995) Proc Natl Acad Sci USA 92. 3938-3942.

57. Griffiths, A.D., Williams, S.C., Hartley, O., Tomlinson, I.M., Waterhouse, P., Crosby, W.L., Kontermann, R., Jones, P.T., Low, N.M., Allison, T.J., Prospero, T.D., Hoogenboom, H.R., Nissim, A., Cox, J.P.L., Harrison, J.L., Zaccolo, M., Gherardi, E. and Winter, G. (1994) EMBO J. 13, 3245-3260.

58. Virnekas, B., Ge, L., Pluckthun, A., Schneider, K.C., Wellnhofer, G. and Moroney, S.E. (1994) Nucleic Acids Res 22, 5600-5607.

59. Akerstrom, B., Nilson, B.H., Hoogenboom, H.R. and Bjorck, L. (1994) J Immunol Methods 177. 151-163.

60. Tomlinson, I.M., Walter, G., Jones, P.T., Dear, P.H., Sonnhammer, E.L. and Winter, G. (1996) J Mol Biol 256, 813-817.

61. Pluckthun, A. and Pack, P. (1997) Immunotechnology 3, 83-105.

62. Hoogenboom, H.R. (1997) Nat Biotechnol 15, 125-126.

63. Low, N.M., Holliger, P.H. and Winter, G. (1996) J Mol Biol 260. 359-368.

64. Irving, R.A., Kortt, A.A. and Hudson, P.J. (1996) Immunotechnology 2, 127-143.

65. Hawkins, R.E., Russell, S.J. and Winter, G. (1992b) J Mol Biol 226, 889-896.

66. Marks, J.D., Griffiths, A.D., Malmqvist, M., Clackson, T.P., Bye, J.M. and Winter, G. (1992)

Bio/Technology 10, 779-783.

67. Stemmer (1996) Nature Medicine 2, 100-102.

68. Giaser, S.M., Yelton, D.E. and Huse, W.D. (1992) f Immunol 149, 3903-39i 3.

69. Jackson, J.R., Sathe, G., Rosenberg, M. and Sweet, R. (1995) J Immunol 154, 3310-3319.

70. Schier, R., Bye, J., Ape!l, G., McCall, A., Adams, G.P., Malmqvist, M., Weiner, L.M. and Marks, J.D. (1996) J Mol Biol 255, 28-43.

71. Yang, W.P., Green, K., Pinz, S.S., Briones, A.T., Burton, D.R. and Barbas, C.r. (1995) J Mol Biol 254, 392-403.

72. Deng, S.J., MacKenzie, C.R., Sadowska, J., Michniewicz, J., Young, N.M., Bundle, D.R. and Narang, S.A. (1994), J Biol Chem 269, 9533-9538.

73. Schier, R., McCall, A., Adams, G.P., Marshall, K.W., Merritt, H., Yim, M., Crawford, R.S., Weiner, L.M., Marks, C. and Marks, J.D. (1996) J Mol Biol 263, 55I-567.

74. Balint, R.F. and Larrick, J.W. (1993) Gene 137, 109-118.

75. Schier, R., Balint, R.F., A., M., G., A., Larrick, J.W. and Marks, J.D. (1996) Gene 169, 147 155.

76. Ignatovich, O., Tomlinson, I.M., Jones, P.T. and Winter, G. (1997) J Mol Biol 268, 69-77.

77. McCafferty, J., Hoogenboom, H.R. and Chiswell, D.J., . The practical approach series, ed. B.D. Hames.. 1996, Oxford: IRL Press.

78. Mattheakis, L.C., Bhatt, R.R. and Dower, W.J. (1994) Proc Natl Acad Sci U S A 91, $9022-$ 
9026.

79. Hanes, J. and Pluckthun, A. (1997) Proc Natl Acad Sci U S A 94, 4937-4942.

80. Nicholls, P.J., Johnson, V.G., Andrew, S.M., Hoogenboom, H.R., Raus, J.C. and Youle, R.J. (1993) J Biol Chem 268, 5302-5308.

81. He, M. and Taussig, M.J. (1997) Nucleic Acids Res 25, 5132-5134.

82. Malmborg, A.C., Duenas, M., Ohlin, M., Soderlind, E. and Borrebaeck, C.A. (1996) J Immunol Methods 198, 51-57.

83. Bradbury, A., Persic, L., Werge, T. and Cattaneo, A. (1993) Biotechnology (N Y) 11, 1565 1569.

84. Van Ewijk, W., de Kruif, J., Germeraad, W.T.V., Berendes, B., Röpke, C., Platenburg, P.P. and Logtenberg, T. (1997) Proc Nall Acad Sci USA 94, 3903-3908.

85. Pasqualini, R. and Ruoslahti, E. (1996) Nature 380, 364-366.

86. Roberts, B.L. (1992) Gene 121, 9-15.

87. Kang, A.S., Barbas, C.F., Janda, K.D., Benkovic, S.J. and Lemer, R.A. (1991) Proc. Na1l Acad. Sci. USA 88, 4363-4366.

88. Ward, R.L., Clark, M.A., Lees, J. and Hawkins, N.J. (1996) J Immunol Methods 189, 73-82 89. Meulemans, E.V., Slobbe, R., Wasterval, P., Ramaekers, F.C. and van, E.G. (1994) J Mol Biol 244, 353-360.

90. Markland, W., Ley, A.C., Lee, S.W. and Ladner, R.C. (1996) Biochemistry 35, 8045-8057.

91. Gramatikoff, K., Georgiev, O. and Schaftner, W. (1994) Nucleic Acids Res 22, 5761-5762.

92. Duenas, M. and Borrebaeck, C.A.K. (1994) Biotechnology 12, 999-1002.

93. Krebber, C., Spada, S., Desplancq, D. and Pluckthun, A. (1995) Febs Lett 377, 227-231.

94. Spada, S., Krebber, C. and Pluckthun, A. (1997) Biol Chem 378, 445-456.

95. Pedrazzi, G., Schwesinger, F., Honegger, A., Krebber, C. and Pluckthun, A. (1997) FEBS Lett 415, 289-293.

96. Malmborg, A.C., Soderlind, E., Frost, L. and Borrebaeck, C.A. (1997) J Mol Biol 273, 544 551 .

97. Holliger, P. and Riechmann, L. (1997) Struchure 5, 265-275.

98. Schier, R. and Marks, J.D. (1996) Hum Antibodies Hybridomas 7, 97-105.

99. Duenas, M., Malmborg, A.C., Casalvilla, R., Ohlin, M. and Borrebaeck, C.A. (1996) Mol Immunol 33, 279-285.

100. Andersen, P.S., Stryhn, A., Hansen, B.E., Fugger, L., Engberg, J. and Buus, S. (1996) Proc Nall Acad Sci USA 93, 1820-1824.

101. Mandecki, W., Chien, Y.C. and Grihalde, N. (1995) J theor Biol 176, 523-530.

102. McCafferty, J., in Phage display of peptides and proteins, B. Kay, L. Winter, and J. McCafferty, Editors. 1996, Academic Press: San Diego. p. 261-276.

103. Stausbol-Gron, B., Wind, T., Kjaer, S., Kahns, L., Hansen, N.J., Kristensen, P. and Clark, B.F. (1996) FEBS Left 391, 71-75.

104. Marks, J.D., Ouwehand, W.H., Bye, J.M., Finnem, R., Gorick, B.D., Voak, D., Thorpe, S.J., Hughes, J.N. and Winter, G. (1993) Biotechnology $N$ Y 11, 1145-1149.

105. Palmer, D.B. George, A.J. and Ritter, M.A. (1997) Immunology 91, 473-478.

106. Siegel, D.L., Chang, T.Y., Russell, S.L. and Bunya, V.Y. (1997) J Immunol Methods 206, 73-85.

107. Pasqualini, R., Koivunen, E. and Ruoslahti, E. (1997) Nat Biotechnol 15, 542-546.

108. Osbourn, J., Derbyshire, E., Vaughan, T., Field, A. and Johnson, K. (1998) 


\section{Immunotechnology in press}

109. Zaccolo, M., Griffiths, A.P., Prospero, T.D., Winter, G. and Gherardi, E. (1997) Eur J Immunol 27, 618-623.

110. Carnemolla, B., Neri, D., Castellani, P., Leprini, A., Neri, G., Pini, A., Winter, G. and Zardi, L. (1996) Int J Cancer 68, 397-405.

111. Lah, M., Goldstraw, A., White, J.F., Dolezal, O., Malby, R. and Hudson, P.J. (1994) Hum Antibodies Hybridomas 5, 48-56.

112. Lindner, P., Bauer, K., Krebber, A., Nieba, L., Kremmer, E., Krebber, C., Honegger, A., Klinger, B., Mocikat, R. and Pluckthun, A. (1997) Biotechniques 22, 140-149.

113. Hochuli, E., Bannwarth, W., Döbeli, H., Gentz, R. and Stüber, D. (1988) Bio/Technology 6. 1321-1325.

114. MeCafferty, J., Fitzgerald, K.J., Earnshaw, J., Chiswell, D.J., Link, J., Smith, R. and Kenten, J. (1994) Appl Biochem Biotechnol 47, 157-171.

115. Goldberg, M.E. and Djavadi, O.L. (1993) Curr Opin Immunol 5, 278-281.

116. Kazemier, B., de Haard, H., Boender, P., van Gemen, B. and Hoogenboom, H.R. (1996) J Immunol Methods 194, 201-209.

117. Ohlin, M., Owman, H., Mach, M. and Borrebaeck, C.A. (1995) Mol Immunol 33, 47-56.

118. Casson, L.P. and Manser, T. (1995) J Exp Med 182, 743-750.

119. Persic, L., Roberts, A., Wilton, J., Cattaneo, A., Bradbury, A. and Hoogenboom, H.R. (1997) Gene 187, 9-18.

120. Persic, L., Righi, M., Roberts, A., Hoogenboom, H.R., Cattaneo, A. and Bradbury, A. (1997) Gene 187, 1-8.

121. Gargano, N. and Cattaneo, A. (1997) FEBS Lett 414, 537-540.

122. Xie, M.H., Yuan, J., Adams, C. and Gumey, A. (1997) Nat Biotechnol 15, 768-771.

123. Souriau, C., Fort, P., Roux, P., Hartley, O., Lefranc, M.P. and Weill, M. (1997) Nucleic Acids Res 25, 1585-1590.

124. Szardenings, M., Tomroth, S., Mutulis, F., Muceniece, R., Keinanen, K., Kuusinen, A. and Wikberg, J.E. (1997) J Biol Chem 272, 27943-27948.

125. Broach, J.R. and Thorner, J. (1996) Nature 384, 14-16.

126. Janda, K.D., Lo, C.H., Li, T., Barbas, C.F., Wirsching, P. and Lerner, R.A. (1994) Proc Natl Acad Sci USA 91, 2532-2536.

127. Hart, S.L., Knight, A.M., Harbottle, R.P., Mistry, A., Hunger, H.D., Cutler, D.R., Williamson, R. and Coutelle, C. (1994) J Bioi Chem 269, 12468-12474.

128. Fuchs, P., Weichel, W., Dubel, S., Breitling, F. and Little, M. (1996) Immunotechnology 2, $97-102$.

129. Georgiou, G., Stathopoulos, C., Daugherty, P.S., Nayak, A.R., Iverson, B. and Curtiss, R. (1997) Nat Biotechnol 15, 29-34.

130. Pausch, M.H. (1997) Trends Biotechnol 15, 487-494.

131. Nygren, P.A. and Uhlen, M. (I997) Curr Opin Struct Biol 7, 463-469.

132. Tramontano, A., Bianchi, E., Venturini, S., Martin, F., Pessi, A. and Sollazzo, M. (1994) J Mol Recognit 7, 9-24.

133. McConnell, S.J. and Hoess, R.H. (1995) J Mol Biol 250, 460-470.

134. Nord, K., Nilsson, J., Nilsson, B., Uhlen, M. and Nygren, P.A. (1995) Protein Eng 8, 601 608.

135. Ku, J. and Schultz, P.G. (1995) Proc Natl Acad Sci U S A 92, 6552-6556. 
136. Houston, M.E., Jr., Wallace, A., Bianchi, E., Pessi, A. and Hodges, R.S. (1996) J Mol Biol 262, 270-282.

137. Miceli, R., Myszka, D., Mao, J., Sathe, G. and Chaiken, I. (1996) Drug Des Discov 13, 95 105.

138. Perez-Paya, E., Forood, B., Houghten, R.A. and Blondelle, S.E. (1996) J Mol Recognit 9. 488-493.

139. Choo, Y., Castellanos, A., Garcia-Hernandez, B., Sanchez-Garcia, I., Klug, A., Choo, Y. and Klug, A. (1997) J Mol Biol 273, 525-532.

140. Vita, C., Roumestand, C., Toma, F. and Menez, A. (1995) Proc Natl Acad Sci US A 92 , 6404-6408.

141. Rottgen, P. and Collins, J. (1995) Gene 164, 243-250.

142. Wang, C.I., Yang, Q. and Craik, C.S. (1995) J Biol Chem 270, 12250-12256.

143. Markland, W., Ley, A.C. and Ladner, R.C. (1996) Biochemistry 35, 8058-8067.

144. Abedi, M.R., Caponigro, G. and Kamb, A. (1998) Nucleic Acids Res 26, 623-630.

145. Nord, K., Gunneriusson, E., Ringdahl, J., Stahl, S., Uhlen, M. and Nygren, P.A. (1997) Nat Biotechnol 15, 772-777.

146. Mikawa, Y.G., Maruyama, I.N. and Brenner, S. (1996) J Mol Biol 262, 21-30.

147. Proba, K., Honegger, A. and Pluckthun, A. (1997) J Mol Biol 265, 161-172.

148. Winter, G. and Milstein, C. (1991) Nature 349, 293-299. 


\section{Chapter 3}

High affinity recombinant phage antibodies to the pan-carcinoma marker epithelial glycoprotein-2 for tumour targeting

Rob C. Roovers, Paula Henderikx, Wijnand Helfrich, Edith van der Linden, Anneke Reurs, Adriaan de Bruïne, Jan-Willem Arends, Lou de Leij and Hennie R. Hoogenboom

Br. J. Cancer 78(11), 1407-1416 (1998) 


\section{Abstract}

The tumour-associated antigen epithelial glycoprotein-2 (EGP-2) is a promising target for detection and treatment of a variety of human carcinomas. Antibodies to this antigen have been successfully used in patients for imaging of small cell lung cancer and for adjuvan treatment of minimal residual disease of colon cancer. We describe here the isolation anc complete characterisation of high affinity single-chain variable fragments (scFv) to the EGP-2 antigen. First, the binding kinetics of four murine whole antibodies directed to EGP-2 (17-1A. 323/A3, MOC-31 and MOC-161) were determined using surface plasmon resonance (SPR). The MOC-31 antibody has the lowest apparent off-rate, followed by MOC-161 and 323/A3. The V. genes of the two MOC-hybridomas were cloned as ScFv in a phage display vector and antigenbinding phage were selected by panning on recombinant antigen. The scFvs compete with the original hybridoma antibodies for binding to antigen and specifically bind to human carcinomas in immunohistochemistry. MOC-31 scFv has an off-rate which is better than those of the bivalen 17-1 A and 323/A3 whole antibodies, providing it with an essential characteristic for tumour retention in vivo. The availability of these high affinity anti-EGP-2 antibody fragments and of their encoding V-genes creates a variety of possibilities for their futur use as tumour targeting vehicles.

\section{Introduction}

During colorectal carcinogenisis, a number of (membrane) antigens is upregulated, mutated or differently processed, providing targets for (adjuvant) immunotherapy of the disease. Several tumour antigens have been described and used for targeting or as indicators of progression of disease (e.g. carcinoembryonic antigen (CEA). TAG72, c-erB2, (underglycosylated) MUC-1, p53). The epithelial glycoprotein-2 (EGP-2, also named CO17-1A antigen, KSA, EGP40 or Ep-CAM) is a tumour-associated antigen present on human simple epithelia and their derived tumours. The abundant expression of EGP-2, on a number of human carcinomas, its limited expression on the luminal side of normal non-squamous epithelia only and the fact that it is not shed into the circulation make this antigen a favourable target for imaging and immunotherapy of cancer. Murine antibodies to EGP-2 have been used in radio immune detection trials [1,2], as well as in phase I and II clinical trials [3]. The most successful study has been the treatment of minimal residual disease (MRD) in patients with Dukes' $\mathrm{C}$ colon carcinoma using the 17-1 A antibody [4]. In this study [5], an overall $30 \%$ reduction in 5-year mortality was observed, proving that passive immunotherapy in an adjuvant setting may be as effective as chemotherapy.

Other therapeutic strategies based on the use of antibodies to EGP-2 have also been 
described. These include the recruitment and activation of T-cells by using a fusion of an EGP-2 reactive antibody fragment with the bacterial superantigen staphylococcal enterotoxin A [6] or by using bispecific antibodies, directed both to EGP-2 and the T-cell CD3 antigen [7]. In a different approach, the conjugation of anti EGP-2 antibodies to different bacterial toxins has been shown to yield potent immunotoxins [8, 9]. These (pre)clinical studies all underline the possibilities of using antibodies (in different format) to EGP-2 for (adjuvant) immunotherapy.

Careful experimental analysis of scFv variants of an anti c-erB2 antibody with a range of affinities indicated that there is a clear correlation between affinity increase and enhanced tumour retention [10]. The availability of high affinity recombinant anti EGP-2 antibody fragments would therefore be highly desirable. Indeed, the potential use of such scFv antibody fragments for imaging of human carcinoma has already been demonstrated with a scFv directed to carcinoembryonic antigen (CEA; [11]).

In this study, we first compared the binding kinetics of four murine whole antibodies (17IA, 323/A3 [12], MOC-31 and MOC-161 [13] to the antigen EGP-2 using SPR in a BIAcore. Our results show that the MOC-31 antibody has by far the lowest off-rate of all antibodies tested and that MOC-161 is comparable to the 323/A3 antibody. The V-genes of the two antibodies. with lowest off-rate (MOC-31 and MOC-161) were cloned in seFv format and the off-rate and specificity of the scFv antibody fragments determined. These high affinity anti EGP-2 scFvs may have important applications in imaging and possibly immunotherapy of different human carcinomas and may provide useful building blocks for further rational therapeutic antibody design.

\section{Materials and Methods}

\section{Anti EGP-2 antibodies}

The antibodies 17-1A, chimeric 17-1A and 323/A3 were a kind gift from Dr. S.O. Warnaar (Centocor, Leiden, the Netherlands). The two hybridomas cloned in this study (MOC-31 $(\mathrm{IgGl} / \mathrm{\kappa})$ and $\mathrm{MOC}-161(\operatorname{lgG} 2 \mathrm{a} / \mathrm{K}))$ ) were generated by hybridoma technology [13]. Bis-1 bispecific antibody [7] is produced by a quadroma clone made from the hybridomas MOC-31 (anti EGP-2) and RIV-9 (anti CD3) and was kindly donated by Dr. B-J Kroesen (University Hospital Groningen).

\section{Kinetic measurement using SPR in a BIAcore}

Recombinant EGP-2 was expressed in the baculovirus system as described [14, 15], a kind gift of Prof. D. Herlyn (the Wistar Institute)). The antigen was covalently coupled to a CM-5 
sensorchip (Pharmacia, Uppsala, Sweden) via free amide chemistry, resulting in a surface of 350 resonance units (RU). All kinetic measurements were performed on this antigen surface. To determine the binding kinetics of different whole antibodies (17-1A, chimeric 17-1 A, 323/A3, MOC-161, MOC-31 and Bis-1) and antibody fragments (MOC-31 scFv and MOC-161 scFv), this 'low density' EGP-2 surface was saturated with antibody (at [200nM]) or antibody fragment using a flow rate of $5 \mu \mathrm{l} / \mathrm{min}$ (Fig. 1). Dissociation rates $\left(\mathrm{k}_{\mathrm{off}}\right)$ were then calculated using the BIAevaluation software (Pharmacia, Uppsala, Sweden) from the sensorgrams depicted in Fig. 1. The off-rates were determined by curve fitting on the time interval $\mathrm{t}=315$ to $320 \mathrm{~s}$, with one exception: because of its very low value, it was impossible to determine the off-rate of the MOC31 whole antibody in this time period. In this case, an average value of three independent fittings on different parts of the curve is given. Since the kinetics of binding of the MOC-161 whole antibody were determined with concentrated hybridoma supernatant, the antibody concentration was unknown and the sensorgram is not shown. However, the same experimental setup was used. in which the antigen surface was saturated with antibody. All measurements were carried out at room temperature.

Association rates $\left(\mathrm{k}_{\mathrm{on}}\right)$ were determined from a plot of $\mathrm{k}_{\mathrm{s}}\left(=\left(\mathrm{k}_{\mathrm{on}} \times \mathrm{C}+\mathrm{k}_{\mathrm{off}}\right)\right)$ versus antibody concentration (C). Briefly, antibodies were run over the low density antigen surface at different concentrations and $k_{\mathrm{s}}$ values were determined using the BIAevaluation software. From a plot of the obtained $\mathrm{k}_{\mathrm{s}}$ values as function of $\mathrm{C}, \mathrm{k}_{\mathrm{on}}$ values were obtained by linear fitting as the slope of the curve. The half life of antibody-antigen complex was calculated as $t_{1 / 2}=\ln 2 / k_{\text {off }}$ (Table 2).

\section{Cloning vectors}

pCANTAB6 is a derivative of pHEN] [16], carrying an additional stretch of six histidine residues (to allow immobilised metal ion aflinity chromatography (IMAC) purification) upstream of the $c$-myc-derived sequence (which allows detection with the $9 \mathrm{E} 10$ antibody). ScFv cassettes are cloned as Sfil - Not I fragments in frame with the upstream pelB leader sequence and $\mathrm{LacZ}$ promoter and with the downstream bacteriophage gene III. The vector also contains an amber stop codon between the $c-m y c$ sequence and gene III, allowing production of soluble scFv in a non-suppressor strain of E.coli. Plasmid pUC119-polyHIS6myc (a kind gift from Dr. A.D. Griffiths) is a derivative of pUC119 and carries 5' Sfil / Ncol and 3' Not cloning sites. ScFv cassettes are cloned in frame with an upstream $L a c Z$ promoter and pelB signal sequence and a downstream cassette of six histidine residues and a $c$-myc derived sequence. As in the related pUC119-His6mycXba [17], the bacteriophage gene III is absent. 
High affinity recombinant phage antibodies to the pan-carcinoma marker EGP-2 for tumour targeting

\section{E.coli strain}

TGI: K12, D(lac-pro), supE, thi, hsdD5/F'traD36, proA'B', lacl', lacZDM15

\section{Oligonucleotides}

Primers used for the amplification of variable parts of the heavy chain (VH) and of the light chain (VL) of murine immunoglobulin genes, for the synthesis of the linker fragment and for re-amplification of the assembled scFv cassettes are listed in Table 1. All primers were purchased from Eurogentec (Liège, Belgium).

\section{Table 1}

Oligonucleotides used for cloning of murine V-genes

\footnotetext{
A. Primers used for the primary amplification of $\mathrm{VH}$

MVHIBACK: 5'-AGG T(C/G)(A/C) A(A/G)C TGC AG(C/G) AGT C(A/T)G G-3*

MVHIFOR-2: 5'-TGA GGA GAC GGT GAC CGT GGT CCC TTG GCC CC-3'

B. Primers used for the primary amplification of $V L$

MVKBACKmix; an equimolar mix of:

-MVKABACK: 5'-GAT GTT TTG ATG ACC CAA ACT CCA-3'

-MVKCBACK: 5'-GAC ATT GTG CT(A/G) ACC CA(A/G) TCT CCA-3'

-MVKDBACK: 5'-GAC ATC CAG ATG AC(T/C/G/A) CAG TCT CCA-3'

-MVKEBACK: 5' -CAA ATT GTT CTC ACC CAG TCT CCA-3'

-MVKFBACK: 5'-GAA AAT GTG CTC ACC CAG TCT CCA-3'

MVKFOR4; an equimolar mix of:

-MJKIFONX: 5 '-CCG TTT GAT TTC CAG CTT GGT GCC-3'

-MJK2FONX: $5^{\prime}$-CCG TTT TAT TTC CAG CTT GGT CCC-3'

-MJK4FONX: 5'-CCG TTT TAT TTC CAA CTT TGT CCC-3'

-MJK 5FONX: 5'-CCG TTT CAG CTC CAG CTT GGT CCC-3'

C. Primers for the synthesis of the linker fragment

MLINKBACK: 5'-GGG ACC ACG GTC AC C GTC TCC TCA-3'

MLINKFORmix; an equimolar mix of:

-MLINK-A-FOR: 5'-TGG AGT TTG GGT CAT CAA AAC ATC CGA TCC GCC ACC GCC AGA GCC-3. -MLINK-C-FOR: 5'-TGG AGA CTG GGT (T/C)AG CAC AAT GTC CGA TCC GCC ACC GCC AGA -3' -MLINK-D-FOR: 5'-TGG AGA CTG NGT CAT CTG GAT GTC CGA TCC GCC ACC GCC AGA GCC-3. -MLINK-E-FOR: 5'-TGG AGA CTG GGT GAG AAC AAT TTG CGA TCC GCC ACC GCC AGA GCC-3* -MLINK-F-FOR: 5'-TGG AGA CTG GGT GAG CAC ATT TTC CGA TCC GCC ACC GCC AGA GCC.3'

D. Re-amplification primers (to introduce restriction sites in the assembled cassette: sequences encoding restriction sites are bold)

MVHIBACKSFI; (introduces a Sfil site at the 5' end of the assembled scFv cassette):

5'-CAT GCC ATG ACT CGC GGC CCA GCE GGC CAT GGC C(C/G)A GGT (C/G)(A/C)A (A/G)CT GCA G(C/G)A GTC (A/T)GG-3'

MVK4FORNOT (introduces a Not I site at the $3^{\prime}$ end of the assembled scFv cassette); an equimolar mix of: -MJK1FORNOT: 5'-GAG TCA TTC TCG ACT TGC GGC CGC CCG TTT GAT TTC CAG CTT GGT GCC-3 -MJK2FORNOT: 5'-GAG TCA TTC TCG ACT TGC GGC CGC CCG TTT TAT TTC CAG CTT GGT CCC-3' -MJK4FORNOT: 5"-GAG TCA TTC TCG ACT TGC GGC CGC CCG TTT TAT TTC CAA CTT TGT CCC-3 -MJK5FORNOT: 5'-GAG TCA TTC TCG ACT TGC GGC CGC CCG TTT CAG CTC CAG CTT GGT CCC-3'

For sequencing :

pUC-FOR: 5'-CGA CGT TGT AAA ACG ACG GCC AGT-3'

DUC-REVERSE: 5'-CAG GAA ACA GCT ATG AC-3"
} 


\section{Cloning of immunoglobulin genes}

Total cellular RNA was extracted from $10^{7}$ cells of each of the hybridoma cell lines MOC-31 and MOC-16I by means of the RNazol ${ }^{\mathrm{TM}}$ method (Biotecx Laboratories, Houston, USA). After precipitation, the RNA was dissolved in $20 \mu \mathrm{l}$ water and used as template to synthesise cDNA using random hexamer primers (Promega, Madison, USA) in a $50 \mu$ reverse transcriptase (RT-) reaction according to standard procedures. Variable domains of both heavy (VH) and light chain (VL) genes were then amplified from cDNA using heavy or light chain specific primer mixes (see Table 1) and assembled with a linker sequence encoding a 15 -residue Gly/Ser sequence by means of Splice Overlap Extension PCR, as described by [18]. The assembled cassette was gel-purified, cut with the restriction enzymes Sfil and NotI and gelpurified again. ScFv cassettes were cloned into Sfil/Notl digested pCANTAB6 DNA and the ligation mix was electroporated into E.coli TG1 using standard procedures. Bacteria were plated on 2 TY $(1.6 \%(\mathrm{w} / \mathrm{v})$ trypton; $1 \%(\mathrm{w} / \mathrm{v})$ yeast extract; $0.5 \%(\mathrm{w} / \mathrm{v}) \mathrm{NaCl})$ plates, supplemented with $2 \%(\mathrm{w} / \mathrm{v})$ glucose and $100 \mu \mathrm{g} / \mathrm{ml}$ ampicillin, and harvested after overnight growth to form a library of transformants.

\section{Selection on recombinant, baculovirus-expressed EGP-2 by panning in immunotubes}

A small repertoire of transformed bacteria (approximately $10^{6}$ in size) containing the MOC-31 seFv ligated into pCANT AB6 was rescued with helper phage M13K07 and phage were parned for binding to the antigen EGP- 2 (coated at $10 \mu \mathrm{g} / \mathrm{ml}$ concentration using immunotubes (Maxisorb; Nunc/Life Technologies, Gaithersburg, U.S.A.)) as described [19]. Two rounds of selection were performed; after each round, single clones were screened for binding to antigen in ELISA as described (see below).

\section{ELISA and competition ELISA}

To identify binding seFvs from the individual clones selected for further analysis, an ELISA using soluble scFv was performed on purified, recombinant EGP-2. Individual bacterial clones were picked and production of soluble scF.v was induced by activation of the upstream LacZ promoter with isopropyl- $\beta$-D-thiogalactopyranoside (IPTGi) as described [19]. ELISA plates (Costar, Cambridge, USA) were coated overnight with $1 \mu \mathrm{g} / \mathrm{ml}$ of EGP-2 in phosphate buffered saline (PBS), washed three times with PBS-T (PBS, 0.5\% (v/v) Tween-20), three times with PBS and blocked during $1 \mathrm{hr}$ at room temperature (rt) with $2 \% \mathrm{MPBS}(2 \%(\mathrm{w} / \mathrm{v})$ Marvel skimmed milk powder- in PBS). After blocking, induced bacterial supernatants were added (50\% ( $\mathrm{v} / \mathrm{v}$ ) in $2 \%$ MPBS) and incubated for $\mathrm{I}^{1 / 2} \mathrm{hrs}$ at $\mathrm{rt}$. Bound antibody fragments were detected with the $9 E 10$ antibody $(50 \%(\mathrm{v} / \mathrm{v})$ hybridoma supernatant in $2 \%$ MPBS), peroxidase-conjugated rabbit anti mouse immunoglobulines (Dako, Glostrup, Denmark; $0.1 \%(\mathrm{v} / \mathrm{v}$ ) in 2\% MPBS) and 
staining with trimethylbenzidine (TMB) and $\mathrm{H}_{2} \mathrm{O}_{2}$. Optical density was measured at 450nm.

For competition ELISA, scFv antibody fragments expressed as pIII fusions on the tip of bacteriophage were detected in the presence of excess whole antibody (due to cross-reactivity of anti-mouse Ig antibodies -used to detect the $9 \mathrm{E} 10$ antibody bound to scFvs- with the original whole murine antibodies, this test was not performed with soluble scFvs). Briefly, MOC-31 and MOC-161 phage were rescued with helper phage M13KO7 as described [19]. Approximately $10^{10}$ colony forming units (cfu) of phage were then mixed with $100 \mu \mathrm{l}$ hybridoma supernatant and simultaneously added to different wells of an antigen-coated ELISA plate. Bound phage were detected with a sheep polyclonal antiserum (sheep anti-fd; Pharmacia, Uppsala, Sweden; 0.02\% (v/v) in 2\% MPBS), peroxidase conjugated rabbit anti goat immunoglobulines (Dako, Glostrup, Sweden; $0.05 \%(v / v)$ in $2 \%$ MPBS) and staining with $\mathrm{TMB} / \mathrm{H}_{2} \mathrm{O}_{2}$.

\section{Sequencing}

The nucleotide sequences of both the MOC-31 and MOC-161 scFvs were determined using the dideoxy sequencing method of Sanger. Products of the sequencing reaction were analysed on a semi-automated sequencer (Alf Express; Pharmacia, Uppsala, Sweden). Oligonucleotides used were pUC-FOR and pUC-REV (Table I).

\section{Production and purification of soluble scFv}

To produce large quantities of both antibody fragments, sç $\mathrm{Fv}$ cassettes were subcloned as Sfi I/Not I fragments into pUC-119polyHIS6myc, lacking the bacteriophage gene III. This expression plasmid ensures less toxicity to bacteria due to expression of gene III during induction and thus a higher yield of antibody. Both the supernatant and the periplasmic fraction of bacteria, grown at three different temperatures and harvested after two different time intervals (growth at $20^{\circ}, 30^{\circ}$ and $37^{\circ} \mathrm{C}$; induction during $4 \mathrm{hrs}$ or overnight) were first tested for the amount of functional scFv in ELISA.

Five hundred $\mathrm{m}$ ! of 2xTY/A/G (2xTY, supplemented with $100 \mu \mathrm{g} / \mathrm{ml}$ ampicillin and $2 \%$ $(\mathrm{w} / \mathrm{v})$ glucose) were inoculated with E.coli $\mathrm{TGI}$ harbouring MOC-31 or MOC-161 scFv in pUC119-polyHIS6myc and bacteria were grown at $37^{\circ} \mathrm{C}$ to an $\mathrm{OD}_{600}$ of 1.0. Bacteria were spun down, resuspended in $2 \times$ TY containing $100 \mu \mathrm{g} / \mathrm{ml}$ ampicillin and IPTG to a final concentration of $1 \mathrm{mM}$, and grown for $4 \mathrm{hrs}$ at $30^{\circ} \mathrm{C}$ while shaking. After $4 \mathrm{hrs}$ of induction, bacteria were pelleted and periplasmic fractions were prepared by resuspending the pellet in $8 \mathrm{ml}$ ice-cold TES (200mM Tris-HCl; $0.5 \mathrm{mM}$ EDTA; $500 \mathrm{mM}$ sucrose: pH8.0), adding $12 \mathrm{ml}$ of ice-cold diluted TES (1:3 in water) and incubation on ice for $30 \mathrm{~min}$. Bacteria were spun down (4500rpm, 15 min, $4^{\circ} \mathrm{C}$ ) and the supernatant was collected. The cell pellet was resuspended again in $10 \mathrm{ml}$ TES, 150 $\mu \mathrm{l} 1 \mathrm{M} \mathrm{MgSO} 4$ was added and the mix was incubated on ice for $30 \mathrm{~min}$. Cells were spun down 
again and the supernatant was added to the first periplasmic preparation. EDTA was largely removed by means of dialysis against $20 \mathrm{mM}$ Tris- $\mathrm{HCl}, 100 \mathrm{mM} \mathrm{NaCl}$ (pH8.O). The Histidinetagged scFv fragments were further purified by means of IMAC on TALONTM resin (Clontech, Palo Alto, USA) using elution with $100 \mathrm{mM}$ imidazole, according to the manufacturers protocol. Monomeric and dimeric forms of the scFvs were separated by gelfiltration chromatography (on a Superdex ${ }^{R}$ column; Pharmacia, Uppsala, Sweden) using a Biologic Apparatus (BioRad, Hercules, U.S.A.). Different fractions were finally analysed by means of SDS-polyacrylamide gel electroforese (SDS-PAGE).

\section{Immunohistochemical analysis of scFv clones}

Six $\mu \mathrm{m}$ frozen sections (of normal colon epithelium, melanoma and colon carcinoma) were cut, mounted on 3-aminopropyl tri-ethoxy silan (APTS) coated glass slides, force-dried on air and fixed in acetone on ice for $15 \mathrm{~min}$. Slides were force-dried on aĩ again, bacterial periplasmic preparations were added $(50 \%(\mathrm{v} / \mathrm{v})$ in PBS/ $1 \%$ bovine serum albumin (BSA)) and incubated for 30 minutes at $4^{\circ} \mathrm{C}$. Slides were washed with PBS and bound scFv antibodies were detected with the $9 \mathrm{E} 10$ antibody $(50 \%(\mathrm{v} / \mathrm{v})$ hybridoma supernatant in $\mathrm{PBS} / 1 \% \mathrm{BSA})$, peroxidaseconjugated rabbit anti mouse immunoglobulines $(0.1 \%(\mathrm{v} / \mathrm{v})$ in PBS $/ 1 \% \mathrm{BSA})$ and staining with diaminobenzidin $(\mathrm{DAB}) / \mathrm{H}_{2} \mathrm{O}_{2}$. The slides were counter stained with haematoxylin.

\section{Results}

\section{Comparison of the binding kinetics of different anti EGP-2 murine whole antibodies}

One of the most important characteristics of antibodies is the rate with which they detach from bound antigen, given by the off-rate of the molecule $\left(\mathrm{k}_{\mathrm{off}}\right)$. To select the antibody with most promising properties for tumour targeting, we set out to screen the binding characteristics (and in particular the off-rate) of four monoclonal antibodies directed to the pan-carcinoma antigen EGP-2: 17-1A (and a chimeric version thereof), 323/A3, MOC-31 and MOC-161. The on- and off-rates of these (whole) antibodies were determined using a BIAcore2000 (Fig. 1 and Table 2).

The off-rate we measured for MOC-31 whole antibody is the lowest of all antibodies tested; it would yield a half-life of the antibody-antigen complex in solution of approximately $4 \mathrm{hrs}$. The antibody that has been most often used for clinical applications, 17-1 A, has an apparent off-rate which translates into an antibody-antigen complex half-life of less than a minute (Table 2). 

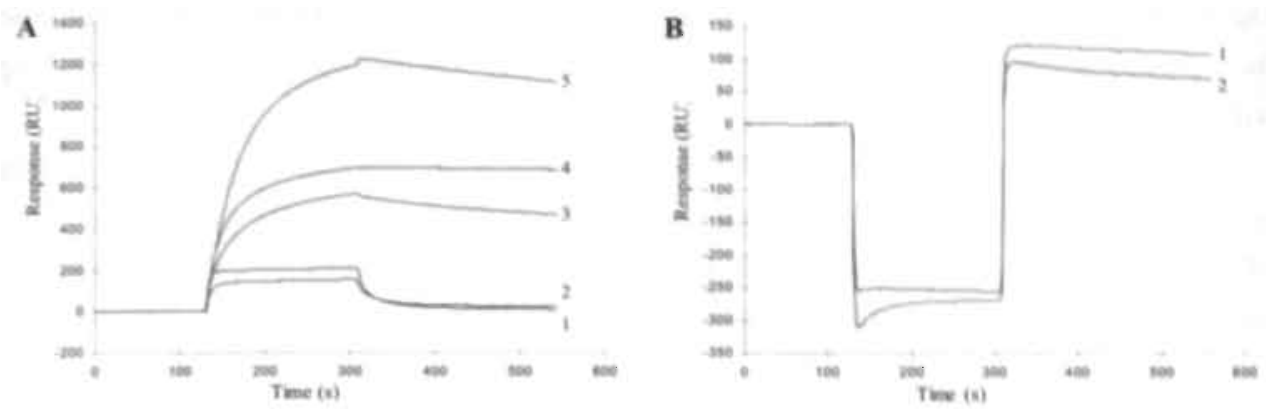

\section{Figure 1}

Sensorgrams showing association and dissociation of different anti EGP-2 antibodies and antibody fragments. A) whole antibodies (1: 17-1A;2: chimeric 17-1A; 3:323/A3; 4: MOC-31; $5: \mathrm{Bis}-1)$

B) antibody fragments (1: MOC-31 scFv; $2: \mathrm{MOC}-161 \mathrm{scFv}$ ) to the antigen coated to the surfaceof a sensor chip. Association starts at $\mathrm{t}=130 \mathrm{~s}$; dissociation starts at $\mathrm{t}=310 \mathrm{~s}$

\section{Table 2}

Kinetic data and affinities of anti EGP-2 antibodies and antibody fragments

\begin{tabular}{|c|c|c|c|c|c|}
\hline Antibody & $\begin{array}{c}\mathrm{k}_{\mathrm{min}} \\
\left(10^{5} \mathrm{M}^{-1} \mathrm{~s}^{-5}\right) \\
+/-\mathrm{SE}\end{array}$ & $\begin{array}{c}\mathrm{k}_{\text {eft }} \\
\left(10^{-3} \mathrm{~s}^{-1}\right)+1-\mathrm{SE} \\
\text { (monovalent) }\end{array}$ & $\begin{array}{c}\mathrm{k}_{\text {off }} \\
\left(10^{-1} s^{-1}\right)+/-\mathrm{SE} \\
\text { (bivalent) }\end{array}$ & $\begin{array}{c}\mathrm{Ka} \\
\left(10^{\prime \prime} \mathrm{M}^{-1}\right)\end{array}$ & $11 / 2$ \\
\hline $17-1 \mathrm{~A}$ & $5.95+/-0.28$ & - & $38.2+1-1.2^{*}$ & N.D. & $18^{\prime \prime}$ \\
\hline chim. 17-1A & $10.9+/-0.2$ & - & $58.3+1-2.2^{*}$ & N.D. & $12^{\prime \prime}$ \\
\hline $323 / \mathrm{A} 3$ & $2.51+/-0.29$ & - & $1.06+/-0.02$ & N.D. & $10^{\prime} 54^{\prime \prime}$ \\
\hline Bis-1 & $0.48+/-0.03$ & $0.25+/-0.03$ & . & 1.92 & $46^{\prime} 13^{\prime \prime}$ \\
\hline MOC-31 & $1.06+1-0.16$ & . & $0.05+/-0.0 !$ & 4.24 & $3 \mathrm{~h} 5 \mathrm{I}^{\prime} 03^{\prime \prime}$ \\
\hline MOC-161 & N.D. & - & $1.55+/-0.01$ & N.D. & $727^{\prime \prime}$ \\
\hline $\mathrm{MOC}-31 \mathrm{scFv}$ & N.D. & $0.34+1-0.05$ & . & N.D. & $33^{\prime} 59^{\prime \prime}$ \\
\hline $\mathrm{MOC}-161 \mathrm{scFv}$ & N.D. & $2.05+/-0.08$ & 。 & N.D. & $5^{\prime} 38^{\prime \prime}$ \\
\hline
\end{tabular}

- Because of the very high off-rates of these antibodies, the low density EGP-2 surface could not be saturated wih antibody (Fig. 1). These off-rates are therefore underestimations of the true values, which may account for tie unexpectedly observed difference.

Antibody MOC-161 has an apparent off-rate which is comparable to that of 323/A3 antibody. These off-rates are apparent values; they are most likely underestimations of the real off-rates because of the bivalent nature of the antibodies causing rebinding events during dissociation of antibody from the antigen surface [20] and they are influenced by the 
experimental conditions used to measure them. However, because all antibodies tested recognise the same epitope on EGP-2 and the same experimental setup was used for all, the relative ranking will be correct.

To obtain absolute values for the binding kinetics of the best antibody, MOC-31, it was necessary to determine those of the monovalent antibody Bis-1, a bispecific antibody with one MOC-31 binding site and one anti-CD3 site. The same antigen surface bound approximately twice the amount (in RUs) of Bis-1 when compared to MOC-31 (Fig. 1). This indicates that, despite the use of a low density EGP-2 surface, simultaneous binding of both Fab arms was a very frequent event for all bivalent molecules, which may be partially explained by the flexibility of the antigen surface. As expected, the off-rate of Bis-I was shown to be higher (approximately 5-fold: Table 2) than that of MOC-31 antibody. It can be concluded that, because MOC-31 has the lowest off-rate of the antibodies tested, followed by MOC-161 and 323/A3 (Table 2), the MOC antibodies were the most promising starting points for the cloning of recombinant antibody fragments.

\section{Cloning of recombinant scFv antibody fragments}

The genes encoding the variable parts of heavy (VH) and light chain (VL) of the hybridomas MOC-31 and MOC-161 were amplified by means of RT-PCR and assembled to form a scFv construct with a 15 residue $\left(G_{1}{ }_{4}\right.$ Ser $)$ linker. The set of oligonucleotides used in this study was similar to the one used by [18], with one important improvement: a re-designed set of MVKBACK primers was used, which was expanded to 5 oligonucleotides on the basis of the collection of murine VK genes present in the Kabat (1991) database [21]; Table 1). Extensive tests indicate that this new primer set successfully amplifies over $95 \%$ of all rearranged murine VK genes (Pope et al, personal communication). For MOC-31, a 250nt by-product was preferentially found during amplification of the $V_{K}$ domain when using a mix of MVKBACK. primers. However, when all BACK primers were used separately in different reactions, the band of expected size (approximately 340nt) was predominantly found ( $>90 \%$ of the PCR product) with primers MVKCBACK and MVKDBACK.

ScFv cassettes were cloned into phagemid vector pCANT AB6 which allows expression as either fusion protein to the bacteriophage gene III product or as soluble scFv in a nonsuppressor strain of E.coli. For MOC-161, binding scFvs were detected by means of ELISA directly after cloning, in a frequency of $11 / 90$. This is a typical frequency when rescuing V-genes from hybridomas [18]. For the MOC-3I hybridoma, however, the initial screen did not reveal any active scFvs. Therefore, a small scFv antibody repertoire (approximately $10^{6}$ recombinant clones in size) derived from the MOC-31 hybridoma was ușed for two successive rounds of phage selection on antigen. After two rounds, antigen binding scFvs were found at a frequency 
of 15 positives in 90 clones analysed. For each of the two hybridomas, several binding scFv clones were further analysed. Eventually, two representative clones were selected on the basis of DNA fingerprint patterns (MOC-31 scFv and MOC-16I scFv respectively; data not shown), for which the data are presented here.

The V-gene nucleic acid sequences of both antibody fragments were determined using a semi-automated sequencer and sequences were submitted to GenBank (accession numbers: U80187-U80190). The primers used to amplify light chain genes were for MOC-31: MVKCBACK. (consistent with the results of the primary amplification of the light chain gene) and MJKIFONX; for MOC-161 these were: MVKDBACK and MJK5FONX. A comparison of the amino acid sequences of MOC-31 and -161 with those of the $323 / \mathrm{A} 3$ and $17-1 \mathrm{~A}$ antibodies is shown in Table 3 (for both MOC-antibodies, primer encoded regions are depicted in lowercase letters). Both hybridomas use very different VH and VK genes. The MOC-31 VH and VK gene segments are members of the Kabat II and VII family respectively; for MOC-161, the designated families are VII and XIV. Both antibody VH-genes use the same germline J-segment, being either JH2 or JH4 (both encoding a 'DY' sequence in the C-terminal end of the CDR3 loop: Table 3). Besides these two residues, the antibodies share an additional two residues ('KG') in the C-terminal half of the VH-CDR3, which are most likely not encoded by any D-segment.

\section{Table 3}

Comparison of deduced aminoacid sequences of anti EGP-2 antibodies

\section{A: Heavy chain V-genes}

\section{FR1 CDR1 FR2 CDR2}

MOC-31 qVqI qqSgPeLKKPGETVKISCKASGYTFT NYGMN WVKQAPGKGLKWMG WINTYTGESTY

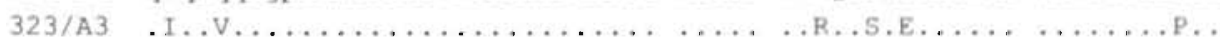

MOC-161 .........IR..TS............ D.WLG ...HR ..H..E.I. D.YPGSDNTY.

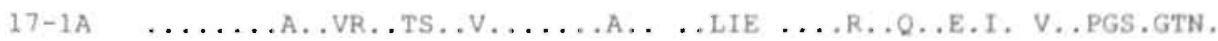

FR3 CDR3 FR4

MOC-37 ADDEKG REAFSLETSASAAYLQINNLKNEDTATYFCAR FAIKGDY wgqgttvtvss

$323 / A 3 \quad$ GE. . . . . . . . . T. . . . . . . . . . GNY. . . . . . . .

MOC-161 HEK... KATLTTDK.S.T..M.LSS.TS..S.V.... -GL...........

1.7-1A NEK... KATLTADK.S.T.M.LSS.TSD.S.V.... DGPWFA. ......... A 


\section{B: Light chain V-genes}

FR1

CDR1

ER2

CDR2

MOC-31 divItqspFSNPVTLGTSASISC RSTKSLLHSNGITYLY WYLQKPGQSPQLLIY QMSNLAS

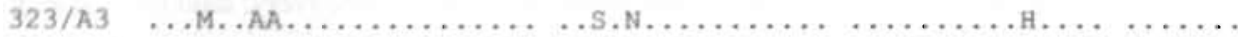

MOC-161 ..qM....S.LSAFS,GKVT.T. KASQD-IK-KS.A.-- ..QH...KG.R...H YT.T.QP

17-1A N..M....K.MSMSV.ERVTLT. KAS - - E-.VV..VS ..Q...E...K.... GA..RYT

FR3 CDR3 FR4

MOC-31 GVPDRFSSSGSGTDFTLRISRVEAEDVGVYYC AQNLEIPRT FGGgtk1eikr

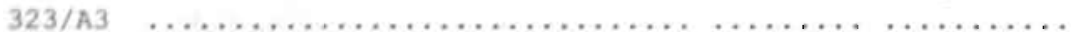

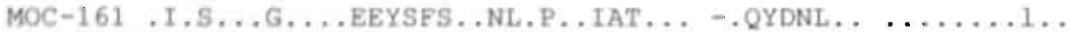

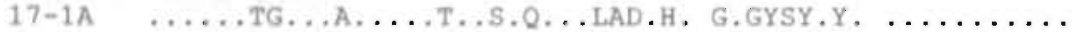

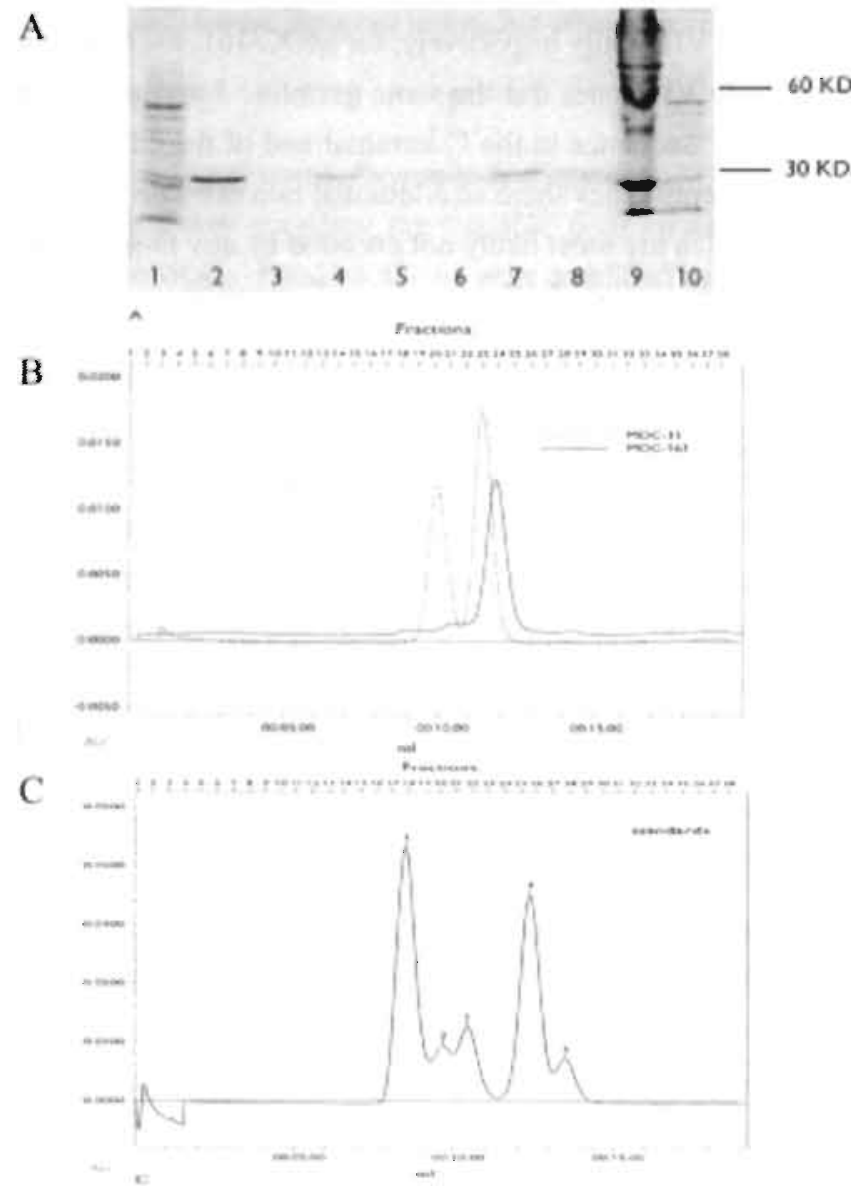

\section{Figure 2}

Purification of scFv antibody fragments by IMAC and gelfiltration chromatography (A: Top) SDS-PAGE analysis of (i) MOC-3! induced bacterial periplasm; (2) IMAC-purified MOC-31 scFv; (3-8) FPLC fractions of IMAC-purified MOC31 scFv (fraction 19-24); (9) Molecular Weight standards: (10) MOC-3I induced bacterial periplasm after IMAC purification. (B: Middle) $\mathrm{OD}_{2 \text { so }}$ profile of the flowthrough after gelfiltration of the different scFv preparations; MOC-31 and MOC-161. (C: Bottom) Protein standards !-5 (1: dextran $\left(\mathrm{V}_{0}\right) ; 2$ albumin (71.7kDa); 3: ovalbumin (45.7kDa); 4: chymotrypsinogen $(20.2 \mathrm{kDa})$ and 5 : ribonuclease $\mathrm{A}$. (15.7kDa)) 


\section{Production and purification of recombinant scFv fragments}

ScFv antibody production was induced in bacteria harbouring the MOC-31 and $-161 \mathrm{scFv}$ cassettes in pUC1 19polyHIS6myc. The highest amount of antibody (as judged by titrating the fractions in ELISA) was observed in the periplasm of bacteria after 4 hrs of induction at $30^{\circ} \mathrm{C}$ (data not shown). These conditions were therefore used to produce soluble scFv for purification. ScFv fragments were then purified from a periplasmic extract of a large scale induced culture of bacteria by means of IMAC. This purification procedure permitted both antibody fragments to be recovered in highly pure form (purity $>95 \%$; Fig. 2). Since scFv fragments have been noted to be capable of forming dimers, the scFv proteins were further purified by gelfiltration chromatography to separate monomers and dimers. The typical yield of purified monomeric scFv antibody after IMAC and gelfiltration was 100-200 $\mu \mathrm{g} / \mathrm{L}$ bacterial culture.

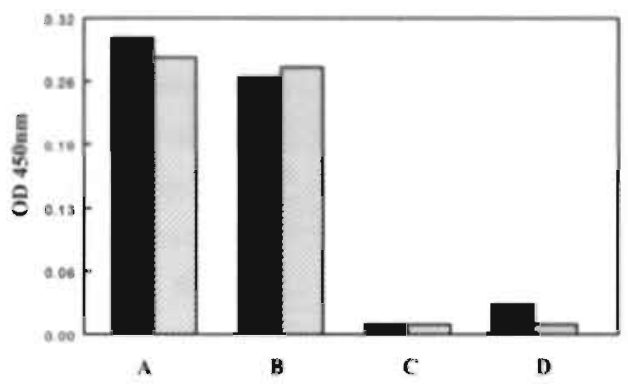

\section{Figure 3}

\section{Specificity ELISA}

Binding of MOC-31 (solid bars) and of MOC-161 (hatched bars) scFv phage antibody to recombinant EGP-2 in the presence of (A) no competing antibody (B) an excess of an irrelevant antibody (RFT5, in anti $\mathrm{CD} 25$ hybridoma), (C) the MOC-31 whole antibody and (D) the MOC-161 whole antibody. OD values ( $\mathrm{Y}$-axis) are corrected for background (whichi was approximately 0.08 ).

\section{Binding analysis of the recombinant scFv antibody fragments}

The isolated scFv antibody fragments specifically bind EGP-2 in ELISA (data not shown). Using competition ELISA, we could demonstrate that the binding of both scFv antibodies, expressed as pIII fusions on the tip of filamentous phage, was competitively inhibited by both of the original bivalent whole antibodies (Fig. 3), whereas an irrelevant antibody (RFT5; an anti-CD25 antibody) failed to inhibit binding of the recombinant antibody fragments to EGP2. This is an indication that the original epitope recognition is retained by these recombinant scFvs.

By means of immunohistochemistry using soluble scFvs, we further showed that both scFv antibody fragments specifically bound EGP-2 positive tissues (Fig. 4). As expected, both antibody fragments reacted with normal and malignant non-squamous epithelia and did not stain malignant tissue reported to be negative for the antigen (melanoma; [4]). 

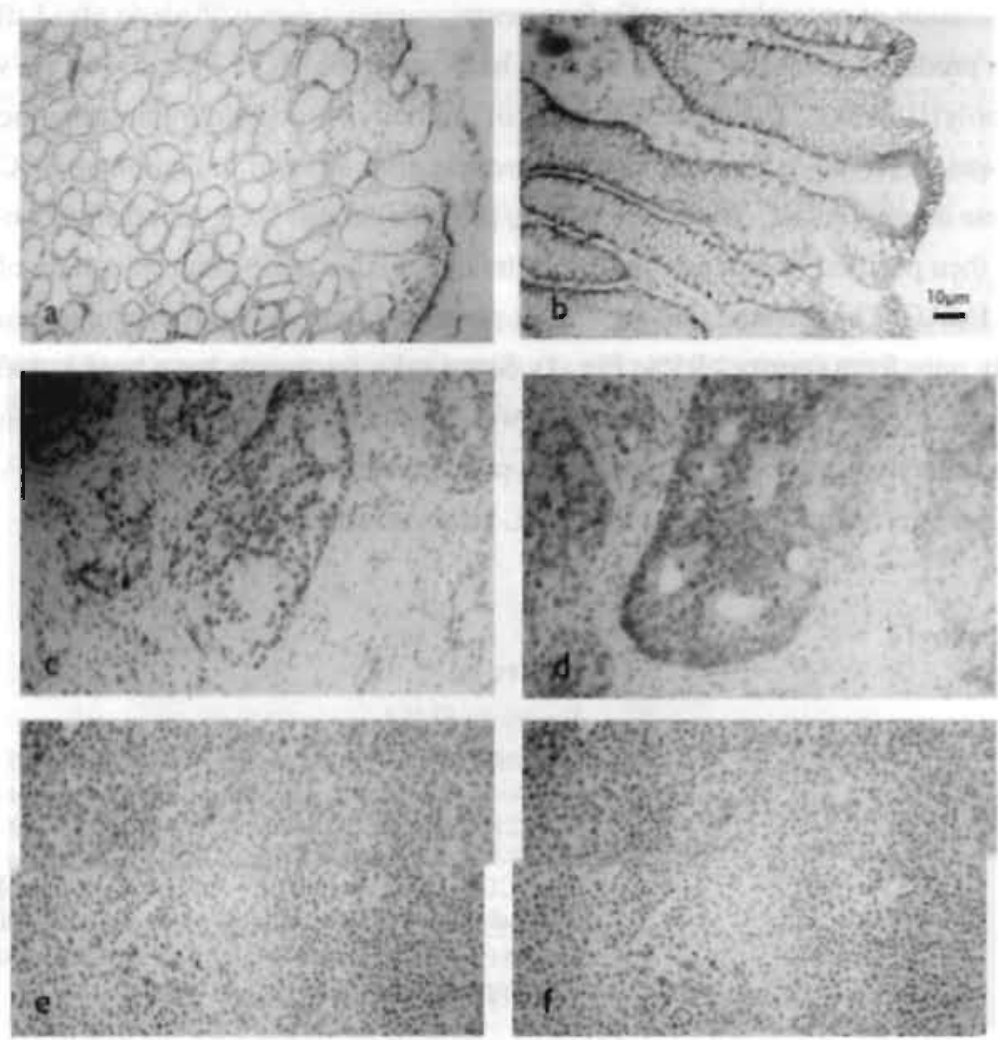

\section{Figure 4}

Immunohistochemi stry with anti EGP$2 \mathrm{scFvs}$

Six um frozen sections of normal colonic epithelium, colon carcinoma and melanoma were stained with MOC-31 scFv $(b, d, f)$ or without primary antibody (negative controls: a,c,e) respectively; sections were. counterstained with haematoxylin. Similar results were obtained with MOC- $|6|$ scFv (data not shown).

The kinetics of binding of purified monomeric scFv antibody fragments were determined using SPR in a BIAcore (Fig. IB and Table 2). The off-rate of monovalent MOC-31 scFv (3.4 $\times 10^{-4} \mathrm{~s}^{-1}$ ) only differs by a factor of less than 1.5 from that of the original monovalent interaction (Bis-1 antibody: $2.5 \times 10^{-4} \mathrm{~s}^{-1}$; Table 2). The monovalent MOC-31 scFv has a three times lower off-rate than the bivalent $323 / \mathrm{A} 3$ antibody and is the best antibody of the present series. The offrate of MOC-161 scFv is significantly higher $\left(2.05 \times 10^{-3} \mathrm{~s}^{-1}\right)$, but still compares well to those of the whole (bivalent) antibodies $323 / \mathrm{A} 3\left(1.06 \times 10^{-3} \mathrm{~s}^{-1}\right)$ and $17-1 \mathrm{~A}\left(38.2 \times 10^{-3} \mathrm{~s}^{-1}\right)$.

\section{Discussion}

We compared the kinetics of binding of four well-characterised antibodies directed to the pan-carcinoma antigen EGP-2, using SPR in a B1Acore (Fig. IA and Table 2). The MOC-3 I whole antibody has by far the lowest apparent off-rate. To account for the avidity of the bivalent 
MOC-31 antibody, we also determined the kinetics of binding of the bispecific antibody Bis-1. As can be seen in Table 2, the absence of a second EGP-2 binding site in Bis-1 is reflected in a 5 -fold increase in off-rate $\left(\mathrm{k}_{\text {off }}=2.5 \times 10^{-4} \mathrm{~s}^{-1}\right)$ when compared to MOC-3I whole bivalent antibody. Since only apparent kinetic constants were obtained, it is difficult to compare our data to affinity values that have been reported for the antibodies (17-1 A: 7x $10^{7} \mathrm{M}^{-1}[22]$ and $323 / \mathrm{A} 3$; $\left.2 \times 10^{9} \mathrm{M}^{-1}[23]\right)$. However, dividing the on-rate of the MOC-31 whole antibody by the off-rate of the monovalent interaction (Bis-1) gives an affinity value of $4.2 \times 10^{8} \mathrm{M}^{-1}$ for this antibody (Table 2). Since the off-rate of the MOC-3I antibody is by far the lowest and the on-rates of MOC-31 and 323/A3 only differ by a factor of two, the affinity of MOC-31 is expected to be higher than that of 323/A3. Unexpectedly, however, the value we find for MOC-31 is approximately five-fold lower than the one reported for 323/A3 [23], which may be due to the different experimental setup used (cell binding versus SPR analysis in a BIAcore). We cannot exclude an effect of the different glycosylation of the recombinant antigen as compared to the antigen present on human tumours on the kinetic parameters we measured. However, there are strong indications that the differences in off-rate we measured are genuine, since affinity differences were also found by means of binding analysis on a human cell line [24].

The short half-life of the 17-1A-antigen complex ( 18 seconds for the bivalent antibody) explains the inefficient in vivo tumour targeting of this antibody [23], but also suggests that the clinical responses obtained with this antibody may be largely caused by other factors than fumour accretion (e.g. the immunogenicity of this antibody). Indeed, treatment of colorectal carcinoma patients with an anti-idiotype antibody to the 17-1 A antibody has been shown to result in a humoral, as well as a cellular immune response to the EGP-2 antigen [25].

The use of the phage display system turnedi out to be necessary to retrieve binding MOC$31 \mathrm{scFv}$ clones; we had to perform two rounds of phage selection of a mini-repertoire in order to find MOC-31 binding scFvs. When cloning V-genes from hybridomas, a certain percentage (typically $50 \%-95 \%$ ) of non-binding or non-functional scFvs may be generated because of errors introduced during PCR amplification of the genes, ig mRNA contribution of the myeloma fusion partner, alterations in the genes introduced by the primer set used, cloning artefacts (e.g. deletions, recombinations, insertions or frameshifts (for review, see [26]) or a combination of these factors. Furthermore, the antigen binding surface might be slightly distorted or deformed by the introduction of a linker sequence between the VH and V $\mathbf{L}$ domains. The use of cloning vectors that allow expression of both secreted soluble scFv molecules and of phage displayed antibodies [16] is therefore recommended for hybridoma V-gene cloning. Using an in vitro model system (Roovers et al., in preparation) we could estimate the enrichment factor of specific MOC-31 phage over non-binding phage to be 150 per selection round, which means that the estimated starting frequency of functional MOC-31 scFv in the small library was at least 1 in 
135000. This very low frequency of functional MOC-31 scFv necessitated the use of the phage display system to retrieve binding clones, an observation that has also been reported by others [27].

The sequences of MOC-31 and MOC-161 antibody V-genes are different from the previously cloned anti EGP-2 antibodies (17-1A: [28]; 323/A3: [24]. MOC-31 is very similar to 323/A 3 in both heavy and light chain sequence: there are 11 amino acid differences for VH and 3 for $\mathrm{V} \mathbf{k}$, with an additional 6 and 2 silent mutations respectively in the non-primer encoded sequences. The CDR3 of the heavy chain is different, but equal in length; the CDR3 of the light chains are identical. The MOC-161 VH on the contrary, shows a higher homology to 17-1 A (with 22 amino acid differences in the non primer-encoded $\mathrm{V}$ gene segment) than to MOC-31 or 323/A3; its $\mathrm{V} \kappa$ is very different from all other reported sequences (Table 3 ). It is intriguing that all anti EGP-2 antibodies studied here use VH-segments with a CDR3 length of 6-7 residues. These homologies may be a reflection of the fact that all four antibodies bind to the same immunodominant epitope on EGP-2.

We have tested and confirmed the fine specificity of the cloned antibody fragments using immunohistochemical staining of human carcinoma, in addition to an ELISA-based assay (data not shown). This is an important issue when cloned antibody fragments are to be used in targeting studies, since the cloning procedure itself may slightly alter the epitope recognition of the antibody.

To use the isolated scFvs in tumour targeting studies, antibody fragments with very low off-rates are required, since the loss of avidity of these monovalent fragments combined with their rapid clearance from blood leads to reduced retention in the tumour [10]. It can be calculated that for efficient tumour retention, off-rates in the region of $10^{-5} \mathrm{~s}^{-1}$ or better are required [29], yielding a half-life of bound complexes of 19 hours or longer. Since the MOC-31 antibody $\mathrm{V}$-genes were cloned in a phagemid vector allowing expression on phage, it is possible to affinity mature the antibody fragments (and in particular the off-rate), for example by chain shuffling or by random mutagenesis of the genes (for review, see [30].

Altematively, rather than affinity maturation, more avid molecules such as bivalent or multivalent versions of MOC-31 scFv may be made (for review, see [31]. A second antigen binding site in the same molecule creates a large avidity effect, which makes the apparent affinity of such bivalent antibody species much higher. ScFv dimers, including non-covalently associated diabodies, have indeed been reported to show superior imaging characteristics of solid tumours than their monovalent counterparts [10,32,33], mainly due to the slower off-rate of these avid molecules. Our cloned scFv antibody fragments already show a variable degree of dimerisation, as shown by gel filtration chromatography of the IMAC-purified scFv preparations (Fig. 2). Noncovalent seFv-dimers or trimers of MOC-31 and MOC-161 may easily be made by shortening 
the linker sequence separating the VH and VK. domains to less than 10 residues to yield diabodies [31], or by deleting the linker completely to generate trimeric molecules [34].

In conclusion, the V-genes encoding these antibodies are useful building blocks for the rational design and generation of immunotherapeutics for the treatment of solid tumours. The antibodies may for example be converted to fully human ones by guided selection [35], which will reduce the chance of inducing a human anti mouse antibody (HAMA) immune response during repeated administration to patients. Alternatively, bispecific antibodies (based on an anti EGP-2 binding site and an anti CD3 binding site) may, together with costimulatory signals, be used to provide T-cells with tumour specificity and cytotoxic potential [7]. We have recently synthesised such a bispecific molecule: a diabody consisting of the MOC-31 V-genes in combination with the $\mathrm{V}$-genes of an anti CD3 antibody. This diabody is capable of in vitro retargeting T-cells to lung cancer cells [36]. Additional antibody enginecring is expected to lead to the development of completely human immunotherapeutics based on the EGP-2 antigen with improved affinity, dissociation rate, format and -thus- pharmacokinetics to achieve maximal clinical efficacy.

\section{Acknowledgements}

We acknowledge Dr. Hans de Haard for his support and valuable discussions on BIAcore experiments and thank Prof. D. Herlyn for her kind gift of purified EGP-2. P. Henderikx was supported by grant PL950252 of the European Community, Biotechnology programme 5.1. This research was further partly financially supported by the Netherlands Technology Foundation (STW), and was coordinated by the Life Sciences, Foundation (SLW) (project MGN55.3858, 805.17.753).

\section{References}

1. Balaban EP, Walker BS, Cox JV, Sein AA, Abrams PG, Salk D, Sheehan RG, Frenkel EP (1991) Radionuclide imaging of bone marrow metastases. with a Tc-99m labeled monoclonal antibody to small cell lung carcinoma. Clin. Nucl. Med. 16: 732-736

2. Kosterink JG, de-Jonge MW, Smit EF, Piers DA, Kengen RA, Postmus PE, Shochat D, Groen HJ, The HT, de-Leij L (1995) Pharmacokinetics and scintigraphy of indium-1 1.1DTPA-MOC-31 in small-cell lung carcinoma. J. Nucl. Med. 36: 2356-2362

3. Frodin JE, Harmenberg U, Biberfeld P, Christensson B, Lefvert AK, Rieger A, Shetye J, Wahren B, Mellstedt H (1988) Clinical effects of monoclonal antibodies (MAb 17-IA) in patients with metastatic colorectal carcinomas. Hybridoma 7: 309-32 I

4. Herlyn M, Steplewski Z, Herlyn D, Koprowski H (1979) Colorectal carcinoma-specific antigen: Detection by means of monoclonal antibodies. Proc. Natl. Acad. Sci. U. S. A. 76: 
1438-1442

5. Riethmüller G, Schneider-Gädicke E, Schlimok G, Schmiegel G, Raab R, Höffken K, Gruber R, Pichlmaier H, Hirche H, Pichlmayer R, Buggisch P, Witte J (1994) Randomized trial of monoclonal antibody for adjuvant therapy of resected Dukes' C colorectal carcinoma. The Lancet 343: 1177-1183

6. Dohlsten M, Abrahmsen L, Bjork P, Lando PA, Hedlund G, Forsberg G, Brodin T, Gascoigne NR, Forberg C, Lind P, Kalland T (1994) Monoclonal antibody-superantigen fusion proteins: tumor-specific agents for T-cell-based tumor therapy. Proc. Natl. Acad. Sci. U. S. A. 91: 8945-8949

7. Kroesen BJ, Buter J, Sleijfer DT, Janssen RAJ, Van der Graaf WTA, Hauw The T, De Leij L, Mulder NH (1994) Phase I study of intraveneously applied bispecific antibody in renal cell cancer patients recieving subcutaneous interleukin 2. Br. J. Cancer 70: 652-661

8. LeMaistre CF, Edwards DP, Krolick KA, McGuire WL (1987) An immunotoxin cytotoxic for breast cancer cells in vitro. Cancer Res. 47: 730-734

9. Zimmermann S, Wels W, Froesch BA, Gerstmayer B, Stahel RA, Zangemeister Wittke U (1997) A novel immunotoxin recognising the epithelial glycoprotein-2 has potent antitumoural activity on chemotherapy-resistant lung cancer. Cancer Immunol. Immunother 44: 1-9

10. Adams GP, McCartney JE, Tai MS, Oppermann H, Huston JS, Stafford WF 3d, Bookman MA, Fand I, Houston LL, Weiner LM (1993) Highly specific in vivo tumor targeting by monovalent and divalent forms of $741 \mathrm{~F} 8$ anti-c-erbB-2 single-chain Fv. Cancer Res. 53: 4026-4034

11. Begent RHJ, Verhaar MJ, Chester KA, Casey JL, Green AJ, Napier MP, Hope-Stone LD, Cushen N, Keep PA, Johnson CJ, Hawkins RE, Hilson AJW, Robson L (1996) Clinical evidence of efficient tumor targeting based on single-chain Fv antibody selected from a combinatorial library. Nat. Med. 2: 979-984

12. Edwards DP, Grzyb KT, Dressler LG, Mansel RE, Zava DT, Sledge GW Jr, McGuire WL (1986) Monoclonal antibody identification and characterization of a $\mathrm{Mr} 43,000$ membrane glycoprotein associated with human breast cancer. Cancer Res. 46: 1306-1317

13. Souhami RL, Beverley PCL, Bobrow LG (1988) Proceedings of the First International Workshop on Small-Cell Lung-Cancer Antigens. Lungr Cancer 4: 1-114

14. Helfrich W, Van Geel M, Hauw The T, De Leij L (1994) Detection of a putative 30-kDa ligand of the cluster-2 antigen. Int. J. Cancer Supplement 8: 70-75

15. Strassburg CP, Kasai Y, Seng BA, Miniou P, Zaloudik J, Herlyn D, Koprowski H, Linnenbach AJ (1992) Baculovirus recombinant expressing a secreted form of a transmembrane carcinoma-associated antigen. Cancer Res. 52: 815-821

16. Hoogenboom HR, Griffiths AD, Johnson KS, Chiswell DJ, Hudson P. Winter Gi (1991) Multi-subunit proteins on the surface of filamentous phage: methodologies for displaying antibody (Fab) heavy and light chains. Nucleic Acids Res. 19: 4133-4137

17. Griffiths AD, Williams SC, Hartley O, Tomlinson IM, Waterhouse P, Crosby WL, Kontermann RE, Jones PT, Low NM, John Allison T, Prospero TD, Hoogenboom HR, Nissim A, Cox JPL, Harrison JL, Zaccolo M, Gherardi E, Winter G (1994) Isolation of high affinity human antibodies directly from large synthetic repertoires. $E M B O J .13$ : $3245-3260$ 
18. Clackson T, Hoogenboom HR, Griffiths AD, Winter G (1991) Making antibody fragments using phage display libraries. Nature 352: 624-628

19. Marks JD, Hoogenboom HR, Bonnert TP, McCafferty J, Griffiths AD, Winter G (1991) By-passing Immunization; Human Antibodies from V-gene Libraries Displayed on Phage. J. Mol. Biol. 222: 581-597

20. Nieba L, Krebber A, Plückthun A (1996) Competition BIAcore for measuring true affinities: large differences from values determined from binding kinetics. Anal. Biochem. 234: 155-165

21. Kabat EA, Wu TT, Perry HM, Gottesman KS, Foeller C (1991) Sequences of Proteins of Immunological Interest. U.S. Department of Health and Human Services, Public Health Services of National Institute of Health, Bethesda, p

22. Herlyn M, Steplewski Z, Herlyn D, Koprowski H (1986) CO 17-1A and related monoclonal antibodies: their production and characterization. Hybridoma 5: \$3-10

23. Velders MP, van-Rhijn CM, Briaire IH, Fleuren GJ, Warnaar SO, Litvinov SV (1995) Immunotherapy with low and high affinity monoclonal antibodies $17-1 \mathrm{~A}$ and $323 / \mathrm{A} 3$ in a nude mouse xenograft carcinoma model. Cancer Res. 55: 4398-4403

24. Velders MP, Litvinov SV, Warnaar SO, Gorter A, Fleuren GJ, Zurawski VR Jr, Coney LR (1994). New chimeric anti-pancarcinoma monoclonal antibody with superior cytotoxicity-mediating potency. Cancer Res, 54: 1753-1759

25. Fagerberg J, Steinitz M, Wigzell H, Askelöf P, Mellstedt H (1995) Human anti-idiotypic antibodies induced a humoral and cellular immune response against a colorectal carcinoma-associated antigen in patients. Proc. Natl. Acad. Sci. U. S. A. 92: 4773-4777

26. Bradbury A, Ruberti F, Werge T, Amati V, Di Luzio A, Gonfloni S, Hoogenboom HR, Piccioli P, Biocca S, Cattaneo A (1995): The Cloning of Hybridoma V Regions for Their Ectopic Expression in Itracellular and Intercellular Immunization. In: Antibody Engineering. 2nd ed. (Borrebaeck CAK) Oxford University Press, New York, 295-362.

27. Krebber A, Bornhauser S, Burmester J, Honegger A, Willuda J, Bosshard HR, Plückthun A (1997) Reliable cloning of functional antibody variable domains from hybridomas and spleen cell repertoires employing a reengineered phage display system. $J$. Immunol. Methods 201: 35-55

28. Caton AJ (1986) Comparative Sequence Analysis of CO17-1A Antigen-Specific Monoclonal Antibodies. Hybridoma 5: 11-16

29. Schier R, Bye J. Apell G, McCall A, Adams GP, Malmqvist M, Weiner LM, Marks JD (1996) Isolation of high-affinity monomeric human anti-c-erbB-2 single chain Fv using affinity-driven selection. J. Mol. Biol, 255: 28-43

30. Winter G, Griffiths AD, Hawkins RE, Hoogenboom HR (1994) Making antibodies by phage display technology. Annu. Rev. Immunol: 12: 433-455

31. Holliger P, Prospero T, Winter G (1993) "Diabodies": small bivalent and bispecific antibody fragments. Proc. Natl. Acad. Sci. U. S. A. 90: 6444-6448

32. Tai MS, McCartney JE, Adams GP, Jin D, Hudziak RM, Oppermann H, Laminet AA, Bookman MA, Wolf EJ, Liu S, Stafford III WF, Fand I, Houston LL, Weiner LM, Huston JS (1995) Targeting c-erbB-2 expressing tumors using single-chain Fv monomers and dimers. Cancer Res. 55: 5983s-5989s

33. Wu AM, Chen W, Raubitschek A, Williams LE, Neummaier M, Fischer R, Hu S-ZZ, Odom-Maryon T, Wong JYC, Shively JE (1996) Tumor localization of anti-CEA single- 
chain Fvs: improved targetting by non-covalent dimers. Immunotechnology 2: 21-36

34. Kortt AA, Lah M, Oddie GW, Gruen CL, Burns JE, Parce LA, Atwell JL, McCoy AJ, Howlett GJ, Metzger DW, Webster RG, Hudson PJ (1997) Single-chain Fv fragments of anti-neuraminidase antibody $\mathrm{NC10}$ containing five and ten-residue linkers form dimers and with zero-residue linker a trimer. Protein Eng. 10: 423-433

35. Jespers LS, Roberts A, Mahler SM, Winter G, Hoogenboom HR (1994) Guiding the selection of human antibodies from phage display repertoires to a single epitope of an antigen. Biotechnology 12: 899-903

36. Helfrich W, Kroesen BJ, Roovers RC, Westers L, Molema G, Hoogenboom HR, de Leij $\mathrm{L}$ (1998) Construction and characterization of a bispecific diabody for retargeting $\mathrm{T}$ cells to human carcinomas. Int. J. Cancer 76: 232-239 


\section{Chapter 4}

Design and application of Diabodies, Triabodies and Tetrabodies for cancer targeting

Aneta Todorovska, Rob C. Roovers, Olan Dolezal, Alexander A. Kortt, Hennie R. Hoogenboom and Peter J. Hudson

Journal Immunol. Methods, in press 


\section{Abstract}

Multivalent recombinant antibody fragments provide high binding avidity and unique specificity to a wide range of target antigens and haptens. This review describes the design and expression of diabodies, triabodies and tetrabodies using examples of scFv molecules that target viruses (influenza neuraminidase) and cancer (Ep-CAM; epithelial cell adhesion molecule). We discuss the preferred choice of linker length between V-domains to direct the formation of either diabodies $(60 \mathrm{kDa})$, triabodies $(90 \mathrm{kDa})$ or tetrabodies $(120 \mathrm{kDa})$, each with size, flexibility and valency suited to different applications for in vivo imaging and therapy. The increased binding valency of these scFv multimers resuits in high avidity (low off-rates). A particular advantage for tumour targeting is that molecules of $60-100 \mathrm{kDa}$ have increased tumour penetration and fast clearance rates compared to the parent $\operatorname{Ig}(150 \mathrm{kDa})$. We highlight a number of cancer-targeting scFv multimers that have recently successfully undergone pre-clinical trials for in vivo stability and efficacy. We also review the design of multi-specific Fv modules suited to cross-link two or more different target antigens. These bi- and tri-specific multimers can be formed by association of different scFv molecules and, in the first examples, have been designed as cross-linking reagents for T-cell recruitment into tumours (immunotherapy), viral retargeting (gene therapy) and as red blood cell agglutination reagents (immunodiagnostics).

\section{Introduction}

Whole antibodies provide excellent target-binding specificity but are limited in clinical imaging applications in vivo due to their long circulating lives and associated effector functions. Similarly, for in vitro diagnostics, antibody fragments alone (without $\mathrm{Fc}$ ) can provide the full range of immunoassays, which represents $30 \%$ of the US $\$ 20$ billion per annum diagnostic industry. Recombinant antibodies and their fragments have become the paradigm for the design of these high-affinity, protein-based targeting reagents (Hudson, 1998; Hudson, 1999; Hudson, 2000; Dall'Acqua and Carter, 1998) which now represent over $30 \%$ of all biological proteins undergoing clinical trials. This has recently culminated in FDA approval for the first engineered cancer therapeutic antibodies (Rituxan ${ }^{\mathrm{TM}}$ and Bexxar ${ }^{\mathrm{TM}}$ for non-Hodgkin lymphorna, Herceptir ${ }^{\mathrm{M}}$ for breast cancer). These immunotherapeutic antibodies are designed to include the $\mathrm{Fc}$ domain for prolonged serum half-life and complement-mediated effects.

Recent successes in the design and applications of engineered antibodies are based on their reduction in size, dissection into minimal binding fragments, and rebuilding into multivalent high-avidity reagents (Fig. 1). Antibody fragments have also been fused with a range of molecules limited only by the imagination, including radioisotopes for cancer imaging, enzymes for prodrug therapy, toxins for targeted cell killing, viruses for gene therapy, lipids for improved 
systemic delivery and biosensors for real-time detection of target molecules. Recombinant antibodies now capture a significant share of the US\$6 billion per annum immunodiagnostic market, from in vitro immunoassays to in vivo tumour and clot imaging reagents.

AVTIBODY Comfermations

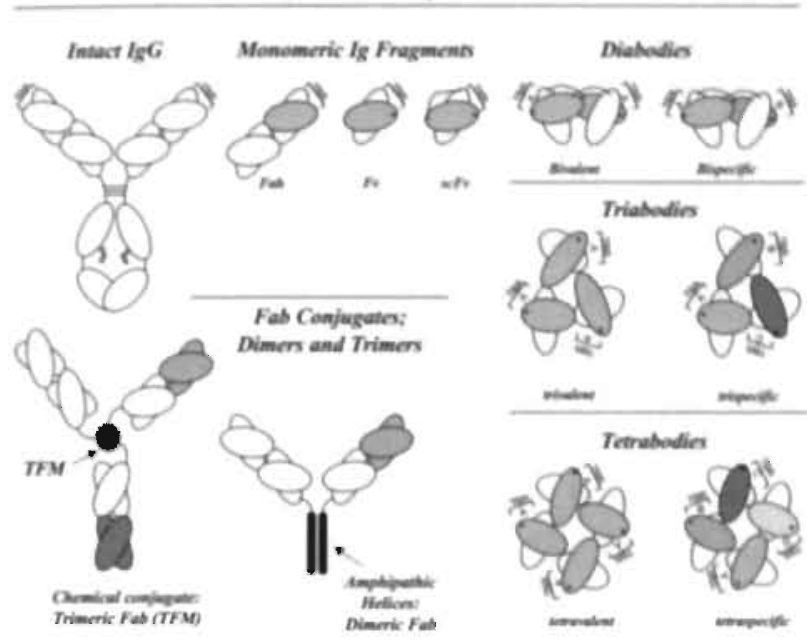

Figure 1

Schematic representation of intact $\mathrm{lg}$ (bivalent) alongside monomeric lg fragments (Fab. $F v, s c F v$ ) and diabodies, triabodies and tetrabodies.

$\mathrm{V}$-domains and $\mathrm{C}$-domains are represented by ovals. The different target binding regions (TBR) of $\mathrm{F}$ modules are labeled TBR-A, TBR-B etc. The different patterns of the $V_{11}$ domains are meant to represent different target specificity. For size comparison, chemically conjugated Fab trimers (cg Celltech's. TFM) and helix-conjugatod Fab dimers are also shown.

Single chain Fv antibody fragments (scFvs) are predominantly monomeric when the $\mathrm{V}_{11}$ and $\mathrm{V}_{\mathrm{L}}$ domains are joined by polypeptide linkers of at least 12 residues (Hudson and Korti, 1999). This review describes how selection of the $\mathrm{V}$-domain orientation as well as linker length between $\mathrm{V}$-domains creates new forms of Fv modules with different size, flexibility and valency suited for in vivo imaging and therapy. An scFv molecule with a linker of 3 to 12 residues cannot fold into a functional Fv domain and instead associates with a second scFv molecule to form a bivalent dimer (diabody, $-60 \mathrm{kDa}$ ). Reducing the linker length below 3 residues can force $\mathrm{scFv}$ association into trimers (triabodies, $-90 \mathrm{kDa})$ or tetramers $(\sim 120 \mathrm{Kda})$ depending on linker length, composition and $\mathrm{V}$-domain orientation. We discuss two of our own model scFv systems in detail; a) the NC10 antibody that targets influenza neuraminidase (Kortt et al., 1997; Atwell et al., 1999) and b) the anti-cancer MOC-3i antibody (Souhami et al., 1988; Roovers et al., 1998) that targets epithelial cell adhesion molecule (Ep-CAM, also known as EGP-2). Further, we review the design and expression of multi-specific Fv modules suited to cross-linking target antigens for cell-recruitment, viral delivery and immunodiagnostics (Segal et al., 1999).

\section{Multivalent antibody fragments}

To expand the versatility of antigen-binding proteins, antibodies have been redesigned 
to tailor binding properties, valency and pharmacokinetic behaviour using genetic engineering and rational protein modeling. Intact antibodies are naturally occurring, multivalent molecules (Fig. 1), which provide a significant increase in functional affinity (avidity), particularly for pentameric IgM molecules which can potentially interact with 10 antigen sites at a time. A similar increase in functional affinity is achievable when Fab or scFv fragments are complexed into dimers, trimers or larger aggregates (Pluckthun and Pack, 1997). Whole Igs allow flexibility between antigen binding sites and this remains important for engineered antibody fragments; in intact Igs the 'elbow' angle within Fab arms and 'hinge' angles between Fab arms allow significant flexibility, and numerous cross-linking geometries (Roux et al., 1997; Roux et al., 1998). Despite this flexibility, intact Igs are often not able to cross-link adjacent receptors on the same viral or cell surface (Thouvenin et al., 1997; Ghetie et al., 1997). Recently, cross-linked whole Igs. (presumably tetravalent) were shown to cross-link adjacent receptors on the same cell surface, and thereby activate intracellular signalling and apoptosis (Ghetie et al., 1997). However, the large $(300 \mathrm{kDa})$ size of cross-linked whole Igs is probably ineffective for tumour penetration. For these very reasons, there have been many attempts to conjugate Fab or seFv molecules into dimers or higher multimers (Fig. 1) to produce high-avidity reagents of optimal size (60$120 \mathrm{kDa})$, capable of rapid tumour penetration without fast renal clearance. Such designs have included chemical cross-linking strategies and a variety of recombinant fusions using adhesive protein domains or peptides (Hudson, 1998; Hudson, 1999; Hudson, 2000; Pluckthun and Pack, 1997). This review describes a far simpler strategy to create multimers, by manipulating the linker length between V domains (Fig. 2; Hudson and Kortt, 1999). These scFv molecules, associate into multimers and can be designed with either high avidity to a single target antigen or with multiple specificities to different target antigens.

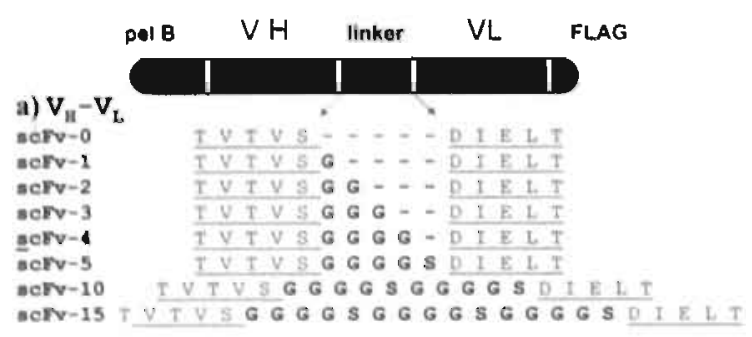

b) $\mathbf{V}_{\mathrm{L}}-\mathrm{V}_{\mathrm{H}}$

serv-0

schv-1

sorv-2

schv-3

scrv-4

scrv-5

$\operatorname{sck}-15$

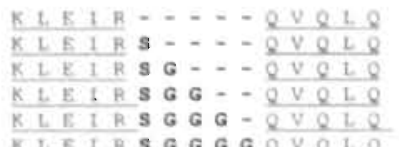

G $\mathrm{Q} \times \mathrm{Q}+\mathrm{Q}$

\section{Figure 2}

Linker sequences used for a) scFv-multimers in the $\mathrm{V}_{\mathrm{H}}-\mathrm{V}_{\mathrm{L}}$ orientation, with linkers joining $\mathrm{SerH}^{112}$ to Aspl' and b) scFv-multimers in the $\mathrm{V}_{\mathrm{L}}-\mathrm{V}_{\mathrm{H}}$ orientation, with linkers joining $\mathrm{ArgL}^{107}$ to GinH!' The gene construct for bacterial periplasmic expression has a pelB leader and Flag octapeptide tag tail. 


\section{Linker design and V-domain orientation in the formation of $\mathrm{scFv}$ multimers}

The single chain variable fragment (scFv) in which the antigen binding domains of an antibody $\left(\mathrm{V}_{\mathrm{H}}\right.$ and $\left.\mathrm{V}_{\mathrm{L}}\right)$ are joined by a flexible polypeptide linker provides the minimal antigen binding format of an antibody which can be expressed in $E$. coli (Huston et al., 1988; Bird et al., 1988). The most common linker designs contain a combination of glycine and serine residues to provide flexibility and protease resistance, although the linker sequence can also be optimised by phage display (Turner et al., 1997). Linkers greater than 12 amino acids in length provide enough flexibility for the $\mathrm{V}_{\mathrm{H}}$ and $\mathrm{V}_{\mathrm{L}}$ domains to assemble in the natural Fv orientation to form a monovalent antigen combining site comparable to the Fab fragment of the parent antibody (Fig. 1; Kortt et al., 1994; Whitlow et al., 1994; Zdanov et al., 1994). Shortening of the linker to 12 residues or less prevents the $V_{H}$ domain from interacting with its attached $V_{L}$ domain in the natural Fv orientation. Instead, two separate scFv molecules are required for complementary $V_{\text {" }}$ $/ V_{L}$ pairs to associate to form a bivalent dimer, termed a diabody (Figs. 2, 3a; Holliger et al., 1993, 1996; Perisic et al., 1994; Atwell et al., 1996). Complete removal of a linker from scFv molecules in $\mathrm{V}_{\mathrm{H}}-\mathrm{V}_{\mathrm{L}}$ orientation drives three scFv molecules to associate into a trimer, termed a triabody (Fig. 3; Kortt et al., 1997; lliades et al., 1997; Pei et al., 1997). Atwell et al. (1999) refined this definition of linker dependent oligomeric transition further and established with the murine $\mathrm{NCl} 0$ (anti neuraminidase) scFvs that triabodies were formed exclusively when linkers of 0-2 residues were used whereas diabodies were formed with linkers of 3-5 residues (Figs. 3a, 4a). The transition from dimer (diabody) to trimer (triabody) was distinct as the linker length was reduced from three to two glycine residues; modeling studies were consistent with three residues as the minimum linker length compatible with diabody formation for $\mathrm{NCl} 10$ (Fig. 3a).

A precise definition of the $\mathrm{N}$ - and $\mathrm{C}$-terminal residues of the $\mathrm{V}$-domains is required when designing the linker length. In this review, antibody residues are numbered according to Kabat et al., (1991). The murine NCI0 scFvs $\left(\mathrm{V}_{\mathrm{H}_{1}}-\mathrm{V}_{\mathrm{L}}\right.$ orientation) were described precisely in Atwell et al. (1999) and had linker residues shown in Fig. 2. The linker sequences were carefully chosen after examination of the $2.4 \AA$ resolution structure from X-ray diffraction analysis of the $\mathrm{NCl} 10$ Fab-NA complexes (Malby et al., 1994; Malby et al., 1998). Ser ${ }^{H 112}$ was selected as the $\mathrm{V}_{H} \mathrm{C}$ terminus because it was not in any direct hydrogen bonded contact with other $V_{H}$ domain residues, whereas $\mathrm{Thr}^{\mathrm{H} 110}$ and $\mathrm{Val}^{\mathrm{HIII}}$ contacted framework residues $\mathrm{Val}^{\mathrm{H12}}$ and $\mathrm{Ser}^{\mathrm{H}}$ respectively. The $V_{L} \mathrm{~N}$-terminal residues were Asp-Ile-Glu in which side chain atoms in Asp ${ }^{L .1}$ and $\mathrm{Ile}^{\mathrm{L2}}$ contacted framework residues $\mathrm{Glu}^{13}$ and $\mathrm{Thr}^{197}$ and could not act as defacto linker residues. Therefore, $\mathrm{V}_{\mathrm{H}} \mathrm{Ser}^{\mathrm{H} 1 \mathrm{H}}$ was joined to $\mathrm{V}_{\mathrm{L}} \mathrm{Asp}^{\mathrm{II}}$ either directly or by additional (flexible) Gly/Ser resides to give linkers of various defined lengths; 0-2 residues formed triabodies, 3-10 residues formed diabodies (Figsi 3a, 4a; Atwell et al., 1999). 
a) Modeis of NC10 Diabodies (4.3 residue linkers) and Triabodies $(2,0)$ b) Models of NC10 scFv-0 Triabodies $\left(V_{2}-V_{2}\right)$ and Tetrabodies $\left(V_{2}-V_{p}\right)$
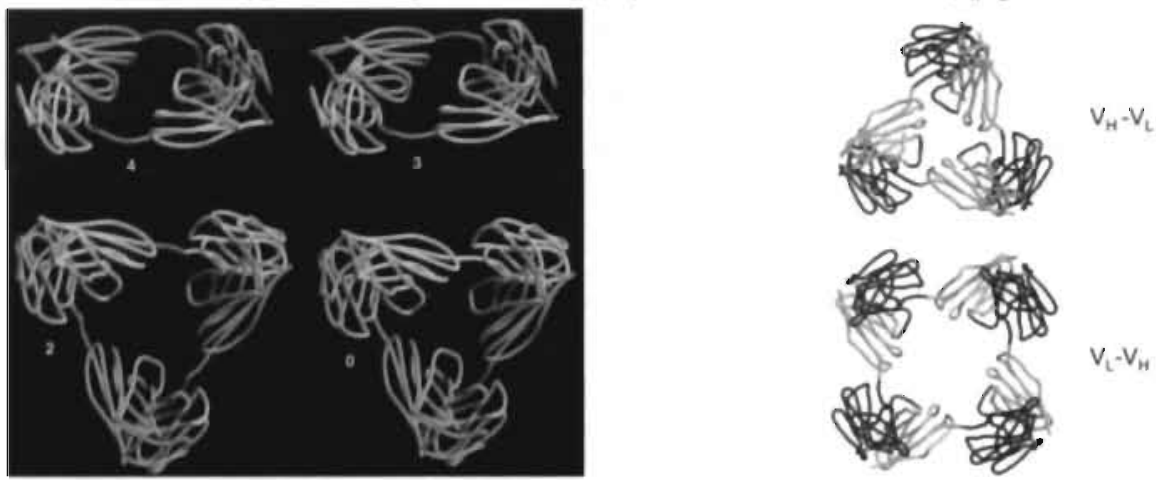

\section{Figure 3}

Structural models of NCIO diabodies, triabodies and tetrabodies prepared using Molscript as described by Kortt et al. (1997).

Fig. 3a shows the effect of linker length in directing formation of NC10 scFv diabody or triabody in $\mathrm{V}_{u}$-linker$V_{1}$ orientation; molecular models ( $\mathrm{C} \alpha$ traces) are shown of diabodies with linkers of 3 or 4 residues and triabodies with linkers of 0 or 2 residues. Diabody orientation corresponds to the crystal structure described by Perisic et al (1994) and triabody orientation is shown with the three-fold symmetry axis perpendicular to the page similar to the model described by Kortt et al. (1997). The Ca backbone for the different seFv molecules are shown in pink, whit and purple; CDR loops in the VH and VL domains are highlighted in blue andyellow and the linkers are coloured green. Fig. 3b shows molecular models ( $\mathrm{C} \alpha$ traces) of NC10 scFv triabody (a) and tetrabody (b) with $\mathrm{V}_{\mathrm{L}}$ linked directly to $V_{11}$. The Fv modules were aligned by rigid 3-fold and 4-fold symmetry for triabody and ietrabody respectively. The $V_{L}$ domains are shaded light grey and $V_{H 1}$ domains are dark grey. To highlight the interactions across the Fv interface and the steric clash in triabody configuration, loops L.15-L17 and L55-L6I are shown n green and magenta, respectively.

Modeling studies based on the X-ray crystal structure of a different diabody (L5MK 16; 5-residue linker scFv) also showed that reducing the linker to 'just one or two residues' seriously strained the diabody association (Perisic et al., 1994). Further, a one-residue linker that joined mismatched $V$-domains ( $V_{H}$ from $B 1-8$ antibody and $V_{L}$ from NQI 1 antibody) indeed formed a triabody, but V-domain orientation was distorted and a CDR loop structure was misplaced (Pei et al., 1997). A report of an scFv 'diabody' library in which $\mathrm{V}_{\mathrm{H}}$ and $\mathrm{V}_{\mathrm{L}}$ domains were joined without a linker confused the field since the molecular mass of these "diabodies" was not determined and many were likely to be triabodies (McGuiness et al., 1996).

Reversal of $\mathrm{V}$-domains to $\mathrm{V}_{\mathrm{L}}-\mathrm{V}_{\mathrm{H}}$ orientation was observed to play a significant role in multimer configuration for the murine NC10 ScFv-0 (Fig 4b). Arg ${ }^{107}$ was selected as the C-terminal residue of $\mathrm{V}_{\mathrm{L}}$ and linked to $\mathrm{G} \mathrm{ln}^{\mathrm{HI}}$ of $\mathrm{V}_{\mathrm{H}}$ either directly or with one to five Gly/Ser residues (Figs. 2,3a,4a; Dolezal et al., 2000). Diabodies were the predominant conformation for 3, 4 and 5 residue linkers whilst tetrabodies were the preferred conformation for $V_{L}-V_{H}$ domains joined 
directly (scFv-0; Fig 4b). The transition between dia/tria/tetrabodies was not as distinct as with $\mathrm{V}_{\mathrm{H}}-\mathrm{V}_{\mathrm{L}}$ orientation; for example, reducing the scFv linker length in $\mathrm{NCl} 10 \mathrm{~V}_{\mathrm{L}}-\mathrm{V}_{\mathrm{H}}$ from 3 to 2 residues did not precisely dictate a transition between diabodies and triabodies. Instead, 2-residue linked $V_{L}-V_{H}$ domains formed a mixture of diabodies, triabodies and tetrabodies. Molecular models of $\mathrm{V}_{\mathrm{L}}-\mathrm{V}_{\mathrm{H}}$ tetrabodies (Fig. 3b; Dolezal et al., 2000) showed that the steric restriction that caused the preference for 4 instead of $3 \mathrm{scFv}$ molecules to combine into tetramers might be due to loop L55-L62 (particularly residues L55-L58) clashing with residues L.15 and L.16 and resulted in unstable $V_{\mathrm{L}}-\mathrm{V}_{\mathrm{H}}$ triabodies (Fig. 3b). The structurally similar loop (H58-H67) in the $V_{\mathrm{H}}-\mathrm{V}_{\mathrm{L}}$ triabodies does not have this steric clash (Fig 3a; Atwell et al., 1999). In addition, other subtle differences in Fv contact interfaces for $\mathrm{NCl} 0$ between $\mathrm{V}_{\mathrm{H}} \mathrm{V}_{\mathrm{L}}$ and $\mathrm{V}_{\mathrm{L}} \mathrm{V}_{\mathrm{H}}$ orientations could be responsible for the different transitions in multimeric state.

We have shown that $\mathrm{NCI} 0$ tetrabodies (scFv-0, Fig. 3b) have 4 fully active antigen binding sites (Dolezal et al., 2000). To date, active tetrabodies have been described for only one other scFv (HD37, targeting CD19; Le Gall et al., 1999). This HD37 antibody had unusual associations since tetrabodies were the preferred form in $\mathrm{V}_{\mathrm{H}}-\mathrm{V}_{\mathrm{L}}$ orientation with a single-residue linker. However, the diabody-triabody-tetrabody transition was not precisely defined since only scFv-18, $-10,-1,-0$ were characterised. HD37 scFv-18 formed a mixture of monomer, dimer and small amount of tetramer, the scFv- 10 formed mainly dimer with some tetramer, the $\mathrm{seF}_{\mathrm{v}-1 \text { formed }}$ exclusively tetramers whilst the scFv-0 formed exclusively trimers. The formation of a tetramer with $\mathrm{scFv}-1$ and a trimer with scFv -0 for $\mathrm{HD} 37$ was unexpected and contradicts our previous data with NCl0 scFvs (Atwell et al., 1999; Dolezal et al., 2000). However, binding assays with the scFv -0 triabody suggested a monovalent interaction with the antigen (Le Gall et al., 1999), indicating that this triabody may be incorrectly folded and is therefore an aberrant molecular form since it did not possess three active antigen binding sites.

It has been documented that $\mathrm{V}_{\mathrm{H}}$ and $\mathrm{V}_{\mathrm{L}}$ domains are not related by a rotation of $180^{\mathrm{C}} \mathrm{C}$ about the pseudo two-fold axis (parallel to the interface), but only by aboui $170^{\circ} \mathrm{C}$ (Huston et al., 199l; Padlan, 1994). Therefore, the $\mathrm{C}$-terminus of $\mathrm{V}_{\mathrm{L}}$ is further away from the $\mathrm{N}$-terminus of $\mathrm{V}_{H}(\sim 39$ 43) than the $C$ terminus of $V_{H}$ is from the $N$-terminus of $V_{L}(-32-34$ ?). Consequently, when the two isomers are linked with identical linkers the greater constraints in the $\mathrm{V}_{\mathrm{L}}$ to $\mathrm{V}_{\mathrm{H}}$ construct would be expected to favour a larger proportion of higher-order oligomers (Plückthun and Pack, 1997). This expectation is contradicted in our studies on NC10 which showed that the scFv-2 and $\mathrm{scFv}-1 \mathrm{~V}_{\mathrm{L}}-\mathrm{V}_{\mathrm{H}}$ protein preparations contain functional dimers (Dolezal et al., 2000) whereas their $\mathrm{V}_{\mathrm{H}}-\mathrm{V}_{\mathrm{L}}$ isomers are trimeric (Atwell et al., 1999). It is tempting to speculate that in the $\mathrm{V}_{\mathrm{L}}-\mathrm{V}_{\mathrm{H}}$ proteins the $\mathrm{C}$-terminal residues of $\mathrm{V}_{\mathrm{L}}$ domain and/or $\mathrm{N}$-terminal residues of $\mathrm{V}_{\mathrm{H}}$ domain provide additional flexibility in the linker region, which dictates the transition between dimers, trimers and tetramers. There is some structural consistency between different antibodies that 
could lead to a generic definition of linker effect even though the association of Fv modules is unlikely to depend on the linker length and linker flexibility alone. The Fv interface in crystal structures of diabodies and triabodies is observed to be almost exclusively between $\mathrm{V}_{\mathrm{H}}$ domains when scFvs are in the $\mathrm{V}_{\mathrm{H}} \mathrm{V}_{\mathrm{L}}$ orientation (Fig. 3a; Malby et al., 1998; Pei et al., 1997; Perisic et al., 1996). The detailed molecular interactions between V-domain interfaces, Fv interfaces and the terminal residues held in contact within the $\mathrm{V}$-domain framework are obviously unique for each antibody and therefore will affect both flexibility and stoichiometry of diabodies, triabodies and tetrabodies.

We can only hypothesize that these studies on murine NC10 and HD37 linker lengths will be representative for other antibody scFvs. Therefore, for other scFvs, we suggest that residues equivalent to NC10 Ser ${ }^{H 112}$ of $\mathrm{V}_{\mathrm{H}}$ and $\mathrm{Asp}^{\mathrm{LI}}$ of $\mathrm{V}_{\mathrm{L}}$ be used to define the zero-residue, minimal contact for $\mathrm{V}$-domains joined in $\mathrm{V}_{\mathrm{H}^{-}} \mathrm{V}_{\mathrm{L}}$ orientation and $\mathrm{Arg}^{\mathrm{L}}{ }^{107}$ of $\mathrm{V}_{\mathrm{L}}$ and $\mathrm{Gln}^{\mathrm{II \prime}}$ of $\mathrm{V}_{\mathrm{H}}$ in $\mathrm{V}_{\mathrm{L}}-\mathrm{V}_{\mathrm{H}}$ orientation. With this numbering, we predict that linkers of 3-12 residues will predominantly, if not exclusively, form diabodies.

\section{Expression and stability of $\mathrm{scFv}$ multimers}

ScFy moiecules can be expressed into the periplasm of $E$.coli with efficient signal peptide excision, correct V-domain folding and disulphide bond formation (Power and Hudson, 2000; Verma et al., 1998). These antibody fragments fold efficiently in the oxidising extracellular environment and are targeted to the periplasm using secretion signals (most commonly pelB and ompA). Bacterial synthesis of scFv molecules was originally done in 'primitive' periplasmic expression vectors using leaky promoters (lac. $t r p$ and $t a c$ ), all of which are not effectively repressed. For example, lac promoters are controlled inefficiently by the lac repressor and are induced by the addition of isopropyl- $\beta$-galactosidase (ITPG). Although these expression systems can be improved (Coia et al., 1996; Kipriyanov et al., 1997) the levels of protein recovered are usually low (below $1 \mathrm{mg}$ /litre from shake flasks). A far more effective strategy is to use strong promoters (tet phoA, araBAD and lambda), initially with tight repression to ensure efficient cell/vector growth, followed by short burst of induction (Power and Hudson, 2000). We have shown that it is possible to extract correctly folded seFv multimers either from the periplasm by osmotic shock, or by recovery in denaturants followed by refolding (Iliades et al., 1997; Kortt et al., 1997). Final purification is most easily achieved by affinity chromatography using an epitope tag such as the octapeptide (FLAG) or $\mathrm{His}_{6}$ fused to the C-terminus of an antibody (Kortt et al., 1994: Casey et al.. 1995). The use of eukaryotic expression systems for recombinant antibody fragments was reviewed by Verma et al.. (1998) and indeed, was recently shown to be successful for bispecific diabodies (5mer linker) (Kontermann and Muller, 1999). Although the 
yeast Pichia pastoris is particularly attractive (Fitzgerald et al., 1997), bacterial systems have provided the most cost-effective route to date for production of small multimeric scFvs in our experience. Prokayotic expression systems routinely produce greater yields of scFv monomers and multimers, particularly if a strong promoter is used to drive product synthesis (Power and Hudson, 2000).

How do scFv multimers assemble in the periplasm? If linker length prevents natural Fv formation, then the V-domains of one scFv molecule will associate with those of an adjacent scFv molecule (Fig. 3). Thus, two scFv molecules will preferably combine into a diabody providing the linker is of sufficient length. For triabodies, two scFv molecules initially combine by association of a single $V_{H}$ to a single $V_{L}$, but linker length prevents the second Fv module from forming correctly, thus allowing combination with a third scFv molecule through the uncomplexed $\mathrm{V}_{\mathrm{H}}$ or $\mathrm{V}_{\mathrm{L}}$ domains. There is a strong preference for the minimum sized, correctly folded structure; thus scFv monomers dominate when the linker is greater than 12 residues (Amdt et al., 1998), and diabodies dominate when the linker is between 3 and 12 residues (Kortt et al., 1997; Atwell et al., 1999). As the linker length is reduced, a higher percentage of triabodies is produced (i.e. there are more triabodies in scFv-3 than scFv-5), since the shorter linker restricts $\mathrm{V}$-domain flexibility and increases the time required for complete diabody association, thus allowing a third scFv to associate into a triabody. Diabodies cannot form with linkers of two residues or less with $\mathrm{NCl} 0 \mathrm{scFv}$ in $\mathrm{V}_{\mathrm{H}} \mathrm{V}_{\mathrm{L}}$ orientation and only higher multimers are produced (with correctly formed Fv modules).

a)

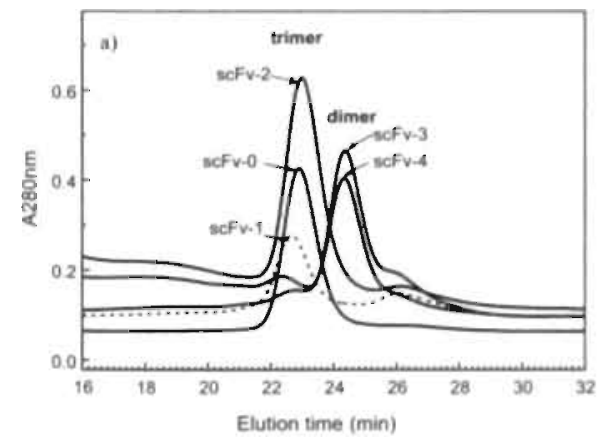

b)

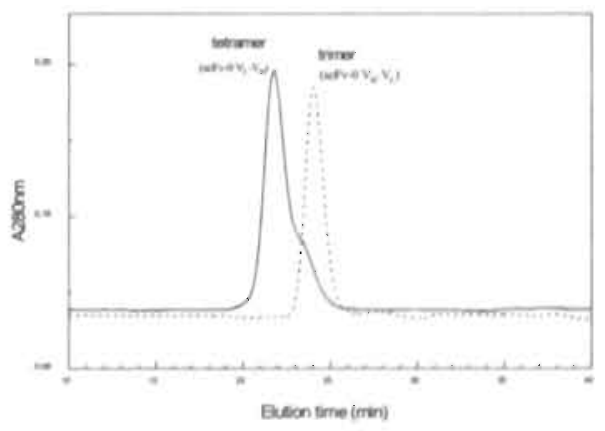

\section{Figure 4}

Size exclusion chromatography on a calibrated Superose 12 HR I0/30 column of affinity purified $\mathrm{NCl} 0 \mathrm{scF}$ vs equilibrated in PBS, pH 7.4 using a flow rate of $0.5 \mathrm{~mL} / \mathrm{min}$. 
a) $\mathrm{ScFv}$ in $\mathrm{V}_{1 \mathrm{r}} \mathrm{V}_{1}$ orientation with profiles superimposed on the same scale for triabodies ( $\mathrm{scFv}-0$, scFv-1, scFv-2) and diabodies (scFv-3, scFv -4). The major peak of scFv-1 (green) and scFv-2 (blue) peakeluted at a similar time to the $\mathrm{scFv}-0$ triabody (red; $\sim 23 \mathrm{~min}, \sim 70 \mathrm{kDa}$ ) while $\mathrm{scFv}-3$ (black) and scFv -4 (aqua) eluted at a time ( $\sim 24.5 \mathrm{~min}$, $\sim 54 \mathrm{kDa}$ ) similar to the scFv-5 diabody of Kortt et al., 1997. b) scFv-0 tetrabody ( $\mathrm{V}_{\mathrm{L}}-\mathrm{V}_{\mathrm{H}}$ orientation; Fig. 2). compared to scFv-0 triabody $\left(\mathrm{V}_{\mathrm{H}}-\mathrm{V}_{\mathrm{L}}\right.$ orientation; Fig. 2$)$.

Concentration of protein sannples, typically to $1 \mathrm{mg} / \mathrm{ml}$, increases multimer formation; thus the monomer/dimer equilibrium in scFvs (linkers greater than 12 residues) becomes biased towards dimers (diabodies). Similarly, concentration can increase the proportion of triabodies and higher aggregates in scFv diabodies (linkers between 3 and 12 residues). This phenomenon suggests that the $\mathrm{V}_{\mathrm{H}} / \mathrm{V}_{\mathrm{L}}$ interface in the Fv module can dissociate, enabling $\mathrm{V}$-domains to shuffle and realign. The rate of Fv dissociation will be unique to each particular antibody. Several methods can be used to increase the stability of Fv modules, including storage as antibodyantigen complex (Lawrence et al., 1998), the addition of buffer components, adjusting pH and ionic strength (Amdt et al., 1998), design of 'knobs-into-holes" mutations (Zhu et al., 1997; Dall'Aqua and Carter, 1998), or by design of inter-domain disulphides (Brinkmann et al., 1997). Alt these methods are effective for seFv momomers and multimers.

\section{Size of scFv multimers and effect on in vivo pharmacokinetics}

ScFiv multimers such as diabodies $(\sim 60 \mathrm{kda})$ and triabodies $(\sim 90 \mathrm{kDa})$ are significantly larger than scFv monomers ( $\sim 30 \mathrm{kDa})$ and thereby have an advantage for in vivo applications by minimising the rapid, first-pass clearance from the circulation (Colcher et al.,1999). This advantage of increased size in clearance rate is offset by decreased tumour penetration, since dissemination rate through the vascular network into tumours is correlated to the size of the in vivo therapeutic molecule. Indeed, the most recent in vivo data using radiolabelled diabodies in three different xenograft tumour models shows that diabodies have a significant advantage over monomeric scFv (Wu et al., 1996; Wu et al., 1999; Adams et al., 1998; Adams et al., 1999; Viti et al., 1999). Similarly, the small size of dia/triabodies has advantages for tumour penetration over the larger multimeric Fab chemical conjugates and intact whole Ig (Fig. 1; Antoniw et al., 1996; Casey et al., 1996). In our own unpublished in vivo studies using murine xenografts, the $60 \mathrm{kD}$ a diabodies gave optimal tumour:blood $(\mathrm{T}: \mathrm{B})$ ratios through to 10 hours post injection at which time the larger $120 \mathrm{kDa} F\left(a b^{\circ}\right)_{2}$ began to outperform diabodies. In these studies, the T: B ratio at 24 hours for an anti-Le diabody was 30:1 and the $F\left(\mathrm{ab}^{y}\right)_{2}$ was 55: 1. Previous investigations with anti-CEA diabodies (Wu et al., 1999) and anti-HER2/neu diabodies (Adams et al., 1998) reported T: B ratios of $48.7: 1$ and $30: 1$ respectively at this time point, while a T: B ratio of 3.7:1 was observed in a study with an anti-CEA F(ab'), (Pedley et al., 1993; Casey et al., 1999). The pharmacokinetic results also concur with the biodistribution observations illustrating 
a rapid terminal clearance from the blood. The anti-CEA diabody gave maximal tumour uptake at 2 hours of $13.68 \% \mathrm{ID} / \mathrm{g}$, with $t_{12} \alpha=0.25 \pm 0.02 \mathrm{hr}$ and $t_{12} \beta=2.89 \pm 0.74 \mathrm{hr}$ (Wu et al., 1999). In comparison, the anti-HER 2 neu ${ }^{125}$ I-labelled C6.5 diabody gave a tumour peak level of $10.1 \%$ ID/g with $t_{12} \alpha=0.67 \mathrm{hr}$ and $t_{12} \beta=6.42 \mathrm{hr}$ (Adams et al., 1998). Two separate investigations with ${ }^{13} \mathrm{I}$-anti-CEA F(ab') ${ }_{2}$ constructs, observed maximal tumour uptakes of $12.8 \% \mathrm{ID} / \mathrm{g}$ at 6 hrs p.i. and $32 \% \mathrm{ID} / \mathrm{g}$ at 8 hours p.i. resectively (Pedley et al., 1993). These pharmacokinetic profiles are typical of antibody based molecules with sizes beneath the renal threshold for first-pass clearance.

The clearance of smaller molecules by the kidney may impair the ability to concentrate the molecule in the tumour (Dillman, 1989). Improvements in the pharmacokinetics of these small, recombinant antibody fragments can be achieved by increasing their surface negative charge, or modifying the radionuclide chemistry, both strategies reducing the frequently observed renal uptake (Pavlinkova et al., 1999a; Arano et al., 1999). These strategies include pre-treatment or co-administration of cationic amino acids such as D-lysine (Behr, 1997; Arano et al., 1999; Carrasquillo, 1998).

The actual benefit for tumour targeting can be estimated by an 'Imaging Figure of Merit' score according to the formula described by Wu et al., (1999). For short-lived radioisotopes ( ${ }^{12} 1,{ }^{1} \mathrm{~F}$ ), $60 \mathrm{kDa}$ diabodies are ideal for in vivo imaging due to the faster clearance rates and greater IFOM score over $90 \mathrm{kDa}$ triabodies and minibodies (scFv-CH3 dimers). For longer half-life radiolabels $\left({ }^{90} \mathrm{Y},{ }^{111} \mathrm{In}\right)$, the slower clearance of triabodies/minibodies compared to diabodies generates a higher IFOM score. An intriguing result by Adams et al., (1998) showed that diabodies had improved tumour targeting compared to scFvs that had been dimerised by disulphide bonds and might reflect higher in vivo stability in the diabodies (Adams et al., 1993; McCartney et al., 1995). Indeed, the linkers in diabodies and triabodies are relatively inaccessible to proteases compared to the long linkers required for monomeric scFv (Fig. 3a).

Although several groups continue to develop covalent scFv dimers (Pavlinkova et al., 1999b; Beresford et al., 1999), we predict that diabodies $(60 \mathrm{kDa})$ will be more stable than these scFv dimers and, since diabodies also provide more rapid tumour penetration and clearance than Fab'2 ( $100 \mathrm{Kda})$, they are therefore the preferred reagent for radioimaging with short half-life radionuclides such as Technetium (gamma) or Fluorine (positron). Conversely, for longer halflife radiolabels designed for immunotherapy $\left({ }^{90} \mathrm{Y},{ }^{\prime \prime}\right.$ 'In), the slower clearance of Fab'2 compared to diabodies generates a higher $\mathrm{T}: \mathrm{B}$ ratio and higher total tumour uptake and radiotherapeutic index. In a study comparing Fab'2 dimers versus Fab'3 trimers (TFM, Fig. 1, Casey et al., 1999), optimal cumulative dose indexes were obtained with Fab' 3 when ${ }^{90} \mathrm{Y}$-labelled and an optimal T:B ratio with Fab'2 when ${ }^{131} \mathrm{I}$-labelled. Following the trend, we would expect that radiolabelled triabodies $(90 \mathrm{kDa})$ and tetrabodies $(120 \mathrm{kDa})$ would outperform diabodies in total tumour 
uptake due to higher avidity and reduced blood clearance (Atwell et al., I999; Hudson and Kortt, 1999; LeGall et al., 1999), which makes them an attractive target for further development and evaluation. Therefore, the optimal construct size is an intelligent prediction that balances the rapidity of blood clearance, the absolute tumour uptake, and the tumour to blood ratios.

\section{Flexibility and avidity in $\mathrm{scFv}$ multimers}

The most important advantage of multivalent scFvs over monovalent scFv and Fab fragments is the gain in functional binding affinity (avidity) to target antigens. High avidity requires that scFv multimers are capable of binding simultaneously to separate target antigens. This avidity gain also occurs from multivalent binding to cancer cell surfaces as demonstrated in the improved in vivo tumour imaging of diabodies over scFv monomers (Wu et al., 1999; Wu et al., 1996; Viti et al., 1999; Adams et al., 1998; Adams et al., 1999). The gain in functional affinity for scFv dia/triabodies compared to scFv monomers is significant and is seen primarily in reduced off-rates, which result from multiple binding to two or more target antigens (on a surface) and to rebinding when one Fv dissociates (Kortt et al., 1997; Pluckthun and Pack, 1997). For these reasons, it is difficult to quantitate accurate kinetic rate constants from binding data measured for multivalent binding interactions on immobilised target antigens, using ELISA or biosensors (Muller et al., 1998a). Multiple binding to surface-bound antigens is dependent on correct alignment and orientation in the Fv modules of diabodies and triabodies. For full avidity, multivalent scFvs must bind to two or more adjacent molecules on the same cell surface and the antigen binding sites must therefore point towards the same direction. If multiple binding is not sterically possible, particularly for surface-bound antigens, then apparent gains in functional affinity are likely to be small and due only to the effect of increased rebinding, which is dependent on diffusion rates and surface antigen concentration. Antigen orientation also affects the ability of diabodies and triabodies to simultaneously bind to multiple antigens on a cell surface, and this factor is particularly important in the design of any therapeutic reagent required to cross-link surface receptors on either the same or adjacent cells (Pluckthun and Pack, 1997; Pack et al., 1995).

Flexibility in both seFv diabodies and triabodies is evident in our single-molecule imaging studies using electron microscopy (Lawrence et al., 1998; Atwell et al., 1999). NC10 diabodies were 'tagged' with Fab arms (using an anti-idiotype Fab fragment as the target antigen) and EM images revealed considerable flexibility with angles between antigen binding sites ranging from 60 to 180 degrees (mean $116^{\circ}$, Lawrence et al., 1998). This flexibility was also noticed in modelling studies of a different (L5MK16) diabody (Holliger et al., 1996) in which the predicted 
angle between the Fv domains was larger than $122^{\circ}$ and ranged from $138^{\circ}$ to $166^{\circ}$. Triabodies are also flexible molecules since only $10 \%$ of the 'tagged' tripod-like projections have three equal inter-arm angles of $120^{\circ}\left( \pm 5^{\circ}\right)$, consistent with the rigid model of 3-fold symmetry (Atwell et al., 1999). The observed distribution of angles between Fab arms in the NC10 triabody complexes ranged around three angles of mean $88^{\circ}, 121^{\circ}$ and $149^{\circ}$ (Atwell et al., 1999; Lawrence et al., 1998). The molecular models of $\mathrm{NC1} 10$ triabodies show that the contacts between Fv modules are minimal and would allow considerable flexibility (Fig. 3). The EM images also showed that all antigen binding sites in diabodies and triabodies were active and capable of binding target antigens. Furthermore, analysis of binding kinetics revealed that the antigen binding sites had equivalent binding affinity, and each site was comparable to the monomeric scFv (Kortt et al., 1997).

\section{In vitro application of multimeric murine MOC-31 scFv (anti Ep-CAM)}

Using MOC-31, a cell-targeting antibody with specificity to Ep-CAM (Souhami et al., 1988; Roovers et al., 1998), we intended to show the first definitive data that both diabodies and triabodies can bind and cross-link adjacent surface receptors in vivo. This will obviously depend on flexibility between the Fv modules and the orientation of the antigen binding sites, as weil as the structure of the receptor. The tumour antigen epithelial cell adhesion molecule (Ep-CAM, also known as EGP-2 receptor and 17-1A antigen) is a type-1 transmembrane protein overexpressed on a variety of human carcinomas (Gottlinger et al., 1986; Balzar et al., 1999). The molecule may function as a homophilic cellular adhesion molecule (Litvinov et al., 1994) and interacts with the cadherin-based junctions (Litvinov et al., 1997; Balzar et al., 1999). Despite the fact that relatively little is known about the exact function of Ep-CAM, a number of clinical studies using murine monoclonal antibodies in cancer patients have validated the approach of targeting this antigen for the treatment and imaging of solid tumours. (Frodin et al., 1988; Riethmuller et al., 1994; Riethmüller et al., 1998; Kosterink et al., 1995). Monomeric and multimeric forms of $\mathrm{MOC}-31$ were constructed in scFv format $\left(\mathrm{V}_{\mathrm{H}}-\mathrm{V}_{\mathrm{L}}\right.$ orientation) containing. 15-, 5- and 0-residue linkers, tagged at the C-terminus with FLAG and His ${ }_{6}$. The linkers consisted of $\left(\mathrm{Gly}_{4} \mathrm{Ser}\right)_{3}$ for the monomer (scFv-15) and $\mathrm{Gly}_{4} \mathrm{Ser}$ for the diabody (scFv-5); the $\mathrm{V}_{H}$ $\mathrm{C}$-terminal was directly fused to the $\mathrm{V}_{\mathrm{L}} \mathrm{N}$-terminus for the triabody ( $\mathrm{scFv}-0$ ). In the design of MOC-31 monomer scFvs (15 residue) and diabodies (5-residue), linkers joining $\mathrm{V}_{\mathrm{H}}$ and $\mathrm{V}_{\mathrm{L}}$ domains are attached immediately following Ser-113 at the C-terminal VTVSS sequence of $V_{\text {H }}$ This is consistent with the numbering system of Peresic et al. (1994) and lliades et al. (1997). However, Ser-113 can be considered to be part of the flexible polypeptide linker and, according 
to the scFv numbering of Atwell et al. (1999) and Dolezal et al. (2000), MOC-31 $15 \mathrm{mer}$ and 5 mer would be described as having sixteen and six residues in the linker, respectively. Similarly, Ser-113 in the MOC-31 0mer would be a single-residue linker according to Atwell et al. (1999) and Dolezal et al. (2000). We show that these scFvs, dependant on the linker length, indeed form monomer scFv, diabody and triabody which are all able to recognise the native antigen present on the cell surface as determined by FACS analysis and present in primary, patient-derived tumour sections as shown by immunohistochemistry. MOC- $31 \mathrm{scFv}-15,-5$ and -0 were isolated from the periplasm and purified by IMAC following expression in E.coli. The molecular mass and multimeric state of each scFv was estimated by size exclusion chromatography on a Superose 12 column (Fig. 5 ).

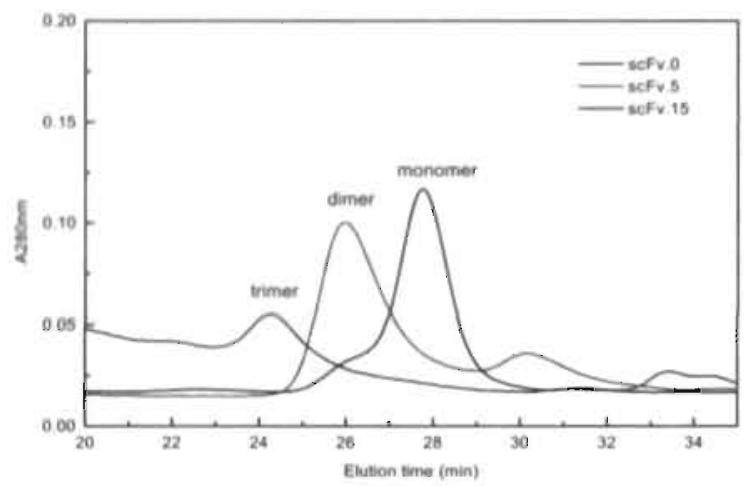

\section{Figure 5}

Size exclusion FPLC on a calibrated' Superose I2 HR 10/30 column (Pharmacia) of IMAC purified' MOC-3I scFv15, $\quad s c F v-5, \quad s c F v-0$ corresponding to monomer, dimer and trimer respectively.

The column was equilibrated with. PBS, $\mathrm{pH} 7.4$ and run at a flow rate of $0.5 \mathrm{~mL} / \mathrm{min}$.

The retention times observed for the major component of each seFv were consistent with a trimer $(24.31 \mathrm{~min})$, dimer $(25.95 \mathrm{~min})$ and monomer $(27.75 \mathrm{~min})$ as previously reported for NC10 $\mathrm{V}_{\mathrm{H}} \cdot \mathrm{V}_{\mathrm{L}}$ scFvs (Kort et al., 1997, Atwell et al., 1999 and Dolezal et al., 2000). The MOC-31 scFy multimers were peak purified on Superose 12 to remove aggregates prior to binding analysis by BIAcore, FACS and immunohistochemistry. In our experience with NC10 and MOC-31 scFvs, the yields of soluble diabodies ( $5 \mathrm{mer})$ and triabodies $(0 \mathrm{mer})$ are marginally lower than monomeric scFv (usually a $15 \mathrm{mer}$ ). However, it would not be correct to state that yields are routinely iower as valency increases and indeed, yields vary widely between different scFv constructs and vector/ host cell expression systems.

Binding of the MOC-31 scFv, diabody and triabody to recombinant Ep-CAM was measured using Surface Plasmon Resonance (BIAcore 2000) (Figure 6). Purified, recombinant Ep-CAM was covalently coupled to a CM5 sensor chip via amine coupling to produce a relatively low density antigen surface of 750 resonance units (RU) to reduce overcrowding of binding sites and 
to allow maximal contact between antibody and antigen. Furthermore, a high flow rate was used to minimize rebinding events during the dissociation phase. Analysis of the kinetics of binding of the MOC-31 scFv, diabody and triabody revealed that the apparnet dissociation rates decreased with increasing valency of the molecules: the bi/trivalent forms of MOC-31 scFv have decreased dissociation - rates compared with the monomeric form (Fig. 6). Although a direct measurement of the cell surface retention was not performed, a decrease in dissociation rate, measured by SPR, has been described to correlate to an extended residence time on the cellsurface (Adams et al., 1998). Thus, the gain in apparent affinity caused by avidity and the increase in size of these multimeric anti-Ep-CAM scFv reagents is expected to improve their in vivo localisation into solid tumours, thereby improving their usefulness as tumour targeting vehicles.

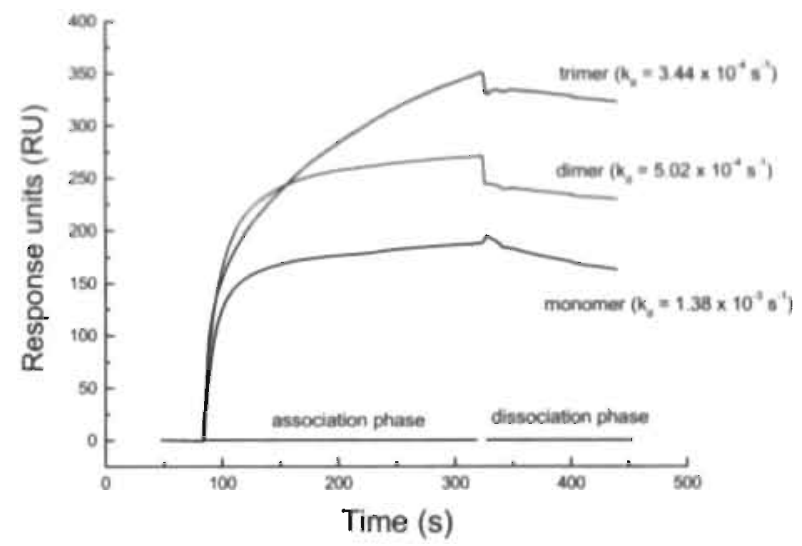

\section{Figure 6}

Sensorgram showing association and dissociation of monomer. dimer and trimer forms of MOC-3l (corresponding to $s c F v-15, s c F v-5$ and $s c F v-0$ respectively).

A BíAcore 2000 was used to analyse the binding of $\mathrm{MOC}-31$ multimer scFvs to Ep-CAM coated onto the surface of a CM5 sensor chip at a density of $750 \mathrm{RU}$ and a flow rate of $20 \mathrm{ul} / \mathrm{min}$. Dissociation rate constants $\left(k_{i}\right)$ were evaluated using BIAevaluation 3.0.2.

Fluorescence activated cell sorting (FACS) was used to assess the ability of each of the MOC-31 scFvs to interact with antigen as presented on the cell surface using the colorectai cancer cell line $\mathrm{CaCo} 2$ (ATCC-HTB37) (Fig 7). An irrelevant scFv was used as a negative control to show that binding of the MOC-31 scFvs was specific. These data demonstrate that the monovalent, bivalent and trivalent MOC-31 scFv conformations are capable of binding to cell surface-expressed Ep $\backsim$ CAM in its natural configuration. To investigate the versatility of this reagent further, we performed immunohistochemistry with cryosections of different tissue samples (Fig. 8). These data show specific labeling with one of the multivalent MOC-3I scFvs to tumour cells in situ. 

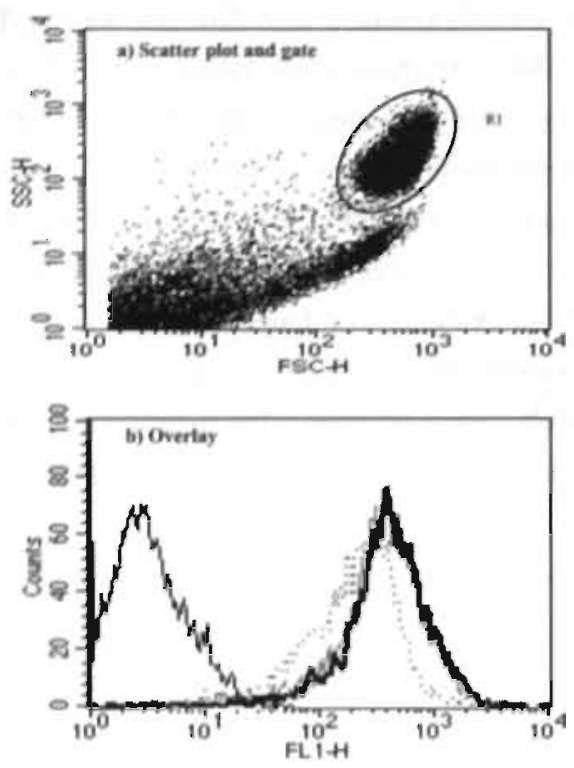

\section{Figure 7}

FACS analysis of IMAC purified multivalent MOC31 scFvs binding to the Ep-CAM' overexpressing $\mathrm{CaCo} 2$ colorectal cancer cell line.

Cancer cells were incubated with an excess of scFv and binding to the $\mathrm{CaCo} 2$ cells was detected with the $\mathrm{M} 2$ ant FLAG antibody and FITC-conjugated rabbit anti mouse antibody. Cells were analyzed by flow cytometry using a FACS-Calibur (Becton \& Dickinson, Heidelberg, Germany) and data were analyzed using the Cellquest software program (Becton \& Dickinson, Heidelberg. Germany). a) Only viable, intact cells were selected as indicated in the region labelad 'R1', b) An overlay of images illustrating the shift in fluorescence intensity of the cell population upon staining with the EP-CAM specific MOC-3I multimeric scFvs; control scFv directed to tetanus toxoid showing background-binding to the $\mathrm{CaCo} 2$ cells (black), monomeric MOC-3! scFv - 15 (blue), dimeric MOC-31 scFv 0-5 (grey) and trimeric MOC-31 scFv-0 (red).

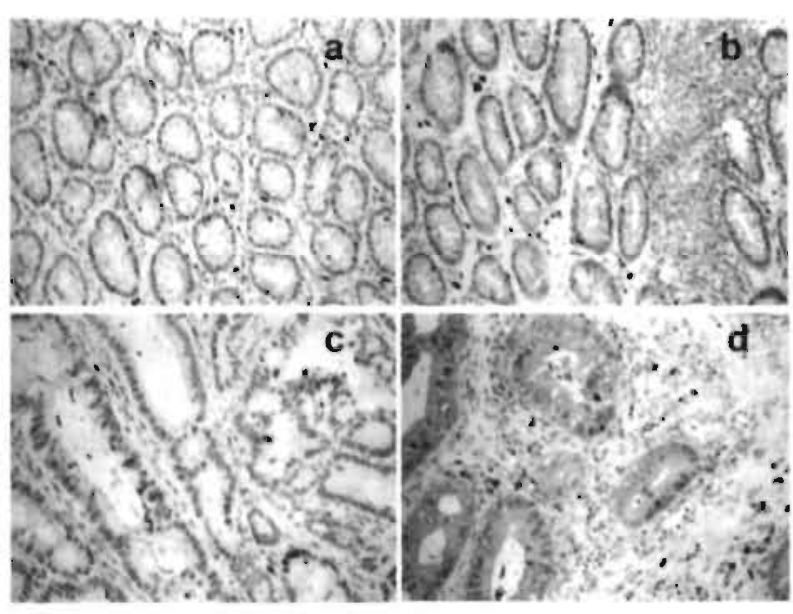

Figure 8

Cryosections of normal colonic epithelium $(a, b)$ and of colorectal carcinoma $(c, d)$.

Bound $5 \mathrm{cFv}$ was detected with an antibody directed to the hexahisticline tag (Dianova) and peroxydase-conjugated rabbit anti-mouse immunoglobulins (Dako). Staining was performed with diaminobenzidin (DAB) $/ \mathrm{H}_{2} \mathrm{O}_{2}$; nuclei were counterstained with hematoxilin. As expected, MOC-31 scFv-5 diabody specifically reacts with epithelial' cells of both normal colon and colorectal carcinoma and does not recognise endothelial cells, fibroblast or other stromal cells and lymphoid cells.

\section{Multispecific seFv multimers}

The discussion above has focussed on the association of identical ScFv molecules to form diabodies, triabodies and tetrabodies that comprise a number of identical Fv modules. These reagents are therefore multivalent, but monospecific. The association of two different scFv 
molecules, each comprising a $V_{H}$ and $V_{L}$ domain derived from different parent Ig can form a fully functional bispecific diabody (Holliger et al., 1993; Atwell et al., 1996). Diabodies still provide the neatest solution for creation of bispecific scFvs and are simpler to design and produce than the fusion of scFvs to adhesive domains as described by Muller et al., (1998b) and Pluckthun and Pack (1997). A unique application of bispecific scFvs is to bind two sites simultaneously on the same target molecule via two (adjacent) surface epitopes (Neri et al., 1995; Robert et al., 1999). These 'biparatopic' reagents or 'CRAbs' gain a significant avidity advantage over a single scFv or Fab fragments with obvious advantages for therapy and diagnosis.

Bispecific diabodies have been synthesized using a bicistronic expression vector that enables the two scFvs to associate in situ, in the E.coli periplasm. Fully active, soluble bispecific diabody can then be isolated by osmotic shock. The construction of tricistronic expression vectors that express three different scFv that fold into trispecific triabodies has not yet been achieved. Multispecific scFvs that are capable of cross-linking different target antigens, are a major goal in clinical therapy particularly for recruitment of cytotoxic T cells for cancer treatment or anergy of T-cells for transplant therapy (Segal et al., 1999). Bispecific diabodies have three advantages over quadromas (bispecific whole Ig); the first is that by lacking Fc domains, bispecific diabodies will only activate T-cells when cross-linked to target (cancer) cells. The second advantage is that the anti-bispecific response in the host is minimised due to the small diabody size (lacking Fc domains) and thirdly, the small size assists in tumour penetration.

In one example (Holliger et al., 1997), bispecific diabodies were designed to cross-link colon cancer cells to serum immunoglobulin $(\mathrm{Ig})$ thereby inducing the complement cascade including mononuclear phagocyte respiratory burst and phagocytosis, and directing synergistic T-cell cytotoxicity. Further, by virtue of binding to serum Ig their half-life (beta-phase) was increased fivefold compared to a control diabody of the same molecular weight. In a second example (Kontermann et al., 1997a), bispecific diabodies with specificity to Clq recruited the complement cascade directly. Most recent examples have focussed on T-cell recruitment; using one Fv module targeted to $\mathrm{CD} 3$ on $\mathrm{T}$-cells and with a second $\mathrm{Fv}$ module targeted to a cancer marker such as EP.CAM, CEA or CD19, in one case via NIP-tagged ligands (Helfrich et al., 1998; Krebs et al., 1998; Kipriyanov et al., 1998; Manzke et al., 1999. Holliger et al., 1999; Arndt et al., 1999). There are also numerous diagnostic applications (immunoassays) that require bispecific crosslinking reagents (Atwell et al., 1996; Kontermann et al., 1997b).

One of the more notable recent achievements has been the design of tandem bispecific antibodies, which effectively behave as tetrabodies and thereby comprise two bivalent components that provide both high target avidity and receptor activation (Kipriyanov et al., 1999). 


\section{Conclusions}

During the past 12 months, there has been a rapid increase in both scientific and commercial interest in multivalent scFvs leading to the large number of publications covered in this review. Clinical interest is due to encouraging results from phase 3 trials which has lead to several recent FDA approvals for humanised therapeutic antibodies (Farah et al., 1998; Hudson, 1999; Hudson, 2000). Scientific interest has stemmed from the elucidation of the key elements required for multivalent antibody design and efficient expression (Hudson and Korth, 1999; Segal et al., 1999). In the next 12 months, it is likely that we will have generic solutions for improved Fv stability, leading to improved expression yields, and generic strategies for the design of multimers, immunotoxins and other innovative fusion proteins. It is likely that these designed reagents will be capable of intracellular targeting, or of redirecting T-cells for cancer therapy and retargeting viruses for gene therapy (Worn et al., 1998; Eshhar, 1997; Wickham et al., 1997; Watkins et al., 1997). By providing a highly stable, protease-resistant scaffold, recombinant scFv multimers will continue to be the paradigm for selection of high-affinity protein-based therapeutic and diagnostic reagents.

\section{Acknowledgements}

We thank all oui colleagues in the antibody engineering program at CSIRO Health Science and Nutrition for their helpful advice on the design and expression of scFv multimers and for their agreement to cite unpublished results in this review. We also thank Airlie McCoy, currently at the Heamatology Dept, Addenbrookes Hospital, University of Cambridge, UK, for the modelling studies on scFv multimers and Mrs. E. van der Linden (Maastricht University, Maastricht, The Netherlands) for excellent technical assistance in immunohistochemical analysis.

\section{References}

Adams, G.P., Schier, R., 1999. Generating improved single-chain Fv molecules for tumour targeting. I Immunol Methods 231, 249-260.

Adams, G.P., McCartney, J.E., Tai, M-S., Opperman, H., Huston, J.S., Stafford, W.F., Bookman, M.A., Fand, 1., Houston, L.L., Weiner, L.M., 1993. Highly specific in vivo tumour targeting by monovalent and divalent forms of $741 \mathrm{~F} 8$ anti-c-erbB-2 single-chain Fv. Cancer Res. 53, 4026-4034.

Adams, G.P., Schier, R., McCall, A.M., Crawford, R.S., Wolf, E.J., Weiner, L.M., Marks, J.D., 1998. Prolonged in vivo tumour retention of a human diabody targeting the extracellular domain of human HER2/neu. Brit. J. Cancer 77, 1405-1412.

Antoniw, P., Farnsworth, A.P., Turner, A., Haines, A.M., Mountain, A., Mackintosh, J., Shochat, D., Humm, J., Welt, S., Old, L.J., Yarranton, G.T., King, D.J., 1996. 
Radioimmunotherapy of colorectal carcinoma xenografts in nude mice with yttrium-90 A33 lgG and Tri-Fab (TFM). Brit. J. Cancer 74, 513-524.

Arano, Y., Fujioka, Y., Akizawa, H., Ono, M., Uehara, T., Wakisaka, K., Nakayama, M., Sakahara, H., Konishi, J., Saji, H., 1999. Chemical design of radiolabeled antibody fragments for low renal radioactivity levels. Cancer Res 59, 128-134.

Amdt, K.M., Muller, K.M., Pluckthun, A., 1998. Factors influencing the dimer to monomer transition of an antibody single-chain Fv fragment. Biochemistry 37, 12918-12926.

Amdt, M.A., Kauss, J., Kipriyanov, S.M., Pfreundschuh, M., Little, M., 1999. A bispecific diabody that mediates natural killer cell cytotoxicity against xenotransplantated human Hodgkin's tumours. Blood 94, 2562-2568.

Atwell, J., Breheney, K.A., Lawrence, L.J., McCoy, A.J., Kortt, A.A, Hudson, P.J., 1999. scFv Multimers: Length of the linker between $\mathrm{V}_{\mathrm{H}}$ and $\mathrm{V}_{\mathrm{L}}$ domains dictates precisely the transition between diabodies and triabodies. Protein Eng. 12, 597-604.

Atwell, J.L., Pearce, L.A., Lah, M., Gruen, L.C., Kortt, A.A., Hudson, P.J., 1996. Design and expression of a stable bispecific scFv dimer with affinity for both glycophorin and N9 neuraminidase Molec. Immunol. 33, 1301-1312.

Balzar, M., Winter, M.J., De Boer, C.J., Litvinov, S.V. 1999. The biology of the 17-1A antigen (Ep-CAM). J. Mol. Med. 77, 699.

Behr, T.M., Sharkey, R.M., Sgouros, G., Blumenthal, R.D., Dunn, R.M., Kolbert, K., Griffiths, G.L., Siegel, J.A., Becker, W.S., Goldenberg. D.M., 1997. Overcoming the nephrotoxicity of radiometal-labeled immunoconjugates: improved cancer therapy administered to a nude mouse model in relation to the internal radiation dosimetry. Cancer. 80, 2591-610.

Beresford, G.W., Pavlinkova, G., Booth, B.J., Batra, S.K., Colcher, D., 1999. Binding. characteristics and tumour targeting of a covalently linked divalent CC49 single-chain antibody. Int J Cancer 81, 911-917.

Bird, R.E., Hardman, K.D., Jacobson, J.W, Johnson, S., Kaufman, B.M., Lee, S-L., Lee, T., Pope, S.H., Riodan, G.S., Whitlow, M., 1988. Single-chain antigen-binding proteins. Science 242, 423-426.

Brinkmann, U., Dicarlo, A., Vasmatzis, G., Kurochkina, N., Beers, R., Lee, B., Pastan, I., 1997. Stabilisation of a recombinant Fv fragment by base-loop interconnection and VH - VL permutation. J. Mol. Biol. 268, 107-117.

Carrasquillo, J.A., Lang, L., Whatley, M., Herscovitch, P., Wang. Q.C., Pastan, I., Eckelman, W.C., 1998. Aminosyn Il effectively blocks renal uptake of $18 \mathbf{F}$-labeled anti-tac disulfide-stabilized Fv. Cancer Res. 58, 2612-2617.

Casey, J.L., Keep, P.A., Chester, K.A., Robson, L., Hawkins, R.E., Begent, R.H., 1995. Purification of bacterially expressed single chain $\mathrm{Fv}$ antibodies for clinical applications using metal chelate chromatography. J Immunol Methods 179, 105-1 16.

Casey, J.L., King, D.J., Chaplin, L.C., Haines, A.M., Pedley, R.B., Mountain, A., Yarranton,

G.T., Begent, R.H., 1996. Preparation, characterisation and tumour targeting of cross-

linked divalent and trivalent anti-tumour Fab' fragments. Brit. J. Cancer 74, 1397-1405.

Casey, J.L., Pedley, R.B., King, D.J., Green, A.J., Yarranton, G.T., Begent, R.H.J., 1999.

Dosimetric evaluation and radioimmunotherapy of anti-tumour multivalent Fab

fragments. Brit J Cancer 81, 972-980.

Coia, G., Hudson, P.J., Lilley, G.G., 1996. Construction of recombinant extended single- 
chain antibody peptide conjugates for use in the diagnosis of HIVI and HIV2.J. Immunol. Methods 192, 13-23.

Colcher, D., Goel, A., Pavlinkova, G., Beresford, G., Booth, B., Batra, S.K., 1999. Effects of genetic engineering on the pharmacokinetics of antibodies. Q. J. Nucl. Med. 43, 132-139.

Dall'Acqua, W., Carter, P., 1998. Antibody engineering. Curr Opin Struct Biol 8, 443-450. Dillman, R.O. 1989. Monoclonal antibodies for treating cancer. Ann Intern Med. 111, 592603.

Dolezal, O., Pearce, L.A., Lawrence, L.J., McCoy, A.J., Hudson, P.J., Kortt, A.A., 2000. ScFv Multimers of the anti-neuraminidase antibody NC10: shortening of the linker in single-chain $\mathrm{Fv}$ fragment assembled in $\mathrm{V}_{\mathrm{L}}$ to $\mathrm{V}_{\mathrm{H}}$ orientation drives the formation of dimers, trimers, tetramers and higher molecular mass multimers. Protein Eng. 13, 565574.

Eshhar, Z., 1997. Tumour-specific T-bodies: towards clinical application. Cancer Immunol Immunother. 45, 131-136.

Farah, R.A., Clinchy, B., Herrera, L., Vitetta, E.S., 1998. The development of monoclonal antibodies for the therapy of cancer. Crit Rev Eukaryot Gene Expr. 8, 321-356.

Fitzgerald, K., Holliger, P., Winter, G., 1997. Improved tumour targeting by disulphide stabilized diabodies expressed in Pichia pastoris. Protein Eng.10, 1221-1225.

Frodin, J.E., Harmenberg, U., Biberfeld, P., Christensson, B., Lefvert, A.K., Rieger, A., Shetye, J., Wahren, B. and Mellstedt, H., 1988. Clinical effects of monoclonal antibodies (MAb 17-1 A) in patients with metastatic colorectal carcinomas. Hybridoma 7, 309-321.

Ghetie, M.A., Podar, E.M., IIgen, Gordon, B.E., Uhr, J.W., Vitetta, E.S., 1997.

Homodimerization of tumour-reactive monoclonal antibodies markedly increases their ability to induce growth arrest or apoptosis of tumour cells. Proc. Natl. Acad. Sci. USA 94, 7509-7514.

Gottlinger, H.G., Funke, I., Johnson, J.P., Gokel, J.M., Riethmuller, G., 1986. The epithelial cell surface antigen 17-1A, a target for antibody-mediated tumour therapy: its biochemical nature, tissue distribution and recognition by different monoclonal antibodies. Int J Cancer 38, 47-53.

Helfrich, W., Kroesen, B.J., Roovers, R.C., Westers, L., Molema, G., Hoogenboom, H.R., De Leij, L., 1998. Construction and characterisation of a bispecific diabody for retargeting T-cells io human carcinomas. Int. J. Cancer 76. 232-239.

Holliger, P., Brissinick, J., Williams, R.L., Thielemans, K., Winter, G., 1996. Specific killing of lymphoma cells by cytotoxic T-cells mediated by a bispecific diabody. Protein Eng. 9 . 299-305.

Holliger, P., Manzke, O., Span, M., Hawkins, R., Fleischmann, B., Qinghua, L., Wolf, J., Diehl, V., Cochet, O., Winter, G., Bohlen, H.C., 1999. Carcinoembryonic antigen (CEA)-specific T-cell activation in colon carcinoma induced by anti-CD $3 x$ anti-CEA bispecific diabodies and $\mathrm{B} 7 \mathrm{x}$ anti-CEA bispecific fusion proteins. Cancer Res. 59 , 2909-2916.

Holliger, P., Prospero, T., Winter, G., 1993. "Diabodies": small bivalent and bispecific antibody fragments. Proc. Natl. Acad. Sci. USA, 90, 6444-6448.

Holliger, P., Wing, M., Pound, J.D., Bohlen, H., Winter, G., 1997. Retargeting serum immunoglobulin with bispecific diabodies. Nature Biotech. 15, 632-636.

Hudson, P.J., 1998. Recombinant Antibody Fragments. Curr Opin Biotech. 9, 395-402. 
Hudson, P.J., 1999. Recombinant Antibody Constructs in Cancer Therapy. Curr Opin Immunology 11, 548-557.

Hudson, P.J., 2000. Recombinant antibodies: a novel approach to cancer diagnosis and therapy. Exp. Opin. Invest. Drugs 9, 1231-1242.

Hudson, P.J., Kortt, A.A., 1999. High Avidity scFv Multimers; Diabodies and Triabodies. J.Immunol. Methods 231, 177-190.

Huston, J.S., Levinson, D., Mudgett-Hunter, M., Tai, M.S., Novotny, J., Margolies, M.N., Ridge, R.J., Bruccoleri, R.E., Haber, E., Crea, R., Opperman, H., 1988. Protein engineering of antibody binding sites: recovery of specific activity in an anti-digoxin single-chain Fv analogue produced in Escherichia coli. Proc. Natl. Acad. Sci. USA, $\mathbf{8 5}, 5879-5883$.

lliades, P., Kortt, A.A., Hudson, P.J., 1997. Triabodies: Single Chain Fv Fragments without a linker form trivalent trimers. FEBS Lett. 409, 437-441.

Kabat, E.A., Wu, T.T., Perry, H.M., Gottensman, K.S., Foeler, C., 1991. Sequences of Proteins of Immunological Interest. US Department of Health and Human Service, US Public Health service, NIH, Bethesda, MD.

Kipriyanov, S.M., Moldenhauer, G., Strauss, G., Little, M., 1998. Bispecific CD3 x CD19 diabody for T cell-mediated lysis of malignant human B cells. Int. J. Cancer 77, 763-772. Kipriyanov, S.M., Moldenhauer, G, Little, M., 1997. High level production of soluble single chain antibodies in small-scale Escherichia coli cultures. J. Immunol. Methods 200, 69. 77.

Kipriyanov, S.M., Moldenhauer, G., Schuhmacher, J., Colchlovius, B., Von der Lieth, C.W., Matys, E.R., Little, M., 1999. Bispecific tandem diabody for tumour therapy with improved antigen binding and pharmacokinetics. J Mol Biol. 293, 4I-56.

Kontermann, R.E., Martineau, P., Cummings, C.E., Karpas, A., Allen, D., Derbyshire, E., Winter, G., 1997b. Enzyme immunoassays using bispecific diabodies. Immunotechnology 3, 137-144.

Kontermann, R.E. and Muller, R., (1999). Intracellular and cell surface displayed single-chain diabodies. I Immunol. Meth. 226, 179-188.

Kontermann, R.E., Wing, M.G., Winter, G. (1997a) Complement recruitment using bispecific diabodies. Nature Biotechnol. 15, 629-631.

Kortt, A.A., Lah, M., Oddie, G.W., Gruen, L.C., Burns, J.E., Pearce, L.A., Atwell, J.L., McCoy, A.J., Howlett, G.J., Metzger, D.W., Webster, R.G., Hudson, P.J., 1997. Single Chain Fv Fragments of anti-neuraminidase antibody NC10 containing five and ten residue linkers form dimers and with zero residue linker a trimer. Protein Eng. 10, 423-428.

Kortt, A.A., Malby, R.L., Caldwell, J.B., Gruen, L.C., Ivancic, N.M, Lawrence, M.C., Howlett, G.J., Webster, R.G., Hudson, P.J., Colman, P.M., 1994. Recombinant antineuraminidase single chain Fv antibody: characterization, formation of dimer and higher molecular mass multimers and the solution of the crystal structure of the scFvneuraminidase complex. Eur. J. Biochem., 221, 151-157.

Kosterink, J.G., De-Jonge, M.W., Smit, E.F., Piers, D.A., Kengen, R.A., Postmus, P.E., Shochat, D., Groen, H.J., The, H.T., De-Leij, L. 1995. Pharmacokinetics and scintigraphy of indium-111-DTPA-MOC-31 in small-cell lung carcinoma. J. Nucl. Med. 36, 2356.

Krebs, B., Ackermann, B., Rose-John, S., 1998. Specific targeting of cytokine-secreting cells: a bispecific diabody recognizing human interleukin-6 and CD3 induces T cell-mediated 
killing. J Interferon Cytokine Res. 18, 783-791.

Lawrence, L.J., Kortt, A.A., Hliades, P., Tulloch, P.A., Hudson, P.J., 1998. Orientation of antigen binding sites in dimeric and trimeric single chain $\mathrm{Fv}$ antibody fragments. FEBS Lett. 425, 479-484.

Le Gall, F., Kipriyanov, S.M., Moldenhauer, G., Little, M., 1999. Di-, tri- and tetrameric single chain Fv antibody fragments against human CD19: effect of valency on cell binding. FEBS Lett. 453, 164-168.

Litvinov, S.V., Balzar, M., Winter, M.J., Bakker, H.A, Briaire-de Bruijn, I.H., Prins, F., Fleuren, G.J., Warnaar, S.O., 1997. Epithelial cell adhesion molecule (Ep-CAM) modulates cell-cell interactions mediated by classic cadherins. J Cell Biol 139, 13371348.

Litvinov, S.V., Velders, M.P., Bakker, H.A., Fleuren, G.J., Warnaar, S.O., 1994. Ep-CAM: a human epithelial antigen is a homophilic cell-cell adhesion molecule. J Cell Biol 125, 437-446.

Malby, R.L., McCoy, A.J., Kortt, A.A., Hudson, P.J., Colman, P.M., 1998. Single-chain fv/neuraminidase complexes: Different stoichiometry in solution and crystals. J. Mol. Biol. 279, 901-910.

Malby, R.L., Tulip, W.R., Harley, V.R., McKimm-Breschkin, J.L., Laver, W.G., Webster, R.G., Colman, P.M., 1994. The structure of a complex between the NC10 antibody and influenza virus neuraminidase and comparison with the overlapping binding site of the NC4I antibody. Structure 2, 733-746.

Manzke, O., Fitzgerald, K.J., Holliger, P., Klock, J., Span, M., Fleischmann, B., Hescheler, J., Qinghua, L., Johnson, K.S., Diehl, V., Hoogenboom, H.R., Bohlen, H., 1999. CD3x anti-nitrophenyl bispecific diabodies: universal immunotherapeutic tools for retargeting T cells to tumours. Int J Cancer 82, 700-708.

MeCartney, J.E., Tai, M-S., Hudziak, R.M., Darns, G.P., Weiner, L.M., Jin, D., Stafford, W.F., Liu, S., Bookman, M.A., Laminet, A.A., Fand, I., Houston, L.L., Oppermann, H. and Huston, J.S., 1995. Engineering disulfide-linked single-chain Fv dimers [( $\left.\left.\mathrm{sFv}^{\prime}\right) 2\right]$ with improved solution and targeting properties: anti-digoxin 26-10 (sFv')2 and anti-cerbB-2 $741 \mathrm{~F} 8\left(\mathrm{sFv}^{\prime}\right) 2$ made by protein folding and bonded through $\mathrm{C}$-terminal cysteinyl peptides. Protein Eng. 8, 301-314.

McGuinness, B.T., Walter, G., Fitzgerald, K., Schuler, P., Mahoney, W., Duncan, A.R., Hoogenboom, H.R., 1996. Phage diabody repertoires for selection of large numbers of bispecific antibody fragments. Nature Biotech. 14, 1149-1154.

Muller, K.M., Arndt, K.M. and Pluckthun, A., 1998b. A dimeric bispecific miniantibody combines two specificities with avidity. FEBS Lett. 432, 45-49.

Muller, K.M., Arndt, K.M., and Pluckthun, A., 1998a. Model and simulation of multivalent binding to fixed ligands. Anal Biochem 261, 149-158.

Neri, D., Momo, M., Prospero, T., Winter, G., 1995, High-alffinity antigen binding by chelating recombinant antibodies (CRAbs). J. Mol. Biol. 246, 367-373.

Pack, P., Muller, K., Zahn, R. and Pluckthun, A., 1995. Tetravalent miniantibodies with high avidity assembling in Escherichia coli. J. Mol. Biol. 246, 28-34.

Padlan E.A., 1994. Anatomy of the antibody molecule. Mol Immunol. 31, 169-2I7.

Pavlinkova, G., Beresford, G., Booth, B.J., Batra, S.K., Colcher, D., 1999a. Charge-modified single chain antibody constructs of monoclonal antibody CC49: generation, 
characterization, pharmacokinetics, and biodistribution analysis. Nucl. Med. Biol. 26, 27 . 34.

Pavlinkova, G., Booth, B.J., Batra, S.K., Colcher, D., 1999b. Radioimmunotherapy of human colon cancer xenografts using a dimeric single-chain Fv antibody construct. Clin. Cancer Res. 5, 2613-2619.

Pedley, R.B., Boden, J.A., Boden, R., Dale, R., Begent, R.H., 1993. Comparative radioimmunotherapy using intact or $\mathrm{F}(\mathrm{ab}) 2$ fragments of 1311 anti-CEA antibody in a colonic xenograft model. Br J Cancer 68, 69-73.

Pei, X.Y., Holliger, P., Murzin, A.G., Williams, R.L., 1997. The crystal structure of a trimeric antibody fragment with non-cognate VH - VL domain pairs shows a rearrangement of VH CDR3. Proc Natl Acad Sci USA 94, 9637-9642.

Perisic, O., Webb, P.A., Holliger, P., Winter, G., Williams, R.L., 1994. Crystal structure of a diabody, a bivalent antibody fragment. Structure 2, 1217-1226.

Pluckthun, A., Pack, P., 1997. New protein engineering approaches to multivalent and bispecific antibody fragments. Immunotechnology 3, 83-105.

Power, B.E., Hudson, P.J., 2000. Synthesis of high avidity antibody fragments (scFv multimers) for cancer imaging. J. Immunol, Methods 242, 193-204.

Riethmuller, G., Schneider-Gadicke, E., Schlimok, G., Schmiegel, W., Raab, R., Hoffken, K., Gruber, R., Pichlmaier, H., Hirche, H., Pichlmayr, R., Buggisch, P., Witte, J., 1994. Randomized trial of monoclonal antibody for adjuvant therapy of resected Dukes' $\mathrm{C}$ colorectal carcinoma. The Lancet 343, 1177-1183.

Riethmüller, G., Holz, E., Schlimok, G., Schmiegel, W., Raab, R., Hoffken, K., Gruber, R., Funke, I., Pichlmaier, H., Hirche, H., Buggisch, P., Witte, J., Pichlmayr, R. 1998. Monoclonal antibody therapy for resected Dukes' $\mathrm{C}$ colorectal cancer: seven-year outcome of a multicenter randomized trial. J. Clin. Oncol. 16, 1788.

Robert, B., Dorvillius, M., Buchegger, F., Garambois, V., Mani, J.C., Pugnieres, M., Mach, J.P., Pelegrin, A., 1999. Tumour targeting with newly designed biparatopic antibodies directed against two different epitopes of the carcinoembryonic antigen (CEA). $I n t . j$ Cancer 81, 285-291.

Roovers, R.C., Henderikx, P., Helfrich, W., van der Linden, E., Reurs, A., de Bruine, A.P., Arends, J.W., de Leij, L., Hoogenboom, H.R., 1998. High-affinity recombinant phage antibodies to the pan-carcinoma marker epithelial glycoprotein-2 for tumour targeting. $\mathrm{Br}$ $J$ Cancer 78, 1407-1416.

Roux, K.H., Strelets, L., Brekke, O.H., Sandlie, I., Michaelsen, T.E., 1998. Comparisons of the ability of human $\operatorname{IgG} 3$ hinge mutants, $\operatorname{IgM}, \operatorname{IgE}$, and $\mathrm{IgA} 2$, to form sma!! immune: complexes: a role for flexibility and geometry. J. Immunol. 161, 4083-4090.

Roux, K.H., Strelets, L., Michaelsen, T.E., 1997. Flexibility of Human IgG subclasses. $J$ Immunol 159, 3372-3382.

Segal, D.M., Weiner, G.J., Weiner, L.M. 1999. Bispecific antibodies in Cancer Therapy. Curr. Opin. Immunol. 11, 558.

Souhami, R.L., Beverley, P.C.L., Bobrow, L.G., 1988. Proceedings of the First International Workshop on Small-Cell Lung-Cancer Antigens. Lung Cancer 4, 1-114.

Thouvenin, E., Laurent, S., Madelaine, M.F., Rasschaert, D., Vautherot, J.F., Hewat, E.A. 1997. Bivalent binding of a neutralising antibody to a calicivirus involves the torsional flexibility of the antibody hinge. J Mol Biol 270, 238-246. 
Turner, D.J., Ritter, M.A., George, A.J.T., 1997. Importance of the linker in expression of single-chain Fv antibody fragments- optimisation of peptide sequences using phage display technology. J Immunol. Methods 205, 43-54.

Verma, R., Boleti, E., George, A.J.T., I998. Antibody engineering: comparison of bacterial, yeast, insect and mammalian expression systems. J. Immunol. Methods 216, 165-181.

Viti, F., Tarli, L., Giovannoni, L., Zardi, L., Neri, D., 1999. Increased binding affinity and valence of recombinant antibody fragments lead to improved targeting of tumoural angiogenesis. Cancer Res. 59, 347-342.

Watkins, S.J., Mesyanzhinov, V.V., Kurochkina, L.P., Hawkins, R.E., 1997. The 'adenobody' approach to viral targeting: specific and enhanced adenoviral gene delivery. Gene Ther: 4. 1004-1012.

Whitlow, M., Filpula, D., Rollence, M.L., Feng, S.-L. Woods, J.F., 1994. Multivalent Fvs: characterisation of single chain Fv oligomers and preparation of a bispecific Fv. Protein Eng. 7, 1017-1026.

Wickham, T.J., Lee, G.M., Titus, J.A., Sconocchia, G., Bakacs, T., Kovesdi, I., Segal, D.M., 1997. Targeted adenovirus-mediated gene delivery to T cells via CD3. J. Virol. 71, 76637669 .

Worn, A., Pluckthun, A., 1998. Mutual stabilization of VL and VH in single-chain antibody fragments, investigated with mutants engineered for stability. Biochemistry 37, 1312013127 .

Wu, A.M., Chen, W., Raubitschek, A., Williams, L.E., Neumaier, M., Fischer, R., Hu, S-Z., Odom-Maryon, T., Wong, J.Y.C., Shively, J.E., 1996. Tumour localisation of anti-CEA single-chain Fvs: improved targeting by non-covalent dimers. Immunotechnology 2, 21 36.

Wu, A.M., Williams, L.E., Zieran, L., Padma, A., Sherman, M., Bebb, G.G., Odom-Maryon, T., Wong, J.Y.C., Shively, J.E., Raubitschek, A.A., 1999. Anti-carcinoembryonic antigen (CEA) diabody for rapid tumour targeting and imaging. Tumour Targeting 4, 47-58.

Zdanov, A., Li, Y., Bundle, D.R., Deng, S-J., MacKenzie, C.R., Narang, S.A., Young, N.M., Cygler, M., 1994. Structure of a single-chain antibody variable domain (Fv) fragment complexed with a carbohydrate antigen at 1.7-A resolution. Proc. Natl. Acad. Sci. USA 91, 6423-6427.

Zhu, Z., Presta, L.G., Zapata, G., Carter, P., 1997. Remodeling domain interfaces to enhance heterodimer formation. Protein Sci. 6. 781-788. 


\section{Chapter 5}

Guided Selection of a Pan Carcinoma Specific Antibody Reveals Similar Binding Characteristics yet Structural Divergence Between the Original Murine Antibody and its Human Equivalent

Sigrid H.W. Beiboer, Anneke Reurs, Rob C. Roovers, Jan-Willem Arends, Nick R.

Whitelegg, Anthony R. Rees and Hennie R. Hoogenboom

J. Mol. Biol. 296(3), 833-849 (2000) 


\section{Abstract}

Antibody engineering provides an excellent tool for the generation of human immunotherapeutics for the targeted treatment of solid fumours. We have engineered and selected a completely human antibody to Epithelial Giycoprotein-2 (EGP-2), a transmembrane glycoprotein present on virtually all human simple epithelia and abundantly expressed on a variety of human carcinomas. We chose to use the procedure of "guided selection" to rebuild a high affinity murine antibody into a human antibody, using two consecutive rounds of variable domain shuf ing and phage library selection. As a starting antibody the murine antibody MOC3 I was used. After the first round of guided selection, where the $\mathrm{VH}$ of $\mathrm{MOC}-31$ was combined in Fab format with a human VL CL library, a small panel of human light chains was identified, originating from a segment of the VkIII family, whereas the MOC-31 VL is more homologous to the VkII family. Nevertheless, one of the chimaeric Fabs, C3, displayed an off-rate similar to MOC-31 scFv. Combining the VL of $\mathrm{C} 3$ with a human VH library, while retaining the VH CDR3 of MOC-31, clones were selected using human VH genes originating from the rarely used VH 7 family. The best clone, $9 E$, shows over 13 amino acid mutations from the germline sequence, has an off-rate comparable to the original antibody and specifically binds to the "MOC-31"epitope on EGP-2 in specificity and competition ELISA, FACS analysis and immunohistochemistry. In both VL and VH of antibody $9 \mathrm{E}$, three germline mutations were found creating the MOC-31 homologue residue. Structural modelling of both murine and human antibodies reveals that one of the germline mutations, $53 \mathrm{Y}$ in VH CDR2, is likely to be involved in antigen binding. We conclude that, although they may bind the same epitope and have similar binding affinity to the antigen as the original murine antibody, human antibodies derived by guided selection may retain only some of the original key elements of the binding site chemistry. The selected human anti-EGP-2 antibody will be a suitable reagent for tumour targeting.

\section{Introduction}

By the expression of tumour-associated antigens (TAA), colorectal carcinoma (CRC) cells may be distinguished from their non-malignant counterparts. Among the identified surfacebound TAAs is epithelial glycoprotein-2 (EGP-2), also known as CO17-1A antigen, KSA, EGP40 or Ep-CAM. The antigen, encoded by the GA733-2 gene, is a 38-kDa transmembrane protein that is present on human non-squamous epithelia and is highly expressed on their derived tumours. In the senim from patients suffering from carcinoma, EGP-2 could not be detected by MOC-31 [1], one of the many murine monoclonal antibodies (mAbs) that have been generated against the EGP-2 antigen. Thus the EGP-2 antigen is not shed into the circulation and is regarded as a suitable target for imaging and immunotherapy of carcinomas. In radioimmune 
detection [2,3], targeting of toxins or chemotherapeutic drugs [4-6] and phase I and II clinical trials [7-9], murine mAbs were successfully used. These studies show the large potential of mAbs to EGP-2 in immunotherapy. In a previous study, we showed that the Mab MOC-31 has the lowest kinetic off-rate of a series of well-characterised anti-EGP-2 antibodies [10]. The Vgenes of this antibody have been cloned as single chain variable fragment (scFv) which competes with the original hybridoma antibody for binding to the antigen. The off-rate of the scFv is better than those of the bivalent 17-1 A and 323/A3 anti-EGP-2 antibodies, providing it with an essential characteristic for tumour retention in vivo [11]. Therefore, the V-genes of MOC-31 will be very suitable for the rational design and generation of human antibody-based immunotherapeutics for the treatment of solid tumours.

A disadvantage of the use of murine antibodies for immunotherapy of human carcinomas is that during the repeated administration of the mAbs to patients, a human anti-mouse antibody (HAMA) immune response can be induced. This may cause serum sickness of the patient and rapid blood clearance of the mAbs, thereby reducing their efficacy [12]. It is expected that human antibodies would evoke a more effective and compatible response with the patient's immune system. Murine antibodies can be humanised by CDR-grafting [13] where the hypervariable loops of the mAb are transplanted to a human antibody, thereby retaining the epitope and specificity. However, such CDR grafted antibodies retain a large proportion of non-human sequences, which include the CDRs as well as framework residues, which are sometimes retained because they are involved (in) directly in antigen binding [14, 15]. Furthermore, humanisation by resurfacing $[16,17]$ involves the retention of non-human framework sequences in all but surface located positions. In all instances some rodent antibody derived sequences are still included in the humanised antibody and thereby may enable the mAb to provoke an immune response. In particular, the transplantation of CDR-loops with "non-human" canonical forms, such as canonical structures 1 and 5 of murine light chain loop $\mathbf{L}$, [ [18] for which there is no human homologue, may both assign a typical murine idiotypic structure to the antibody combining surface, as well as provide unique T-cell epitopes for HAMA induction.

An alternative method termed guided selection has been developed, to convert murine antibodies into completely human antibodies with similar binding characteristics [19]. In this method the murine $\mathrm{V}$ domains are sequentially or in parallel replaced by human $\mathrm{V}$ domains, using phage selection to derive the human antibody with the best affinity. Two published examples demonstrate the power of this method. Figini et al. (1998), [20] shuffled the light chain of a murine anti-hapten phenyl-oxazolone antibody, NQ10.12.5, with a repertoire of human heavy chains. After a second shuffle of the selected VH s with a repertoire of human VL s, entirely human antibodies were generated. In a similar approach, starting with the murine. $\mathrm{VH}$, a murine anti-TNF $\alpha$ (tumour necrosis factor) antibody was converted into a human version [19]. 
The combination of shuffling of $\mathrm{V}$-genes and selection on antigen provides a means to direct the isolation of a human V-gene pair with largely similar binding characteristics as the starting antibody.

in order to obtain a human anti-EGP-2 antibody with the same binding characteristics as MOC-31, which may be used for immunotherapy, we chose the method described by Jespers et al. (1994) for the humanisation of the MOC-31 mAb by guided selection. In two sequential chain shuffles, the murine VL and VH were replaced by fully hurnan antibody V genes, while maintaining both specificity and affinity. The murine and fully human antibodies were modeled and structural analogies and differences are discussed.

\section{Materials and Methods}

\section{Escherichia coli strain}

Escherichia coli TG1: K12, $\Delta$ (lac-pro), supE, thi, hsdD5/F'traD36, proA'B', lacl', lacZ $\triangle \mathrm{M} 15 \mathrm{~K} 12$.

\section{Humanisation of light and heany chains}

The V-genes of MOC-31 were cloned in the phagemid pCESI Fab format vector [21]. The ApaLl-Ascl fragment of the cloned VL CL was replaced by the VL-CL s from a library $(9$ * 106 clones), which was prepared from total RNA isolated from a human fresh spleen using random primers (Promega) for the preparation of eDNA. For the 2nd round of chain shuffling, the selected human VL.CL was combined with a human VH library. To retain the heavy chain CDR3 of MOC-31 the H3 MOC-31-for-primer (5'-ACT CGA GAC GGT GAC CAG GGT ACC TTG GCC CCA GTA GTC CCC CTT AAT AGC GAA TCT TGC ACA G(AT)A ATA CA.C GGC CGT GTC-3’) was used with an equimolar mixture of VHBACKSfi primers [21] for PCR amplification of the VH genes from cDNA derived from at human spleen [21]. The cDNA was prepared from total RNA using random primers (Promega) as described [2I]. The PCR products were cloned as a Sfil-BstEIl fragment in pCESI containing the selected human light chain and a human gamma-1 $\mathrm{CH} 1$ gene fused to filamentous phage gene III, as described by de Haardl et al. [21].

\section{Affinity selection}

Recombinant EGP-2 was expressed in the baculovirus system as described (Strassburg et al., 1992; a kind gift from Professor D. Herlyn (the Wistar Institute)) and was biotinylated with NHS-SS-biotin (Pierce) according to the manufacturers descriptions. The biotinylated EGP-2 was 
Guided selection of a pan-carcinoma specific antibody reveals similar binding characteristics yet structural divergence between the original murine antibody and its human equivalent

tested with MOC-31 on a streptavidin-coated sensorchip in a BLAcore2000 (Biacore AB, Sweden). Selections were performed on biotinylated EGP-2 as described by Hawkins et al. (1992) with some modifications: phage were incubated on a rotator wheel for one hour in $2 \% \mathrm{M}$ PBST (PBS supplied with $2 \%(\mathrm{w} / \mathrm{v})$ skimmed milk powder and $0.1 \%(\mathrm{v} / \mathrm{v})$ Tween-20). Meanwhile, $100 \mu \mathrm{l}$ Streptavidin-conjugated paramagnetic beads (Dynal, Oslo, Norway) were incubated on a rotator wheel for two hours in 2\% M-PBST. Different amounts of biotinylated EGP-2 were added to the pre-incubated phage (for the VL -shuffle: $10^{12} \mathrm{TU}$ for round $1,10^{11} \mathrm{TU}$ for subsequent rounds; for the VH-shuffle: $10^{12} \mathrm{TU}$ ) and incubated on a rotator wheel for 30 minutes. Next, beads were added and the mixture was left on the rotator wheel for 15 minutes. After 14 washes with $2 \%$ M-PBST and one wash with PBS, phage particles were eluted with 950 $\mu \mathrm{l} 0.1 \mathrm{M}$ triethylamine for five minutes. The eluate was neutralised by the addition of $0.5 \mathrm{ml}$ Tris- $\mathrm{HCl}(\mathrm{pH} 7.5)$ and was used for infection of log-phase E.coli TGI cells. The TGI cells were infected for 30 minutes at $37^{\circ} \mathrm{C}$ and were plated on 2 TTY ( $16 \mathrm{~g}$ Bacto-trypton, $10 \mathrm{~g}$ Yeast-extract and $5 \mathrm{~g} \mathrm{NaCl}$ per litre) agar plates, containing $2 \%(\mathrm{w} / \mathrm{v})$ glucose and $100 \mathrm{mg} / \mathrm{ml}$ ampicillin. After overnight incubation at $30^{\circ} \mathrm{C}$, the colonies were scraped from the plates and used for phage rescue as described [22].

\section{ELISA and kinetic measurement using SPR in BLAcore}

Soluble scFvs and Fabs were produced as described [10]. ELISAs and kinetic measurements using SPR in a BIAcore TM 2000 instrument (BIAcore AB, Uppsala, Sweden) were performed as described by Roovers et al. (1998). For the specificity ELISA, wells were coated with $10 \mathrm{mg} / \mathrm{ml}$ bovine serurn albumin (Sigma) in PBS, $3 \mathrm{mg} / \mathrm{ml}$ hen egg white lysozyme (Boehringer Mannheim) in $0.1 \mathrm{M} \mathrm{NaHCO} 3$ ( $\mathrm{pH} 9.6$ ), $10 \mathrm{mg} / \mathrm{ml}$ Tetanus Toxoid in $0.1 \mathrm{M}$ $\mathrm{NaHCO} 3$ (pH 9.6), or with $0.5 \mathrm{mg} / \mathrm{ml} \mathrm{EGP-2}$ in PBS. For the competition ELISA, Fab antibodies expressed as pIII fusions on the tip of bacteriophage were detected in the presence of excess whole antibody as described by Roovers et al. (1998). Approximately 1013 colony-forming units (cfu) of phage (and 1 in 2, 1 in 4 etc. serial dilutions hereof) were mixed with $50 \mathrm{ml}$ of hybridoma supernatant containing approximately $1 \mathrm{mg} / \mathrm{ml}$ whole antibody: For affinity measurements, the non-biotinylated antigen was covalently coupled to a CM-5 sensorchip (BIAcore AB, Uppsala, Sweden), resulting in a surface of 500 resonance units (RU). All kinetic measurements were performed on this antigen surface. Using TBS (20 mM Tris, pH 7.4, $150 \mathrm{mM}$ $\mathrm{NaCl}$ ) containing $2 \mathrm{mM} \mathrm{MgCl} 2$ and $0.01 \%(\mathrm{v} / \mathrm{v})$ Tween-20 as a running buffer, the Fabs/scFvs were passed over the sensorchip at a flow rate of $20 \mathrm{ml} /$ minute at $25^{\circ} \mathrm{C}$. The rate constant ( $\mathrm{k}_{\mathrm{od}}$ ) was obtained by direct fitting and fitted to the data according to a single-site model, using the BIAevaluation 2.1 software (BIAcore AB, Uppsala, Sweden). The off-rates (koff) of 9E and MOC-31 are, respectively, an average of eight and five curves made with different antibody 
dilutions. Association rates (kon) were determined from a plot of $[\mathrm{ks}=\mathrm{kon} * \mathrm{C} / \mathrm{koff}]$ versus antibody concentration (C).

\section{DNA sequence analysis}

The nucleotide sequences of the selected Fabs were determined using the dideoxy sequencing method of Sanger. Products of the sequencing reaction were analysed on a semiautomated sequencer (AIf Express, Pharmacia), Oligonucleotides used were pUC-REVERSE: 50 -CAG GAA ACA GCT ATG AC-30 and CHIFOR: 50 -GTC CTT GAC CAG GCA GCC CAG GGC-30. Alignments of V gene sequences were performed using V BASE on webpage: http://www.mrc-cpe.cam.ac.uk/imt-doc/restricted/DNA.PLOT.html. Canonical class assignments were performed using webpage: http://www.biochem.ucl.ac.uk/ martin/abs/chothia.html

\section{Structural modelling}

1. Building the framework and canonical CDRs

The framework and canonical CDR backbones were modelled by an improved version (N.R.W. \& A.R.R., unpublished) of the original AbM algorithm [23]. As a result of studies which showed that certain residue positions in canonical loops were conserved in chi- 1 angles, the side-chains of those positions were built using maximum-overlap, rather than using the CONGEN iterative side-chain placement algorithm [24]. The non-conserved side-chains were not built at this point, but were built simultaneously with the non-conserved $\mathrm{H} 3$ side-chains (see below).

\section{Building non-canonical non-H3 CDRs}

These were built using a modified version (Whitelegg, 1999; N.R.W. Searle \& A.R.R., unpublished) of the combined antibody modelling algorithm (CAMAL; [23]). Of special note are the force field modifications in which the stand-alone implementation of VFF [25] was used to energy-sereen the generated conformations, instead of Eureka. In addition, the candidate conformations were energy-minimised using VFF.

\section{Building $\mathrm{H} 3$ loops}

Recent studies have shown that in the many instances, CDR-H3 loops exhibit a "kinked" Cteminal region [26]; [27]. The kink is determined by a number of sequence-based rules, and the antibodies modelled here conformed to those rules. These features were added to CAMAL and taken into account in the following way when modelling $\mathrm{H} 3$ loops. First, the $\mathrm{C}$-alpha to $\mathrm{C}$-alpha database search [23] was performed, using only the set of kinked H3 crystal structures to derive the $\mathrm{C}$-alpha to $\mathrm{C}$-alpha distance constraints (in order to bias the database hits in favour of kinked structures). The database hits were then subjected to energy minimisation after grafting, to 
Guided selection of a pan-carcinoma specific antibody reveals similar binding characteristics yet structural divergence between the original murine antibody and its human equivalent

minimise poor loop/framework joins. Subsequently, the CONGEN [24] and the Go and Scheraga chain closure algorithm [37] were used to rebuild a five-residue segment at the apex of each database loop. Finally, each conformation was subjected to minimisation by VFF [25] to relieve any residual high energy in the loops, and the lowest energy loops, as measured by VFF, were clustered using RMSD as the criterion.

\section{Final screen}

To select the final $\mathrm{H} 3$ backbone conformation, a screen based on similarity (measured by RMSD) to the known structures of the particular $\mathrm{H} 3$ length being modeled was used. It has been observed that certain length $\mathrm{H} 3$ loops have similar conformations in the majority of examples, notably eight and ten residue loops. A similarity score for each of the clustered conformations was calculated: Score \& _ all known structs (1/dx ) $\mathrm{mx}$ where $\mathrm{dx}$ is the RMS deviation between the model and structure $\mathrm{x}$, and $\mathrm{mx}$ is the sequence similarity (using the MDM matrix, [ $[1,28]$ between the sequence of the model and structure $\mathrm{x}$. The structure being modeled was excluded from the list of known structures while performing this screen. Finally, side-chains were modeled using the dead-end elimination algorithm (see below). H3 and non-conserved side-chain modeling The final stage was to build side-chains on the selected backbone model. Analyses of antibodies have shown that for certain residue types, the chi-1 values of the four $\mathrm{C}$-terminal H3 residues are conserved (N.R.W. \& A.R.R., unpublished). Therefore, these were built using the average observed chi- 1 values. For the chi- 2 of these residues, either the extended conformation was used or the mean of frequently observed $(64-88 \%$ ) values was used, depending on whether the chi- 2 was conserved for that residue type and position. All remaining $\mathrm{H} 3$ and canonical nonconserved side-chains (as well as all side-chains on the non-canonical non-H3 loops) were built simultaneously on the final selected backbone, using a modified version of the dead-end elimination algorithm [29]. In this procedure an attempt is made to find a global minimum by successively eliminating rotamers from a rotamer library which have a higher "lowest" energy of interaction with their environment than the "highest" energy of interaction of the other rotamers for that residue. The Connolly structures [38] were generated using the program InsightII 97.0 (MSI) and the images shown are of the solvent- accessible surfaces, as opposed to the van der Waals surfaces.

\section{FACS analysis and immunohistochemistry}

Fabs and scFvs were tested by FACS analysis for specific binding to EGP-2 positive cells as described by Henderikx et al. (1998) [30] with some minor modifications. The colon cell line $\mathrm{CaCo} 2$ (American Type Culture Collection, Rockville, MD) was stained using scFv (MOC-31) or Fab (clones $\mathrm{C} 3$ and $9 \mathrm{E}$ ) periplasmatic fractions. After the last incubation with FITC- 
conjugated rabbit anti-mouse (DAKO, Giostrup, Denmark; diluted 1:50 in incubation buffer), detection of bound scFvs or Fabs was performed by means of flow cytometry on a FACScalibur (Becton Dickinson) and results were analysed with the CELLQuest program (Becton Dickinson). Fabs were tested immunohistochemically as described for scFv by Roovers et al. (1998).

\section{Results}

\section{Humanisation of the light chain}

In the first guided selection step we aimed to replace the murine light chain with a human version. The variable heavy chain gene of MOC-31 was cloned into the pCESI Fab format vector [21 j and the obtained chimaeric VH CH 1 was combined with $\mathrm{k}$ and I light chain libraries derived from human spleen separately, yielding two libraries of $i 0^{8}$ clones (k) and $2 * 107$ clones (l). We chose to use spleen as a source of human V-genes to access maximal germline and somatic hypermutation diversity (of both $\operatorname{IgM}$ and $\operatorname{IgG~B}$ cells). Phage were rescued and $8 \times 10^{12}$ transforming units (TU) of the $\mathrm{k}$ library were used for the first selection round. Schier $e t$ al. [31, 32] obtained higher-affnity monomeric scFv fragments on phage only by selecting in solution using limiting concentrations of biotinylated antigen, followed by screening the selected binders for their koff in BIAcore. In order to obtain high affinity antibodies to tumour antigen EGP-2, selections were performed on biotinylated EGP-2 with concentrations varying from $1 \mathrm{nM}$ down to $10 \mathrm{pM}$ (Table 1).

\section{Table 1}

Binding frequency of selected Fab is from $\times$ library.

\begin{tabular}{l|c|c|c|c}
\hline & \multicolumn{4}{|c}{ Round of selection } \\
[Ag] used during selection (nM) & 1 & 2 & 3 & 4 \\
\hline I (rd1); I (rd2); I (rd3); I (rd4) & $4 / 30$ & 36737 & $12 / 16$ & nd \\
I (rd1);0.1 (rd2); 0.1 (rd3); 0.1 (rd4) & $4 / 30$ & 36737 & $11 / 16$ & nd \\
$0.1(\mathrm{rd} 1) ; 0.1(\mathrm{rd} 2) ; 0.1 \mathrm{rd} 3) ; 0.1(\mathrm{rd} 4)$ & $0 / 32$ & 36737 & $7 / 16$ & $12 / 16$ \\
$0.1(\mathrm{rd} 1) ; 0.01(\mathrm{rd} 2) ; 0.01(\mathrm{rd} 3) ; 0.01(\mathrm{rd} 4$ & $0 / 32$ & 36737 & $6 / 16$ & 36737 \\
\hline
\end{tabular}

nd, not determined; rd, round

After each round of selection, polyclonal phage was prepared and the frequency of binders to EGP-2 was determined in ELISA. The ELISA results in Table 1 show that in all selection rounds binders were retrieved. Clones positive in ELISA and selected in the third 
round, were tested for their affinity in BIAcore: some Fabs show an off-rate similar to the starting antibody MOC-31 (Table 2). The VL -gene nucleic acid sequence of these clones was determined and submitted to GenBank (accession numbers: AF209862-AF209866). Alignment using V-BASE, revealed that the light chains originate from the human VkIII family (Figure 1). No correlation can be found between the used antigen concentration and the off-rate of the selected clones. For instance, clones $\mathrm{C} 1, \mathrm{C} 5$ and $\mathrm{E} 4$, which by sequencing appeared identical, were selected using an EGP-2 concentration of $1 \mathrm{nM}(\mathrm{C} 1)$ and $0.1 \mathrm{nM}(\mathrm{C} 5)$ or a combination of these (E4, see Table 2). To produce more reliable off-rates, the Fabs with the lowest off-rates were produced in large amounts, purified and analysed in BIAcore. As shown in Table 2, the purified Fabs show an off-rate in the same range as MOC-31 (between $10^{-4} \mathrm{~s}^{-1}$ and $10^{-3} \mathrm{~s}^{-1}$ ). Clone $\mathrm{C} 3$ was chosen to guide the selection of the human heavy chain. Compared to the sequence of the germline segment, C3 shows 16 nucleotide and nine amino acid substitutions.

Table 2

On- and off-rates of (half) human Fabs and scFv MOC.3I

\begin{tabular}{|c|c|c|c|c|c|c|}
\hline \multirow[b]{2}{*}{ Clone" } & \multicolumn{3}{|c|}{$[\mathrm{Ag}]^{5}(\mathrm{nM})$} & \multirow[b]{2}{*}{$k_{\text {eff }}\left(10^{-4} \mathrm{~s}^{-1}\right)$} & \multirow[b]{2}{*}{$k_{e f f}\left(10^{-4} \mathrm{~s}^{-1}\right)^{*}$} & \multirow[b]{2}{*}{$k_{e m}\left(10^{5} \mathrm{M}^{-1} \mathrm{~s}^{-1}\right)^{*}$} \\
\hline & $1^{\text {st }} \mathrm{rd}$ & $2^{\text {nd }} \mathrm{rd}$ & $3^{\text {rd }} \mathrm{rd}$ & & & \\
\hline $\mathrm{Cl}$ & 1 & 1 & 1 & 1.5 & nd & \\
\hline $\mathrm{C} 5$ & 0.1 & 0.1 & 0.1 & 1.6 & nd & \\
\hline $\mathrm{E} 4$ & 1 & 0.1 & 0.1 & 1.2 & 4.4 & \\
\hline G5 & 0.1 & 0.1 & 0.1 & 1.8 & 3.6 & \\
\hline E3 & 1 & 0.1 & 0.1 & 1.8 & 2.1 & \\
\hline C 3 & 1 & 0.1 & 0.1 & 0.84 & 3 & 0.9 \\
\hline $\mathrm{C} 4$ & 1 & 0.1 & 0.1 & 34 & nd & \\
\hline $9 \mathrm{E}^{+}$ & 100 & 100 & 100 & nd & 4.4 & 0.86 \\
\hline$M O C-31^{\ddagger}$ & na & na & na & nd & 5.7 & 1.2 \\
\hline
\end{tabular}

"Clones selected in $3^{\text {rd }}$ round

$\S$ The Ag concentration used in the selection round 1,2 and 3

* Off-rate of purified Fab's and scFv as determined by BIAcore

$\dagger$ Fab 9E is completely human

¥ scFv MOC-31 is completely murine

na, not applicable; nd, not determined; rd, round 


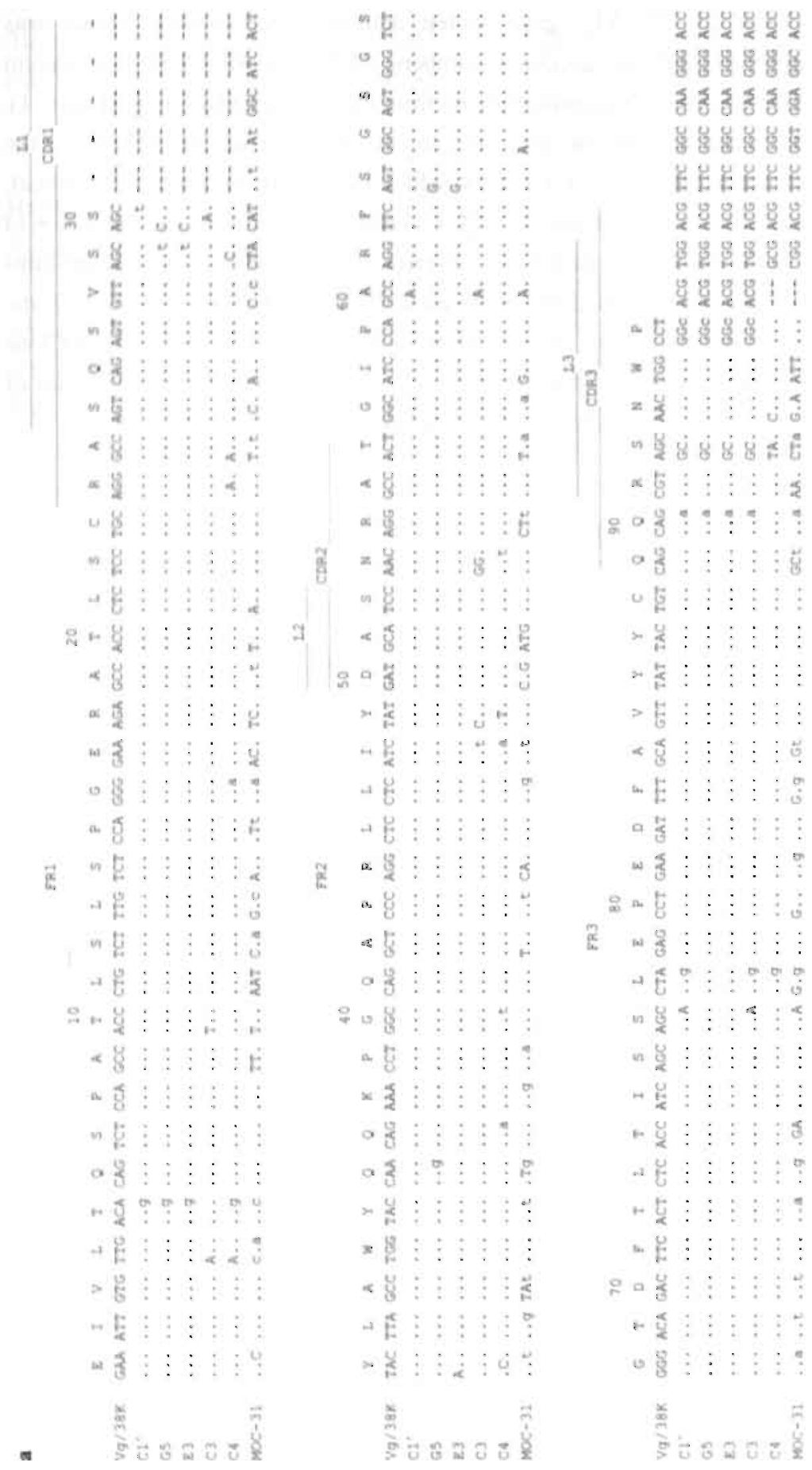


Guided selection of a pan-carcinoma specific antibody reveals similar binding characteristics yet structural divergence between the original murine antibody and its human equivalent

b

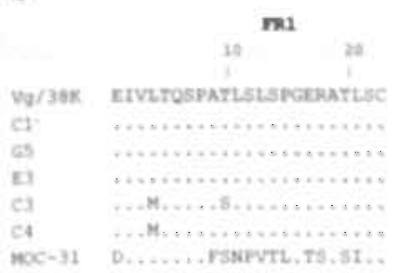

$m 3$

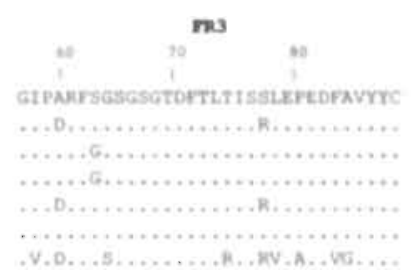

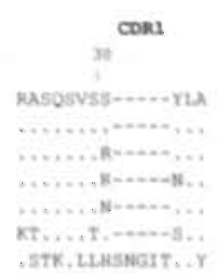

$\cos 3$

,

ochsonr

....A. . . GTw

......., GTht

........

........9T⿰亻丨

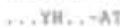

A. MIXI, - RT

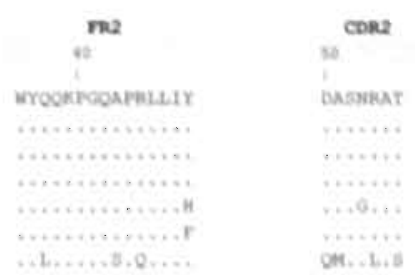

ma

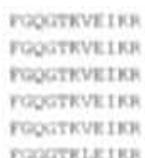

\section{Figure 1}

DNA and aminoacid sequence alignment of selected human variable light chains and MOC-31 $V_{L}$.

(a) DNA sequence; (b) amino acid sequence. The DNA sequences of the $V_{1}$ of of half human Fabs (mouse $V_{14}$. human $\mathrm{V}_{\mathrm{L}}$ ) and of $\mathrm{MOC}-3 \mathrm{i}$ are aligned to $\mathrm{Vg} / 38 \mathrm{~K}$, the human germline gene with highest homology tothe selected human light chains as determined by V-BASe (http://www.mre-cpe.cam.ac.uk/imt-doc/restricted/DNAPLOT.html) Framework (FR) and $\mathrm{CDR}$ regions are indicated. Numbering and loop regions ( $\mathrm{L} \mid \mathrm{L}=\mathrm{L} 3$ ) are according to structuri criteria defined by Chothia (Chothia et al., 1992; Tomlinson et al., 1992, 1995; Williams et al., 1996). CDRs are according to Kabat et al. (1991). Silent mutations from germline are indicated using small characters. T The DNA and amino acid sequence of clone $\mathrm{C} 1$ are identical to those of clones $\mathrm{C} 5$ and $\mathrm{E} 4$.

As shown in Table 3, the selected human VL s have a different canonical structure for Ll (fold 2) to that used by MOC-31 VL (fold 4). No differences in lengths or canonical loops were observed for $\mathrm{CDR} 2$. Three of the selected light chains used the same canonical siructure for $\mathrm{L} 3$ (fold 1) as $\mathrm{MOC}-31$. The structure for $\mathrm{L} 3$ of the other selected VL $\mathrm{s}$ (having one extra residue in L3) could not be determined, since these chains have a threonine at position 96 , whereas fold 5 (with seven residues in the L3 region) uses a proline at this position [18]. Furthermore, no significant amino acid homology was found between the CDRs of the human VL $s$ and those of the MOC-31 VL (Figure 1). In parallel to the selections with the k library, selections were performed with the I library. No enrichment could be found after three rounds of selection and no EGP-2 binding clones were detected in ELISA. Most likely, for replacement of the murine $\mathrm{k}$ : chain, there was no VH or antigen binding-compatible I light chain available in the human $\lambda$ repertoire. 
Table 3

$V$-gene classifications and structural predictions of the CDR-loops of $V$-genes

\begin{tabular}{|c|c|c|c|c|c|c|c|}
\hline \multirow[t]{2}{*}{ V-gene } & \multirow[t]{2}{*}{$\begin{array}{l}\text { Human } \\
\text { V-gene } \\
\text { family* }\end{array}$} & \multicolumn{2}{|c|}{$\begin{array}{l}\text { No. of mutations from } \\
\text { Germline }\end{array}$} & \multicolumn{3}{|c|}{$\begin{array}{l}\text { Canonical } \\
\text { structure" }\end{array}$} & \multirow[t]{2}{*}{$\begin{array}{c}\text { Closest } \\
\text { human* } \\
\text { germline gene }\end{array}$} \\
\hline & & nucleotides & amino acids & Ll & L2 & L3 & \\
\hline $\mathrm{VL}-\mathrm{Cl}^{*}$ & VkIII & 11 & 4 & 2 & 1 & ? & $3 \mathrm{~A} 9$ \\
\hline VL-G5 & VxIII & 11 & 4 & 2 & 1 & ? & $\mathrm{Vg} / 38 \mathrm{~K}$ \\
\hline VL-E3 & VkIII & 11 & 5 & 2 & 1 & $?$ & $\mathrm{Vg} / 38 \mathrm{~K}$ \\
\hline VL-C3 & VkIIII & 16 & 9 & 2. & 1 & ? & $3 \mathrm{~A} 9$ \\
\hline $\mathrm{VL}-\mathrm{C} 4$ & VkIII & 16 & 8 & 2 & 1 & 1 & $\mathrm{Vg} / 38 \mathrm{~K}$ \\
\hline VL-MOC-31 & VкII & 109 & 44 & 4 & 1 & 1 & DPK13/O11 \\
\hline VH-9E & $V_{H} 7$ & 23 & 13 & 1 & 2 & NA & $V I-4.1 b$ \\
\hline $\mathrm{VH}-\mathrm{MOC}-3 \mathrm{I}$ & $\mathrm{V}_{\mathrm{H}} 7$ & 70 & 26 & 1 & 2 & NA & YAC- $10 / 1 \mathrm{~d} 37$ \\
\hline
\end{tabular}

*V-gene families and closest human germlines (for MOC-31) were deduced from V BASE

"Germline genes used are $\mathrm{Vg} / 38 \mathrm{~K}$ for the light chains and $\mathrm{V} \mid \mathrm{L}-4.1 \mathrm{~b}$ for the heavy chains.

"Canonical structures were assigned according to Chothia et al. (1989 \& 1992). Selected human $V_{L}$ 's were assigned in combination with MOC-3i $V_{H}$. Selected human $V_{H}(9 E)$ was assigned in combination with the $\mathrm{V}_{\mathrm{L}}$ of $\mathrm{C} 3$.

t The DNA sequence and therefore the $\mathrm{V}$-gene classifications and structural predictions of CDR-loops of elone $\mathrm{C} !$ is identical to clones $\mathrm{C} 5$ and $\mathrm{E} 4$

? No canonical of the same loop length could be found using webpage:

http://www.biochem.ucl.ac.uk/ martin/abs/chothia.html. But according to Tomlinson et al. (1995) canonical structure 5 might be assigned to $L 3$ of these clones.

\section{Humanisation of the heavy chain}

For the chain shuffling of the heavy chain, the selected human light chain of clone $\mathrm{C} 3$ was first cloned into pCESI not carrying any VH genes to avoid later contamination of the MOC$31 \mathrm{VH}$. Human $\mathrm{VH}$ genes were amplified from the RNA of human spleen using oligonucleotide H3-MOC-3I-FOR, introducing the MOC-31 CDR3 in all sequences. This product was cloned as indicated in Materials and Methods into the C3-light chain containing vector, to create a library of $1.2 \times 10^{7}$ clones. This was subjected to three rounds of selection. Under stringent selection conditions (decreasing phage input titres and decreasing antigen concentration, as before), no human EGP-2 binding antibodies were identified. After three rounds of selection, 
EGP-2 binding antibodies were obtained using non-stringent conditions (phage input $1012 \mathrm{TU}$, $100 \mathrm{nM}$ antigen). Figure 2 shows that all 11 clones tested are specific for EGP-2, but signals do not reach values above 0.7 .

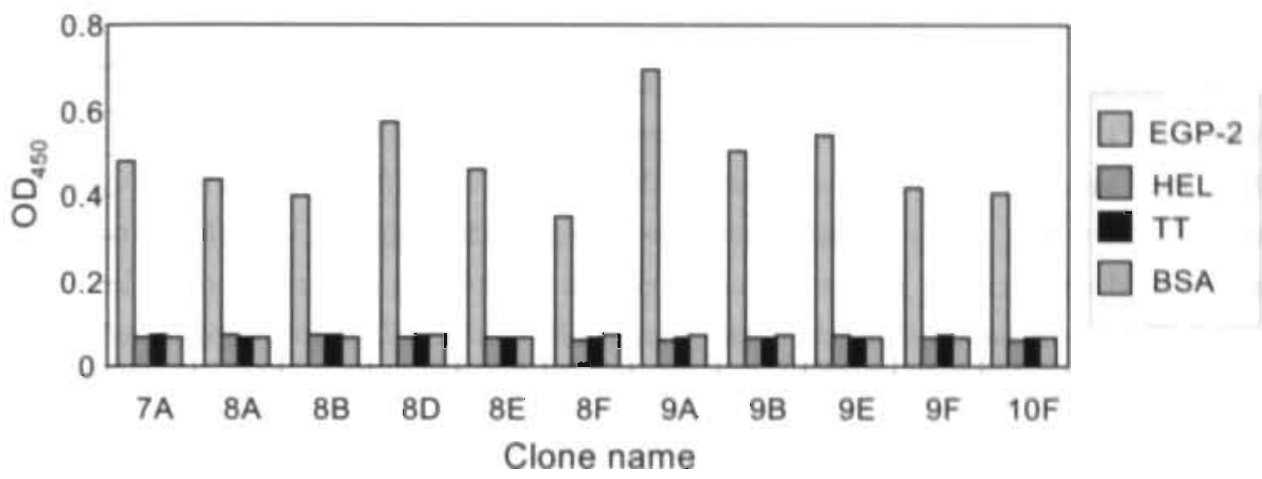

\section{Figure 2}

Specificity ELISA of clones selected after second chain shuffle.

The specificity of the selected Fabs was tested in an ELISA using plastic-immobilised bovineserum albumin (BSA), hen egg-white lysozyme (HEL), tetanus toxoid (TT) and epithelial glycoprotein-2 (EGP-2). Bound soluble Fib fragments from individual clones were detected with anti-mye tag antibody $9 \mathrm{E}$ I0.

DNA sequencing of four EGP-2 specific clones (including clone 9E) revealed that these clones all contained the same $\mathrm{VH}$. This $\mathrm{VH}$ was completely human and its DNA sequence was submitted to GenBank (accession number: AF209860). V BASE sequence alignment showed it originated from the small but discrete VH 7 family [33] with 23 nucleotide and 13 amino acid mutations compared to the germline sequence (Figure 3). As shown in Figure 3, the amino acid sequence in the CDR3 and framework 4 regions of MOC-31 $\mathrm{VH}$ were retained during the shuffling. BIAcore experiments with the representative clone, $9 \mathrm{E}$, purified from 0.5 litres of culture, show that it has an affinity in the same order of magnitude as MOC-3I (Table 2). The human Fab 9E specifically binds EGP-2 positive cells as shown by FACS analysis (Figure 4) and competes with MOC-31 for binding to recombinant EGP-2 in ELISA (Figure 5). The Fab was also tested in immunohistochemistry and a similar staining was observed as shown by Roovers et al. (1998): the Fab reacts with normal and malignant non-squamous epithelia and does not stain. malignant tissue reported negative for the antigen (melanoma; data not shown; [34]. This confirms the specificity. The variable chains of MOC-31 and $9 \mathrm{E}$ were modelled as described in Materials and Methods. The coordinates of the V-genes of MOC-3I and 9E were deposited in the PDB-database with the accession numbers Idx2 and $1 \mathrm{~d} \times 3$, respectively. As shown in Figures 6 and 7 and discussed in more detail in the Discussion section, the structural modeling revealed 
large differences between the murine and the human antibodies, in particular between their light chains.

\section{Discussion}

We cloned the repertoire of human light chains into the phagemid pCESI containing the MOC-31 VH. Since MOC-31 scFvs have a tendency to dimerise [10], we used a Fab format for the humanisation. In this way we can screen the antibodies for affinity rather than avidity and also select with less avidity mediated problems for high affinity binders. We selected on soluble biotinylated antigen using stringent selection conditions (low Ag concentration and low phage input). These selections yielded chimaeric murine VH / human VL antibodies with comparable off-rates as the parent seFv MOC-31. In contrast to the rapid and successful chain shuffling of the light chain, the shuffling of the heavy chain was more difficult: only by increasing the antigen concentration and the phage input could binders be selected. The lower expression yields of the fully human Fab 9E (34 $\mu \mathrm{g} /)$ versus the Fab C3 $(80 \mu \mathrm{g} /)$ as well as its reduced affinity are most likely responsible for the higher antigen concentration required to select the phage antibody. This emphasises the importance of the empirical approach for determining optimal conditions for affinity-selections. Sequence alignment using V BASE showed that MOC-31 VL has more homology to the VkII family than to the VkIII family from which the selected human light chains originated. Thus unlike other examples [20]; Salfeld et al., 1997), the light chain guided selection did not yield the most homologous human counterpart sequence. Nevertheless, there are signs of amino acid conservation between the MOC 31 VL and the selected human VL s. Remarkably, the most abundant clones, C1, C5 and E4, which are selected on different antigen concentrations and are identical at the nucleotide level, are completely germline in sequence except for two mutations in FR3. At both sites, the germline residues are replaced by equivalent residues present in the original MOC-3i VL sequence (A60D; S77R; Figure !). The VL of another selected clone, C3, shows the same mutations as well as a similar type mutation in FRI (TIOS). Of all selected human light chains, the VL of clone $\mathrm{C} 3$ has both the highest level of amino acid substitutions from germline (Table 3) and the highest level of amino acid homology to MOC-31 VL. This may well indicate the involvement of some of these residues in antigen binding. Structural modelling of seFvs MOC-31 and $9 \mathrm{E}$ (which carries the $\mathrm{C} 3$ light chain; see Figure 6) revealed that $60 \mathrm{D}$ is quite close (6 A E ) to $54 \mathrm{R}$ in the L2 loop. but faces the other way and hence cannot form a salt bridge with it. The conformation of its side-chain, however, is similar to that in MOC-31. 


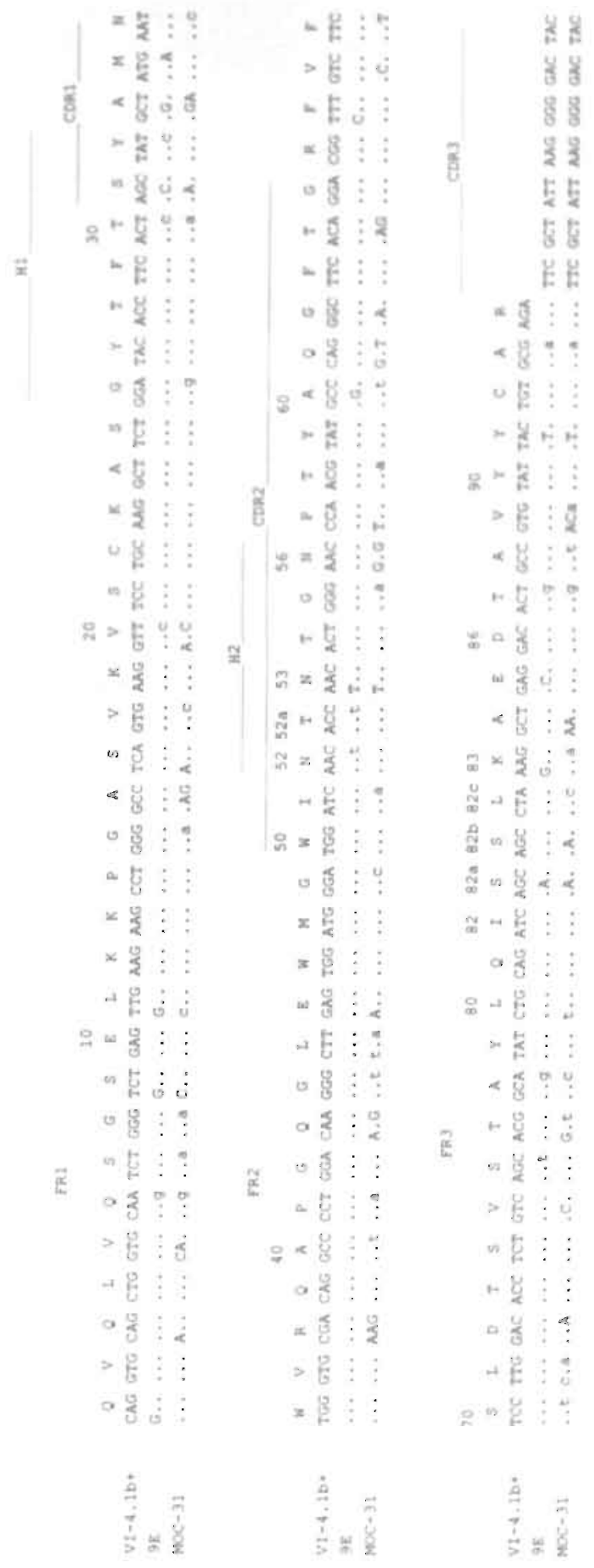


b

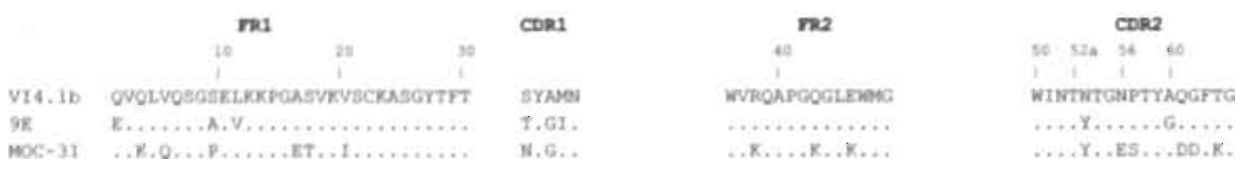

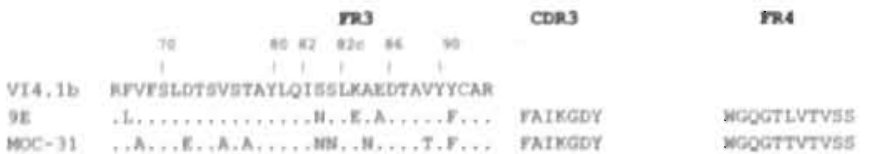

\section{Figure 3}

DNA and amino acid sequence of the selected human variable heavy chain and MOC-3I $V_{H}$.

(a) DNA sequence; (b) amino acid sequence. The DNA sequence of the human heavy chainfrom the selected antiEGP-2 clone and of MOC-31 are aligned to VI-4.1b, thehuman germline gene with highest homology to the selecte human heavy chain as deduced from V-BASE (http://www.mre-cpe.cam.ac.uk/imt-doc/restricted/DNA-PLOT.html) Framework (FR) and CDR regions are indicated. Numbering and loop regions $(\mathrm{H} 1-\mathrm{H} 3)$ are according to structura criteria defined by Chothia (Chothia et al., 1992; Tomlinson et al., 1992, 1995; Williams et al., 1996). CDRs are according to Kabat ef al. (199i). Silent mutations from germline are indicated using small characters.

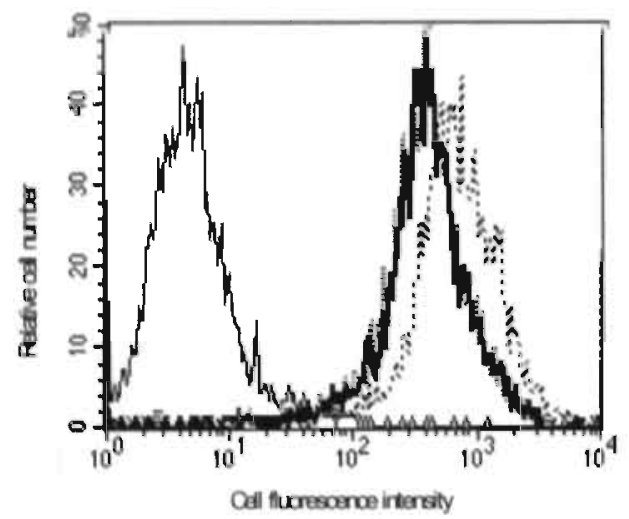

\section{Figure 4}

Binding of soluble scFv MOC-31 and Fabs C3 and $9 E$ to $\mathrm{CaCo} 2$ cells in flow cytometry.

Thin line is negative control (9E l0); thick line is binding of scFv MOC-31; thin dotted line is half human Fab C3 and thin striped line is human Fab 9E.

\section{Figure 5}

Competition ELISA.

Binding of Fab 9E phage antibody to recombinant EGP-2 in the presence of $(\mathbf{\Delta})$ no competing antibody. (- in an excess of an irrelevant antibody (UIC2, anti-P-glycoprotein hybridoma), or ( $\bullet$ the MOC-31 whole antibody.

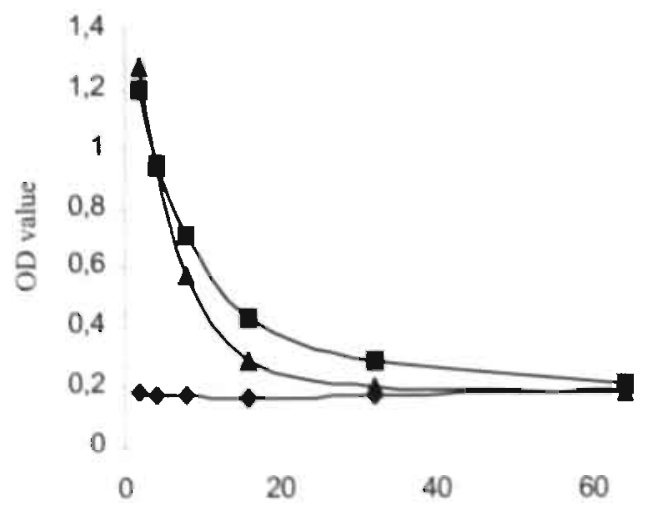


Guided selection of a pan-carcinoma specific antibody reveals similar binding characteristics yet structural divergence between the original murine antibody and its human equivalent
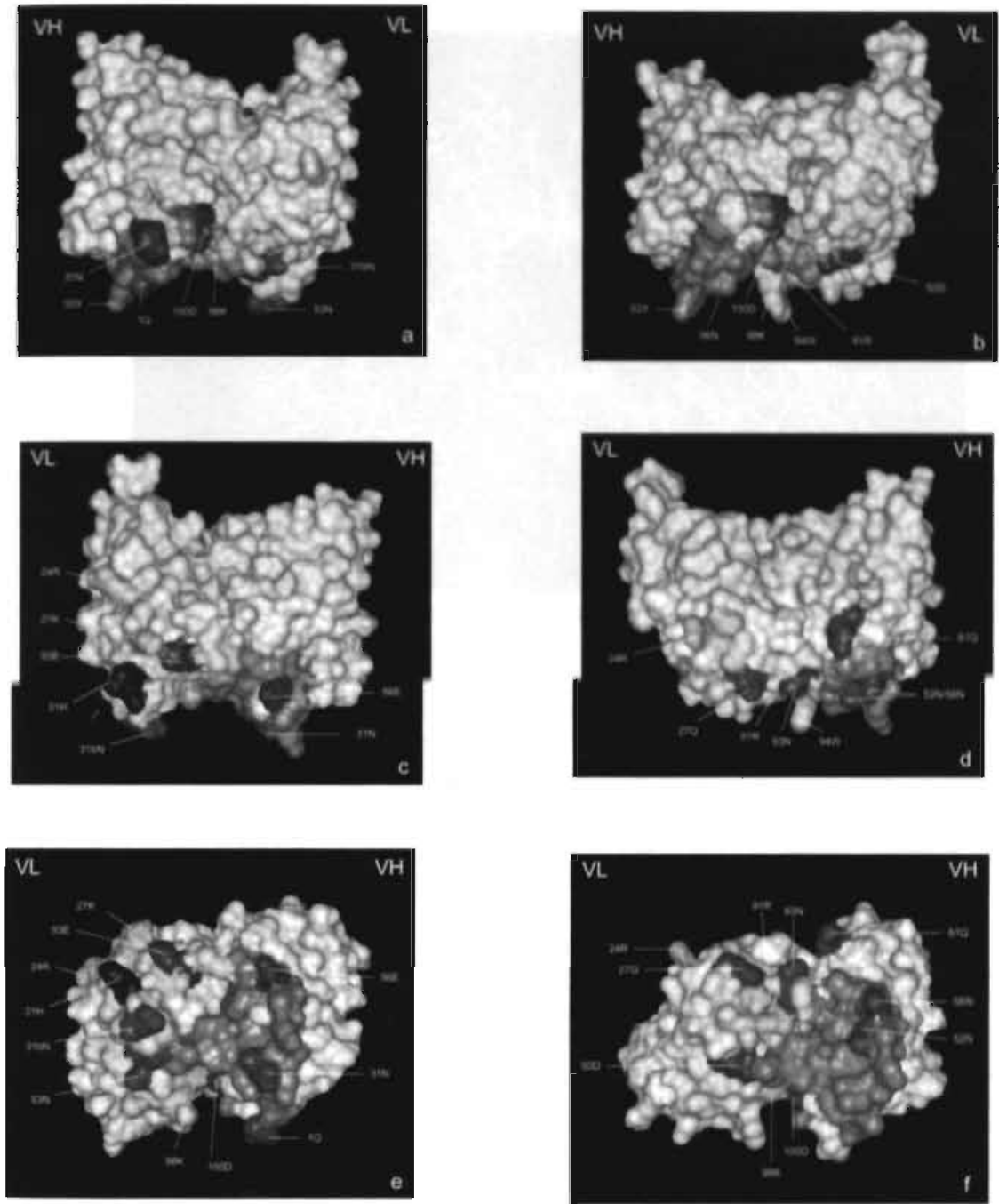

\section{Figure 6}

Connolly solid-surface structures of the monoclonal MOC-31 and the human Fab $9 E$.

The variable chains only are shown. (a) and (b): the opposite views of (c) and (d) respectively. (e) and (f): top view showing the antigen-binding sites. (a), (c) and (e) MOC-31; (b), (d) and (f) 9E. The Conolly structures wee generated using the program Insight-II 97.0 (MSI) and show the solvent-accessible, rather than the van der Waak surface. 


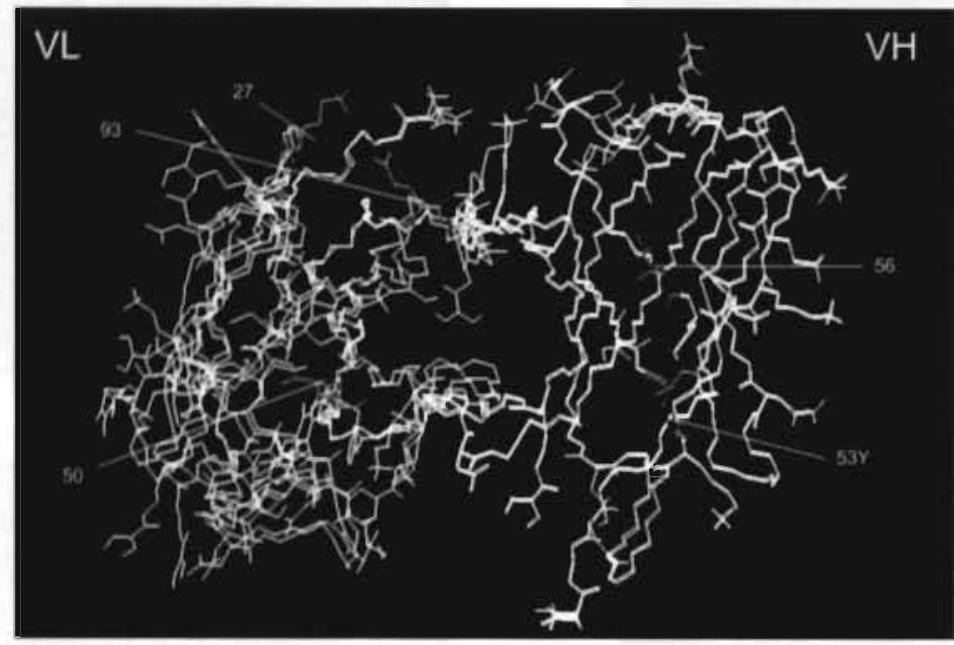

\section{Figure 7}

Superimposition of the antigen binding sites of the monoclonal MOC-31 and the human Fab $9 E$. The variable chains only are shown. The two models were superimposed using least-square fitting on conserved framework regions adjacent to the DCRs. Residues with similar positions are shown in red (9E) or green (MOC-31)

The other germline mutations are in the same conformation in both MOC-31 and $9 \mathrm{E}$ and appear to be largely unimportant, being framework residues distant from the CDRs which, additionally, point sideways or interact only with the framework. As shown in Figure 6(c) and (d), the exposed residues $24 \mathrm{R}, 27 \mathrm{~K}, 31 \mathrm{H}, 93 \mathrm{E}$ present in the MOC-31 VL were not retained in C3-VL except for $24 \mathrm{R}$, but this residue is projected from the side of the Fv and is therefore unlikely to be involved in antigen binding. In the humanised $C 3$ light chain the exposed residues are 24R, 50D, 54R, $91 \mathrm{R}$ and to some extent $28 \mathrm{~S}, 30 \mathrm{~S}$ and $32 \mathrm{Y}$. Residue $54 \mathrm{R}$ is projected downwards and sideways, away from the binding site (not shown in Figure 6). When we compare the side views of both Fvs, we observe the bulky residue $94 \mathrm{~W}$ in the centre of $9 \mathrm{E}$ (see Figure 6(b) and (d), which is absent in MOC-31 (Figure 6(a) and (c)). These observations suggest that for the light chain guided selection, sequence homology is not required to maintain an antigen-antibody interaction with the same or similar kinetics of binding. This may be caused by the often-dominant role of the heavy chain in antigen binding. Sequence alignment using V BASE of the VH of MOC-3I showed that this chain has the highest homology with germline YAC-0/Id 37 of the human VH 7 family. Indeed, the selected human heavy chain of clone $9 \mathrm{E}$ originated from the VH 7 family, albeit from a different germline segment (VI-4.1b). It differs only moderately from the murine 
MOC-31 VH (Table 3), in total in $29 \%$ (26/90 amino acids, in which the 90 aa are encoding the region after the FR1-part encoded by the PCR-primers and up to and including FR4). The antibody models were used to investigate possible common features around the antibody combining site. The main structure of the heavy chain CDR3 was, as expected, maintained. For example, from Figure $6(\mathrm{e})$ and $(\mathrm{f})$ it is clear that the heavy chain residues $98 \mathrm{~K}$ and $100 \mathrm{D}$ are buried in both antibodies. Of the 13 amino acid germline mutations found in $9 \mathrm{E}$, three are mutations that create the MOC-31 homologue residue (A33G in CDR1, N53Y in CDR2 and $\mathrm{S} 82 \mathrm{aN}$ in FR3). As shown in Figure 6, of the exposed residues 53Y, 56E and to some extent 28T in MOC-31 VH, only $53 \mathrm{Y}$ is retained in $9 \mathrm{E}-\mathrm{VH}$, suggesting the involvement of this residue in antigen binding. The superimposition of the binding sites of both antibodies, shown in Figure 7 , reveals that some residues have very similar positions and that they are actually in corresponding positions in the CDR loops. In particular, this is very obvious for the $\mathrm{VH}$ residues at positions 53 and 56. The pattern of mutations and the fact that a non-homologous human VL and a human heavy chain with close homology to its MOC-31 counterpart were selected, suggest that the heavy chain of MOC-31 is more essential for the specific binding of the antibody to EGP-2 than the light chain. Thus, the guided selection procedure yields a human antibody with similar binding characteristics as the original murine MOC-31 antibody, yet with minimal structural conservation. This contrasts with the data from Figini et al. (1994), in which an anti-phenyloxazolone antibody was humanised with the same procedure; in this case, $6 / 7$ of the putative contact residues were retained in the fully human version. The structural solution to the recognition of a particular epitope within a larger protein antigen is less stringent. For example, minimal structural homology has been noted in two anti-influenza virus neuraminidase antibodies binding to overlapping epitopes [35]. This reduced stringency on conservation of critical binding site residues within the antibody-protein antigen interaction, apparently allows structurạl divergence of antibodies obtained by guided selection. Using humanisation technique of guided selection, we have isolated a fully human antibody directed to EGP-2. Since I994, several groups have used the guided selection technique to obtain human antibodies by sequential chain shuffling (Salfeld et al., 1997; [20,36, 37]. Watzka et al. (1998) described that the second shuffle (of the VH ) led to the selection of a humanised antibody, which recognised an epitope present only on the immobilised (coated) antigen. In principle, the modulation of fine-specificity may be caused by the possible different chemical interactions with a similar area on the antigen. However, in this case it appears that a suboptimal selection procedure has interfered with the structure of the epitope, causing failure of the guided selection procedure, and selection of antibodies to completely different epitopes on the antigen. Since the heavy chain CDR3 is the main loop involved in antigen binding and its species origin cannot be traced easily due to its highly diverse nature anyway, several groups have opted to maintain this loop in the guided 
selection procedure. Similarly, we have succeeded in humanising an anti-CD30 antibody, which had the same epitope specificity as the original murine $\mathrm{Ki}-4$ antibody, by retaining only the murine heavy chain CDR3 (Klimka et al., unpublished results). Rader et al. (1998) humanised the murine antibody LM609 (directed to human integrin $\alpha v \beta 3$ ) by guided selection, retaining the murine CDR3 $\mathrm{s}$ of both heavy and light chain. In contrast, our data suggest that it may not always be necessary to maintain the CDR3 of the murine light chain during the guided selection as was suggested by Rader et al. (1998). Thus, guided selection of rodent antibody V-genes provides a powerful tool for interspecies conversion of antibodies. Due to the different chemistry of the human antibody-antigen interaction, it can be envisaged that in some cases guided selection may alter the antibody-mediated triggering or signal transduction of the starting rodent antibody (i.e. antibody internalisation, receptor crosslinking). Therefore, any resulting antibody will need to be screened for loss (or gain) of such secondary binding feature.

In conclusion, we have obtained a high affinity antibody which specifically binds EGP-2 as confirmed by FACS analysis, immunohistochemistry and specificity ELISA and may be useful for tumour targeting studies. For instance, bispecific antibodies can be generated by combining the isolated human a-EGP-2 antibody with an a-CD3 antibody. Together with co-stimulatory signals, these bispecific antibodies can be used to provide $\mathrm{T}$ cells with tumour specificity and cytotoxic potential (Kroesen et al., 1994). Recently, such a bispecific molecule was synthesised: the $\mathrm{V}$-genes of MOC-31 were combined with those of an a-CD3 antibody. This diabody was capable of retargeting $\mathrm{T}$ cells to lung cancer cells in vitro [38]. Thus, the human a-EGP-2 antibody may be suitable as a building block for the generation of immunotargeting therapeutics such as immunotoxins, immunocytokines or bispecific, whole or radiolabelled antibodies.

\section{Acknowledgements}

We thank Dr Hans de Haard for his support and valuable discussions and Professor D. Herlyn for her kind gift of EGP-2. E. van der Linden and M.G.S. Kunen are acknowledged for technical support and expertise. This research was financially supported by the Netherlands Technology Foundation (S.T.W.) and was coordinated by the Earth and Life Sciences Foundation (A.L.W., project MGN55.3858, 805.17.753). N.R.W. and A.R.R. acknowledge support from the Cancer Research Campaign.

\section{References}

1. Balaban EP, Walker BS, Cox JV, Sein AA, Abrams PG, Salk D, Sheehan RG, Frenkel EP (1991) Radionuclide imaging of bone marrow metastases with a Tc-99m labeled 
monoclonal antibody to small cell lung carcinoma. Clin. Nucl. Med. 16: 732-736

2. Kosterink JG, de-Jonge MW, Smit EF, Piers DA, Kengen RA, Postmus PE, Shochat D, Groen HJ, The HT, de-Leij L (1995) Pharmacokinetics and scintigraphy of indium-111DTPA-MOC-31 in small-cell lung carcinoma. J. Nucl. Med. 36: 2356-2362

3. Frodin JE, Harmenberg U, Biberfeld P, Christensson B, Lefvert AK, Rieger A, Shetye J, Wahren B, Mellstedt H (1988) Clinical effects of monoclonal antibodies (MAb 17-1A) in patients with metastatic colorectal carcinomas. Hybridoma 7: 309-321

4. Herlyn M, Steplewski Z, Herlyn D, Koprowski H (1979) Colorectal carcinoma-specific antigen: Detection by means of monoclonal antibodies. Proc. Natl. Acad. Sci. U.S. A. 76: 1438-1442

5. Riethmüller G, Schneider-Gädicke E, Schlimok G, Schmiegel G, Raab R, Höffken K, Gruber R, Pichlmaier H, Hirche H, Pichlmayer R, Buggisch P, Witte J (1994) Randomized trial of monoclonal antibody for adjuvant therapy of resected Dukes' C colorectal carcinoma. The Lancet 343: 1177-1183

6. Dohlsten M, Abrahmsen L, Bjork P, Lando PA, Hedlund G, Forsberg G, Brodin T, Gascoigne NR, Forberg C, Lind P, Kalland T (1994) Monoclonal antibody-superantigen fusion proteins: tumor-specific agents for T-cell-based tumor therapy. Proc. Natl. Acad'. Sci. U.S. A. $91: 8945-8949$

7. Kroesen BJ, Buter J, Sleijfer DT, Janssen RAJ, Van der Graaf WTA, Hauw The T, De Leij L, Mulder NH (1994) Phase I study of intraveneously applied bispecific antibody in renal cell cancer patients recieving subcutaneous interleukin 2. Br. J. Cancer 70: 652-661

8. LeMaistre CF, Edwards DP, Krolick KA, McGuire WL (1987) An immunotoxin cytotoxic for breast cancer cells in vitro. Cancer Res. 47: 730-734

9. Zimmermann S, Wels W, Froesch BA, Gerstmayer B, Stahel RA, Zangemeister Wittke U (1997) A novel immunotoxin recognising the epithelial glycoprotein-2 has potent antitumoural activity on chemotherapy-resistant lung cancer. Cancer immunol. Immunother 44: 1-9

10. Adams GP, McCartney JE, Tai MS, Oppermann H, Huston JS, Stafford WF 3d, Bookman MA, Fand I, Houston LL, Weiner LM (1993) Highly specific in vivo tumor targeting by monovalent and divalent forms of 74IF8 anti-c-erbB-2 single-chain Fv. Cancer Res. 53: 4026-4034

11. Begent RHJ, Verhaar MJ, Chester KA, Casey JL, Green AJ, Napier MP, Hope-Stone LD, Cushen N, Keep PA, Johnson CJ, Hawkins RE, Hilson AJW, Robson L ( 1996) Clinical evidence of efficient tumor targeting based on single-chain $\mathrm{Fv}$ antibody selected from a combinatorial library. Nat. Med. 2: 979-984

12. Edwards DP, Grzyb KT, Dressler LG, Mansel RE, Zava DT, Sledge GW Jr, McGuire WL (1986) Monoclonal antibody identification and characterization of a $\mathrm{Mr} 43,000$ membrane glycoprotein associated with human breast cancer. Cancer Res. 46: 1306-1317

13. Souhami RL, Beverley PCL, Bobrow LG (1988) Proceedings of the First International Workshop on Small-Cell Lung-Cancer Antigens, Lung Cancer 4: 1-114

14. Helfrich W, Van Geel M, Hauw The T, De Leij L (1994) Detection of a putative 30-kDa ligand of the cluster-2 antigen. Int. J. Cancer Supplement 8: 70-75

15. Strassburg CP, Kasai Y, Seng BA, Miniou P, Zaloudik J, Herlyn D, Koprowski H, 
Linnenbach AJ (1992) Baculovirus recombinant expressing a secreted form of a transmembrane carcinoma-associated antigen. Cancer Res. 52: 815-821

16. Hoogenboom HR, Griffiths AD, Johnson KS, Chiswell DJ, Hudson P, Winter G (1991) Multi-subunit proteins on the surface of filamentous phage: methodologies for displaying antibody (Fab) heavy and light chains. Nucleic Acids Res. 19: 4133-4137

17. Griffiths AD, Williams SC, Hartley O, Tomlinson IM, Waterhouse P, Crosby WL, Kontermann RE, Jones PT, Low NM, John Allison T, Prospero TD, Hoogenboom HR, Nissim A, Cox JPL, Harrison JL, Zaccolo M, Gherardi E, Winter G (1994) Isolation of high affinity human antibodies directly from large synthetic repertoires. EMBO J. 13: 3245-3260

18. Clackson T, Hoogenboom HR, Griffiths AD, Winter G (1991) Making antibody fragments using phage display libraries. Nature 352: 624-628

19. Marks JD, Hoogenboom HR, Bonnert TP, McCafferty J, Griffiths AD, Winter G (1991) By-passing Immunization; Human Antibodies from V-gene Libraries Displayed on Phage. J. Mol. Biol. 222: 581-597

20. Nieba L, Krebber A, Plückthun A (1996) Competition BIAcore for measuring true affinities: large differences from values determined from binding kinetics. Anal. Biochem. 234: 155-165

21. Kabat EA, Wu TT, Perry HM, Gottesman KS, Foeller C (1991) Sequences of Proteins of Immunological Interest. U.S. Department of Health and Human Services, Public Health Services of National Institute of Health, Bethesda, p

22. Herlyn M, Steplewski Z, Herlyn D, Koprowski H (1986) CO 17-1A and related monoclonal antibodies: their production and characterization. Hybridoma 5: S3-10

23. Velders MP, van-Rhijn CM, Briaire IH, Fleuren GJ, Warnaar SO, Litvinov SV (1995) Immunotherapy with low and high affinity monoclonal antibodies $17-1 \mathrm{~A}$ and $323 / \mathrm{A} 3 \mathrm{in}$ a nude mouse xenograft carcinoma model. Cancer Res. 55: 4398-4403

24. Velders MP, Litvinov SV, Warnaar SO, Gorter A, Fleuren GJ, Zurawski VR Jr, Coney L.R (1994) New chimeric anti-pancarcinoma monoclonal antibody with superior cylotoxicity-mediating potency. Cancer Res, 54: 1753-1759

25. Fagerberg J, Steinitz M, Wigzell H, Askelöf P, Mellstedt H (1995) Human anti-idiotypic antibodies induced a humoral and cellular immune response against a colorectal carcinoma-associated antigen in patients. Proc. Natl. Acad. Sci. U. S. A. 92: 4773-4777

26. Bradbury A. Ruberti F, Werge T, Amati V, Di Luzio A, Gonfloni S, Hoogenboom HR, Piccioli P. Biocca S, Cattaneo A (1995): The Cloning of Hybridoma V Regions for Their Ectopic Expression in Itracellular and Intercellular Immunization. In: Antibody Engineering. 2nd ed. (: Borrebaeck CAK) Oxford University Press, New York, 295-362.

27. Krebber A, Bornhauser S, Burmester J, Honegger A, Willuda J, Bosshard HR, Plückthun A (1997) Reliable cloning of functional antibody variable domains from hybridomas and spleen cell repertoires employing a reengineered phage display system. J. Immunol. Methods 201: 35-55

28. Caton AJ (1986) Comparative Sequence Analysis of CO17-1A Antigen-Specific Monoclonal Antibodies, Hybridoma 5: 11-16

29. Schier R, Bye J, Apell G, McCall A, Adams GP, Malmqvist M, Weiner LM, Marks JD (1996) Isolation of high-affinity monomeric human anti-c-erbB-2 single chain Fv using affinity-driven selection. J. Mol. Biol. 255: 28-43 
30. Winter G, Griffiths AD, Hawkins RE, Hoogenboom HR (1994) Making antibodies by phage display technology. Annu. Rev. Immunol. 12: 433-455

31. Holliger P, Prospero T, Winter G (1993) "Diabodies": small bivalent and bispecific antibody fragments. Proc. Natl. Acad. Sci. U. S. A. 90: 6444-6448

32. Tai MS, McCartney JE, Adams GP, Jin D, Hudziak RM, Oppermann H, Laminet AA. Bookman MA, Wolf EJ, Liu S, Stafford III WF, Fand I, Houston LL, Weiner LM, Huston JS (1995) Targeting c-erbB-2 expressing tumors using single-chain Fv monomers and dimers. Cancer Res. 55: $5983 \mathrm{~s}-5989 \mathrm{~s}$

33. Wu AM, Chen W, Raubitschek A, Williams LE, Neummaier M, Fischer R, Hu S-Z, Odom-Maryon T, Wong JYC, Shively JE (1996) Tumor localization of anti-CEA singlechain Fvs: improved targetting by non-covalent dimers. Immunotechnology 2: 21-36

34. Kortt AA, Lah M, Oddie GW, Gruen CL, Burns JE, Parce LA, Atwell JL, McCoy AJ, Howlett GJ, Metzger DW, Webster RG, Hudson PJ (1997) Single-chain Fv fragments of anti-neuraminidase antibody $\mathrm{NC10}$ containing five and ten-residue linkers form dimers and with zero-residue linker a trimer. Protein Eng. 10: 423-433

35. Jespers LS, Roberts A, Mahler SM, Winter G, Hoogenboom HR (1994) Guiding the selection of human antibodies from phage display repertoires to a single epitope of an antigen. Biotechnology 12: 899-903

36. Helfrich W, Kroesen BJ, Roovers RC, Westers L, Molema G, Hoogenboom HR, de Leij $\mathrm{L}$ (1998) Construction and characterization of a bispecific diabody for retargeting T cells to human carcinomas. Int. J. Cancer 76: 232-239

37. Go N, Sheraga HA (1970) Ring closure and local conformational deformations of chain molecules. Macromolecules 3: 178-185

38. Connolly ML (1983) Analytical molecular surface calculation. J. Appl. Crystallog. 16: $548-554$ 


\section{Chapter 6}

\section{In vitro characterisation of a monovalent and bivalent form of a fully human anti Ep-CAM phage antibody}

Rob C. Roovers, Edith van der Linden, Adriaan P. de Bruïne, Jar-Willem Arends and Hennie R. Hoogenboom

Cancer Immunol. Immunother, accepted for publication 


\begin{abstract}
Antibodies to tumour-associated antigens are increasingly being used as targeting vehicles for the visualisation and also therapy of human solid tumours. The Epithelial cell adhesion molecule (Ep-CAM) is an antigen that is overexpressed on a variety of human solid tumours and constitutes an attractive target for immunotargeting. We have set out to obtain fully human antibodies to this antigen by selection from a large antibody repertoire displayed on bacteriophage. Two single-chain variable antibody fragments (scFv) were identified that specifically bound recombinant antigen in vitro. One of the selected antibodies (VEL-1) crossreacted with extracellular matrix components in immunohistochemistry of colon carcinoma, whereas the other scFv (VEL-2) specifically recognised coion cancer cells. The latter antibody was further characterised with respect to epitope specificity and kinetics of antigen-binding. It showed no competition with the well-characterised anti Ep-CAM MOC-31 monoclonal antibody and had an off-rate of $5 \times 10^{-2} \mathrm{~s}^{-1}$. To obtain an antibody format more suitable for in vivo tumourtargeting and to increase the apparent affinity through avidity, the genes of scFv VEL-2 were reformatted by fusion to a human $(\gamma \mathrm{l})$ hinge region and $\mathrm{CH} 3$ domain. This "minibody" was expressed in E.coli, specifically bound the Ep-CAM antigen and showed a 20-fold reduced offrate in surface plasmon resonance (SPR) analysis. These results show that phage antibody selection, combined with antibody engineering may result in fully human antibody molecules with promising characteristics for in vivo use in tumour targeting.
\end{abstract}

\title{
Introduction
}

During malignant transformation, a number of cellular (self-) antigens is upregulated or mutated, providing targets for immunotherapy of human cancer. The Epithelial Cell Adhesion Molecule (Ep-CAM, also known as EGP-2, EGP40, KSA, CO17-1A antigen or GA733-2 antigen) is a type I transmembrane glycoprotein which is abundantly expressed on a variety of human carcinomas, notably on colorectal carcinoma (CRC). The protein is present on almost all cell types derived from the ectoderm and endoderm germlineages [1] and has been reported to function as an intercellular adhesion molecule [2]. Recently, Ep-CAM was shown to modulate cadherin-based intercellular junctions, causing a redistribution of E-cadherin and catenins and a downregulation of $\alpha$-catenin in transfected L-cells and epithelial cells [3]. This suggests a role for the antigen in tumour metastasis: increased expression of Ep-CAM may lead to a decrease of the number of cadherin-based junctions, thereby possibly destabilising intercellular contacts and promoting metastasis (for review, see [4]). In CRC, adenomas show a low, heterogeneous expression of the antigen, whereas carcinomas are found to be homogeneously positive [5], providing the antigen with an essential characteristic for use as target in immuno-targeting. In 
addition, it is not shed into the circulation [6], which further increases its usefulness.

Ep-CAM has been widely used as a target for immunotargeting of solid tumours. In most clinical trials, murine monoclonal antibodies have been used, either for visualisation $[7,8]$, or for treatment [9-12]. However, the therapeutic use of most murine antibodies in humans is limited by the induction of a HAMA (human anti-mouse antibody; [13]) response. And although part of this response may consist of an anti-idiotype antibody network which is expected to augment the therapeutic effect, the induction of this cascade has been reported not to correlate with the response of patients treated with the 17-1A anti-Ep-CAM antibody [14]. On the other hand, therapeutic strategies designed on anti idiotype antibodies and the induction of the antiidiotype network have been shown to induce clinical responses [15-17].

To partially overcome the problems inherent to the use of murine antibodies in humans, chimeric and humanised versions of murine antibodies to Ep-CAM have been developed [18, 19]. To date, only very few fully human antibodies have been described that recognise the native antigen [20,21].

Therefore, to improve on existing modalities for antibody targeting of Ep-CAM expressing solid tumours, we have used the power of phage display to select fully human antibodies to the antigen. From a large, non-immune single-chain Fv (scFv) phage antibody repertoire [22], two clones were selected that recognised recombinant antigen in virro. However, one of these antibodies also reacted with extracellular matrix components in immunohistochemistry of colon carcinoma, which made the antibody unsuited for in vivo use. The second antibody specifically bound the antigen in several in vitro tests, but showed a relatively fast dissociation rate in kinetic analysis. Therefore, to improve the apparent affinity by means of avidity and to obtain a suitable antibody format for in vivo use, the genes of scFv VEL2 were re-formatted as minibody. This fully human VEL-2 minibody is shown to be a promising candidate for further evaluation as tumour-targeting vehicle.

\section{Materials and Methods}

\section{E.coli strain}

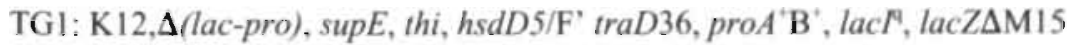

\section{Phage antibody selection on recombinant Ep-CAM}

A large phage antibody repertoire in scfv format [22] was used for selection. The library was rescued with helper phage M13K07 and phages were panned for binding to antigen. Two selection methods were used: panning on antigen coated to immunotubes ( [23]), or panning on 
biotinylated antigen in solution ( $100 \mathrm{nM}$ concentration), followed by retrieval on streptavidin coated magnetic beads, as described ( [24]). Three selection rounds were performed on purified, recombinant, baculovirus-expressed Ep-CAM ( [25]; a kind gift of Prof. D. Herlyn, the Wistar Insitute, Philadelphia, Pennsylvania, U.S.A.). After the second and third round of selection, individual clones were tested for binding to antigen in ELISA.

\section{ELISA and competition ELISA}

Individual bacterial clones were picked and expression of soluble scFv fragments was induced by activation of the upstream LacZ promotor with isopropyl- $\beta$-D galactopyroside (IPTG) as described [23]. The assay is further described by Roovers et al. [26]. Recombinant minibody was detected with a polyclonal antiserum to human Fc regions (Jackson ImmunoResearch Laboratories, West Grove, Pennsylvania, U.S.A.: $0.1 \%(\mathrm{v} / \mathrm{v}))$ and peroxidase-conjugated rabbit anti goat immunoglobulines (Dako, Glostrup, Denmark: $0.1 \%(\mathrm{v} / \mathrm{v})$ ). Staining was performed as described [26].

For competition experiments, individual clones were rescued with helper phage M13K07 as described [23]. Phages expressing the respective scFv were then mixed with a 10-fold molar excess of MOC31 monoclonal antibody [27] or an irrelevant control antibody (the $\mathrm{Ki}-4$ antiCD30 antibody: [28]) and added to antigen-coated wells. Phages were then detected with a polyclonal sheep antiserum to fd phage (Pharmacia, Uppsala, Sweden) and peroxidaseconjugated rabbit anti goat immunoglobulines (Dako). Staining was performed as described [26].

Analysis of antibody binding to cell surface-expressed antigen by means of flow cytometry

Colorectal cancer cell line CaCo2 (ATCC number HTB37) was cultured in Dulbecco's Modification of Eagle's Medium. (DMEM; Dulbecco, Life Technologies) supplemented with. $10 \%(\mathrm{v} / \mathrm{v})$ fetal calf serum and $2 \mathrm{mM}$ glutamine at $37^{\circ} \mathrm{C}$ in a humidified atmosphere containing $5 \%(\mathrm{v} / \mathrm{v}) \mathrm{CO}_{2}$. Cells were harvested by a short treatment with trypsin/EDTA, washed in phosphate buffered saline (PBS) and aliquots of approximately 500,000 cells. were made in polystyrene FACSscan tubes (Falcon: Becton \& Dickinson, Heidelberg, Germany). All incubations were carried out during one hour at $\mathrm{rt}$ in $2 \%(\mathrm{w} / \mathrm{v})$ skimmed milk powder (Marvel) in PBS, containing $0.05 \%(\mathrm{w} / \mathrm{v}) \mathrm{NaN}_{3}\left(2 \% \mathrm{MPBS} / \mathrm{N}_{3}\right)$. Three washes, each consisting of centrifugation of the cells $\left(400 \mathrm{~g}, 3^{\prime}, \mathrm{rt}\right)$ and resuspension in $1 \mathrm{ml}$ of $2 \% \mathrm{MPBS} / \mathrm{N}$, were performed between every incubation step. Cells were stained with recombinant scFv fragments (approximately $100 \mu \mathrm{g} / \mathrm{ml}$ concentration), the $9 \mathrm{E} 10$ monoclonal antibody [29], directed to the Cterminal c-myc-derived epitope tag $\left(0.1 \%(\mathrm{v} / \mathrm{v})\right.$ in $\left.2 \% \mathrm{MPBS} / \mathrm{N}_{3}\right)$ and FITC-labeled rabbit antimouse immunoglobulines (Dako, Glostrup, Denmark; $2 \%(\mathrm{v} / \mathrm{v})$ in $2 \%$ MPBS $/ \mathbb{N}_{3}$ ). Finally, cells were washed three times with $2 \% \mathrm{MPBS} / \mathrm{N}_{3}$, once with PBS, resuspended in $500 \mu \mathrm{l}$ PBS and 
analysed by flow cytometry using a FACS-Calibur (Becton \& Dickinson, Heidelberg, Germany). Data were analysed using the Cellquest software program (Becton \& Dickinson, Heidelberg, Germany).

\section{Table 1}

Primer sequences

\begin{tabular}{|c|c|}
\hline Name & Sequence \\
\hline CL-ASS-BACK & 5-TAA TAA GGC GCG COC GGT GGA GGC GGT AAT TCT ATT TCA AGG AGA CAG T.J \\
\hline Hinge-CH1-FOR & 5-CCA CCG CAC GGT GGG CAT GTG TGA GT TTG TCA CAA GAT TTG GGC TCA AC-3' \\
\hline $\begin{array}{l}\text { Hinge-L-CH3- } \\
\text { BACK(1) }\end{array}$ & $\begin{array}{l}\text { 5.-CAC ACA TGC CCA CCG TGC GGT GGA GOC GGT TCA GGC GGA GGT GGC TCT GGG } \\
\text { CAG CCC CGA GAA CCA CAG G-Y }\end{array}$ \\
\hline His6-CH3-FOR & $\begin{array}{l}\text { 5.TTC TCG ACT GAA TTC TTA TTA GTG ATG GTG ATG ATG ATG TT ACC CGG AGA CAG } \\
\text { GGA GAG-3. }\end{array}$ \\
\hline $\begin{array}{l}\text { Hinge-L-CH3- } \\
\mathrm{BACK}(2)\end{array}$ & 5.TTC TCG ACT GCG GCC GCA GAC AAA ACT CAC ACA TGC CCA.J \\
\hline M13-FOR & 5:-CGC CAG GGT TTT CCC AGT CAC GAC-3' \\
\hline
\end{tabular}

Cloning of an engineered minibody

PCR was performed using Expand ${ }^{\mathrm{TM}}$ High Fidelity Taq polymerase (Boehringer Mannheim, Mannheim, Germany) together with the buffer supplemented by the manufacturer in a. $50 \mu \mathrm{l}$ reaction containing $1,25 \mathrm{mM} \mathrm{MgCl}, 250 \mu \mathrm{M}$ of each of the 4 different desoxyribonucleoside triphosphates (dATP, dTTP, dCTP, dGTP), 500pM of both primers (BACK and FOR), 100pg of DNA template and $0.1 \mathrm{U}$ of DNA polymerase. PCR was performed by 25 cycles of $\left(94^{\circ} \mathrm{C}, 45 \mathrm{sec} ; 55^{\circ} \mathrm{C}, 45 \mathrm{sec}\right.$ and $\left.72^{\circ} \mathrm{C}, 1 \mathrm{~min} .30 \mathrm{sec}\right)$ and products were analysed by agarose gel electrophoresis with ethidium bromide staining using standard techniques [30].

The human $(\operatorname{IgG} 1) \mathrm{CHI}$ gene, present in vector pCESI [31] was amplified with primers CL-ASS-BACK and Hinge-CHI-FOR (Table 1), which introduces the human IgGI hinge region at the $3^{\prime}$ end of the $\mathrm{CH} 1$ gene. The human (IgGl) $\mathrm{CH} 3$ gene was amplified from vector $\mathrm{VH}$ Express [32] with primers Hinge-L-CH3-BACK(1) and His6-CH3-FOR (Table 1). This introduces part of the hinge region and a flexible (Gly Ser) ${ }_{2}$ linker at the 5 ' end of the $\mathrm{CH}_{3}$ gene and a hexa-histidine (His6) tag, two stop codons and an EcoRI restriction site for cloning at the 3' end of the $\mathrm{CH} 3$ gene. Both fragments (CHI-Hinge and Hinge-L-CH3-His6) were purified from the PCR mix with the Wizard PCR prep purification kit (Promega, Madison, U.S.A.). Approximately $75 \mathrm{ng}$ of both DNA fragments, were then joined using 10 cycles of Splice Overlap Extension PCR (SOE-PCR: [33]) without primers and re-amplified by 20 cycles using outer 
primers (CL-ASS-BACK and His6-CH3-FOR). The re-amplified PCR product was then purified from the reaction mixture using the Wizard PCR prep purification kit, cut with the restriction enzymes EcoRI and BstEII and ligated into pCES1, thereby replacing the bacteriophage gene III and creating vector $\mathrm{PCESI/CH}$.

To synthesise a minibody of scFv VEL-2, the human IgG1 hinge region, linker sequence and $\mathrm{CH} 3$ domain, present in $\mathrm{pCES1} / \mathrm{CH} 3$, were amplified with primers Hinge-L-CH3-BACK(2) and M13-FOR (Table 1). This introduces a Not 1 restriction site at the 5 ' end of the hinge region and removes the first five residues ('EPKSC' amino acid sequence) of this domain. The PCR product was cut with restriction enzymes NotI and EcoR! and cloned into pCANTAB6 [34], creating $\mathrm{PC} 6 / \mathrm{CH}$. This removes the bacteriophage gene III from the vector. Antibody $\mathrm{V}$-genes of VEL-2 in scFv format were excised from plasmid DNA of VEL-2/pCANTAB6 using restriction sites $\mathrm{Sfil}$ and $\mathrm{Not}$ and cloned into $\mathrm{PC} 6 / \mathrm{CH} 3$, resulting in minibody VEL-2. Both vectors $\mathrm{pCES1} / \mathrm{CH} 3$ and $\mathrm{PC} 6 / \mathrm{CH} 3$ were sequenced using the dideoxy chain termination method [35] to ensure that no mutations were introduced in the genes due to amplification.

\section{Production and purification of soluble antibody fragments}

For large-scale purification, the selected scFv antibody fragment VEL-2 was re-cloned in an expression vector lacking the bacteriophage gene III (as Sfi I / Not I fragment in pUCI19polyliis6MYC, a kind gift of Dr. Andrew Griffiths, MRC Laboratory of Molecular Biology, Cambridge, U.K.) This method ensures less toxicity to the E.coli host due to expression of the bacteriophage gene III during induction and thus a higher yield of protein. Production of soluble scFv and minibody fragments and purification from the E.coli periplasmic space using immobilised metal ion affinity chromatography (IMAC) and fast protein liquid chromatography (FPLC) were performed as described for scFv by Roovers et al. [26].

\section{Western blotting}

Atter purification of recombinant minibody fragment, different samples were analysed by means of SDS-polyacrylamide gel electroforese (SDS-PAGE; [36]). Samples were either dissolved in reducing loading buffer (containing dithiothreitol: DTT) or in non-reducing loading buffer (lacking DTT) and loaded onto a 10\% (w/v) polyacrylamide gel. Proteins were separated according to size, electroblotted to nitrocellulose using standard techniques [30] and blots were dried on air. Minibody was then visualised with a polyclonal antiserum to human Fc regions (Jackson ImmunoResearch Laboratories, West Grove, Pennsylvania, U.S.A.: 0.1\%(v/v/)) and peroxidase-conjugated rabbit anti goat immunoglobulines (Dako: $0.1 \%(\mathrm{v} / \mathrm{v})$ ). Staining was performed with diaminobenzidine $\mathrm{H}_{2} \mathrm{O}_{2}$. 
Kinetic measurement using SPR with BlAcore technology

To determine the kinetics of binding of different antibody fragments, recombinant EpCAM [25] was covalently coupled to a CM5 sensor chip via amine coupling, resulting in an antigen surface of 900 resonance units (RU). IMAC- (and for ScFv: FPLC-) purified antibody fragments were then run over the surface at high $(20 \mu \mathrm{l} / \mathrm{min})$ flow rate to saturation of binding. From the obtained sensorgrams, off-rates were determined by curve-fitting on the first $10 \mathrm{sec}$. of the dissociation phase using the BIAevaluation (version 2) software (Pharmacia, Uppsala, Sweden).

\section{Immunohistochemical analysis of antibody specificity}

Cryosections of different tissues (normal colonic epithelium and colon carcinoma) were cut and mounted on 3-aminopropyl-2-ethoxysilane (APTS-) coated glass slides. Sections were subsequently stained with recombinant antibody fragments, an antibody to the hexaHistidine tag (SeroTec, Raleigh, U.S.A.; 0.1\% (v/v)) and peroxidase-conjugated rabbit anti mouse antibodies essentially as described [26].

\section{Results}

Selection and in vitro characterisation of human anti Ep-CAM scFv antibodies

We set out to select fully human antibodies to the tumour antigen Ep-CAM for the purpose of inmmunotargeting of human cancer. To this aim, we first performed phage antibody selections on recombinant antigen coated in immunotubes, using a large, non-immunised single chain Fv (scFv) phage antibody library [22]. After three and four rounds of selection, individual clones were picked and DN/A-fingerprinted as described [23]. One predominant clone was found (data not shown) and selected for further analysis. Soluble scFv was then expressed as described [37], and shown to specifically recognise recombinant antigen in ELISA (Fig. 1).

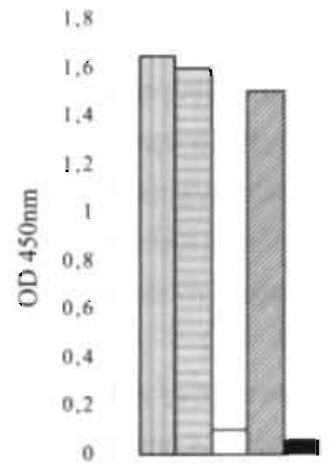

Ep-CAM

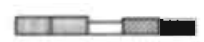

Tet. Tox

\section{Figure 1}

Specificity ELISA of recombinant antibody fragments

ScFv VEL-1 (vertically striped bars), scFv VEL-2 (horizontally striped bars) and minibody VEL-2 (diagonally striped bars) were tested on the antigens Ep-CAM (epithelial cell adhesion molecule) Tet Tox. (tetanus toxoid) and BSA (bovine serum albumin). Negative controls for scFv (open bars) and minibody (solid black bars) are also indicated.

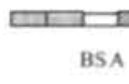


However, when the antibody was used to stain cryosections of primary colorectal carcinoma, staining of fibroblasts and extraceliular matrix components was also observed, apart from the (expected) epithelial cell reactivity (Fig. 2).

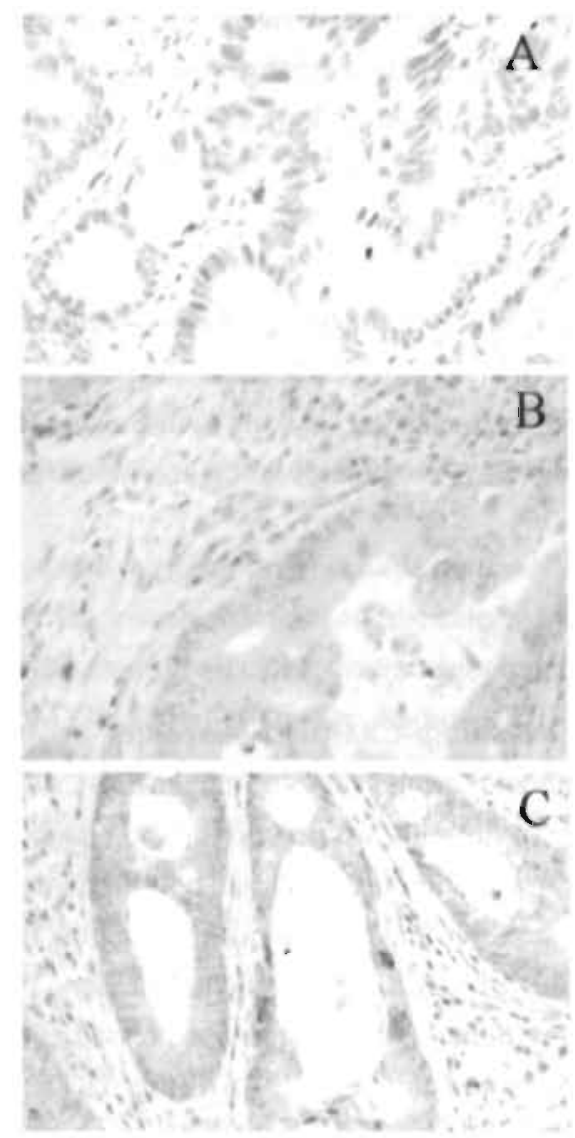

\begin{abstract}
Figure 2
Immunohistochemical analysis of selected human antibody fragments

Staining of primary colorectal carcinoma with $\mathrm{A}$ ) an irrelevant: $\mathrm{scFv}$ as negative control; B) clone scFv VEL-I and C) clone scFv VEL-2. Bound antibody fragments were detected with the $9 \mathrm{E} 10$ antibody and peroxidase-conjugated rabbit anti-mouse immunoglobulines.
\end{abstract}

When the epitope specificity of the scFv fragment was compared to that of the well-characterised MOC-31 antibody [27] in a competition ELISA, clone VEL-1 did not compete with this antibody (data not shown). Measurement of the kinetics of antigen binding of ScFV VEL-1 was performed using surface plasmon resonance (SPR) in a BlAcore. The off-rate of the monomeric scFv was measured to be $8.4 \times 10^{-3} \mathrm{~s}^{-1}$ under the conditions used (Table 2). To

further characterise the epitope recognised by the VEL-1 antibody, the Ep-CAM antigen was treated with $\mathrm{NaIO}_{4}$ (as described by [38]), which cleaves carbohydrate vicinal hydroxyl groups under mild acidic pH [39]. The reactivity of scFv VEL-1 with the antigen in ELISA was slightly inhibited by $\mathrm{NaIO}_{4}$-treatment (data not shown), revealing that the epitope recognised by this selected antibody fragment could be partially composed of a carbohydrate structure. This may explain (part of the) cross-reactivity with different cell types and extracellular stroma, observed in immunohistochemical analysis (Fig. 2).

To possibly overcome the problem of selecting antibodies to cross-reactive epitopes of the Ep-CAM antigen, which may be caused by the partial denaturation of the antigen upon 
coating the antigen to immunotubes, a different selection procedure was chosen. Selections were performed on biotinylated antigen in solution using retrieval with streptavidin-coated magnetic beads [24]. Again, one predominant clone was found after three rounds of selection, as determined by DNA-fingerprint analysis (data not shown). This ScFv (VEL-2) was also shown to specifically recognise the Ep-CAM antigen in ELISA (Fig. 1). In addition, it specifically stained Ep-CAM positive epithelial tumour cells in immunohistochemical analysis of primary colorectal carcinoma; it did not show the cross-reactivity observed with scFv VEL-1 (Fig. 2). However, the off-rate of the monovalent ScFv was higher than that of the VEL-1 antibody: $5.0 \times 10^{-2} \mathrm{~s}^{-1}$ (Table 2).

\section{Table 2}

Characteristics of the binding kinetics of selected anti Ep-CAM antibodies

\begin{tabular}{l|c|c}
\hline Antibody: & $\mathrm{k}_{\text {off }}+/ \cdot \operatorname{SE}\left(10^{-3} \mathrm{~s}^{-1}\right)$ & $\mathrm{t}_{1 / 2}(\mathrm{~s})^{*}$ \\
\hline VEL-1 scFv & $8.4+/-0.145$ & 83 \\
VEL-2 scFv & $50+/-4$ & 14 \\
Minibody (VEL-2) & $2.2+/-0.3^{* *}$ & 315 \\
MOC-31 scFv & $0.34+/-0.05$ & 2039 \\
\hline
\end{tabular}

$\mathrm{t}_{1 / 2}$ calculated as $\mathrm{t}_{1 / 2}=\ln 2 / \mathrm{k}_{\text {off }}$

" apparent (bivalent) dissociation rate constant

For comparison: the off-rate of the high affinity monovalent MOC31 scFv has been reported to be $3.4 \times 10^{-4} \mathrm{~s}^{-1}$ [26] (Table 2). As was determined for the VEL-I antibody, the VEL2. scFv did not cross-react with the MOC-3! antibody in competition ELISA (data not shown). In addition, the reactivity of the VEL-2 antibody was not affected by $\mathrm{NaIO}_{4}$ treatment of the EpCAM antigen (data not shown), showing that the epitope recognised is most probably composed of a protein sequence. The amount of scFv purified from E.coli was measured to be between 100 and $200 \mu \mathrm{g}$ per liter of bacterial culture.

Sequencing of the V'-genes of both ScFv's VEL-1 and VEL-2 and alignment of the genes to their closest germile V-segment using V-base thttp://www.mrc-cpe.cam.ac.uk/imt-doc /restricted/DNAPLOT.html) revealed that they originated from commonly used VH and VL gene families: the VH- and VL-gene of scFv VEL-I are both derived from the largest VH (VH3) and $\mathrm{V} \lambda$ (V $\lambda 3$ 3) V-gene families (Table 3). Only a few mutations were found in the non primerencoded $\mathrm{VH}$-gene segment and the $\mathrm{V} \lambda$ gene showed no mutations at all (Table 4). Mutations in the VH gene were largely confined to the CDR1, except for two mutations in FR3 $(E(85) \rightarrow G$ and $\mathbf{K}(94) \rightarrow \mathrm{R}$ ). The observed mutations in $\mathrm{V} \lambda$-CDR3 are probably due to the $\mathrm{J}$-segment usage and 
junctional diversity (Table 3 and 4).

\section{Table 3}

Germline segment usage of selected anti Ep-CAM antibodies:

\begin{tabular}{c|c|c|c|c|c}
\hline & & V-gene & & & \\
Antibody & V-gene & family & Used V-segment & Used D-segment & Used J-segment \\
\hline VEL-1 & VH & VH3 & DP-47/V3-23 & D6-25 & JH3a \\
VEL-1 & VL & V $\lambda 33$ & DPL16/VL3.1 & n.a. & J $\lambda 2 / \mathrm{J} \lambda 3 \mathrm{a}$ \\
VEL-2 & VH & VH1 & DP-7/21-2 & D6-19 & JH3b \\
VEL-2 & VL & V $\lambda 33$ & DPL16/VL3.1 & n.a. & J $\lambda 2 / \mathrm{J} \lambda 3 \mathrm{a}$ \\
\hline
\end{tabular}

'n.a. not applicable

The V-genes of scFv VEL-2 belonged to the VHI and V $\lambda 3$ V-gene families (Table 3). Strikingly, the VH gene of seFv VEL-2 is different from that of scFv VEL-1, but the VL gene shows a marked homology to that of scFv VEL-1. Both VL genes are derived from the same germline V $\lambda$ segment, show no mutations compared with this segment, but have a different CDR3 (Table 4). In addition, both VL genes also use the same J-segment (J $\lambda 2 / \mathrm{J} \lambda 3 \mathrm{a}$ : Table 3$)$. The $\mathrm{VH}$ gene of scFv VEL-2 also shows no mutations compared with the germline V-segment (Table 4).

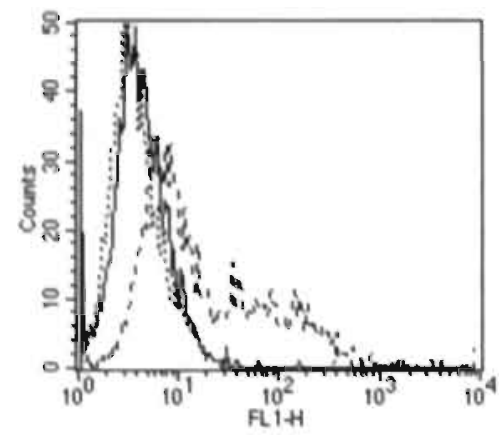

\begin{abstract}
Figure 3
Flow cytometric analysis of antibody binding to the $\mathrm{CRC}$ cell line $\mathrm{CaCo} 2$ Number of events (counts) as function of the fluorescence intensity of the cells (FL1H). Thin line: negative control; dotted line: scFv VEL-1 and striped line: ScFv VEL-2.
\end{abstract}

Finally, both scFv antibodies were tested for their ability to bind to cell surface-expressed antigen by means

of flow cytometry and only scFv VEL-2 was shown to recognise the Ep-CAM positive CRC cell line $\mathrm{CaCo} 2$ (Fig. 3). This made only the VEL-2 antibody suitable for development as vehicle to target Ep-CAM positive malignancies. 


\section{Synthesis and characterisation of a bivalent minibody of the anti Ep-CAM scFv VEL-2}

To increase the apparent affinity of the specific anti Ep-CAM scfv VEL-2 through avidity and to obtain a suitable antibody format for use in in vivo targeting of tumours, the "minibody" format [40] was chosen. In this format, the scFv cassette is genetically linked to a human hinge region, a flexible peptide linker and human $\mathrm{CH}_{3}$ domain that causes dimerisation of the monovalent scFv moiety. In addition, it causes an increase of the molecular weight to approximately $90 \mathrm{kDa}$, which is a suitable size for radio-immuno imaging purposes using the commonly used ${ }^{90 \cdot T} \mathrm{Tc}$ radionuclide [41]. The VEL-2 scFv was linked to an engineered human IgGl hinge region that was truncated at the 5 ' end of the gene, as described by Alt et al. [42]. In contrast to the sequence originally described by Hu et al. [40], the first five amino acid residues 'EPKSC' were omitted to avoid the presence of an unpaired cysteine in the final construct (Fig. 4). In addition, three extra alanine residues were introduced between the C-terminus of the VL domain and the $\mathrm{N}$-terminus of the hinge region, to encode the Not restriction site (Fig. 4).

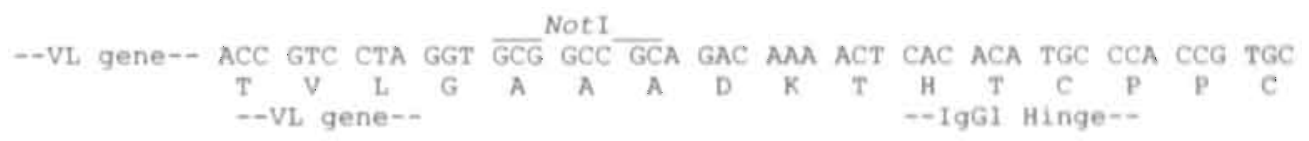

GGT GGA GGC GGT TCA GGC GGA GGT GGC TCT GGG CAG CCC CGA --IgG1 CH3 gene--

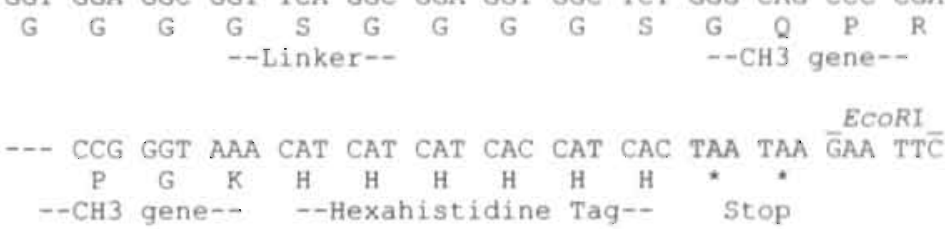

\section{Figure 4}

Features of minibody $V E L-2$

Nucleotide sequence and aminoacid translation of the engineeredscFv-Hinge-L-CH3 region and $\mathrm{C}$-terminal region of the $\mathrm{CH} 3$ domain. The construct contains a C-terminal hexahistidine (H6) tag for Immobilised Metal ion Affiniy Chromatography (IMAC).

Expression of this cassette in E.coli resulted in dimeric molecules of the expected molecular weight $(+/-90 \mathrm{kDa})$, as determined by Western blotting using a polyclonal anti human $\mathrm{Fc}(\gamma)$ specific serum (Fig. 5). Under reducing conditions, a $45 \mathrm{kDa}$ band was found, corresponding to the scFv-hinge-linker-CH3 cassette and a $15 \mathrm{kDa}$ band, corresponding to free $\mathrm{CH} 3$ domains. This indicated that proteolytic cleavage occurred in the linker between the seFv moiety and $\mathrm{CH} 3$ domain. Under non-reducing conditions, several bands were found that corresponded to various degradation products of the minibody (Fig. 5). Most probably due to its; 
increased size, the expression level of minibody VEL-2 was only between 50 and $100 \mu \mathrm{g}$ per liter bacterial culture. Minibody VEL-2 bound avidly to antigen, as witnessed by the off-rate of this antibody format which was reduced by a factor of approximately 20 compared with the parental scFv $\left(2.2 \times 10^{-3} \mathrm{~s}^{-1}\right.$ versus $50 \times 10^{3} \mathrm{~s}^{1}$ : Table 2$)$ in SPR analysis. As expected, it bound specifically to the Ep-CAM antigen in ELISA (Fig. 1) and immunohistochemistry, showing a staining pattern comparable to that of the VEL-2 scFv (Fig. 2). Furthermore, by using a human Fc-specific antiserum as detecting antibody in ELISA, the physical link between the scFv moiety and Fc tail (CH3 domains) could be demonstrated (Fig. 1). As was shown for the scFv, minibody VEL-2 also recognised cell-surface expressed Ep-CAM antigen, demonstrated by flow cytometric analysis using the $\mathrm{CaCo} 2$ cell line (data not shown).

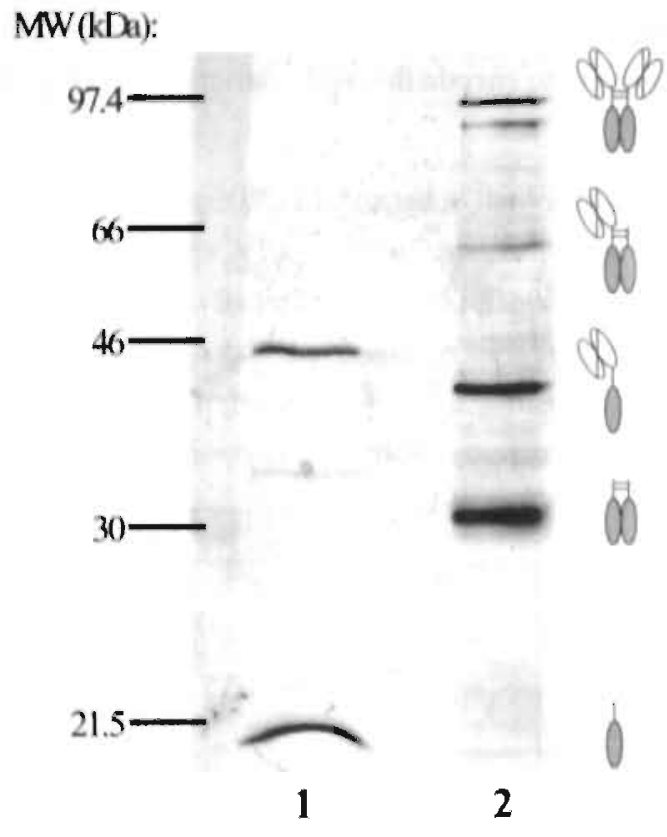

\section{Figure 5}

Analysis of minibody expression by means of Western blotting IMAC-purified VEL-2 minibody was loaded onto a $10 \%(\mathrm{w} / \mathrm{v})$ polyacrylamide gel in either reducing (lane 1) or non-reducing (lane 2) loading buffer. Proteins were separated according to size. blotted to sitrocellulose and visualised by means of a polyclonal goat antiserum to human $\mathrm{Fc}$ regions, peroxidase-conjugated rabbbit anti goat immunoglobulines and staining with $\mathrm{DAB} / \mathrm{H}_{2} \mathrm{O}_{2}$. Molecular weight markers are indicated on the left. Antibody formats corresponding to the respective bands are depicted on the right. Open ovals: VH and VL domain of scFv moiety: horizontally striped ovals: $\mathrm{CH} 3$ domains.

\section{Discussion}

To improve on existing modaities for immunotargeting of solid tumours expressing the Ep-CAM antigen, we have used phage display to select fully human antibody fragments specific for the antigen. Two different selection procedures were used to obtain anti Ep-CAM antibodies: whereas panning on antigen coated in immunotubes only resulted in an antibody that crossreacted with extracellular matrix components, selection on biotinylated antigen in solution did 
result in a specific anti Ep-CAM scFv. Since this scFv antibody showed a relatively fast dissociation rate from antigen and since the scFv antibody format is not optimal for use in in vivo tumour targeting, the genes of scFv VEL-2 were re-formatted into the minibody format. This engineered minibody was expressed in E.coli, showed specific binding to antigen in several in vitro tests and had a markedly reduced off-rate compared with the parental scFv. Therefore, this fully human minibody is a promising candidate for further evaluation as tumour targeting vehicle.

In agreement with a recent report [20], we were unable to select an antibody that was truly specific for the Ep-CAM antigen by panning a large phage antibody library [22] on recombinant antigen coated in immunotubes. This selection procedure may have the disadvantage of selecting antibodies directed to otherwise cryptic epitopes of an antigen that may become exposed upon coating the protein in immunotubes. In this respect it is noteworthy that the VEL-1 and VEL-2 scFv antibodies differ mostly in their VH domain and use very similar VL domains (Table 3 and 4). This emphasises the importance of the VH domain for the exact epitope specificity, a phenomenon that has also been noted by others [21].

It is surprising that neither the VEL-1, nor the VEL-2 antibody compete with the MOC-31 murine anti Ep-CAM antibody. Most of the well-characterised anti Ep-CAM antibodies made via the hybridoma technology (e.g. 17-1 A: [43]; 323/A3: [44] and MOC-31: [27]) all recognise an overlapping epitope on the antigen that is apparently immunodominant in vivo but is not targeted during in vitro phage antibody selection. However, this possibility of selecting antibodies directed to non-immunogenic epitopes of an antigen is a known feature of the phage display technology $[45,46]$ and is not uncommon. Whether the epitope specificity of the anti Ep-CAM antibody VEL-2 will have an effect on its in vivo targeting properties remains to be determined.

The off-rates of the scFv fragments we measured are typical for phage antibodies selected from large, non-immunised repertoires $[22,31,47]$, except for the VEL-2 scFv (Table 2). It may seem surprising that this scFv was selected, despite of its relatively fast off-rate. This may be explained by multivalent expression on phage, even in the phagemid system used, which compensates the fast off-rate through rebinding (avidity).

Since there is a clear correlation between the off-rate of an antibody and its in vivo tumour targeting [48] performance and since differences in off-rate measured by SPR in al BIAcore can be correlated with different retention times on the surface of tumour cells [48], we decided to improve the apparent affinity of scFv VEL-2 for the Ep-CAM antigen by increasing the valency of the molecule. Indeed, the off-rate of the VEL-2 minibody was approximately 20 -fold lower than that of the VEL-2 scFv (Table 2). 


\section{Table 4}

$V$-segment alignments of selected $V$-genes and their closest germline match

I. VH sequences:

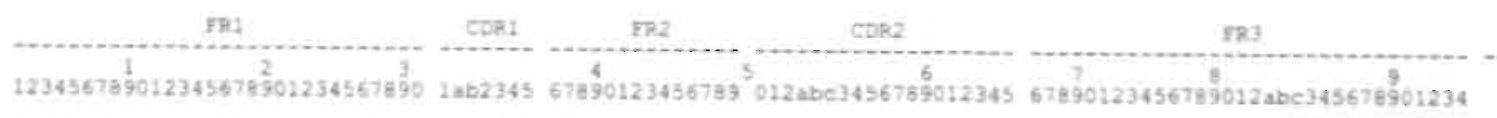

COR3

res

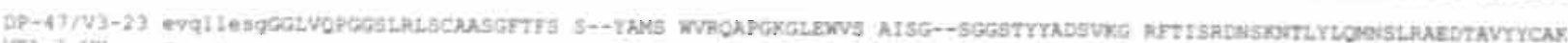

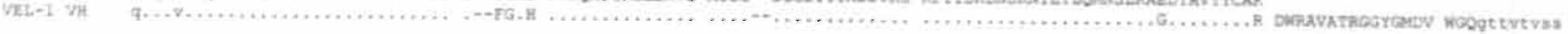

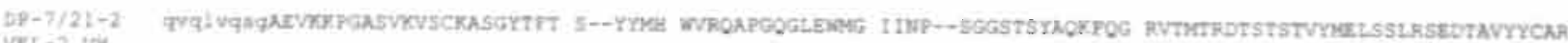

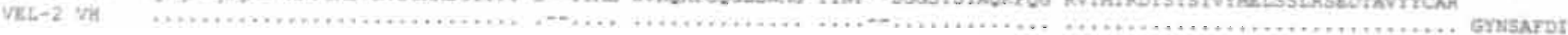

Cymisampt

\section{2. $V \lambda$ sequences}

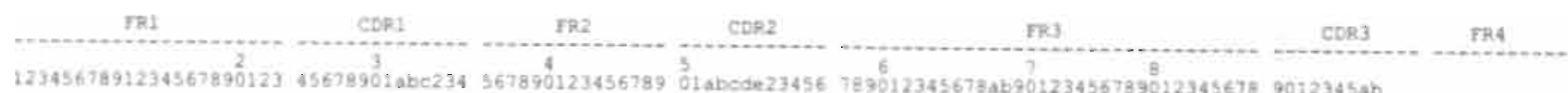

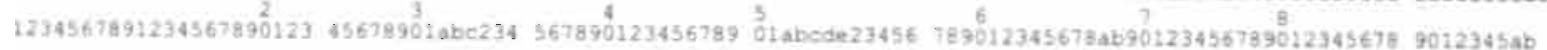

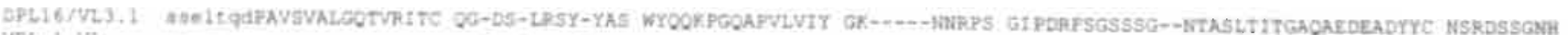

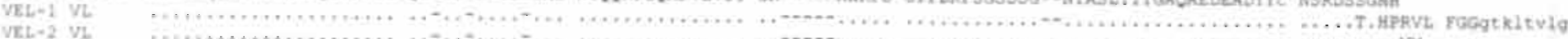

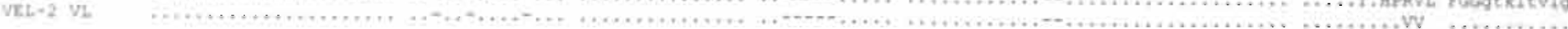

Primer-encoded sequences are indicated with lower case letters. 
This effect of bivalency is in good agreement with what has been r eported for the C6.5 scFv antibody directed to the c-erB-2 antigen [49], but is larger than the avidity effect reported for triabodies [50, 51]; for review, see [52]. Although this effect of multivalency heavil y depends on the particular antibody used and on the density of the target antigen on the cel I surface, the flexibility of both antigen-binding sites in a minibody will increase the likelihoo d of rebinding of one arm when the other has dissociated from antigen, which may partially explai n these contradictory data.

As judged by Western blotting using non-reducing conditions, not all of the expresse $d$ minibody was disulphide-bridged (Fig. 4), but the majority (approximately $60-70 \%$ ) of the product contained one or two s-s bridges between the two chains. Proteolysis of the minibod $y$ was evident and was mostly confined to the flexible linker between the scFv moiety and $\mathrm{CH} 3$ domain (Fig. 4). This constitutes a problem for the synthesis of protein to be used in in vivo tumour targeting studies. However, this may be solved by c hoosing a protease-deficient E.coli strain for expression, or by expressing the genes in a suitable eukaryotic expression system [40]

The different epitope specificity of the VEL-2 antibody compared with that of most of the murine anti Ep-CAM antibodies offers possibilities for the design and engineering of targeting molecules directed to the Ep-CAM antigen. We have recently reported on the successfu I cloning and humanisation of the murine MOC-31 antibody $[21,26]$. The combination of bot $h$ of these specificities into one molecule to develop a chelating antibody or "CRAb" [53] would significantly enlarge the targeting potential of these molecules.

We conclude that minibody VEL-2 is a promising candidate for further evaluation as tumour targeting vehicle. It is an engineered form of one of the first fully human anti Ep-CA. M antibodies described to date and it combines a suitable antibody format for in vivo tumour targeting with increased affinity compared with the parental scFv.

\section{Acknowledgements}

We thank Prof. Dr. D. Herlynn for her kind gift of purified, recombinant Ep-CAM antigen.

\section{References}

1. Gottlinger HG, Funke I, Johnson IP, Gokel JM, Riethmuller G (1986) The epithelial ce!! surface antigen 17-1A, a target for antibody-mediated turnor therapy: its biochemica I nature, tissue distribution and recognition by different monoclonal antibodies. Int. $J$. Cancer 38: 47-53

2. Litvinov SV, Velders MP, Bakker HA, Fleuren GJ, Warnaar SO (1994) Ep-CAM: a human epithelial antigen is a homophilic cell-cell adhesion molecule. J. Cell Biol. 125: 


\section{7-446}

3. Litvinov SV, Balzar M, Winter MJ, Bakker HA, Briaire-de Bruijn IH, Prins F, Fleuren GJ, Warnaar SO (1997) Epithelial cell adhesion molecule (Ep-CAM) modulates cell-cel I interactions mediated by classic cadherins. J. Cell Biol. 139: 1337-1348.

4. Balzar M, Winter MJ, de Boer CJ, Litvinov SV (1999) The biology of the 17-1A antige n (Ep-CAM). J. Mol. Med. 77: 699-712

5. Ogura E, Senzaki H, Yoshizawa K, Hioki K, Tsubura A (1998) Immunohistochemica I localization of epithelial glycoprotein EGP-2 and carcinoembryonic antigen in norma 1 colonic mucosa and colorectal tumors. Anticancer Res. 18: 3669-3675

6. Steplewski Z, Chang TH, Herlyn M, Koprowski H (1981) Release of monoclona 1 antibody-defined antigens by human colorectal carcinoma and melanoma cells. Cancer Res. 41: 2723-2727

7. De Jonge MWA, Kosterink JGW, Bin YY, Bulte JWM, Kengen RAM, Piers DA, Hau w The T, De Leij L (1993) Radioimmunodetection of Human Small Cell Lung Cance $\mathbf{r}$ Xenografts in the Nude Rat Using 11 I In-labeled Monoclonal Antibody MOC-31. Eur. J. Cancer 29A: 1885-1890

8. Meredith RF, Khazaelli MB, Plott WE, Spencer SA, Wheeler RH, Brady LW, Woo DV, LoBuglio AF (1995) Initial clinical evaluation of iodine-125-labeled chimeric 17-1A for metastatic colon cancer. J. Nucl. Med. 36: 2229-2233

9. Saleh MN, LoBluglio AF, Wheeler RH, Rogers KJ, Haynes A, Lee JY, Khazaeli MB (1990) A phase II trial of murine monoclonal antibody 17-1A and interferon-gamma : clinical and immunological data. Cancer Immunol. Immunother 32: 185-190

10. Ragnhammar P, Fagerberg J, Frodin JE, Hjelm AL, Lindemalm C, Magnusson I, Masucci $\mathrm{G}_{3}$ Mellstedt $\mathrm{H}$ (1993) Effect of monoclonal antibody 17-1A and GM-CSF in patient s with advanced colorecial carcinoma--long-lasting, complete remissions can be induced. Int. J. Cancer 53: 751-758

11. Riethmüller G, Schneider-Gädicke E, Schlimok G, Schmiegel G, Raab R, Höffken K, Gruber R, Pichlmaier H, Hirche H, Pichlmayer R, Buggisch P, Witte J (1994) Randomized trial of monoclonal antibody for adjuvant therapy of resected Dukes' $\mathrm{C}$ colorectal carcinoma. The Lancet 343: 1177-1183

12. Riethmüller G, Holz E, Schlimok G, Schmiegel W, Raab R, Hoffken K, Gruber R, Funke I. Pichlmaier H, Hirche H. Buggisch P, Witte J, Pichlmayr R (1998) Monoclona I antibody therapy for resected Dukes' $\mathrm{C}$ colorectal cancer: seven-year outcome of a multicenter randomized trial. J. Clin. Oncol. 16: 1788-1794

13. Isaacs JD (1990) The antiglobulin response to therapeutic antibodies. Semin. Immunol. 2: $449-456$

14. Gruber R, van Haarlem LJ, Warnaar SO, Holz E, Riethmuller G (2000) The human antimouse immunoglobulin response and the anti-idiotypic network have no influenc e on clinical outcome in patients with minimal residual colorectal cancer treated wit $h$ monoclonal antibody CO17-1A. Cancer Res. 60: 1921-1926

15. Robins RA, Denton GW, Hardcastle JD, Austin EB, Baldwin RW, Durrant LG (1991) Antitumor immune response and interleukin 2 production induced in colorectal cancer patients by immunization with human monoclonal anti-idiotypic antibody. Cancer Res. 51: $5425-5429$

16. Samonigg H, Wilders-Truschnig M, Loibner H, Plot R, Rot A, Kuss I, Werner G, Stoger 
H, Wrann M, Herlyn D, et al. (1992) Immune response to tumor antigens in a patient with colorectal cancer after immunization with anti-idiotype antibody. Clin. Immunol. Immunopathol. 65: 271-277

17. Fagerberg J, Steinitz M, Wigzell H, Askelöf P, Mellstedt H (1995) Human anti-idiotypic antibodies induced a humoral and cellular immune response against a colorecta I carcinoma-associated antigen in patients. Proc. Natl. Acad. Sci. U. S. A. 92: 4773-4777

18. Buchsbaum DJ, Brubaker PG, Hanna DE, Glatfelter AA, Terry VH, Guilbault DM, Steplewski Z (1990) Comparative binding and preclinical localization and therapy studies with radiolabeled human chimeric and murine 17-1A monoclonal antibodies. Cancer Res. 50: $993 \mathrm{~s}-999 \mathrm{~s}$

19. Weiden PL, Breitz HB, Seiler CA, Bjorn MJ, Ratliff BA, Mallett R, Beaumier PL, Appelbaum JW, Fritzberg AR, Salk D (1993) Rhenium-186-labeled chimeric antibody NR-LU-13: pharmacokinetics, biodistribution and immunogenicity relative to murin $\mathrm{c}$ analog NR-LU-10. J. Nucl. Med. 34: 2111-2119

20. Huls GA, Heijnen IAFM, Cuomo ME, Koningsberger JC, Wiegman L, Boel E, van der Vuurst de Vries A-R, Loyson SAJ, Helfrich W, van Berge Henegouwen GP, van Meijer M, de Kruif J, Logtenberg T (1999) A recombinant, fully human monoclonal antibody with antitumor activity constructed from phage-displayed antibody fragments. Nat. Biotechnol. 17: 276-281

21. Beiboer SH, Reurs A, Roovers RC, Arends JW, Whitelegg NR, Rees AR, Hoogenboom HR (2000) Guided Selection of a Pan Carcinoma Specific Antibody Reveals Simila r Binding Characteristics yet Structural Divergence Between the Original Murine Antibod y and its Human Equivalent. J. Mol. Biol. 296: 833-849

22. Vaughan TJ, Williams AJ, Pritchard K, Osboum JK, Pope AR, Eamshaw JC, MeCaffert y J, Hodits RA, Wilton J, Johnson KS (1996) Human Antibodies with Sub-nanomola r Affinities Isolated from a Large Non-immunized Phage Display Library. Nat. Biotechnol. 14: $309-314$

23. Marks JD, Hoogenboom HR, Bonnert TP, McCafferty J, Griffiths AD, Winter G (1991) By-passing Immunization; Human Antibodies from V-gene Libraries Displayed on Phage. J. Mol. Biol. 222: 581-597

24. Hawkins RE, Russell SJ, Winter G (1992) Selection of phage antibodies by binding affinity. Mimicking affinity maturation. J. Mol. Biol. 226: 889-896

25. Strassburg CP, Kasai Y, Seng BA, Miniou P, Zaloudik J, Herlyn D, Koprowski H, Linnenbach AJ (1992) Baculovirus recombinant expressing a secreted form of a transmembrane carcinoma-associated antigen. Cancer Res: 52: 815-821

26. Roovers RC, Henderikx P, Helfrich W, van der Linden E, Reurs A, de Bruine AP, Arends JW, de Leij L, Hoogenboom HR (1998) High-affinity recombinant phage antibodies to the pan-carcinoma marker epithelial glycoprotein-2 for tumour targeting.

Br. J. Cancer 78: 1407-1416

27. Souhami RL, Beverley PCL, Bobrow LG (1988) Proceedings of the First International Workshop on Small-Cell Lung-Cancer Antigens, Lung Cancer 4: 1-114

28. Horn-Lohrens $\mathrm{O}$, Tiemann M, Lange H, Kobarg J, Hafner M, Hansen H, Sterry W, Parwaresch RM, Lemke H (1995) Shedding of the soluble form of CD30 from the Hodgkin-analogous cell line L540 is strongly inhibited by a new CD30-specific antibod y (Ki-4). Int. J. Cancer 60: $539-544$ 
29. Munro S, Pelham HR (1986) An Hsp70-like protein in the ER: identity with the $78 \mathrm{k} \mathrm{d}$ glucose-regulated protein and immunoglobulin heavy chain binding protein. Cell 46: 291300

30. Sambrook T, Fritsch EF, Maniatis T (1989) eds. Molecular Cloning: A Laboratory Manual. Cold Spring Harbor Laboratory Press, Cold Spring Harbour, p

31. de Haard H.J, van Neer N, Reurs A, Hufton SE, Roovers RC, Henderikx P, de Bruine AP, Arends J-W, Hoogenboom HR (1999) A large non-immunized human Fab fragmen $t$ phage library that permits rapid isolation and kinetic analysis of high affinity antibodies. J. Biol. Chem. 274: 182:18-18230

32. Persic L, Roberts A, Wilton J, Cattaneo A, Bradbury A, Hoogenboom HR (1997) A n integrated vector system for the eukaryotic expression of antibodies or their fragments after selection from phage display libraries. Gene 187: 9-18

33. Ho SN, Hunt HD, Horton RM, Pullen IK, Pease LR (1989) Site-directed mutagenisis by overlap extension using the polymerase chain reaction. Gene 77: 51-55

34. McCafferiy J, Fitzgeraid KJ, Earnshaw J, Chiswell DJ, Link J, Smith R, Kenten J (1994) Selection and rapid purification of murine antibody fragments that bind a transition-stat $e$ analog by phage display. Appl. Biochem. Biotechnol. 47: 157-171

35. Sanger F, Nicklen S, Coulson AR (1977) DNA sequencing with chain-terminating inhibitors. Proc. Natl. Acad. Sci. U. S. A. 74: 5463-5467

36. Laemmli UK (1970) Cleavage of structural proteins during the assembly of the head of bacieriophage T4. Nature 227: 680-685

37. Hoogenboom HR, Griffiths AD, Johnson KS, Chiswell DJ, Hudison P, Winter G (1991) Multi-subunit proteins on the surface of filamentous phage: methodologies for displaying antibody (Fab) heavy and light chains. Nucleic Acids Res. 19: 4133-4137

38. Woodward MP, Young WW Jr, Bloodgood RA (1985) Detection of monoclona I antibodies specific for carbohydrate epitopes using periodate oxidation. J. Immunol. Wethods 78: 143-153

39. Bobbill JM (1956), Adv, Carbohydrate Chem. Biochem. 11: 1

40. Hu S, Shively L, Raubitschek A, Sherman M, Williams LE, Wong JY, Shive ly JE, Wu AM (1996) Minibody: A novel engineered anti-carcinoembryonic antigen antibod y fragment (single-chain Fv-CH3) which exhibits rapid, high-level targeting of xenografts. Cancer Res. 56: 3055-3061

41. Williams LE, Lit A, Wu AM, Odom-Maryon T, Chai A, Raubitschek AA, Wong J Y (1995) Figures of merit (FOMs) for imaging and therapy using monoclo nal antibodies. Med. Phys. 22: 2025-2027

42. Alt M, Muller R, Kontermann RE (1999) Novel tetravalent and bispecific IgG-like antibody molecules combining single-chain diabodies with the immunoglobulin gamma 1 Fc or CH3 region. FEBS Lett. 454: 90-94

43. Herlyn M, Sieplewski Z, Herlyn D, Koprowski H (1979) Colorectal carcinoma-specific antigen: Detection by means of monoclonal antibodies. Proc. Natl. Acad. Sci. U.S. A. 76: $1438-1442$

44. Edwards DP, Grzyb KT, Dressler LG, Mansel RE, Zava DT, Sledge GW Jr, McGuire WL (1986) Monoclonal antibody identification and characterization of a $\mathrm{Mr} 43,000$ membrane glycoprotein associated with human breast cancer. Cancer Res. 46: 1306-1317 45. Griffiths AD, Malmqvist M, Marks JD, Bye JM. Embleton MJ, McCafferty J, Baier M, 
Holliger KP, Gorick BD, Hughes-Jones NC, Hoogenboom HR, Winter G (1993) Human anti-self antibodies with high specificity from phage display libraries. EMBOJ. 12: 725 734

46. Winter G, Griffiths AD, Hawkins RE, Hoogenboom HR (1994) Making antibodies by phage display technology. Annu. Rev. Immunol. 12: 433-455

47. Sheets MD, Amersdorfer P, Finnem R, Sargent P, Lindqvist E, Schier R, Hemingsen G, Wong C, Gerhart JC, Marks JD (1998) Efficient construction of a large nonimmun e phage antibody library: the production of high-affinity human single-chain antibodies to protein antigens. Proc. Natl. Acad. Sci. U. S. A. 95: 6157-6162

48. Adams GP, Schier R, Marshall K, Wolf EJ, McCall AM, Marks JD, Weiner LM (1998) Increased affinity leads to improved selective tumor delivery of single-chain F v antibodies. Cancer Res. 58: 485-490

49. Adams GP, Schier R, McCall AM, Crawford RS, Wolf EJ, Weiner LM, Marks JD (1998) Prolonged in vivo tumour retention of a human diabody targeting the extracellula $\mathrm{r}$ domain of human HER2/neu. Br. J. Cancer 77: 1405-1412

50. Iliades P, Kortt AA, Hudson PJ (1997) Triabodies: single chain Fv fragments without a linker form trivalent trimers. FEBS Lett. 409: 437-441

51. Kortt AA, Lah M, Oddie GW, Gruen CL, Burns JE, Parce LA, Atwell JL, McCoy AJ, Howlett GJ, Metzger DW, Webster RG, Hudson PJ (1997) Single-chain Fv fragment s of anti-neuraminidase antibody $\mathrm{NCl} 10$ containing five and ten-residue linkers form dimer s and with zero-residue linker a trimer. Protein Eng. 10: 423-433

52. Todorovska A, Roovers RC, Dolezal O, Kortt AA, Hoogenboom HR, Hudson PJ (2000) Design and application of Diabodies, Triabodies and Tetrabodies for Cancer Targeting. J. Immunol. Methods in press:

53. Neri D, Momo M, Prospero T, Winter G (1995) High-affinity antigen binding by chelating recombinant antibodies (CRAbs). J. Mol. Biol. 246: 367-373 


\section{Chapter 7}

Model systems to study the parameters determining the success of phage antibody selections on complex antigens

Ricardo Mutuberria, Hennie R. Hoogenboom, Edith van der Linden, Adriaan P. de Bruïne and Rob C. Roovers

Journal Immunol. Methods 231 (1-2), 65-81 (1998) 


\section{Abstract}

Phage antibody display technology offers a powerful tool for the isolation of specific antibodies to defined target antigens. Most selection strategies described to date have relied on the availability of purified -and often recombinant-- antigen, providing the possibility to perform selections on a well-defined antigen source. However, when the target antigen is non-purifiable (e.g. an integral membrane protein), or if the antigen is unknown (e.g. when searching for novel markers on cells or tissues), panning of phage antibody libraries has to be performed on complex antigen sources such as cell surfaces or tissue sections, or even by in vivo selection methods. This provides a series of technical and experimental challenges.

A main focus of our research is to select antibodies directed to novel cancer-induced antigens expressed by tumours and by the tumour vasculature. To understand the parameters governing selections on complex antigen sources and to assess the efficiency of these phage library selections, we have set up two model selection systems in which both tumour cells and vascular endothelial cells serve as target "antigen". We describe a model based on phage antibodies directed to the tumour antigen epithelial glycoprotein-2, to compare phage antibody selections on a range of different antigen sources, including purified-, recombinant antigen, whole live cells, tissue cryosections and in vivo grown solid tumours. Secondly, we describe a model based on a phage antibody directed against the endothelial cell inducible adhesion molecule E-selectin. We compare selections on cultured cell monolayers with selections on cells suspensions immobilised on columns, to determine which selection approach is most suitable for the identification of novel tumour endothelial cell markers.

Our data provide insight into the efficiency and thus potency of different selection strategies and show that there are very large differences regarding recovery and enrichment of binding phage between the different methods tested. Our results further demonstrate the feasibility of phage antibody selections on whole, intact cells and show that these may sometimes compare favourably to selections on purified antigen. Selections on endothelial cells immobilised on columns compare favourably with selections on cell-monolayers; the most favourable conditions for both selection procedures are described. The implications of our data for phage antibody selections on these different complex antigen sources using either non-immune or immune phage antibody repertoires are discussed. The use of model systems such as the ones described here will help to determine optimal experimental conditions for phage library selections on complex antigens and aid in developing more powerful selection procedures for target discovery.

\section{Introduction}

Ever since its first description [1], antibody phage display has been a powerful tool for 
the selection of antibodies to defined target antigens. Large (non-immune or synthetic) "singlepot" antibody repertoires have been made and displayed on phage from which specificities to a whole range of antigens have been be obtained [2,3]; for review, see [4] and [5]. Most phage antibody selection strategies have relied on the availability of purified and/or recombinant antigen. This permits the immobilisation of antigen onto solid supports and thus permits phage antibody selections to be performed under well-defined conditions. Proteins are often noncovalently coated to immunotubes and phage antibody repertoires are panned for binding to antigen. After extensive washing with detergent supplemented-buffers, phage antibodies that are specifically bound to antigen can be retrieved, for example by a change in pH [2], by the use of chaotropic agents [6] or by proteolytic digestion [7].

If, however, a protein requires the presence of a lipid bilayer for its native structure (as e.g. in 7-transmembrane receptors), or if the aim of selections is to identify novel celi surface markers specific for certain tissues, cell types, or cells at specific differentiation or diseaseinduced states, phage antibody selections have to be performed on a much more complex source of antigen [8-10]. The outcome of selections on complex antigens is governed by a number of parameters that can roughly be divided into antigen-related factors and selection-related factors. Important antigen-related factors include the amount (and thus concentration) of antigen, the quality of the antigen (integrity during the selection procedure), the nature of the antigen (intemalisation, accessibility, glycosylation, presence of immunodominant epitopes, expression profile on different cell types, environment-dependent expression) and generation of neo-epitopes due to preparation of the antigen. Selection-related parameters include the phage library used (e.g. V-gene source of the library, antibody display format, size of the library, ...), method of phage preparation, conditions and time of incubation of phage with the antigen, blocking and washing during selection, method of elution and the use of subtraction and depletion strategies or 'directed'-seiection proceciures (specific elution, P'roximol ${ }^{\mathrm{TM}}$ selections or surface epitope masking: [11-13].

The main focus of oij research is to develop antibody-based immunotherapeutics for use in cancer treatment. Tumour targeting may be based on antibodies with specificity for tumour associated antigens [14], or for antigens on the endethelium lining the turnour vasculature [15]. To date, however, only a limited number of antigens expressed by tumours or by the turnour vasculature have been described as possible target molecules. Novel tumour antigens may possibly be identified by differential cell selection using large 'single pot' phage antibody repertoires. Since phage display works outside the immune system [2], these repertoires will also contain antibodies to non-immunogenic and self-antigens, thereby avoiding possible restrictions induced by in vivo tolerance mechanisms. Thus, by using a powerful selection procedure for phage library selection on cell surfaces, it may be possible to identify novel tumour antigens by 
virtue of the antibodies that recognise them.

To isolate antibodies with these desired specificities, phage library selections have to be performed on tumour- or tumour vasculature-derived antigen sources. However, it is unclear how efficient phage library selections on these complex antigens are when compared with selections on purified targets, in terms of enrichment of specific phage antibodies over nonrelevant clones and of recovery of phage. To better understand the parameters governing phage library selections on complex antigens, we have set up model selection systems for the enrichment of phage antibodies specific for the tumour antigen epithelial glycoprotein-2, (EGP-2), and the endothelial cell inducible adhesion molecule E-selectin.

EGP-2 is a transmembrane glycoprotein abundantly expressed on a variety of human carcinomas [16, 17]. We have previously reported on the isolation and characterisation of high affinity single-chain variable antibody fragments (scFv, called MOC-31 and MOC-161) to this tumour antigen [18]. In the present study, we set out to use these MOC phage antibodies in a model for the selection of phage antibody repertoires on tumour material, including purified recombinant protein, cell surfaces, tissue cryosections and in vivo grown solid tumours.

The second model is based on the selection efficiency of a phage displayed scFv derived from ENA-1 [19], an antibody directed against the inducible endothelial cell-surface adhesion molecule E-selectin. E-selectin is a $116 \mathrm{kDa}$ membrane glycoprotein, which plays a role in the recruitment of leukocytes into sites of inflammation. It is largely absent from the endothelium of normal tissues [20] and is transiently expressed on activated endothelial cells in several conditions, such as tissue regeneration and wound healing, as well as on the endothelial cells of some neoplastic tissues [21-23]. E-selectin expression can be induced by a variety of inflammatory mediators such as interleukin-1 (IL-1), interferon gamma (IFN- $\gamma$ ), and tumour necrosis factor alpha (TNF- $\alpha$ ). This model system allows us to estimate the feasibility and the efficiency of selection of phage antibodies directed to antigens differentially expressed on activated endothelium.

In our model experiments, the enrichment of specific phage was determined after a single round of selection on different antigen sources. Our results demonstrate the feasibility of phage antibody selections on these 'alternative' complex antigen sources and demonstrate the differences between various selection regimens, as well as the differences between the two target antigen sources. This study has implications for the design of experiments aimed at targeting particular (integral) membrane proteins or at identifying novel (disease-induced) antigen structures on cells and tissues. Knowledge of the applicability and relative potency of different. selection procedures and of the effect of the different parameters governing the efficiency of these selections is now being used for the isolation of phage antibodies for tumour-cell or tumour-vasculature targeting. 


\section{Materials and Methods}

\section{Phage antibodies}

The V-genes of the anti EGP-2 murine hybridomas MOC-31 and MOC-161 were cloned in scFv format for the expression on bacteriophage as described [18]. The vector pCOMB3, containing the cloned V-genes of the murine anti human E-selectin antibody ENA-1 [19] in Fab format was kindly provided by Dr. van Zonneveld (Dept. of Biochemistry, Academic Medical Center, University of Amsterdam, the Netherlands). The variable domains of both heavy- and light chain of ENA-1 were PCR-amplified from purified plasmid DNA and cloned for display in scFv format containing a flexible 15-residue Gly-Ser linker as described [18, 24]. Phage fdDOGI has previously been described [24]; fd-DOG1-D1.3 contains the V-genes of the anti hen egg lysozyme (HEL) antibody D1.3 [25], cloned as scFv in fd-DOG1 [1]. MOC-31, -161 and ENA-1 expressing phage confer ampicillin (AMP) resistance to the bacterial host upon infection, whereas fd-DOG1 and fd-DOG1-DI.3 phage confer tetracyclin (TET) resistance to bacteria.

\section{E.coli strain}

TG1: K12, $\Delta$ (lac-pro), supE, thi, hsdD5/F'traD36, proA 'B', lacI', lacZAM15

\section{Cell lines}

Colorectal cancer ceil lines CaCo2, LS174T and SW480 were obtained from the American Type Culture Collection (ATCC; numbers HTE37, CL188 and CCL228 respectively). Cells were cultured in Dulbecco's Minimal Essential Medium (DMEM; Dulbecco, Life Technologies) supplemented with $10 \%(\mathrm{v} / \mathrm{v})$ fetal calf serum and $2 \mathrm{mM}$ glutamine. Primary human umbilical vein-derived endothelial cells (HUVEC) were isolated as described [26] and cultured in RPMI 1640 medium (Dulbecco, Life Technologies), supplemented with $20 \%$ (v/v) heat-inactivated human serum, $2 \mathrm{mM}$ glutamine, $0.1 \mathrm{mg} / \mathrm{ml}$ streptomycin and $100 \mathrm{U} / \mathrm{ml}$ penicillin. E-selectin expression was induced on subconfluent monolayers of HUVEC by a 4 hours incubation with 10ng/ml TNF- $\alpha$ (Pepro Tech EC Ltd., London, England) in fresh RPM! medium. Non-activated (control) cells were incubated with fresh medium only. All cells were kept at $37^{\circ} \mathrm{C}$ in a humidified atmosphere containing $5 \% \mathrm{CO}_{2}$. Since mycoplasm infection has been reported to influence the level of antigen expression on the cell surface [27], all cell lines used were regularly tested for mycoplasm infection and consistently found to be negative.

\section{Epithelial Glycoprotein-2 (EGP-2)}

Recombinant EGP-2 was expressed in the baculovirus expression system and purified as described [28]. The protein was a kind gift from Prof. Dr. Dorothee Herlyn, the Wistar Insitute 
of Anatomy and Biology, Philadelphia, Pennsylvania, U.S.A.

\section{Analysis of phage antibody binding by means of flow cytometry}

Phage antibodies MOC-3I and ENA-1 were rescued with helper phage M13K07 as described [2]. Es coli TGl, infected with phage fd-DOGl or fd-DOGl-Dl. 3 were grown for $24 \mathrm{hrs}$ at $30^{\circ} \mathrm{C}$ in $2 \times$ TY medium $(1.6 \%(\mathrm{w} / \mathrm{v})$ tryptone; $1.0 \%(\mathrm{w} / \mathrm{v})$ yeast exiract; $0.5 \%(\mathrm{w} / \mathrm{v}) \mathrm{NaCl})$, supplemented with $25 \mu \mathrm{g} / \mathrm{ml}$ tetracyclin. All phage were purified and concentrated by precipitation from the bacterial culture supernatant with polyethylene glycol (PEG)/ $\mathrm{NaCl}$ as described [29]. Cells were harvested by trypsinisation (CaCo2) or EDTA treatment (HUVEC) and aliquots of approximately $5 \times 10^{5}$ cells were made in polystyrene FACSscan tubes (Falcon: Becton \& Dickinson, Heidelberg, Germany). HUVEC were fixed with $1 \%(w / v)$ paraformaidehyde in PBS for 30 minutes $\left(30^{\prime}\right)$ at room temperature $(\mathrm{rt})$ and blocked with $2 \%$ (w/v) skimmed milk powder (Marvel) in PBS (2\% MPBS) for 30 minutes at $\mathrm{rt}$ before staining. All further incubations were carried out for one hour at $\mathrm{r}$; three washes, each consisting of centrifugation of the cells $\left(400 \mathrm{~g}, 3^{\prime}, \mathrm{rt}\right)$ and resuspension in $1 \mathrm{ml}$ of $2 \%$ MPBS, were performed between every incubation step. Cells were stained with approximately $10^{11}$ colony forming units (cfu) of phage in $500 \mu \mathrm{l} 2 \%$ MPBS, a polyclonal sheep antiserum to fd phage (Pharmacia, Uppsala, Sweden: $0.02 \%(\mathrm{v} / \mathrm{v})$ in $2 \% \mathrm{MPBS})$ and FITC-labeled rabbit anti-goat immunoglobulines (Dako, Glostrup, Denmark; $2 \%(\mathrm{v} / \mathrm{v})$ in $2 \%$ MPBS). Finally, cells were washed four times with PBS, resuspended in $500 \mu$ PBS and analysed by flow cytometry using a FACS-Calibur (Becton \& Dickinson, Heidelberg, Germany). Data were analysed using the Cellquest software program (Becton \& Dickinson, Heidelberg, Germany).

\section{Model selections by panning on different EGP-2 positive antigen sources}

Phage were prepared as described (see section 2.5). An excess of fd phage (fd-DOG1 or fdDOGI-D1.3) was then mixed with either MOC-31 or -161 phage and the resulting mixture was panned for binding to antigen. A schematic representation of the model is depicted in Fig. 1. All selections were performed in 2\%MPBS as blocking agent for non-specific interactions. For all selections, the total amount of input phage used was between $10^{10}$ and $10^{12} \mathrm{cfu}$.

Selections on purified EGP-2 were performed by panning in antigen-coated (at $10 \mu \mathrm{g} / \mathrm{ml}$ ) immunotubes as described [2]. All selections on cell lines were performed in suspension with $1 \times 10^{7}$ cells in a volume of $5 \mathrm{ml} 2 \%$ MPBS. Briefly, cells $(4 \mathrm{ml})$ and phage $(1 \mathrm{ml})$ were blocked in $2 \%$ MPBS for I hr at $\mathrm{rt}$; phage were then added to the cells and incubated for two hours at $\mathrm{rt}$ with gentle shaking. Cells were pelleted $\left(400 \mathrm{~g}, 3^{\prime}, \mathrm{rt}\right)$, washed ten times with $5 \mathrm{ml}$ of $2 \%$ MPBS and twice with $5 \mathrm{ml}$ of PBS (by resuspension and centrifugation) and phage were eluted with different elution buffers $(10 \mathrm{mM} \mathrm{HCl} ; 100 \mathrm{mM} \mathrm{HCl} ; 100 \mathrm{mM}$ TEA or by directly adding exponentially 
growing E.coli TG1 to the selection mixture). Incubations of phage in these strong acidic or basic solutions for $10 \mathrm{~min}$. have been shown to have a neglegible effect on phage infectivity [30, 31$]$. $\mathrm{HCl}$ or TEA-containing elution buffers were then neutralised with half a volume of $1 \mathrm{M}$ Tris- $\mathrm{HCl}$ ( $\mathrm{pH} 7.4$ ) and phage were titrated by serial dilution in 2 XTY medium, followed by infection into exponentially growing E.coli TGI and parallel plating on AMP and TET containing agar plates.

For selections on tissue cryosections, a patient-derived primary colorectal tumour (obtained after surgery) was used. Five $\mu \mathrm{m}$ cryosections were cut, mounted on 3-aminopropyl-tri-ethoxy silane (APTS) coated glass slides, air-dried and fixed with $1 \%(w / v)$ paraformaldehyde in PBS for $10 \mathrm{~min}$. at $\mathrm{rt}$. The tissue was then blocked with $2 \%$ MPBS for $30 \mathrm{~min}$. at $\mathrm{rt}$, phage were applied in $500 \mu \mathrm{l} 2 \%$ MPBS and incubated for 1.5 hours at $\mathrm{rt}$. Slides were washed ten times with $4 \mathrm{ml}$ of $2 \%$ MPBS, twice with PBS and phage were eluted with $500 \mu 1100 \mathrm{mM}$ TEA. Titration of input and output phage were as described.

Titers of input and output phage were corrected for different volumes and expressed as the total amount of colony forming units (cfu). Recovery of specific phage was calculated as the percentage of AMP-resistant colonies (cfu) recovered after one round of selection. Enrichment factors were calculated as the product of ratios of AMP and TET-resistant colonies before and after selection, according to the formula:

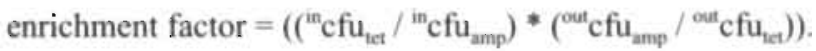

(in = input titer; out $=$ output titer)

\section{Model' selections by panning on TNF- $\alpha$-activated HUVEC monolayers}

HUVEC were cultured in 24-well or 6-well culture dishes $(50.000$ and $140,000 \mathrm{ce} \| \mathrm{ls} / \mathrm{well}$ respectively) and activated by pre-incubation with TNF $-\alpha$ or used without activation (see section 2.3). Cells were washed twice with $\mathrm{PBS} / 0.1 \%(\mathrm{w} / \mathrm{v})$ bovine serum albumin (BSA) and either used directly for selection, or fixed with $1 \%$ paraformaldehyde prior to selection. Fixed cells were blocked with PBS * (PBS, containing, $1 \mathrm{mM} \mathrm{MgSO}_{4}$ and $\mathrm{CaCl}_{2}$ )/ $\%$ BSA or $2 \% \mathrm{MPBS}^{+}$for $30^{\prime}$ at $\mathrm{rt}$. Cell panning was performed by incubating HUVEC with $1 \mathrm{ml}$ of a pre-blocked phage mix (as in section 2.6, but alternatively blocking was also performed in PBS $1 / 1 \%$ BSA) for one hour at $\mathrm{rt}$. Phage bound to HUVEC monolayers were then subjected to different washing $(5,10$, or 20 washes with $1 \mathrm{ml}$ of either PBS $* / 1 \%$ BSA, or $2 \%$ MPBS ) and elution conditions ( $100 \mathrm{mM}$ $\mathrm{HCl}$ or $100 \mathrm{mM}$ TEA) and ratios of AMP and TET resistant cfu were determined before and after selection as described.

\section{Model selections on activated HUVEC using a high gradient magnetic separation column}

For column selections, TNF- $\alpha$-activated HUVEC were harvested by EDTA treatment, washed. twice with PBS $/ 0.1 \%$ BSA, fixed with $1 \%$ paraformaldehyde and blocked with $\mathrm{PBS} / 1 \% \mathrm{BSA}$ as 
described. Approximately $5 \times 10^{5}$ cells were then incubated for $30^{\prime}$ at $\mathrm{rt}$ in $1 \mathrm{ml} \mathrm{PBS} / 0.1 \% \mathrm{BSA}$ containing a 1:50 dilution of the anti CD31 mouse monoclonal antibody EN4 (Monosan, Uden, the Netherlands). Cells were washed twice with PBS $/ 0.1 \% \mathrm{BSA}$ and either magnetically labeled by resuspension in $100 \mu \mathrm{l}$ PBS $/ 0.1 \% \mathrm{BSA}$, containing $20 \mu \mathrm{l}$ of goat anti-mouse IgG MACS magnetic microbeads (Miltenyi Biotec, Bergisch Gladbach, Germany), or first incubated with $1 \mathrm{ml}$ of pre-blocked phage mix (for one hour at $\mathrm{rt}$ ) before labeling. Unreacted beads were removed by two washes with $1 \mathrm{ml}$ PBS $/ 0.1 \%$ BSA and labelled cells were resuspended in $100 \mu$ legasified PBS/0.1\%BSA. Cells were loaded onto a MiniMACS-MS column pre-equilibrated with $1 \mathrm{ml}$ PBS $/ 0.1 \% \mathrm{BSA}$ and placed in a magnetic field (Miltenyi Biotec, Bergisch Gladbach, Germany). For phage panning on the column, $1 \mathrm{ml}$ of pre-blocked phage were passed five times through the MACS column (equiped with a flow rate restricting needle) retaining magnetically labeled HUVEC. The column was washed ten times with $2 \mathrm{ml}$ of PBS/1\%BSA and subsequently drained by removal from the magnetic field. For phage panning on the column, cells were washed twice again with $\mathrm{Iml}$ of PBS/0.1\%BSA to equal the amount of washing steps. Bound phage were eluted from HUVEC by TEA elution (see section 2.6) and titrated before and after selection as described.

\section{In vivo selections}

Athymic (nude) mice were xenografted with the EGP-2 positive human colorectal carcinoma cell ine LS174T. When tumours reached a diameter of approximately $0.5 \mathrm{~cm}$, mice were anaesthetised and $200 \mu 1$ phage mix (in PBS) was injected into the tail vein (intravenously: i.v.) or directly into the interstitium of the tumour. After 5 or 30 minutes, mice were sacrificed and organs were removed and snap-frozen in isopentane at $-70^{\circ} \mathrm{C}$. Phage were then eluted from different organs essentially as described [32]. Briefly, organs were weighed, thawed and mechanically sheared by blending with a Polytron PT1200 (Kinematica AG, Switzerland) in five $\mathrm{ml}$ of RPMI medium (Dulbecco, Life Technologies) containing $1 \mathrm{mM}$ of the protease inhibitor phenylmethylsulfonyl fluoride (PMSF). Five $\mathrm{ml}$ of exponentially growing E.coli TGI were then added and the suspension was incubated for $30^{\prime}$ at $37^{\circ} \mathrm{C}$. Phage were then titrated by serially diluting the mixture in $2 \times$ TY medium and plating in parallel on AMP and TET containing agar. plates. Output phage titers were corrected for the weight of the organ and expressed as $\mathrm{cfu} / \mathrm{mg}$ of tissue; input phage titers are given as the total number of cfu injected. Enrichment factors and recovery of specific phage were calculated as described (see section 2.6).

\section{Results}

To better understand phage antibody selections on complex antigen sources such as whole live cells, we set out to develop models that would permit us to compare various selection strategies 
and assess the most important parameters for selection. As a model for tumour-cell selection, we used the high affinity MOC-31 and MOC-161 scFv phage antibodies directed to the pancarcinoma marker EGP-2 [18] and fd-DOGl or fd-DOGI-D1.3 phage as non-binding controls. The two anti EGP-2 scFv antibody fragments recognise at least partially overlapping epitopes on EGP-2, which permits their direct comparison in these model experiments. As a model for tumour endothelial-cell selection, we cloned the anti E-selectin antibody ENA-1 [19] as scFv for the expression on phage and used it in combination with fd-DOG1 and fd-DOG1-D1.3 for selection on TNF- $\alpha$-activated endothelial cells. In a typical model experiment, phage mixtures of an excess of (non-binding) control phage over specific phage were selected on antigen. Since antigen-specific and control phage confer a different antibiotic resistance to the bacterial host upon infection, enrichment and recovery of binding phage can easily be determined by titration and parallel selection on both antibiotics (Fig. 1).

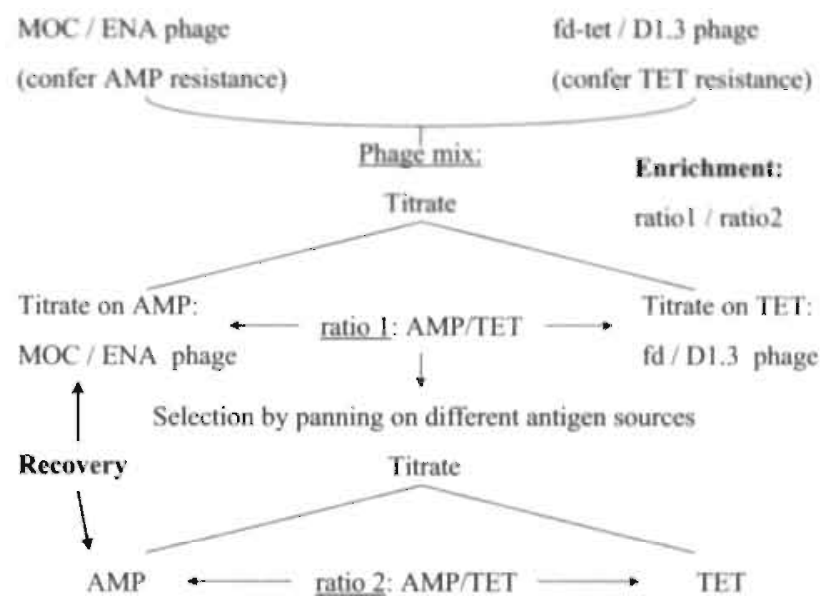

\section{Figure I}

Schematic outline of a model experiment

A phage mix of MOC or ENA-phage with an excess of fd-DOGI or fdDOG1-D1. 3 phage was panned for binding to different antigen sources. Enrichment of specific phage was calculated from the input and output ratios of AMP and TET resistant colonies (cfu). Recovery of specific phage was determined as the percentage of AMP resistant colonies recovered after a single round of selection.

Cell binding of all phage antibodies, was first demonstrated by means of flow cytometric analysis using the target cell lines $\mathrm{CaCo} 2$ (expressing EGP-2) and TNF- $\alpha$-activated (expressing E-selectin), or non-activated HUVEC (Fig. 2). As expected, MOC-31 or -161 scFv expressing phage bound the EGP-2 positive cell line $\mathrm{CaCo} 2$ (shown for MOC-31 only) and ENA-1 scFv expressing phage stained TNF- $\alpha$-activated HUVEC, but not the non-activated cells. Fd-DOG1 and fd-DOG1-D1.3 phage were negative on all cells tested (Fig. 2). 

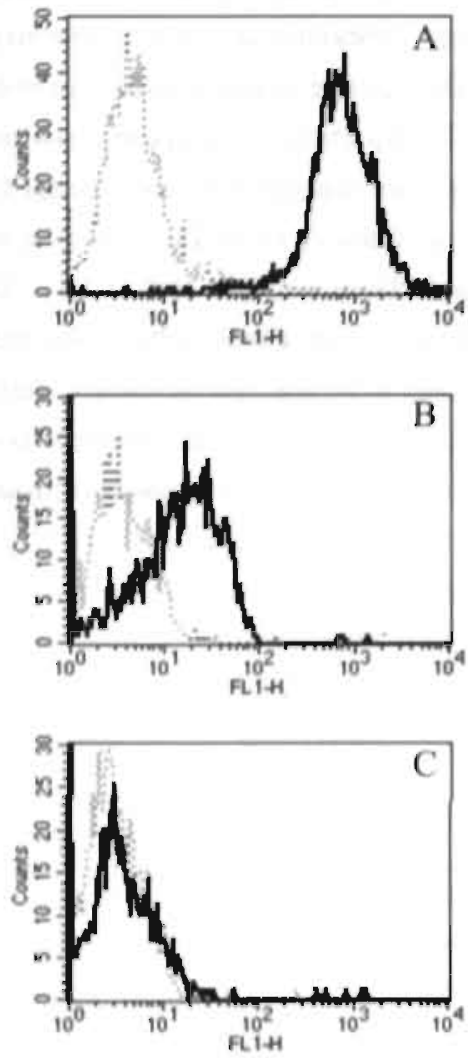

Figure 2

Analysis of phage antibody binding to different cell lines by flow cytometry

A: Colorectal cancer cell line $\mathrm{CaCo} 2$ was stained with $\mathrm{MOC}-31$ scFv expressing phage (thick line) and fd-DOGl phage as negative control (thin line).

B: TNF- $\alpha$ activated HUVEC were stained with ENA-1 scFv expressing phage (thick line), or fd-DOGI phage as negative control (dashed line).

C: Non-activated HUVEC were stained with ENA-1 scFv expressing phage (thick line), or fd-DOGI phage as negative control (dashed line).

In all experiments, bound phage were detected with a polyclond sheep antiserum to fd phage and FITC-conjugated rabbit anti goat immunoglobulins.

In the first model experiments, we selected a mixture of specific (MOC-31 or MOC-161) and control phage (fd-DOG1) on recombinant EGP-2 antigen by panning in immunotubes (Table 1). Our results confirm the very low recovery reported for selections on recombinant antigen [30]. This may be largely due to very inefficient coating of the antigen, thereby decreasing the effective antigen concentration during selection, or due to modification of the epitope upon coating. A consistent difference in enrichment factor was found between the MOC-31 and MOC-161 phage antibodies, although recovery of specific phage was similar. Expression of a control seFv (anti hen egg lysozyme (HEL) antibody DI.3) on the non-specific phage (fd-DOGI) did not significantly alter the enrichment, nor the recovery of specific phage (Table 1). Apparently, the non-specific binding of phage to the antigen-coated solid phase was independent of antibody expression.

As a first step in the study of cell-based selection strategies, we compared different elution conditions to retrieve $\mathrm{MOC}-31$ phage after selection on the colorectal cancer cell line $\mathrm{CaCo} 2$. Cells were harvested by short trypsinisation before selection, as immunocytochemical analysis showed no influence of this treatment on the recognition of EGP-2 by the parental hybridoma. antibodies (data not shown). However, we cannot exclude that part of the antigen expressed on the cell surface was lost because of the preparation method. We determined the viability of $\mathrm{CaCo} 2$ cells before and after one round of selection (with 12 washes) to be $90 \%$ and $70 \%$ respectively (by trypan blue exclusion: data not shown). This indicates that in our model experiments, loss of antigen through cell lysis before elution probably does not significantly influence the selection efficiency. 
Table 1

Model selections on purified, recombinant EGP-2

\begin{tabular}{|l||c|l|l|l|l|l|c|}
\hline $\begin{array}{l}\text { Spec. } \Phi \\
\text { Non-rel. } \Phi\end{array}$ & Elution & $\begin{array}{l}\text { Input } \\
\text { titers* }\end{array}$ & $\begin{array}{l}\text { Output } \\
\text { titers }\end{array}$ & $\begin{array}{l}\text { Input } \\
\text { ratio** }\end{array}$ & $\begin{array}{l}\text { Output } \\
\text { ratio }\end{array}$ & $\begin{array}{l}\text { Enrich- } \\
\text { ment } \\
\text { factor }\end{array}$ & $\begin{array}{l}\text { Recovery } \\
(\% \text { total) }\end{array}$ \\
\hline \hline $\begin{array}{l}\text { MOC-31/ } \\
\text { fd-DOGl }\end{array}$ & $\begin{array}{c}100 \mathrm{mM} \\
\text { TEA }\end{array}$ & $\begin{array}{c}7.5^{*} 10^{8} \\
6^{*} 10^{11}\end{array}$ & $\begin{array}{c}1.5^{*} 10^{4} \\
2.7^{*} 10^{3}\end{array}$ & $1: 800$ & $5.55: 1$ & 4440 & 2 \\
\hline $\begin{array}{l}\text { MOC-31/ } \\
\text { fd-DOG1- } \\
\text { D1.3 }\end{array}$ & $\begin{array}{c}100 \mathrm{mM} \\
\text { TEA }\end{array}$ & $\begin{array}{c}7.5^{*} 10^{8} \\
4.75^{*} 10^{10}\end{array}$ & $\begin{array}{c}4.68^{*} 10^{4} \\
2.4^{*} 10^{3}\end{array}$ & $1: 63$ & $19.5: 1$ & 1229 & 62 \\
\hline $\begin{array}{l}\text { MOC-161/ } \\
\text { fd-DOG1 }\end{array}$ & $\begin{array}{c}100 \mathrm{mM} \\
\text { TEA }\end{array}$ & $\begin{array}{c}1.5^{*} 10^{9} \\
6^{*} 10^{11}\end{array}$ & $\begin{array}{c}3.15^{*} 10^{4} \\
1.2^{*} 10^{5}\end{array}$ & $1: 400$ & $1: 3.81$ & 105 & 21 \\
\hline $\begin{array}{l}\text { MOC-161/ } \\
\text { fd-DOG1- } \\
\text { D1.3 }\end{array}$ & $\begin{array}{c}100 \mathrm{mM} \\
\text { TEA }\end{array}$ & $\begin{array}{c}1.5^{*} 10^{9} \\
4.75^{*} 10^{10}\end{array}$ & $\begin{array}{c}8.4^{*} 10^{3} \\
3.6^{*} 10^{3}\end{array}$ & $1: 32$ & $2.33: 1$ & 75 & 56 \\
\hline
\end{tabular}

- Titers are given for AMP resistant cfu (top) and TET resistant cfu (bottom)

** ratios are given for (AMP : TET) resistant cfu

Very harsh elution conditions (100 $\mathrm{mM} \mathrm{HCl}$ or $100 \mathrm{mM}$ TEA) were shown to be necessary to retrieve all MOC-31 phage, which is probably due to the relatively high affinity of the scFv (Table 2; for simplicity and clarity, phage titers have been omitted from this and subsequent tables). Indeed, it has been reported that such conditions are sometimes necessary to retrieve phage antibodies with high affinity $[31,33]$. When E.coli TG1 were used as the "elution" moiety (adding exponentially growing bacteria to the selection mixture), the selection efficiency was roughly equal to that using strong basic or acidic elution (Table 2). This probably reflects $\mathrm{MOC}$ 31 -expressing phage detaching from antigen during the incubation with bacteria. The majority of seFv-expressing phage will be monovalent [34] and in theory, $50 \%$ of monovalent phage bound to antigen would detach over 30 minutes (calculated from the off-rate of the antibody: [18]. The fact, however, that the enrichment factor and recovery of MOC-3i phage were similar, hints towards the possibility that MOC-3lphage still bound to antigen are also capable of infecting E.coli. The addition of an excess of non-binding helper phage M13 K07 (confering kanamycin resistance to the bacterial host) to block non-specific interactions of phage with the cell surface did not result in an improved enrichment of specific phage (data not shown). Apparently, a low level of background binding of phage to cell surfaces cannot be prevented in this way. 


\section{Table 2}

Model selections on EGP-2 expressing colon cancer cell lines; (A) effects of elution buffer and (B) effect of differences in antibody off-rate

A

\begin{tabular}{|l||c|c|l|l|l|c|}
\hline $\begin{array}{l}\text { Spec. } \Phi \\
\text { Non-rel. } \Phi\end{array}$ & $\begin{array}{l}\text { Cell line } \\
\text { used: }\end{array}$ & $\begin{array}{l}\text { Elution } \\
\text { condition }\end{array}$ & $\begin{array}{l}\text { Input } \\
\text { ratio }\end{array}$ & $\begin{array}{l}\text { Output } \\
\text { ratio }\end{array}$ & $\begin{array}{l}\text { Enrichment } \\
\text { factor }\end{array}$ & $\begin{array}{l}\text { Recovery } \\
\text { (\% total) }\end{array}$ \\
\hline $\begin{array}{l}\text { MOC-31 } \\
\text { fd-DOG1 }\end{array}$ & CaCo2 & $\begin{array}{c}10 \mathrm{mM} \\
\mathrm{HCl}\end{array}$ & $1: 100$ & $90: 1$ & 9000 & 24 \\
\hline $\begin{array}{l}\text { MOC-31 } \\
\text { fd-DOG1 }\end{array}$ & $\mathrm{CaCo2}$ & $\begin{array}{c}100 \mathrm{mM} \\
\mathrm{HCl}\end{array}$ & $1: 30000$ & $1: 2.5$ & 12000 & 6 \\
\hline $\begin{array}{l}\text { MOC-31 } \\
\text { fd-DOG1 }\end{array}$ & $\mathrm{CaCo2}$ & $\begin{array}{c}100 \mathrm{mM} \\
\text { TEA }\end{array}$ & $1: 30000$ & $1: 3$ & 10000 & 5 \\
\hline $\begin{array}{l}\text { MOC-31 } \\
\text { fd-DOG1 }\end{array}$ & $\mathrm{CaCo2}$ & $\begin{array}{c}\text { E.coli } \\
\text { TG1 }\end{array}$ & $1: 8600$ & $1: 1$ & 8600 & 37 \\
\hline
\end{tabular}

B

\begin{tabular}{|l||l|l|l|l|l|c|}
\hline $\begin{array}{l}\text { Spec, } \Phi \\
\text { Non-rel. } \Phi\end{array}$ & $\begin{array}{l}\text { Cell line } \\
\text { used: }\end{array}$ & $\begin{array}{l}\text { Elution } \\
\text { condition }\end{array}$ & $\begin{array}{l}\text { Input } \\
\text { ratio }\end{array}$ & $\begin{array}{l}\text { Output } \\
\text { ratio }\end{array}$ & $\begin{array}{l}\text { Enrichment } \\
\text { factor }\end{array}$ & $\begin{array}{l}\text { Recovery } \\
(\% \text { total })\end{array}$ \\
\hline $\begin{array}{l}\text { MOC-31 } \\
\text { fd-DOGI }\end{array}$ & LS174T & $\begin{array}{c}100 \mathrm{mM} \\
\text { TEA }\end{array}$ & $1: 2417$ & $6.4: 1$ & 15469 & 425 \\
\hline $\begin{array}{l}\text { MOC-31 } \\
\text { fd-DOGI-D1.3 }\end{array}$ & LS174T & $\begin{array}{c}100 \mathrm{mM} \\
\text { TEA }\end{array}$ & $1: 292$ & $54.7: 1$ & 15972 & 205 \\
\hline $\begin{array}{l}\text { MOC-161 } \\
\text { fd-DOG I }\end{array}$ & LS174T & $\begin{array}{c}100 \mathrm{mM} \\
\text { TEA }\end{array}$ & $1: 3125$ & $1: 1.15$ & 2717 & 89 \\
\hline $\begin{array}{l}\text { MOC-161 } \\
\text { fd-DOGI-D1.3 }\end{array}$ & LS174T & $\begin{array}{c}\text { I00mM } \\
\text { TEA }\end{array}$ & $1: 283$ & $10: 1$ & 2830 & 88 \\
\hline
\end{tabular}

To assess the effect of differences in antibody off-rate on the outcome of cell-based selections, we compared MOC-31 scFv to MOC-161 scFv (which has a six-fold higher off-rate than MOC$31)$ in our model selection system. First, three different colorectal cancer cell lines ( $\mathrm{CaCo} 2$, LS174T and SW480) were used as "antigen" in model selections to compare selections on different colorectal cancer cell lines. Results from these selections indicated that LS174T has the highest expression level of EGP-2, resulting in an enrichment factor of approximately 15,000 and recovery of $\mathrm{MOC}-31$ phage of $6 \%$ (data not shown). When comparing MOC-31 to MOC-161 in selections on whole cells (Table 2), a consistent difference in enrichment and recovery was found, showing that a faster off-rate not only reduces the enrichment of specific over non-specific 
phage, but also dramatically decreases the recovery (Table 2). The observed difference in selection efficiency cannot be attributed to differences in expression level between the two scFy phage antibodies, because Western blot analysis of total phage using a monocional antibacteriophage pIII antibody [35] revealed that, on the contrary, MOC-161 scFv was expressed to a higher level on phage ( $27.5 \%$ of all plll-containing protein was scFv-pIII fusion) than MOC. 31 scFv ( $14.2 \%$ of scFv-plll fusion, based on densiometry: data not shown).

Since it has been shown that antigen expression on solid tumours can vary as a result of external signals [36], cell lines may not reflect the antigen expression of that particular cell type in vivo. As an alternative antigen source that mimics the in vivo antigen expression more closely, tissue cryosections of patient-derived material may be used, provided a suitable selection procedure can be established. We first analysed several patient-derived primary tumours by means of immunohistochemistry for their EGP-2 expression; a tumour was then chosen that homogeneously stained positive with the MOC-3I parental whole antibody (data not shown). Since EGP-2 is a membrane antigen, the amount of protein available in these cryosections will be very limited, although some intracellular antigen will also be exposed. As expected, the selection efficiency dropped dramatically compared with panning on whole live cells expressing EGP-2: the enrichment factor was decreased by a factor of 100-200; the recovery by a factor of 20-50 (Tables 2 and 3). No difference in enrichment or recovery between MOC-31 and 161 was observed.

\section{Table 3}

Model selections on tissue cryosections

\begin{tabular}{|l||c|c|c|c|c|}
\hline $\begin{array}{l}\text { Spec. } \Phi \\
\text { Non-rel. } \Phi\end{array}$ & $\begin{array}{l}\text { Elution } \\
\text { condition }\end{array}$ & Input ratio & $\begin{array}{l}\text { Output } \\
\text { ratio }\end{array}$ & $\begin{array}{l}\text { Enrichment } \\
\text { factor }\end{array}$ & $\begin{array}{l}\text { Recovery } \\
\text { (\% total) }\end{array}$ \\
\hline \hline $\begin{array}{l}\text { MOC-31 } \\
\text { fd-DOG1 }\end{array}$ & $\begin{array}{c}100 \mathrm{mM} \\
\text { TEA }\end{array}$ & $1: 2000$ & $1: 37.6$ & 53 & 25 \\
\hline $\begin{array}{l}\text { MOC-31 } \\
\text { fd-DOG1-D1.3 }\end{array}$ & $\begin{array}{c}100 \mathrm{mM} \\
\text { TEA }\end{array}$ & $1: 200$ & $1: 11.8$ & 17 & 2 \\
\hline $\begin{array}{l}\text { MOC-161 } \\
\text { fd-DOG1 }\end{array}$ & $\begin{array}{c}100 \mathrm{mM} \\
\text { TEA }\end{array}$ & $1: 3000$ & $1: 37.5$ & 80 & 24 \\
\hline $\begin{array}{l}\text { MOC-161 } \\
\text { fd-DOG1-D1.3 }\end{array}$ & $\begin{array}{c}\text { 100mM } \\
\text { TEA }\end{array}$ & $1: 300$ & $1: 7.94$ & 38 & 2 \\
\hline
\end{tabular}

To preserve the in vivo antigen expression even better, in vivo selection strategies could also be considered (as first described by [32]). Therefore, we determined if MOC-3 I-expressing phage could be enriched in an in vivo selection model using athymic mice xenografted with the 
human colorectal cancer cell line LS174T. We determined the number of phage present in the tumour and in muscle as antigen-negative control organ. No enrichment of specific phage could be observed in the tumour compared to muscle, when phage were injected intravenously (i.v.) into the tail vein of xenografted mice (Table 4). When using the rescued "empty" phagemid vector pCANTAB6 in a control experiment, no difference between this control phage and MOC31 expressing phage could be observed with regard to preferential retention in the tumour (Table 4). However, when a phage mix of MOC-31 and fd-DOGI was injected directly into the tumour, an approximate 10-fold enrichment of MOC-31 phage was observed (comparing tumour with muscle), proving that antigen-binding phage were specifically retained in the tumour. Recovery of phage was approximately $0.001 \%$ of the input, per mg of tumour.

\section{Table 4:}

In vivo model selections in LS174T xenografted mice

\begin{tabular}{|c|c|c|c|c|}
\hline $\begin{array}{l}\text { Spec. } \Phi \\
\text { Non-rel. } \Phi\end{array}$ & $\begin{array}{l}\text { Selection } \\
\text { condition }\end{array}$ & $\begin{array}{l}\text { Input ratio } \\
\text { (AMP:TET) }\end{array}$ & $\begin{array}{l}\text { Output ratios } \\
\text { (AMP:TET)* }\end{array}$ & $\begin{array}{l}\text { Enrichment } \\
\text { factors }\end{array}$ \\
\hline $\begin{array}{l}\text { MOC-31 } \\
\text { fd-DOGI }\end{array}$ & $\begin{array}{l}30^{\prime} \\
\text { i.v. }\end{array}$ & $1: 10000$ & $\begin{array}{l}\text { tu: } 1: 3400 \\
\text { mu: } 1: 4285\end{array}$ & $\begin{array}{l}\text { tu: } 2.94 \\
\text { mu: } 2.33\end{array}$ \\
\hline $\begin{array}{l}\text { pCANTAB6 } \\
\text { fd-DOGI }\end{array}$ & $\begin{array}{l}5 \\
\text { i.v. }\end{array}$ & $1: 16.5$ & $\begin{array}{l}\text { tu: } 1: 5.8 \\
\text { mu: } 1: 3.4\end{array}$ & $\begin{array}{l}\mathrm{tu}: 2.84 \\
\mathrm{mu}: 4.85\end{array}$ \\
\hline $\begin{array}{l}\text { MOC-31 } \\
\text { fd-DOG1 }\end{array}$ & $\begin{array}{l}5^{\prime} \\
\text { i.v. }\end{array}$ & $1: 41$ & $\begin{array}{l}\text { tu: } 1: 15.3 \\
\text { mu: } 1: 10.8\end{array}$ & $\begin{array}{l}\text { tu: } 2.68 \\
\text { mu: } 3.8\end{array}$ \\
\hline $\begin{array}{l}\text { MOC-3 I } \\
\text { fd-DOGI }\end{array}$ & $\begin{array}{c}5^{\prime} \\
\text { intratumoural }\end{array}$ & $1: 100$ & $\begin{array}{l}\text { tu: } 1: 2.57 \\
\text { mu: } 1: 24\end{array}$ & $\begin{array}{l}\text { tu: } 38.9 \\
\text { mu: } 4.17\end{array}$ \\
\hline
\end{tabular}

- Output ratios are given for tumour (tu) and muscle (mu); phage titers were corrected for the weight of the organ and expressed as cfu/mg.

In a second model, we have investigated the use of more refractive endothelial cells for phage panning. We cloned the anti E-selectin antibody ENA-1 into scFv format containing a flexible 15-residue Gly-Ser linker using a cloning procedure and primers as described by [18]. For model selections on activated versus non-activated endothelium, we first selected mixtures of anti-E selectin scFv expressing phage and control phage (fd-DOG1) on human umbilical vein endothelial cells (HUVEC) monolayers. E-selectin expression on HUVEC was induced by a 4 hr incubation with TNF- $\alpha$.

Different phage mixtures of control and E-selectin specific phage were selected on TNF- $\alpha$ 
stimulated and non-stimulated human endothelial cells, grown either in 24- or 6-well plates (Table 5A and $\mathrm{B}$ respectively). As expected, phage could not be enriched by panning on Eselectin negative, non-activated endothelial cells (Table 5A). However, after a single selection round on E-selectin-expressing, activated endothelial cells, different degrees of enrichment of ENA-1 displaying phage were obtained, with an average of 44 fold enrichment for all selections performed, and a maximum enrichment of 72 fold (Table 5B).

\section{Table 5}

Model cell selections on HUVEC monolayers

A

\begin{tabular}{|l||l|c|l|l|l|c|}
\hline Treatment & $\begin{array}{l}\text { Washing } \\
\text { Blocking }\end{array}$ & $\begin{array}{l}\text { Elution } \\
\text { condition }\end{array}$ & $\begin{array}{l}\text { Input } \\
\text { Ratio }\end{array}$ & $\begin{array}{l}\text { Output } \\
\text { Ratio }\end{array}$ & $\begin{array}{l}\text { Enrichment } \\
\text { factor }\end{array}$ & $\begin{array}{l}\text { Recovery } \\
(\%)\end{array}$ \\
\hline \hline $\begin{array}{l}\text { Fixed } \\
\text { cells }\end{array}$ & $\begin{array}{l}10 \mathrm{X} \\
\text { MPBS }\end{array}$ & $\begin{array}{c}100 \mathrm{mM} \\
\mathrm{HCL}\end{array}$ & $1: 53$ & $1: 54$ & $\begin{array}{c}\text { No } \\
\text { Enrichment }\end{array}$ & 0.013 \\
\hline \hline $\begin{array}{l}\text { Fixed } \\
\text { cells }\end{array}$ & $\begin{array}{l}10 \mathrm{X} \\
\text { MPBS }\end{array}$ & $\begin{array}{c}100 \mathrm{mM} \\
\text { TEA }\end{array}$ & $1: 53$ & $1: 6$ & 8.8 & 0.057 \\
\hline $\begin{array}{l}\text { + AZIDE } \\
+ \text { TNF } \alpha\end{array}$ & $\begin{array}{l}\text { 10X } \\
\text { MPBS }\end{array}$ & $\begin{array}{c}100 \mathrm{mM} \\
\text { TEA }\end{array}$ & $1: 53$ & $1: 7.9$ & 6.7 & 0.049 \\
\hline $\begin{array}{l}\text { Fixed } \\
\text { cells }\end{array}$ & $\begin{array}{l}\text { MPX } \\
\text { MPBS }\end{array}$ & $\begin{array}{c}100 \mathrm{mM} \\
\mathrm{HCL}\end{array}$ & $1: 53$ & $1: 5.3$ & 10 & 0.045 \\
\hline $\begin{array}{l}\text { Fixed } \\
\text { cells } \\
+ \text { TNF } \alpha\end{array}$ & $\begin{array}{l}10 \mathrm{X} \\
\text { PBS-BSA }\end{array}$ & $\begin{array}{c}100 \mathrm{mM} \\
\mathrm{HCL}\end{array}$ & $1: 53$ & $1: 7$ & 7.6 & 0.06 \\
\hline
\end{tabular}

In order to prevent internalisation of E-selectin [37], ceils were treated either with azide or mildly fixed with $1 \%$ paraformaldehyde. Fixation of the cells generally resulted in increased enrichment and recovery. This is probably due to the higher integrity of fixed vs azide-treated cell monolayers during selection. Both MPBS or PBS/BSA were tested as blocking/washing agents during selections. Both agents demonstrated similar blocking/washing capacity, but MPBS was overall a better agent. We also compared elution of binding phage using $100 \mathrm{mM} \mathrm{HCl}$ or $100 \mathrm{mM}$ TEA, since it has been reported that elution buffers can have an effect on overall recovery of phage [38]. Both methods are efficient in eluting specific phage; however, $\mathrm{HCl}$ elution resulted in higher enrichment factors. 
B

\begin{tabular}{|l||l|l|l|l|l|c|}
\hline Treatment & $\begin{array}{l}\text { Washing/ } \\
\text { Blocking }\end{array}$ & $\begin{array}{l}\text { Elution } \\
\text { condition }\end{array}$ & $\begin{array}{l}\text { Input } \\
\text { ratio }\end{array}$ & $\begin{array}{l}\text { Output } \\
\text { ratio }\end{array}$ & $\begin{array}{l}\text { Enrichment } \\
\text { factor }\end{array}$ & $\begin{array}{l}\text { Recovery } \\
(\%)\end{array}$ \\
\hline $\begin{array}{l}\text { Fixed } \\
\text { cells }\end{array}$ & $\begin{array}{l}10 \mathrm{X} \\
\text { MPBS }\end{array}$ & $\begin{array}{c}100 \mathrm{mM} \\
\mathrm{TEA}\end{array}$ & $1: 60$ & $1: 1.8$ & 33.3 & 0.14 \\
\hline $\begin{array}{l}\text { Fixed } \\
\text { cells } \\
+ \text { TNF- } \alpha\end{array}$ & $\begin{array}{l}10 \mathrm{X} \\
\text { MPBS }\end{array}$ & $\begin{array}{c}100 \mathrm{mM} \\
\mathrm{HCL}\end{array}$ & $1: 60$ & $1: 1.2$ & 72 & 0.123 \\
\hline $\begin{array}{l}\text { Fixed } \\
\text { cells }\end{array}$ & $\begin{array}{l}5 \mathrm{X} \\
\text { MPBS }\end{array}$ & $\begin{array}{c}100 \mathrm{mM} \\
\mathrm{HCL}\end{array}$ & $1: 914$ & $1: 16$ & 57.1 & 0.34 \\
\hline $\begin{array}{l}\text { Fixed } \\
\text { cells }\end{array}$ & $\begin{array}{l}\text { 20X } \\
\text { MPBS }\end{array}$ & $\begin{array}{c}100 \mathrm{mM} \\
\mathrm{HCL}\end{array}$ & $1: 914$ & $1: 14$ & 65.3 & 0.094 \\
\hline
\end{tabular}

To iest the effect of the amount of antigen on selection efficiency in this model, selections were performed on cell monolayers grown in both 24 and 6-well plates. After 10 washes, enrichment on 6 well plates was, on average, 6.4 fold higher than on 24 well plates. Recovery of specific phage was also higher, increasing with (on average) $0.08 \%$ for selections on 6 well plates (Table 5A and B). Variations of the washing procedure were then tested to increase the selection efficiency. Extensive washing decreased phage recovery, but did not have a significant effect on the enrichment of specific phage (Table 5B). Phage recovery was dependent on the number of washes: recovery of ENA-1 phage was found to be reduced from $0.34 \%$, after 5 washes, to $0.09 \%$ after 15 additional washes. Therefore, as can be calculated from the data in Table 5, an average of $13 \%$ of the phage input was lost per wash during the first 5 washes, and an average $1.6 \%$ per wash during the subsequent 15 washes. After the first 5 washes, additional washing increased the enrichment only 1.14 fold (Table 5B).

Selection on endothelial-cell monolayers was then compared with selection on columnimmobilised cells, since this method can be simultaneously used for library selections on endothelial cells isolated from tumors by magnetic activated cell sorting (MACS). For the first column selections, cells were magnetically labelled via anti-CD31 and anti mouse microbeads and caught onto a MACS column. Cell panning was then performed by running the phage mix through the cell-loaded column. This method resulted in enrichment factors similar to the average enrichment obtained after selections on monolayers, most likely because it does not allow extensive interaction between phage antibodies and cell surface antigens (Table 5 and 6). However, incubation of phage with cells for $1 \mathrm{hr}$ prior to loading the cells on the MACS column and extensive washing of the column gave a 460 fold enrichment, which was far superior to any 
selection on cell monolayers (Table 5 and 6). In this model, column-immobilised cell selection appears therefore to be more effective than selections on monolayers. This is probably due to a more efficient washing procedure, since the number of phage recovered in the washes from columns was on average over 10 fold higher than the number of phage recovered from monolayer washes (data not shown). The increased stringency of washing also correlates with the low recovery of specific phage after selection on MACS columns (Table 6).

\section{Table 6}

Model selections on HUVEC using a high gradient magnetic separation column; (A) phage loading on the column. (B) panning on cells in suspension, prior to loading on the column

A

\begin{tabular}{|l|l|l|l|l|l|}
\hline Treatment & Elution condition & $\begin{array}{l}\text { Input } \\
\text { Ratio }\end{array}$ & $\begin{array}{l}\text { Output } \\
\text { Ratio }\end{array}$ & Enrichment & $\begin{array}{l}\text { Recovery } \\
(\%)\end{array}$ \\
\hline \hline+ TNF- $\alpha$ & $100 \mathrm{mM}$ TEA & $40: 1$ & $1.2: 1$ & 33 & 0.00033 \\
\hline- TNF- $\alpha$ & $100 \mathrm{mM}$ TEA & $40: 1$ & $220: 1$ & -5.5 & 0 \\
\hline
\end{tabular}

\section{B}

\begin{tabular}{|l|l|l|l|l|l|}
\hline Treatment & Elution condition & $\begin{array}{l}\text { Input } \\
\text { Ratio }\end{array}$ & $\begin{array}{l}\text { Output } \\
\text { Ratio }\end{array}$ & Enrichment & $\begin{array}{l}\text { Recovery } \\
(\%)\end{array}$ \\
\hline \hline$+\mathrm{TNF}-\alpha$ & $100 \mathrm{mM}$ TEA & $100: 1$ & $1: 4.6$ & 460 & 0.00058 \\
\hline$-\mathrm{TNF}-\alpha$ & $100 \mathrm{mM}$ TEA & $100: 1$ & $69: 1$ & 1.4 & 0 \\
\hline
\end{tabular}

\section{Discussion}

In the present report, we describe the design and use of model systems to study the enrichment of phage antibodies on a number of complex antigen sources, including celf surfaces, tissue cryosections and in vivo grown solid tumours. This is the first report to directly compare these different selection strategies with regard to enrichment and recovery of specific phage. Furthermore, we have compared selections on tumour cells expressing high levels of EGP-2 to selections on vascular endothelial cells that can be stimulated to express physiological levels of E-selectin.

Antibody phage display has proven to be a very powerful method for the isolation of antibodies to defined target antigens [2, 39, 40], for review see [4, 5]. However, many applications of the technology require selections on non-purifiable (integral membrane-) antigens 
[41], while in other cases, the target antigen is unknown $[8,42]$. We are using the phage display technology to identify novel tumour-cell and tumour endothelial cell-markers by selecting large 'single pot' repertoires on these two cell types. Phage antibodies specifically recognising one of these two cell types then may define novel antigens. In all of these cases, selections have to be performed on complex mixtures of antigens, which makes retrieval of the desired specificity much more complicated for a number of reasons.

The antigen concentration (e.g. the density on the cellular surface) may be very low, thereby dramatically decreasing the chance of selecting antibodies, in particular those with lower affinity. In our model experiments, we found large differences in enrichment and recovery of specific phage, depending on the cell type, and antibody, and the selection strategy used (Table 2, 5 and 6). These differences may be caused by the antigen density on the cell surface and/or the nature of the antigen [38]. The expression level of E-selectin on HUVEC, induced by TNF- $\alpha$ activation of these cells, has not been described, but EGP-2 is present in high copy numbers on colorectal cancer cell lines $\left(10^{6}\right.$ copies/cell: [27]. Our model antigens EGP-2 and E-selectin both have the same overall architecture, being type I transmembrane molecules. Thus, their accessibility on the cell surface is most likely comparable. Indeed, both antigens are accessible for binding of phage antibodies, as demonstrated hy FACS analysie using FNA 1 and MOC 31 exproosing phage (Fig. 2). The large difference in FACS staining obtained using comparable amounts of phage (Fig. 2) is probably due to differences in expression level between the two antigens; however, it may also be explained by diffences in the level of antibody display and/or differences in antibody affinity.

As expected, enrichment on whole cells was clearly dependent on the affinity of the antibody, as shown by the reduced selection efficiency of MOC-161 compared with MOC-31. Both scFv antibodies recognise at least partially overlapping epitopes on EGP-2, which excludes possible effects of epitope inaccessibility on the selection efficiency. They differ in off-rate by a factor of approximately six [18], resulting in a six-fold lower enrichment factor and a two-and-a-half fold lower recovery of MOC-161 (Tabie 2). As shown, this factor is an understimate, since MOC-161 scFv was expressed to a higher level on phage than MOC-31, giving MOC-161 some avidity advantage.

Antigen expression on cells is highly dependent on the cellular environment and on cell-cell and cell-matrix interactions [36]. The antigenic expression of endothelium e.g. is dependent on its microenvironment: factors such as cell-cell interactions, cell-matrix interactions and other exogenous factors such as mechanical forces, soluble growth promoters and inhibitors, cytokines and plasma lipids and -proteins all influence the endothelial cell phenotype. Therefore, we decided to use primary endothelial cell monolayers directly for selection, maintaining cell-cell and partial cell-matrix interactions. In addition, this endothelial cell culture induces a proliferative phenotype [43], which can further be modulated to mimic the tumour-endothelial 
phenotype e.g. by the addition of soluble growth factors, cytokines and tumour conditionedmedium. However, the low enrichment and recovery obtained from the selections on monolayers indicated that this procedure needs optimisation. By optimisation of washing, blocking and elution and increasing the amount of antigen, we could achieve enrichment factors up to 72 on HUVEC monolayers (Table 5), indicating the importance of these selection parameters for more efficient phage library selections.

Highly pure cell populations may be isolated from complex cell mixtures (e.g tumour homogenates) by the use of MACS for selection purposes. This method allows simultaneous selection and depletion, since the phage library can be incubated with the cell mixture prior to the column isolation, resulting in the loss of phage antibodies binding to non target cells. As a first test for column based selections, we decided to use indirect labeling of HUVEC with an anti CD31 antibody and magnetic beads for model selections on a high gradient magnetic separation column. Panning on cells in suspension prior to loading on the column resulted in an improved enrichment factor (460-fold) compared with selection by direct panning on column immobilised cells or with selection on HUVEC monolayers (Table 5 and 6 ). This may be attributed to the improved interaction between cells and phage and to the efficient elimination of background phage by washing on the column. However, because of the nature of the washes on columns, mild for the cells and stringent for removal of unbound phage, recovery of ENA-1 phage was also dramatically decreased (Table 6). This effect will be most pronounced for lower affinity antibodies, thereby decreasing their chance for selection. These column-based selections appear to be particularly suitable to combine with subtractive selection strategies.

As an altemative to selections on cells, other antigen sources may be used that faithfuly mimic the in vivo antigen expression profile and that allow appropriate in vitro selection procedures to be used. Selection on tissue cryosections has been described [44], but this has not yet been compared with selection on other complex antigens. Our comparative analysis shows that enrichment and recovery of phage were reduced compared with selection on whole live cells (Table 2 and 3), most likely due to the limited amount of antigen present. Despite the fact that we used primary, patient-derived tumours instead of artificially grown Colo205 xenografts for selection, recovery of specific phage $(0.02 \%$ of input: Table 3$)$ was similar to what has been descibed for selections on cryosections (output/input ratio $10^{-4}:[44]$. However, the presence of extracellular matrix components and other (antigen-negative) cell types in the sections we used for selection may have caused increased recovery of background phage, thereby explaining the lower enrichment factors we found in our mode! system (80-fold versus 1500 fold). Indeed, recovery of background phage was more than 50-fold higher than reported (output/input ratio $5 \times 10^{-6}$ versus $<10^{-7}$, [44]. Furthermore, the abundance of intracellular antigens in such tissue sections may hamper the selection of cell-surface reactive antibodies, making subtractive 
selection strategies necessary.

A novel strategy to identify tumour specific antibodies is the in vivo selection method. The feasability of this selection strategy, first described for the selection of peptide phage [10, 32], was first tested in our model for the selection of tumour cell-specific markers. In this model, no enrichment of MOC-31 expressing phage could be observed in the tumour (compared to muscle) of LS174T-xenografted mice, by injecting phage mixtures into the tail vein (Table 4). This may be explained by limited contact with antigen, since during the 5 ' circulation, phage do not cross the endothelial lining of blood vessels and penetrate into the organ interstitium to encounter antigen [32]. This hypothesis was strengthened by injecting a phage mixture directly into the tumour, which did result in a ten-fold enrichment of MOC-31 expressing phage (comparing tumour to muscle: Table 4). Therefore, this selection procedure seems more suitable for the isolation of tumour endothelial cell-specific markers. In a preliminary experiment using a model of human skin grafted onto athymic mice (as desribed by [45], activation of endothelial cells through local injection of TNF- $\alpha$ and i.v. administration of a phage mix, ENA-1 expressing phage could indeed be enriched in the skin graft. Phage were allowed to circulate for $10^{\prime}$ or $4 \mathrm{hrs}$ in vivo, resulting in a 39-fold and 141-fold enrichment of ENA-1 expressing phage respectively (data not shown). This also shows the beneficial effect of longer circulation times on the in vivo selection efficiency in this model. However, the very large quantities of unbound phage present in blood, which are only slowly cleared, still limit the chances for successful in vivo selections. Other possibilities to decrease the recovery of background phage than the prolonged incubation time (allowing physiological removal of unbound phage), include e.g. in vivo perfusion of the animal and washing of the homogenised tumour after removal from the animal.

The enrichment factors and recoveries of specific phage antibodies found for the different selection methods described in this report have implications for the design of selections on complex antigen, such as tumour cells or endothelial cells of the tumour vasculature. The enrichment factors reported here for selections on whole live cells compare very favourably with those previously reported [46, 47]; 25- and 12-fold respectively versus the 60 to 10,000 -fold reported here, for a single round of selection). These enrichment factors are particularly important when using very large libraries, containing $10^{9}$ to $10^{10}$ different antibodies $[40,48,49]$. Due to the large diversity of these repertoires, only a limited number of phage particles per clone is generated after rescue of the unselected library. To retrieve the total population of binding antibodies after the first, critical round of selection, the efficiency of selection must be high enough to bridge the difference in input and output phage numbers. If selection efficiency in the first round is low, then even high affinity clones like MOC-31 might be lost from such large repertoires. For example, when the output titer of phage is $10^{6}$ for the first round of selection and the diversity of the repertoire is $10^{10}$. MOC-31 would most likely be retrieved by panning on 
whole live cells in suspension (with enrichment factors $>10^{4}$ ). However, when using less efficient selection regimens, even this high affinity clone may be lost. Lower selection efficiencies then mean that only a fraction of the total binding population will be retrieved, resulting in different selected antibodies every time a series of selections is repeated.

A difficulty of the use of large, non-immune or synthetic repertoires for selection on complex antigens is that they contain antibodies to a whole range of epitopes expressed on the antigenic surface $[2,50]$. Therefore, antibodies with the desired specificity may be largely obscured by clones binding to irrelevant epitopes. To direct the selection of phage antibodies towards specific epitopes, subtraction and depletion strategies have been devised and successfuly used $[42,51$ 55]. The removal of non-relevant clones can also be achieved by alternating selection on different antigen sources to home in on antigen-binding clones [56].

Alternatively, phage antibody repertoires may be used in which the starting frequency of antigen-specific clones in the primary library is increased by immunisation with the antigen of interest (in those cases, where the antigen is known: [51, 57] or by using patient-derived repertoires (in case the antigen is unknown: [42]. Since these repertoires are shaped by the immune system, they contain a higher starting frequency of binding antibodies that will have overall higher affinities, which will increase the chances of selecting those with the desired specificity.

We conclude that these model systems are valuable tools to study phage antibody selections on different complex antigen sources. This is the first report that directly compares selections on recombinant antigen to cell-based panning, selections on tissue cryosections and to an in vivo model. Our data clearly demonstrate the feasibility of using complex antigen sources for selections, but also indicate that part of the total binding population may be lost, if the procedure is not carefuly designed. This report provides valuable information for the application of phage display technology in the search for novel tumour associated-antigens. Recently, we have used the experimental conditions derived from our model experiments to design and perform selections on HUVECS and $\mathrm{CaCo} 2$ cells. Indeed, by direct panning without subtraction or depletion strategies, we were able to identify a large number of antibodies directed to both cell types and some antibodies selected on activated HUVEC display tumour endothelial cell specificity. The latter may serve as novel anti-cancer targeting moieties.

\section{Acknowledgements}

We would like to thank Prof: Dr. D. Herlyn for her gift of the EGP-2 antigen and Dr. van Zonneveld for his gift of the pCOMB3 vector containing the cloned V-genes of the ENA-I 
antibody. This research was partially financially supported by the Netherlands Technology Foundation (STW) and was coordinated by the Life Sciences Foundation (SLW: project MGN55.3858, 63-95). R.M. was financially supported by the Basque Country government (grant nr. BF195.155AK).

\section{References}

1. McCafferty J, Griffiths AD, Winter G, Chiswell DJ (1990) Phage antibodies: filamentous phage displaying antibody variable domains. Nature 348: 552-554

2. Marks JD, Hoogenboom HR, Bonnert TP, McCafferty J, Griffiths AD, Winter G (1991) By-passing Immunization; Human Antibodies from V-gene Libraries Displayed on Phage. J. Mol, Biol. 222: 581-597

3. Griffiths AD, Williams SC, Hartley O, Tomlinson IM, Waterhouse P, Crosby WL, Kontermann RE, Jones PT, Low NM, John Allison T, Prospero TD, Hoogenboom HR, Nissim A, Cox JPL, Harrison JL, Zaccolo M, Gherardi E, Winter G (1994) Isolation of high affinity human antibodies directly from large synthetic repertoires. EMBO.J. 13: 3245-3260

4. Winter G, Griffiths AD, Hawkins RE, Hoogenboom HR (1994) Making antibodies by phage display technology. Annu. Rev. Immunol. 12: 433-455

5. Hoogenboom HR, de Bruïne AP, Hufton SE, Hoet RM, Arends JW, Roovers RC (1998) Antibody phage display technology and its applications. Immunotechnology 4: 1-20

6. Smith GP, Scott JK (1993) Libraries of peptides and proteins displayed on filamentous phage. Methods Enzymol. 217: 228-257

7. Ward RL, Clark MA, Lees J, Hawkins NJ (1996) Retrieval of human antibodies from phage-display libraries using enzymatic cleavage. J. Immunol. Methods 189: 73-82

8. van Ewijk W, de Kruif J, Germeraad WTV, Berendes P, Röpke C, Platenburg PP, Logtenberg T (1997) Substractive isolation of phage-displayed single-chain antibodies to thymic stromal cells by using intact thymic fragments. Proc. Natl. Acad. Sci. U. S. A. 94: $3903-3908$

9. Siegel DL, Chang TY, Russell SL, Bunya VY (1997) Isolation of cell surface-specific human monoclonal antibodies using phage display and magnetically-activated cell sorting: applications in immunohematology. J. Immunol. Methods 206: 73-85

10. Rajotte D, Arap W, Hagedorn M, Koivunen E, Pasqualini R, Ruoslahti E (1998) Molecular Heterogeneity of the Vascular Endothelium Revealed by In Vivo Phage Display. J. Clin. Invest. 102: 430-437

11. Meulemans EV, Slobbe R, Wasterval P, Ramaekers FC, van Eys GJ (1994) Selection of phage-displayed antibodies specific for a cytoskeletal antigen by competitive elution with a monoclonal antibody. J. Mol, Biol. 244: 353-360

12. Osbourn JK, Derbyshire EJ, Vaughan TJ, Field AW, Johnson KS (1998) Pathfinder selection: in situ isolation of novel antibodies. Immunotechnology 3: 293-302

13. Shen R, Su ZZ, Olsson CA, Goldstein NI, Fisher PB (1994) Surface-epitope masking: a strategy for the development of monoclonal antibodies specific for molecules 
expressed on the cell surface. J. Natl. Cancer Inst. 86: 91-98

14. Riethmüller G, Schneider-Gädicke E, Schlimok G, Schmiegel G, Raab R, Höffken K, Gruber R, Pichlmaier H, Hirche H, Pichlmayer R, Buggisch P, Witte J (1994) Randomized trial of monoclonal antibody for adjuvant therapy of resected Dukes' C colorectal carcinoma. The Lancet 343: 1177-1183

15. Thorpe PE, Burrows FJ (1995) Antibody-directed targeting of the vasculature of solid tumors. Breast Cancer Res. Treat. 36: 237-251

16. Gottlinger HG, Funke I, Johnson JP, Gokel JM, Riethmuller G (1986) The epithelial cell surface antigen 17-1A, a target for antibody-mediated tumor therapy: its biochemical nature, tissue distribution and recognition by different monoclonal antibodies. Int. J. Cancer 38: 47-53

17. Mattes MJ, Major PP, Goldenberg DM, Dion AS, Hutter RV, Klein KM (1990) Patterns of antigen distribution in human carcinomas. Cancer Res, 50: $880 \mathrm{~s}-884 \mathrm{~s}$

18. Roovers RC, Henderikx P, Helfrich W, van der Linden E, Reurs A, de Bruine AP, Arends JW, de Leij L, Hoogenboom HR (1998) High-affinity recombinant phage antibodies to the pan-carcinoma marker epithelial glycoprotein-2 for tumour targeting. Br. J. Cancer 78: 1407-1416

19. Leeuwenberg JF, Jeunhomme TM, Buurman WA (1989) Induction of an activation antigen on human endothelial cells in vitro. Eur. J. Immunol. 19: 715-720

20. Kuzu I, Bicknell R, Fletcher CD, Gatter KC (1993) Expression of adhesion molecules on the endothelium of normal tissue vessels and vascular tumors. Lab. Invest. 69: 322328

21. Kraling BM, Razon MJ, Boon LM, Zurakowski D, Seachord C, Darveau RP, Mulliken JB, Corless CL, Bischoff J (1996) E-selectin is present in proliferating endothelial cells in human hemangiomas. Am. J. Pathol. 148: 1181-1 i9]

22. Renkonen J, Paavonen T, Renkonen R (1997) Endothelial and epithelial expression of sialyl Lewis $(\mathrm{x})$ and sialyl Lewis(a) in lesions of breast carcinoma. Int. J. Cancer 74: 296-300

23. Nguyen M (1997) Angiogenic factors as tumor markers. Invest. New Drugs 15: 29-37

24. Clackson T, Hoogenboom HR, Griffiths AD, Winter G (1991) Making antibody fragments using phage display libraries. Nature 352: 624-628

25. Amit AG, Mariuzza RA, Phillips SE, Poljak RJ (1986) Three-dimensional structure of an antigen-antibody complex at 2.8 A resolution. Science 233: 747-753

26. Relou IA, Damen CA, van der Schaft DW, Groenewegen G, Griffioen AW (I998) Effect of culture conditions on endothelial cell growth and responsiveness. Tissue \& Cell 30: $525-530$

27. Oredipe OA, Barth RF, Rotaru JH, Hinkle GH, Steplewski Z (1990) Alterations in monoclonal antibody affinity and antigenic receptor site expression on mycoplasmainfected human colorectal cancer cells. Proc. Soc. Exp. Biol. Med. 194: 301-307

28. Strassburg CP, Kasai Y, Seng BA, Miniou P, Zaloudik J, Herlyn D, Koprowski H, Linnenbach AJ (1992) Baculovirus recombinant expressing a secreted form of a transmembrane carcinoma-associated antigen. Cancer Res. 52: 815-821

29. Sambrook T, Fritsch EF, Maniatis T (1989) eds. Molecular Cloning: A Laboratory 
Manual. Cold Spring Harbor Laboratory Press, Cold Spring Harbour, p

30. Kretzschmar T, Zimmermann C, Geiser M (1995) Selection procedures for nonmatured phage antibodies: a quantitative comparison and optimization strategies. Anal. Biochem. 224: 413-419

31. Schier R, Marks JD (1997) Efficient in vitro affinity maturation of phage antibodies using B!Acore guided selections. Hum. Antibodies Hybridomas 7: 97-105

32. Pasqualini R, Ruoslahti E (1996) Organ targeting in vivo using phage display peptide libraries. Nature 380: 364-366

33. de Bruin R, Spelt K, Mol J, Koes. R, Quattrocchio F (1999) Selection of high-affinity phage antibodies from phage display libraries. Nat. Biotechnol. 17: 397-399

34. Garrard LJ, Yang M, O'Connell MP, Kelley RF, Henner DJ (1991) Fab assembly and enrichment in a monovalent phage display system. Biotechnology (N. Y.) 9: 1373-1377

35. Tesar M, Beckmann C, Rottgen P, Haase B, Faude U, Timmis KN (1995) Monoclonal antibody against pIII of filamentous phage: an immunological tool to study pIII fusion protein expression in phage display systerns. Immunotechnology 1: 53-64

36. Greiner JW, Hand PH, Noguchi P, Fisher PB, Pestka S, Schlom J (1984) Enhanced expression of surface tumor-associated antigens on human breast and colon tumor cells after recombinant human leukocyte alpha-interferon treatment. Cancer Res. 44: 32083214

37. Kuijpers TW, Raleigh M, Kavanagh T, Janssen H, Calafat J, Roos D, Harlan JM (1994) Cytokine-activated endothelial cells internalize E-selectin into a lysosomal compartment of vesiculotubular shape. A tubulin-driven process. J. Immunol. 152: 5060-5069

38. Hoogenboom HR, Lutgerink JT, Pelsers MMAL, Rousch MJMM, Coote J, Van Neer N, de Bruïne A, van Nieuwenhoven FA, Glatz JFC, Arends J-W (1999) Selectiondominant and nonaccessible epitopes on cell- surface receptors revealed by cell-panning with a large phage antibody library. Eur. J. Biochem. 260: 774-784

39. Griffiths AD, Malmqvist M, Marks JD, Bye JM, Embleton MJ, McCafferty J, Baier M, Holliger KP, Gorick BD, Hughes-Jones NC, Hoogenboom HR, Winter G (1993) Human anti-self antibodies with high specificity from phage display libraries. EMBO J. 12: $725-734$

40. Vaughan TJ, Williams AJ, Pritchard K, Osbourn JK, Pope AR, Earnshaw JC, McCafferty J, Hodits RA, Wilton J, Johnson KS (1996) Human Antibodies with Subnanomolar Affinities Isolated from a Large Non-immunized Phage Display Library. Nat. Biotechnol, 14: 309-3!4

41. Marks JD, Ouwehand WH, Bye JM, Finnem R, Gorick BD, Voak D, Thorpe SJ, Hughes-Jones NC, Winter G (1993) Human antibody fragments specific for human blood group antigens from a phage display library. Biotechnology (N.Y.) 11: 1145-1149

42. Cai X, Garen A (1995) Anti-melanoma antibodies from melanoma patients immunized with genetically modified autologous tumor cells: Selection of specific antibodies from single-chain Fv fusion phage libraries. Proc. Natl. Acad. Sci. U. S. A. 92: 6537-6541

43. Grant DS, Tashiro K, Segui-Real B, Yamada Y, Martin GR, Kleinman HK (1989) Two different laminin domains mediate the differentiation of human endothelial cells into capillary-like structures in vitro. Cell 58: 933-943 
44. Tordsson J, Abrahmsen L, Kalland T, Ljung C, Ingvar C, Brodin T (1997) Efficient selection of scFv antibody phage by adsorption to in situ expressed antigens in tissue sections. J. Immunol. Methods 210: 11-23

45. Otulakowski G, Zhou L, Fung-Leung WP, Gendimenico GJ, Samuel SE, Lau CY (1994) Use of a human skin-grafted nude mouse model for the evaluation of topical retinoic acid treatment. J. Invest. Dermatol. 102: 515-518

46. Watters JM, Telleman P, Junghans RP (1997) An optimized method for cell-based phage display panning. Immunotechnology 3: 21-29

47. Pereira S, Maruyama H, Siegel D, Van-Belle P, Elder D, Curtis P, Herlyn D (1997) A model system for detection and isolation of a tumor cell surface antigen using antibody phage display. J. Immunol. Methods 203: 11-24

48. Sheets MD, Amersdorfer P, Finnern R, Sargent P, Lindqvist E, Schier R, Hemingsen G, Wong C, Gerhart JC, Marks JD (1998) Efficient construction of a large nonimmune phage antibody library: the production of high-affinity human single-chain antibodies to protein antigens. Proc, Natl. Acad. Sci. U.S. A. 95:6157-6162

49. de Haard HJ, van Neer N, Reurs A, Hufton SE, Roovers RC, Henderikx P, de Bruĭne AP, Arends J-W, Hoogenboom HR (1999) A large non-immunized human Fab fragment phage library that permits rapid isolation and kinetic analysis of high affinity antibodies. J. Biol. Chem. 274: 18218-18230

50. Nissim A, Hoogenboom HR, Tomlinson IM, Fiyn G, Midgley C, Lane D, Winter G (1994) Antibody fragments from a 'single pot' phage display library as immunochemical reagents. EMBO J. 13: 692-698

51. Ames RS, Tornetta MA, Jones CS, Tsui P (1994) Isolation of neutralizing anti-C5a monoclonal antibodies from a filamentous phage monovalent Fab display library. $J$. Immunol. 152: 4572-4581

52. de Kruif J, Terstappen L, Boel E, Logtenberg T (1995) Rapid selection of cell subpopulation-specific human monoclonal antibodies from a synthetic phage antibody library. Proc. Natl. Acad. Sci. U. S. A. 92:3938-3942

53. Kipriyanov SM, Kupriyanova OA, Little M, Moldenhauer G (1996) Rapid detection of recombinant antibody fragments directed against cell-surface antigens by flow cytometry. J. Immunol. Methods 196: 51-62

54. Parsons HL, Earnshaw JC, Wilton J, Johnson KS, Schueler PA, Mahoney W, McCafferty J (1996) Directing phage selections towards specific epitopes. Protein Eng. 9: 1043-1049

55. Stausbol-Gron B, Wind T, Kjaer S, Kahns L, Hansen NJ, Kristensen P, Clark BF (1996) A model phage display subtraction method with potential for analysis of differential gene expression. FEBS Lett. 391: 71-75

56. Andersen PS, Stryhn A, Hansen BE, Fugger L, Engberg J, Buus S (1996) A recombinant antibody with the antigen-specific, major histocompatibility complexrestricted specificity of T cells. Proc. Natl. Acad. Sci. U.S. A. 93: 1820-1824

57. Chester KA, Begent RH, Robson L, Keep P, Pedley RB, Boden JA, Boxer G, Green A, Winter G, Cochet O, et al. (1994) Phage libraries for generation of clinically useful antibodies. The Lancet 343: 455-456 


\section{Chapter 8}

Identification of colon tumour-associated antigens by phage antibody sellections on primary colorectal carcinoma

Rob C. Roovers, Edith van der Linden, Adriaan P. de Bruïne, Jan-Willem Arends and Hennie R. Hoogenboom

Submitted for publication 


\begin{abstract}
İmmunotargeting of solid tumours using antibodies, has become a valuable tool for the detection of cancer metastases and the treatment of minimal residual disease. However, only few tumour antigens useful for targeting have been described to date. To identify cell-surface targets on colorectal carcinoma, we selected a large, human phage antibody repertoire on freshly isolated colon tumour cells. Two antibodies were identified that reacted with epithelial cell-restricted cellsurface antigens, whereas one clone preferentially reacted with stromal cells. These antigens are tumour-associated antigens, as shown by their uniform expression in tumours of different patients and of different differentiation stages and their limited expression on normal tissues. The pattern of reactivity in immunohistochemistry and ELISA suggests that these antigens are different from previously identified tumour-associated antigens (e.g. Ep-CAM or c-ERB-2). This phage antibody-based method may lead to the cloning of novel tumour antigens that are useful for immunotargeting of solid tumours.
\end{abstract}

\title{
Introduction
}

Colorectal cancer (CRC) is the second most prevalent cancer in western world. The principal treatment modality is surgical removal of the primary tumour and adjuvant chemotherapy (at present, 6 months of fluorouracil (5-FU) plus leucovorin (folinic acid) can be considered standard therapy) for metastatic disease. However, especially for minimal residual disease, immunotherapy using monoclonal antibodies directed to tumour-associated antigens has proven to be a promising new treatment modality $[1,2]$. However, most of the target antigens described to date for colon cancer (e.g. CEA, c-ERB-2, TAG72, Ep-CAM) are tumour-associated and thus are also expressed on normal colon. This may give rise to toxicity problems when these antigens are used as target for the treatment of patients [3].

The search for new target antigens expressed on cancer has traditionally involved the immunization of mice with cancer cells, cell lines or cell-extracts and the subsequent screening of hybridomas for antibodies that bind the target cell [4]. In addition, tumour antigens have been identified by the cloning of T-cells that recognise MHC-I restricted peptides derived from the antigen [5]. More recently, genetic approaches are increasingly being used to define genes that are associated with malignant transformation [6] or to define distinct genetic subtypes of malignancies [7] at the transcriptional level.

Antibody phage display (reviewed in [8]) has also been used as a means to quickly select. antibodies specific for certain cell types or tissues [9, 10] or known tumour antigens [11, 12]. This strategy may be used to identify cell-surface structures on cancer cells: novel antigens can then be defined by means of the antibodies that recognise them. Although this approach has 
already been successfully applied to melanoma $[13,14]$ and to a lesser extent also to lung carcinoma [15], untill now, only one study has been reported that describes the selection of antibodies reactive CRC antigens [16].

The success of this approach depends on many parameters, including the phage antibody library size and quality and particularly on the selection method used. We have previously described a study of phage antibody selections on complex antigens, such as cell surfaces, in which we investigated the parameters important for successful selection [17]. These models were used to define selection criteria for efficient selection on whole tumour cells. Here, we describe the use of these protocols for the selection of human antibody fragments reactive with colon cancer. By direct panning of a large, non-immunised phage antibody repertoire [18] on freshly isolated colon tumour cells, we retrieved antibodies that recognise patient-derived tumour material in immunohistochemistry (IHC). The antigens recognised by these selected antibody fragments proved to be tumour-associated antigens by their uniform expression in tumours of a number of different CRC patients. On the basis of their expression pattern in normal tissues, they cannot be classified as any of the colon tumour-antigens known to date. However, the selected antibodies failed to recognise the native antigen, revealing that the target epitopes were dependent on chemical modification of the proteins.

This study shows that phage antibody technology may successfully be used to select antibodies with reactivity to possibly novel colon tumour antigens.

\section{Materials and Methods}

\section{E.coli strain}

TGI: K12, $\Delta$ (lac-pro), supE, thi, hsdD5/F'traD36, proA 'B', lacl', lacZuMI5

\section{Cell line}

Colorectal cancer cell line $\mathrm{CaCo} 2$ was obtained from the American Type Culture Collection (ATCC; number HTB37) and was cultured in Dulbecco's Modified Eagle Medium (DMEM; Dulbecco, ICN Pharmaceuticals, Costa Mlesa, CA-USA) supplemented with I0\% (v/v) fetal calf serum and $2 \mathrm{mM}$ glutamine. Cells were kept at $37^{\circ} \mathrm{C}$ in a humidified atmosphere containing $5 \% \mathrm{CO}_{2}$.

\section{Phage antibody selection on primary colorectal carcinoma}

A large, non-immunised phage antibody repertoire [18] was used for selection. The library was rescued with helper phage $\mathrm{M} 13 \mathrm{~K} 07$ and phages were purified and concentrated from 
the bacterial culture supernatant by polyethylene glycol (PEG) precipitation as described [19]. After each selection round, the percentage of bacterial clones containing complete (Fab) insert was also determined, since a loss of clones containing $\mathrm{V}$-gene insert is representative of inefficient selection.

After surgery, primary colorectal cancer tissue was obtained from the department of Pathology. Tissue was rinced three times with $20 \mathrm{ml}$ of PBS $(50 \mathrm{mM}$ phosphate buffer $\left.\left(\mathrm{KH}_{2} \mathrm{PO}_{4} / \mathrm{Na}_{2} \mathrm{HPO}_{4}: \mathrm{pH} 7.4\right) ; 150 \mathrm{mM} \mathrm{NaCl}\right)$, cut in smali pieces using a sterile scalpel blade and rinced again with PBS. Tissue pieces were allowed to settle and buffer supernatant was removed. Cells were detached by overnight incubation at $4^{\circ} \mathrm{C}$ in isolation buffer (PBS, containing $1 \mathrm{mM}$ EDTA, ImM EGTA and $0.5 \mathrm{mM}$ DTT) with gentle shaking. Next day, cells were harvested by centrifugation $\left(100 \mathrm{~g}, 3 \mathrm{~min}, 4^{\circ} \mathrm{C}\right)$, washed three times with $10 \mathrm{ml}$ of PBS by centrifugation and resuspension and fixed in $5 \mathrm{ml} 0.25 \%$ (w/v) paraformaldehyde in PBS for $20 \mathrm{~min}$ at $4^{\circ} \mathrm{C}$. Cells were washed three times again with $10 \mathrm{ml}$ of PBS, pelleted $\left(100 \mathrm{~g}, 3 \mathrm{~min}, 4^{\circ} \mathrm{C}\right)$ and resuspended in $1 \mathrm{ml}$ of PBS. Phages were blocked for $1 \mathrm{~h}$ at it in $1 \mathrm{ml}$ of $4 \%(\mathrm{w} / \mathrm{v})$ Marvell (skimmed milk powder) in PBS (4\%MPBS), added to the cell suspension and incubated for $1 \frac{1}{2} \mathrm{~h}$ at room temperature $(\mathrm{rt})$ with gentle shaking. Cells were washed five times with $5 \mathrm{ml}$ of PBS by centrifugation and resuspension and phages were eluted with $1 \mathrm{ml}$ of $100 \mathrm{mM}$ tri-ethylamine (TEA) for $10 \mathrm{~min}$ at $\mathrm{rt}$. The eluate was neutralised with $0.5 \mathrm{ml} 1 \mathrm{M} \mathrm{Tris} \cdot \mathrm{Cl}(\mathrm{pH} \mathrm{7.5)}$ and phages were allowed to infect exponentially growing E.coli TGI and titrated as described [19].

Characterisation of selected antibody fragments by DNA-fingerprinting and immunohistochemistry

After selection, antibody-encoding $\mathrm{V}$-genes of selected antibody fragments were amplified by PCR from a single bacterial colony using primers pUC-reverse (5'-AGC GGA TAA CAA TTT CAC ACA GG-3') and fd-TET seq (5'-TTT GTC GTC TTT CCA GAC GTT AGT-3). The percentage of bacterial clones containing complete (Fab) insert was then determined, since a decrease of clones containing $\mathrm{V}$-gene insert is representative of inefficient selection. Finally, antibody V-genes were DNA-fingerprinted as described [19].

For immunohistochemistry (IHC), five micrometer cryosections of different cancerous and normal tissues were cut and mounted on Starfrost Adhesiv (Klinipath, Duiven, the Netherlands) glass slides. Slides were dried overnight at room temperature $(r t)$ and stained with recombinant Fab antibody fragments as described for single-chain Fv (scFv) by Roovers et al. [20]. Large scale production and purification of antibodies reactive in IHC using immobilised metal ion affinity chromatography (IMAC) and fast protein liquid chromatography (FPLC) were as described for scFv by Roovers er al. [20]. 
Analysis of cell surface-binding of selected antibody fragments by means of flow cytometry

Adherently growing $\mathrm{CaCo} 2$ cells were harvested at subconfluency by trypsin/EDTA treatment and washed once with PBS. Cells were either used directly, or fixed with $1 \%(\mathrm{w} / \mathrm{v})$ paraformaldehyde in PBS for $20 \mathrm{~min}$ at $\mathrm{rt}$. Subsequently, cells were washed twice with $2 \%$ (w/v) bovine serum albumin (BSA) in PBS and aliquots of approximately $5 \times 10^{5}$ cells were made. All incubations were carried out for one hour at $\mathrm{rt}$ in either $2 \% \mathrm{MPBS}$ containing $0.05 \%(\mathrm{w} / \mathrm{v}) \mathrm{NaN}_{\text {, }}$ $\left(2 \% \mathrm{MPBS} / \mathrm{N}_{3}\right)$ for untreated cells, or in $2 \% \mathrm{MPBS}$ for paraformaldehyde-fixed cells. Cells were washed twice with $0.5 \mathrm{ml}$ of the respective buffer between every incubation step. Staining was performed with purified, recombinant antibody fragments (100nM), the $9 E 10$ antibody ( [21]; $50 \%(\mathrm{v} / \mathrm{v})$ hybridoma supernatant) and FITC-conjugated rabbit anti mouse immunoglobulines (Dako, Glostrup, Denmark; $2 \%(\mathrm{v} / \mathrm{v})$ ). Cells were finally resuspended in $0.5 \mathrm{ml}$ of PBS and staining was visualised by flow cytometry using a FACS-Calibur (Becton \& Dickinson, Heidelberg, Germany).

\section{Results}

To identify possibly novel cell-surface antigens on colorectal carcinoma, we set out to select phage antibodies with specificity for colon tumour cells by panning a very large Fab phage antibody repertoire [18] against freshly isolated tumour cells. For practical reasons, a new tumour-cell isolation from a tumour of a different patient was performed for every round of selection; therefore, the amount of cells differed between selections. Table 1 shows the results of selections: there is no clear increase in phage titer, but this may be explained by the differences in cell number used for selection. However, the percentage of clones containing full-length Fab insert did increase with every selection round, hinting towards successful selection (Table 1).

After four and five rounds of selection, the diversity of the selected phage antibody population was examined and clones having a distinct fingerprint pattern ( 25 after round four and 17 after round five) were subsequently tested for their reactivity towards colorectal cancer tissue in immunohistochemistry (IHC). After four rounds of phage selection, no positive signals were observed in the screening of different selected antibodies by means of IHC on colon tumour tissue of a different patient. However, after five rounds of selection, three out of 17 different $B s t N$ I fingerprint patterns tested were scored positive in IHC (Fig. 1). 


\section{Table 1}

Characteristics of phage antibody selections and percentage of clones containing full-length insert

\begin{tabular}{c|l|l|l|l|c}
\hline $\begin{array}{l}\text { Selection } \\
\text { round: }\end{array}$ & $\begin{array}{l}\text { Input titer* } \\
\text { (i) }\end{array}$ & $\begin{array}{l}\text { Output titer* } \\
(\mathrm{o})\end{array}$ & Ratio o/i & $\begin{array}{l}\text { Enrichment } \\
\text { factor** }\end{array}$ & $\begin{array}{l}\text { \% full-length } \\
\text { clones }\end{array}$ \\
\hline 1 & $4.2 \times 10^{12}$ & $2.6 \times 10^{7}$ & $6.2 \times 10^{-6}$ & n.a. & n.d. \\
2 & $2.4 \times 10^{13}$ & $5.0 \times 10^{7}$ & $2.1 \times 10^{-6}$ & 0.34 & n.d. \\
3 & $1.8 \times 10^{13}$ & $3.3 \times 10^{8}$ & $1.8 \times 10^{-5}$ & 8.57 & 83 \\
4 & $8.0 \times 10^{12}$ & $4.9 \times 10^{7}$ & $6.1 \times 10^{-6}$ & 0.34 & 94 \\
5 & $2.5 \times 10^{13}$ & $4.1 \times 10^{8}$ & $1.6 \times 10^{-5}$ & 2.62 & 100 \\
\hline
\end{tabular}

* titers are given as colony-forming unit (cfu)/ml

*" enrichment factor is defined as:

(Ratio o/i selection round $\mathrm{n}+1) /($ Ratio $o / \mathrm{i}$ selection round $\mathrm{n}$ )

n.a. nor applicable

n.d. not determined
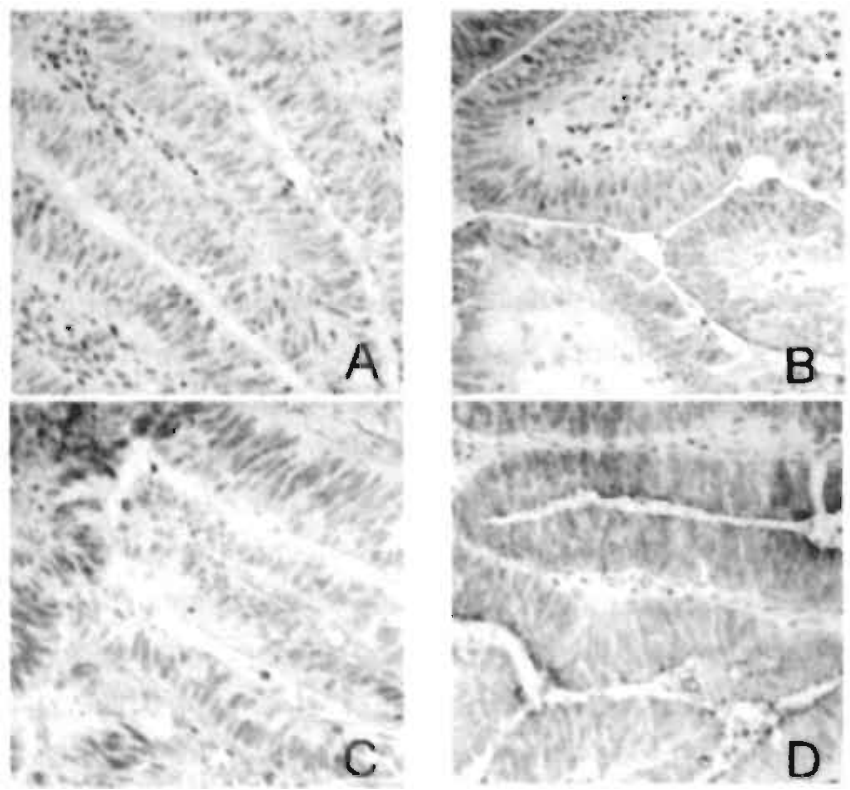

\section{Figure 1}

Immunohistochemical staining of tissue cryosections of colon carcinoma using recombinant Fab antibody fragments.

Bound antibody fragments were detected with the 9EI0 antibody recognising a C-mye-derived epitope tag and peroxydase-labeled anti mouse antibodies.

A: negative control (a Fab antibody directed to tetanus toxoid); $\mathrm{B}$ : clone B5; C: clone B8 and D: clone C8.

Two of the antibodies exclusively stained malignant epithelial cells (clones B5 and C8): the observed staining pattern was mostly membranous, but also partially cytoplasmic (Fig. Ib and 
Id). The remaining clone (B8) reacted very slightly with epithelial cells, but strongly stained stromal cells (e.g. fibroblasts: Fig. Ic). The V-genes of these selected antibodies were sequenced and shown to originate from different, but commonly used V-gene families (Table 2). VH genes were all derived from the largest (VH3) gene family and light chain genes originated from both isotypes (Vא2 and 3 and $V \lambda 3$ families: Table 2). Production of the antibodies as soluble Fab fragments in E.coli revealed that all antibodies were expressed as disulfide-bridged heterodimers of light and heavy chain of approximately $45 \mathrm{kDa}$. All antibodies could be purified to more than $90 \%$ by one-step immobilised metal-ion affinity chromatography (IMAC: Fig. 2a). In addition, fast protein liquid chromatography (FPLC) analysis of IMAC-purified Fab showed a single peak at the retention time expected for a protein of approximately 50kDa (Fig. 2b). The yield of purified antibody fragment varied between 600 and $800 \mu \mathrm{g}$ per L of bacterial culture.

\section{Table 2}

Overview of $V$ - D- and J-segment usage of selected phage antibodies.

\begin{tabular}{|c|c|c|c|c|}
\hline V-gene: & $\begin{array}{l}\text { V-gene } \\
\text { family }\end{array}$ & $\begin{array}{l}\text { Closest germline } \\
\text { V-gene segment }\end{array}$ & D-segment used & $\mathrm{J}$-segment used \\
\hline VH (clone B5) & $\mathrm{VH} 3$ & DP-77/WGHl6+ & D5-5 & $\mathrm{JH} 4 \mathrm{~b}$ \\
\hline VL (clone B5) & $V \times 3$ & $\mathrm{Vg} / 38 \mathrm{k}$ & n.a. & $\mathbf{J} \leqslant 2$ \\
\hline VH (clone B8) & $\mathrm{VH} 3$ & VHGL3.7/DP-82 & D6-25 & JH6b \\
\hline VL (clone B8) & $\mathrm{V} \kappa 2$ & DPK27/A29+ & n.a. & n.d. \\
\hline VH (clone C8) & $\mathrm{VH} 3$ & $\cos -8 / \mathrm{hv} 3005 \mathrm{f} 3$ & D6-13/DNI & $\mathrm{JH} 4 \mathrm{~b}$ \\
\hline VL (clone C8) & $V \lambda 3 i$ & DPL16/VL3.1 & n.a. & JL2/JL3a \\
\hline
\end{tabular}

n.a.: not applicable

n.d.: using the sequence alignment software of V-base: (http://www.mre-cpe.cam.ac.uk/imt-doc/restricted DNAPLOT htmi), the segment could not be determined

To validate the antigens recognised by the selected antibody fragments as putative colon tumour antigens, their presence on several different colon tumours $(n=10)$ of various differentiation (Dukes' A through C) was tested by immunohistochemical analysis. All three antigens were expressed in all tumours tested, giving the same staining pattern as shown in Fig. 1. To examine whether the target antigens were also expressed in different adenocarcinomas than $\mathrm{CRC}$, staining of carcinomas the stomach, lung and breast was performed. Clone C8 showed strong homogeneous positivity for all tumours; Fab B5 showed strong positivity for breast and lung carcinoma, but was more heterogeneous reactive with stomach carcinoma and clone B8 was negative on all tumours. 
of the antigen (data not shown). In addition, immunoprecipitation using capture of native antigen in solution did neither result in the precipitation of a specific protein (data not shown). These results show that the epitopes recognised by the antibody fragments could well be dependent on chemical modification of the antigen expressed on the cell-surface.

Indeed, flow cytometric analysis of $\mathrm{CaCo} 2$ cells using Fab fragments $\mathrm{B} 5$ and $\mathrm{C} 8$ showed that antibody reactivity was abolished when cells were not fixed with paraformaldehyde (Fig. 3) or treated with a reducing agent (dithiothreitol (DTT): data not shown). However, both antibody fragments did strongly stain paraformaldehyde-fixed whole $\mathrm{CaCo} 2$ cells, proving that the antigens recognised by antibodies $\mathrm{B} 5$ and $\mathrm{C} 8$ are cell-surface markers.
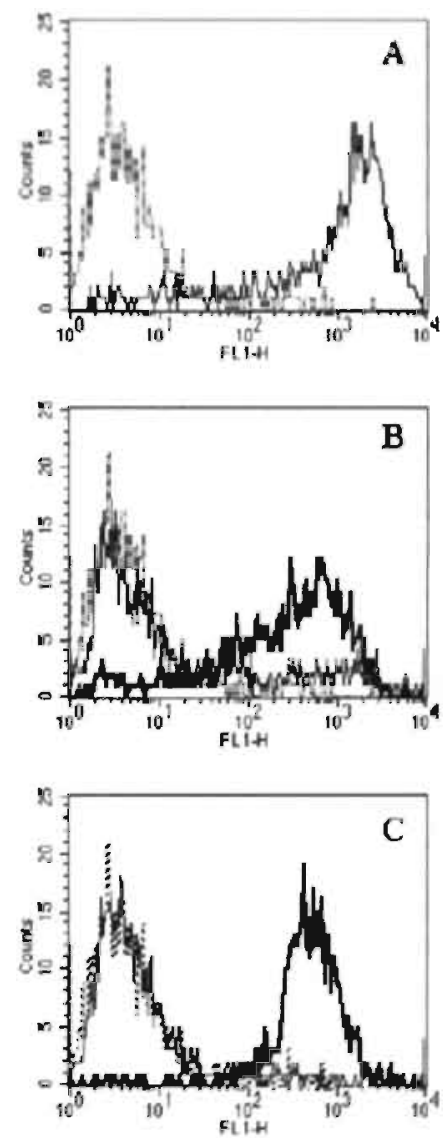

Figure 3,

Cell-surface binding of purified, recombinant antibody fragments $B 5$ and C8 as demonstrated by flow cytometric analysis using the CRC cell lime $\mathrm{CaCo}$.

Histogram plots showing the number of gated whoic cells (counts) as a function of their fluorescence intensity ( $\mathrm{FLi}-\mathrm{H})$. Cells were either untreated, or fixed with $1 \%(\mathrm{w} / \mathrm{v})$ paraformaldehyde prior to staining. Negative control staining (an antibody to the antigen tetanus toxoid) is shown in all panels by a dotted line.

A: the anti Ep-CAM antibody MOC3! (thin line) as positive control; B: Fab B5 staining of untreated celk (thin line) and fixed cels (thick line); $\mathrm{C}$ : Fab C8 staining of untreated cells (thin line) and fixod cells (thick line) 
Table 3

Expression profile of antigens recognised by selected phage antibody fragments

\begin{tabular}{|c|c|c|c|}
\hline Tissue & Staining by Fab B5 & Staining by Fab B 8 & Staining by Fab C8 \\
\hline Breast & $\begin{array}{l}\text { membranous and } \\
\text { cytoplasmic }+ \text { on } \\
\text { epithelial cells }\end{array}$ & n.d. & 一 \\
\hline Colon & $\begin{array}{l}\text { membranous + on } \\
\text { epithelial cells }\end{array}$ & $\begin{array}{l}\text { smooth muscle cells } \\
\text { and endothelial cells } \\
\text { slightly }+\end{array}$ & $\begin{array}{l}\text { membranous }+ \text { on } \\
\text { epithelial cells }\end{array}$ \\
\hline Ileum & $\begin{array}{l}\text { mostly membranous + on } \\
\text { epithelial cells only }\end{array}$ & - & $\begin{array}{l}\text { membranous and } \\
\text { cytoplasmic }+ \text { on } \\
\text { epithelial cells only }\end{array}$ \\
\hline Kidney & $\begin{array}{l}\text { only distal tubuli }+ \\
\text { glomeruli - }\end{array}$ & - & $\begin{array}{l}\text { piroximal/distal } \\
\text { tubuli + } \\
\text { glomeruli - }\end{array}$ \\
\hline Larynx & - & - & - \\
\hline Liver & $\begin{array}{l}\text { only bile ducts slightly }+ \\
\text { hepatocytes - }\end{array}$ & - & $\begin{array}{l}\text { bile ducts and } \\
\text { hepatocytes + }\end{array}$ \\
\hline Lung & $\begin{array}{l}\text { bronchial, kubic } \\
\text { epithelium + }\end{array}$ & - & $\begin{array}{l}\text { bronchial, cubic } \\
\text { epithelium + }\end{array}$ \\
\hline Lymph node & & & - \\
\hline Muscle & & $\begin{array}{l}\text { endothelial cells } \\
\text { slightly }+\end{array}$ & \\
\hline Ovarium & & & inclusion-cysts + \\
\hline Pancreas & $\begin{array}{l}\text { exocrine part + } \\
\text { endocrine part - }\end{array}$ & n.d. & $\begin{array}{l}\text { exocrine part }+ \\
\text { endocrine part - }\end{array}$ \\
\hline Skin & & & - \\
\hline Spleen & - & & \\
\hline $\begin{array}{l}\text { Stomach: } \\
\text { antrum }\end{array}$ & $\begin{array}{l}\text { membranous and } \\
\text { cytoplasmic + on } \\
\text { epithelial cells }\end{array}$ & $\begin{array}{l}\text { very locally + } \\
\text { mostly - }\end{array}$ & $\begin{array}{l}\text { membranous and } \\
\text { cytoplasmic + on } \\
\text { epithelial cells }\end{array}$ \\
\hline Thyroid & (focally), very slightly + & $\begin{array}{l}\text { some smooth muscle } \\
\text { cells slightly }+\end{array}$ & $\begin{array}{l}\text { strongly } \\
\text { membranous + with } \\
\text { apical accentuation }\end{array}$ \\
\hline Uterus & - & & $\begin{array}{l}\text { epithelium of basal } \\
\text { parts of tubules }+\end{array}$ \\
\hline
\end{tabular}




\section{Discussion}

In this report, we describe the successful isolation of antibodies with specificity for antigens expressed in colorectal carcinoma by panning a large, non-immunised phage antibody library on colon tumour cells isolated from patient-derived tissue. Antibodies B5 and C8 recognise epithelial cell-specific antigens and antibody B8 preferentially reacts with stromal cells in colon tumours only. These antigens are of interest, because they are expressed in sections of all $(n=10)$ colon tumours tested and in only a limited panel of normal epithelial tissues. They are not tumour-specific in the strict sense, but may be classified as tumour-associated antigens. Future quantitative expression studies are needed to further validate these antigens as tumour markers.

The selection protocol used for phage antibody selection was designed to direct the selection towards epitopes common to different tumours and to avoid possible selection of antibodies directed to antigens unique for one patient (e.g. HLA molecules). Therefore, tumours used were not matched or selected for any stage or differentiation stage. Indeed, the three phage antibodies selected showed reactivity towards CRC tissue of all different patients tested $(\mathrm{n}=10)$. However, the abundance of clones that did not react in IHC (14 out of 17 different antibodies tested after five rounds of selection) may indicate that numerous antibodies specific for a subset of patients were selected. Since the selected pool of antibodies after five selection rounds was still diverse and only a limited number of the selected clones was sampled, it is expected that many more specificities may be identified by additional screening.

Selections were performed on patient-derived tumour material which was treated with DTT to extract tumour cells from the surrounding extracellular matrix and tumour cells were fixed with paraformaldehyde to preserve the cell surface during the selection procedure. Therefore, it is no surprise that the epitope recognised by all three selected antibody fragments depends on modification of the cell surface. These antibody fragments themselves are therefore not useful for in vivo targeting of CRC, but may be of value for immunodiagnosis of CRC. In this respect it is noteworthy that Fab C8 recognises its antigen in formaline-fixed, paraffin-embedded tissue sections, which may enlarge its usefulness for diagnostic applications.

The use of a direct selection strategy without depletion or subtraction does not avoid the retrieval of antibodies that cross-react with normal tissue, as witnessed by the reactivity of the selected clones towards a subset of normal tissues (Table 3 ). To direct the selection towards tumour-specific epitopes, depletion and/or subtraction strategies should be used $[9,13,16]$. In addition, future experiments should be designed such that the selection of antibodies reactive with modified antigens is avoided. A number of different selection strategies may be envisioned, including selections on labelled cell lysates or membrane preparations, or the use of tissue sections. Phage antibody selections on tissue cryosections of patient material have already been 
successfully used [22]. Indeed, in the model system we have described before [17], we aiso found that moderate enrichment factors of specific phage can be achieved on this source of antigen. Therefore, we have explored this selection strategy for the selection of antibodies to colon tumour antigens. However, after multiple rounds of selection, a loss of phage clones containing Fab insert was observed, indicating that the selection pressure was not sufficient for the selection of binding phage (data not shown). This was probably caused by the limited amount of antigen present in tissue cryosections.

Expression of tumour-associated antigens in normal tissue may cause toxicity in patients when an antigen is used as target for immunotherapy [3]. However, for radio-immunodiagnosis, low-level expression in normal tissue may be less of a problem [23, 24]. In the latter setting, less antibody is given to patients causing less toxicity problems in antigen-positive normal tissues, even when the antigen is shed into the circulation [25]. The normal tissues that are important for dose-limiting toxicity are blood cells when radio-immuno targeting (RAIT) is used [26] and mainly the liver and kidney when unconjugated antibody is used. The antigen recognised by selected antibody B5 is not present on hepatocytes and only on the distal tubuli in the kidney, thereby probably avoiding an important cause of toxicity in patients. In addition, none of the target antigens was expressed on lymphocytes, as witnessed by the absence of staining in lymph node tissue. This shows that by direct phage antibody selection on primary CRC, antigens with promising tissue distribution for immunotargeting of cancer may be identified.

On the basis of their expression pattern, the antigens targeted by the selected antibody fragments do not correspond to any of the known colon tumour-antigens c-ERB-2 [27], CEA. [28] or Ep-CAM [29]. This was confirmed in ELISA using the purified proteins (data not shown). Whether the exact epitope recognised by the selected antibodies is composed of a carbohydrate structure was not yet assessed. Therefore, it cannot be excluded that the selected. antibodies are directed to a cancer-associated carbohydrates (e.g. TAG-72 / Sialyl-Tn [30]). However, this seems very unlikely since the immunoreactivity of selected antibodies could be restored by treatment with a reducing agent (data not shown), which does not affect carbohydrate structures. Further characterisation of these antigens using appropriately treated cell preparations is expected to reveal the molecular nature of these antigens.

In conclusion, we have shown that phage antibody display provides a powerful means to quickly select anti-tumour antibodies which show limited cross-reactivity with normal tissues and may identify suitable targets for immunotargeting of CRC.

\section{Acknowledgements}

We thank Prof. D, Herlyn and Dr, P. Carter for their generous gift of antigen. 


\section{References}

1. Saleh MN, LoBuglio AF, Wheeler RH, Rogers KJ, Haynes A, Lee JY, Khazaeli MB (1990) A phase II trial of murine monoclonal antibody 17-1A and interferon-gamma: clinical and immunological data. Cancer Immunol. Immunother 32: 185-190

2. Riethmüller G, Holz E, Schlimok G, Schmiegel W, Raab R, Hoffken K, Gruber R, Funke I, Pichlmaier H, Hirche H, Buggisch P, Witte J, Pichlmayr R (1998) Monoclonal antibody therapy for resected Dukes' C colorectal cancer: seven-year outcome of a multicenter randomized trial. J. Clin. Oncol. 16: 1788-1794

3. Knox SJ, Goris ML, Tempero M, Weiden PL, Gentner L, Breitz H, Adams GP, Axworthy D, Gaffigan S, Bryan K, Fisher DR, Colcher D, Horak ID, Weiner LM (2000) Phase II trial of yttrium-90-DOTA-biotin pretargeted by NR-LU-10 antibody/streptavidin in patients with metastatic colon cancer. Clin. Cancer Res. 6: 406-414

4. Verstijnen CP. Arends JW, Moerkerk PT, Pijls M, Kuypers-Engelen B, Bosman FT (1989) Colonic epithelium reactive monoclonal antibodies. Identification and immunohistochemical localization of the target epitopes. Histochemistry 92:397

5. Boon $\mathrm{T}$, van-der-Bruggen $\mathrm{P}$ (1996) Human tumor antigens recognized by $\mathrm{T}$ lymphocytes. J. Exp. Med. 183: 725-729

6. Yang GP, Ross DT, Kuang WW, Brown PO, Weigel RJ (1999) Combining SSH and cDNA microarrays for rapid identification of differentially expressed genes. Nucleic Acids Res. 27: 1517-1523

7. Alizadeh AA, Eisen MB, Davis RE, Ma C, Lossos IS, Rosenwald A, Boldrick JC, Sabet H, Tran T, Yu X, Powell JI, Yang L, Marti GE, Moore T, Hudson J Jr, Lu L, Lewis DB, Tibshirani R, Sherlock G, Chan WC, Greiner TC, Weisenburger DD, Armitage JO, Warnke R, Staudt LM, et al. (2000) Distinct types of diffuse large B-cell lymphoma identified by gene expression profiling [see comments]. Nature 403: 503-511

8. Hoogenboom HR, de Bruine AP, Hufton SE, Hoet RM, Arends JW, Roovers RC (1998) Antibody phage display technology and its applications. Immunotechnology 4: 1-20

9. de Kruif J, Terstappen L, Boel E, Logtenberg T (1995) Rapid selection of cell subpopulation-specific human monoclonal antibodies from a synthetic phage antibody library. Proc. Natl. Acad. Sci. U. S. A. 92: 3938-3942

10. van Ewijk W, de Kruif J. Germeraad WTV, Berendes P, Röpke C, Platenburg PP, Logtenberg T (1997) Substractive isolation of phage-displayed single-chain antibodies to thymic stromal cells by using intact thymic fragments. Proc. Natl. Acad. Sci. U. S. A.

94: $3903-3908$

11. Topping KP, Greenman J, Monson JR (1997) Isolation of anti-colorectal tumour antibodies fíom a phage-display library. Biochem. Soc. Trans. 25: $268 \mathrm{~S}$

12. Tordsson JM, Ohlsson LG. Abrahmsen LB, Karlstrom PJ, Lando PA, Brodin TN (2000) Phage-selected primate antibodies fused to superantigens for immunotherapy of malignant melanoma. Cancer Immunol. Immunother 48: 691-702

13. Cai X, Garen A (1995) Anti-melanoma antibodies from melanoma patients immunized with genetically modified autologous tumor cells: Selection of specific antibodies from single-chain Fv fusion phage libraries. Proc. Natl. Acad. Sci. U. S. A. 92: 6537-6541

14. Kupsch JM, Tidman NH, Kang NV, Truman H, Hamilton S, Patel N, Newton Bishop JA, Leigh IM, Crowe. JS (1999) Isolation of human tumor-specific antibodies by selection of 
an antibody phage library on melanoma cells [In Process Citation]. Clin. Cancer Res. 5: 925-93 ॥

15. Ridgway JB, Ng E, Kern JA, Lee J, Brush J, Goddard A, Carter P (1999) Identification of a human anti-CD55 single-chain. Fv by subtractive panning of a phage library using tumor and nontumor cell lines. Cancer Res. 59: 2718-2723

16. Topping KP, Hough VC, Monson JR, Greenman J (2000) Isolation of human colorectal tumour reactive antibodies using phage display technology. Int. J. Oncol. 16: 187-195

17. Mutuberria R, Hoogenboom HR, van der Linden E, de Bruïne AP, Roovers RC (1999) Model systems to study the parameters determining the success of phage antibody selections on complex antigens. J. Immunol. Methods 231: 65-81

18. de Haard HJ, van Neer N, Reurs A, Hufton SE, Roovers RC, Henderikx P, de Bruïne AP, Arends J-W, Hoogenboom HR (1999) A large non-immunized human Fab fragment phage library that permits rapid isolation and kinetic analysis of high affinity antibodies. J. Biol. Chem. 274: 18218-18230

19. Marks JD, Hoogenboom HR, Bonnent TP, McCafferty J, Griffiths AD, Winter G (1991) By-passing Immunization; Human Antibodies from V-gene Libraries Displayed on Phage. J. Mol. Biol. 222: $581-597$

20. Roovers RC, Henderikx P, Helfrich $W$, van der Linden E, Reurs A, de Bruine AP, Arends JW, de Leij L, Hoogenboom HR (1998) High-affinity recombinant phage antibodies to the pan-carcinoma marker epithelial glycoprotein-2 for tumour targeting. Br. J. Cancer 78: 1407-1416

21. Munro S, Pelham HR (1986) An Hsp70-like protein in the ER: identity with the $78 \mathrm{kd}$ glucose-regulated protein and immunoglobulin heavy chain binding protein. Cell 46: 291 300

22. Tordsson J, Abrahmsen L, Kalland T, Ljung C, Ingvar C, Brodin T (1997) Efficient selection of scFv antibody phage by adsorption to in situ expressed antigens in tissue sections. J. Immanol. Methods 210: 11 -23

23. De Jonge MWA, Kosterink JGW, Bin YY, Bulte JWM, Kengen RAM, Piers DA, Hauw The T, De Leij L. (1993) Radioimmunodetection of Human Small Cell Lung Cancer Xenografts in the Nude Rat Using 111 In-labeled Monoclonal Antibody MOC-31. Eur. J. Cancer 29A: 1885-1890

24. Begent RHJ, Verhaar MJ, Chester KA, Casey J, Green AJ, Napier MP, Hope-Stone LD, Cushen N, Keep PA, Johnson CJ, Hawkins RE, Hilson AJW, Robson L (1996) Clinical evidence of efficient tumor targeting based on single-chain Fv antibody selected from a combinatorial', library. Nat. Med. 2: 979-984

25. Griffin TW, Brill AB, Stevens S, Collins JA, Bokhari F, Bushe H, Stochl MC, Gionet M, Rusckowski M, Stroupe SD, et al. (1991) Initial clinical' study of indium-111-labeled clone 110 anticarcinoembryonic antigen antibody in patients with colorectal cancer. $J$. Clin. Oncol. 9: 631-640

26. Welt S, Divgi CR, Kemeny N, Finn RD, Scott AM, Graham M, Germain JS, Richards EC, Larson SM, Oettgen HF, et al. (1994) Phase III study of iodine 131-labeled monoclonal antibody A33 in patients with advanced colon cancer. J. Clin. Oncol. 12: 1561-1571

27. Schechter AL, Stern DF, Vaidyanathan L, Decker SJ, Drebin JA, Greene MI, Weinberg RA (1984) The neu oncogene: an erb-B-related gene encoding a. 185.000-Mr tumour 
antigen. Nature 312: 513-516

28. Grunert F, Abuharfeil N, Luckenbach GA, von Kleist S (1984) Isolation and characterization of two proteins copurifying with carcinoembryonic antigen. Tumour Biol. 5: 221-232

29. Gottlinger HG, Funke I, Johnson JP, Gokel JM, Riethmuller G (1986) The epithelial cell surface antigen 17-1A, a target for antibody-mediated tumor therapy: its biochemical nature, tissue distribution and recognition by different monoclonal antibodies. $I n t . J$. Cancer 38: 47-53

30. Johnson VG, Schlom J, Paterson AJ, Bennett J, Magnani JL, Colcher D (1986) Analysis of a human tumor-associated glycoprotein (TAG-72) identified by monoclonal antibody B72.3. Cancer Res. 46: 850-857 


\section{Chapter 9}

Evidence for a bias towards intracellular antigens in the local humoral anti-tumour immune response of a colorectal cancer patient revealed by phage display

Rob C. Roovers, Edith van der Linden, Han Zijiema, Adriaan de Bruïne, Jan-Willem Arends and Hennie R. Hoogenboom

Submitted for publication 


\begin{abstract}
Many patients with colorectal carcinoma (CRC) mount a cellular as well as a humoral immune response to the tumor. To investigate the nature and specificity of the humoral immune response in a CRC patient, lymphocytes infiltrating the primary colorectal tumor and lymph nodes draining the tumor were used as antibody variable (V)-gene pools for the construction of phage antibody repertoires. These libraries were first validated by selection on the antigen tetanus toxoid and shown to contain antibodies that were probably derived from both naive and memory B-cells. The repertoires were then screened for the presence of antibodies directed to CRC by selection on the cell line $\mathrm{CaCo}$. For comparison, the same selections were performed with a phage antibody repertoire made from B-cells of healthy donors. Striking differences were observed in the panel of specificities selected from these different repertoires: although a large panel of antibodies reactive with patient-derived primary tumors was obtained from the immune repertoires, none of these were reactive with cell-surface antigens. However, selections using the non-immune library did result in numerous antibodies that recognised cell-surface markers on $\mathrm{CaCo}$. These data suggest a bias in the local humoral immune response in this CRC patient, directed primarily towards intrace!lular epithelial-cell specific target antigens.
\end{abstract}

\title{
Introduction
}

In patients with cancer, a humoral immune response directed to known tumor (associated) antigens has been demonstrated by the presence of circulating antibodies in serum [1-5]. Therefore, lymphoid lissue obtained from patients with cancer may constitute an enriched source of B-cells secreting antibodies to tumor antigens. In addition, it may be particularly useful for the deveiopment of immunotherapeutic protocols to know what antigens are target of an immune response in cancer patients [6].

Phage display of antibody fragments [7] has proven to be a powerful tool to select antibodies with a desired specificity from 'immune' or non-immune repertoires [8-12]. The technique has been used as a tool to synthesise 'artificial' antibody repertoires of high diversity in vitro for the selection of high affinity ligands [13, 14]. Alternatively, it may also be exploited to study in vivo humoral immune responses to particular antigens $[5,15,16]$.

We set out to study the humoral immune response in a colorectal cancer (CRC) patient by screening phage antibody repertoires made from patient material for the presence of antibodies reactive with colon tumors. Since lymph node tissue has proven to be a valuable source of variable (V)-genes for the construction of phage antibody repertoires [17] and since this tissue has also been shown to be a rich source of antibodies to known tumor antigens [5], we decided to use patient-derived lymph nodes (LN) draining a CRC for the construction of 'immune' phage 
antibody repertoires. In addition, as has successfuly been described for melanoma [18], we used the lymphocytes infiltrating the tumor (tumor infiltrating lymphocytes: TIL) as a source of antitumor antibodies.

The phage antibody repertoires constructed from these two tissues were subsequently screened for antibodies reactive with colon tumors by selection on the colorectal cancer cell line $\mathrm{CaCo}$. To assess whether these immune repertoires were biased in the spectrum of specificities they contain, thereby revealing possible in vivo tolerance mechanisms, we performed a comparative analysis by selecting a large, non-immnune phage antibody repertoire [11] on the same cell line. Large differences were observed in the specificities of antibodies selected from immune and non-immune libraries. From both V-gene sources, antibodies that were reactive with patient-derived primary CRC could be obtained. However, all antibodies selected from the local immune sources were directed to intracellular (cytoplasmic and nuclear) targets only, whereas non-immune phage antibody repertoires yielded a diverse scala of specificities to cell-surface markers. These data points towards the presence of a humoral immune response in this CRC patient that is strongly biased towards intracellular and epithelial cell-specific target antigens.

\section{Materials and Methods}

\section{E.coli strain}

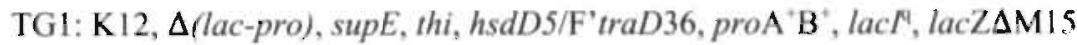

\section{Cell line}

Colorectal cancer cell line $\mathrm{CaCo} 2$ was obtained from the American Type Culture Collection (ATCC; number HTB37). Cells were cultured in Dulbecco's Modified Eagle's Medium (DMEM; Dulbecco, Life Technologies) supplemented with $10 \%(\mathrm{v} / \mathrm{v})$ fetal calf serum and $2 \mathrm{mM}$ glutamine in a humidified atmosphere containing $5 \% \mathrm{CO}_{2}$.

\section{Library construction}

Total RNA was isolated from two lymph nodes ( $\mathrm{LN}$, obtained after surgery) draining a colorectal tumor, or from part of the primary tumor (TIL), by means. of the RNazol method (Cinna Bioteckx Laboratories, Houston, U.S.A.). RNA was dissolved in water; possibly contaminating chromosomal DNA was digested with (RNase-free) RQ1-DNase (Promega, Madison, U.S.A.) for 30 minutes at $37^{\circ} \mathrm{C}$ and RNA was extracted again with RNAzol. $10 \mu \mathrm{g}$ of total RNA was then reverse transcribed (RT) using random hexamer primers (Promega, Madison, U.S.A.) and MMLV reverse transcriptase (Boehringer Mannheim, Mannheim, Germany) in a 
$50 \mu \mathrm{l}$ RT-reaction according to standard procedures [19]. For the LN-derived RNA, a CH1 $(\gamma 1)$ specific primer (CHI-FOR: 5'-GTC CTT GAC CAG GCA GCC CAG GGC-3') was used in parallel for cDNA synthesis. Variable domains of immunoglobulin heavy chain genes (VH) and complete (variable- and constant domain) light chain genes (VLCL) were then amplified by PCR from cDNA ( $5 \mu \mathrm{l}$ cDNA was used as template) using a mixture of family-based forward (FOR) primers with one of the family-based backward (BACK) primers in a separate reaction. Oligonucleotides used contained restriction sites for cloning and were as described by [12]. Amplification conditions for $\mathrm{VH}$ were: 30 cycles of $94^{\circ} \mathrm{C}, 1^{\prime} ; 55^{\circ} \mathrm{C}, 1^{\prime}$ and $72^{\circ} \mathrm{C}, 2^{\prime}$. Light chain genes $\left(\kappa\right.$ and $\lambda$ ) were amplified separately by 30 cycles of $94^{\circ} \mathrm{C}, 1^{\prime} ; 60^{\circ} \mathrm{C}, 1^{\prime}$ and $72^{\circ} \mathrm{C}, 2^{\prime}$. The primary PCR products (VH(RP; obtained from random primed $\mathrm{cDNA}), \mathrm{VH}(\operatorname{IgG}$; obtained from CHI(IgGy 1) primed $\mathrm{CDNA}$ ), VKCK and $\mathrm{V} \lambda \mathrm{C} \lambda$ ) were pooled per V-gene, digested with the appropriate resiriction enzymes (SfiI and BstEII for VH; ApaLI and AscI for VLCL) and ligated into the pCESI vector to yield different 'single-domain'-repertoires (VH(RP), $V \kappa C \kappa$ and $V \lambda C \lambda$ for both the LN- and TIL-derived RNA and VH(IgG) for the LN-derived RNA only). Ligated DNA was purified by phenol exiraction, precipitated with ethanol, electroporated [20] into E.coli TGI and bacteria were plated on $2 \times$ TY $/ \mathrm{A} / \mathrm{G}$ plates $(2 \times \mathrm{TY}$ medium plates $(1.6 \%(\mathrm{w} / \mathrm{v})$ trypton; $1 \%(\mathrm{w} / \mathrm{v})$ yeast extract; $0.5 \%(\mathrm{w} / \mathrm{v}) \mathrm{NaCl} ; 1.2 \%(\mathrm{w} / \mathrm{v})$ bacto-agar), supplemented with $2 \%(\mathrm{w} / \mathrm{v})$ glucose and $100 \mu \mathrm{g} / \mathrm{ml}$ ampicillin). Bacteria were harvested after overnight growth at $30^{\circ} \mathrm{C}$ in 2XTY/A/G medium and frozen in $2 \times T Y / A / G$, supplemented with $15 \%(\mathrm{v} / \mathrm{v})$ glycerol at $-80^{\circ} \mathrm{C}$. Plasmid DNA was then extracted from $500 \mu$ l of glycerol stock (of $\mathrm{OD}_{600}=100$, corresponding to approximately $10^{10}$ bacteria) of each of the 'single-domain'-repertoires using the QIAgen midi plasmid isolation kit (Qiagen, Hilden, Germany) and digested with ApaLI and Ascl. The resulting 750 base pair (bp) $\mathrm{V} \kappa \mathrm{CK}$ and $\mathrm{V} \lambda \mathrm{C} \lambda$ restriction fragments were gel-purified, pooled and ligated in the (ApaLI and Ascl-) digested heavy chain (VH) repertoires to yield full length Fab libraries. After transformation to E.coli TGI and overnight growth, individual bacterial clones were picked and analysed for the presence of full-length insert by means of PCR using the primers pUCBACK (5'-AGC GGA TAA CAA TTT CAC ACA GG-3') and fdTET-FOR (5'-TTT GTC GTC TTT CCA GAC GTT AGT-3').

\section{Phage selection on purified Tetanus Toxoid}

The two different lymph node repertoires (VH(RP) and VH(lgG)) were rescued separately with helper phage M13K07 and phages were panned for binding to purified tetanus toxoid (TT: Behringwerke, Marburg, Germany) in immunotubes as described [10]. The antigen was coated. at $10 \mu \mathrm{g} / \mathrm{ml}$ in $100 \mathrm{mM}$ carbonate buffer $(\mathrm{pH} 9.6)$; during the second selection round, the antigen concentration was lowered to $5 \mu \mathrm{g} / \mathrm{ml}$. After two selection rounds, individual bacterial clones. were tested for binding to antigen in ELISA. 


\section{ELISA}

After selection, individual bacterial clones were picked and expression of soluble Fab fragments was induced by activation of the upstream $L a c Z$ promotor with isopropyl- $\beta$-D galactopyranoside (IPTG) as described [10], [21]. After overnight growth at $30^{\circ} \mathrm{C}$, bacteria were pelleted $\left(4000 \mathrm{rpm}, 15^{\prime}, \mathrm{rt}\right)$ and the resulting supernatant was used in the assay. Antigens were coated overnight at $500 \mathrm{ng} / \mathrm{ml}$ and $4^{\circ} \mathrm{C}$ in $100 \mathrm{mM}$ carbonate buffer $(\mathrm{pH} 9.6)$ to flexible 96-wells ELISA plates (Falcon: Becton \& Dickinson, Heidelberg, Germany). The assay was further carried out as described for scFv by Roovers et al. [22].

For serological analysis, patient serum and serum of a healthy donor were decomplemented by heat-inactivation $\left(30\right.$ minutes at $56^{\circ} \mathrm{C}$ ) and serially diluted in $2 \%$ Marvell (skimmed milk powder) in PBS (2\%MPBS). Diluted sera were then added to antigen (TT)-coated wells and incubated for one hour at $\mathrm{rt}$. Bound $\mathrm{IgG}$ was then detected with a polyclonal rabbit antihuman IgG antiserum (Dako, Glostrup, Denmark; 0.1\% (v/v) in 2\%MPBS), peroxidase-coupled goat anti-rabbit immunoglobulines (Dako, Glostrup, Denmark; $0.1 \%(\mathrm{v} / \mathrm{v}$ ) in 2\%MPBS) and Trimethylbenzidin $(\mathrm{TMB}) / \mathrm{H}_{2} \mathrm{O}_{2}$ staining.

\section{Phage selection on colorectal cancer cell line $\mathrm{CaCo} 2$}

Approximately $10^{7} \mathrm{CaCo} 2$ cells were harvested at subconfluency by trypsine/EDTA treatment and cells were washed once with PBS. Constructed 'immune' phage antibody repertoires were rescued with helper phage M13K07 as described Marks et al. [10]. In parallel, a large, non-immune phage antibody repertoires was used [11]. Phages were panned for binding to live cells in suspension as described by Mutuberria et al. [23]. Four rounds of selection were performed using either the immune ( $\mathrm{LN}$ - and TIL-derived) or non-immune libraries.

\section{Analysis of antibody binding to cells by means of flow cytometry.}

Phage antibodies were rescued with helper phage Mi3K07 as described [10] and phage were purified and concentrated by precipitation from the bacterial culture supernatant with polyethylene glycol (PEG)/ $\mathrm{NaCl}$ as described [19]. $\mathrm{CaCo} 2$ cells were harvested by trypsinisation and aliquots of approximately $5 \times 10^{5}$ cells were made in polystyrene FACSscan tubes (Falcon: Becton \& Dickinson, Heidelberg, Germany). The assay was further carried out as described by Mutuberria et al. [23].

\section{Sequencing of $V$-genes}

V-genes of selected antibody fragments were sequenced according to the dideoxy chain termination method [24]. DNA was extracted from plasmid-containing bacteria by means of the QIAgen mini plasmid purification kit (QIAgen, Hilden, Germany) and used as template for 
sequencing reactions using the thermo sequenase fluorescent labeled primer cycle sequencing kit. (Amersham Pharmacia Biotech, Buckinghamshire, England) with 5-Cy labeled primers CH1FOR en pUC-BACK. Products of sequencing reactions were then analysed on a semi-automated sequencer (AlfExpress: Pharmacia, Uppsala, Sweden); obtained sequences were aligned to their closest germline match by alignment to V-base: http:/www.mrc-cpe.cam.ac.uk/imt-doc/ restricted/DNAPLOT.html.

\section{Immunohistochemical analysis of anibody specificity}

Cryosections of different tissues (normal colonic epithelium, colon carcinoma and melanoma) were cut and mounted on APTS coated slides. Sections were dried, fixed with 1\% $(w / v)$ paraformaldehyde in PBS and blocked with $1 \%(w / v)$ bovine serum albumin (BSA) in PBS. Silides were then stained with recombinant antibody fragments, the 9E10 antibody and peroxidase-coupled rabbit anti mouse immunoglobulines (Dako, Glostrup, Denmark) as described for scFv by Roovers et al. [22]. Diaminobenzidin (DAB)/ $\mathrm{H}_{2} \mathrm{O}_{2}$ staining was finally used to visualise bound antibody fragments.

\section{Results}

Construction of immune Fab phage antibody repertoires

To study the spectrum of antibody specificities secreted by B-cells of a CRC patient, we set out to construct Fab phage antibody repertoires either from the lymph nodes (LN) draining the colorectal carcinoma or from the TILs of that same carcinoma. First, tumor morphology of a number of different cases was examined histologically. For the construction of 'immune' phage antibody repertoires, a tumor localised in the rectum of a 62-year old male was selected. Histology of this case showed an adenocarcinoma with two important features: a wide differentiation spectrum of the tumor itself and a very dense mononuclear inflammatory infiltrate in the tunor stroma (Fig. 1A). The former theoretically ensures the presentation of a large diversity of tumor antigens to the host immune system and the latter reflects the immune response of the host. Morphologically, the carcinoma was on the one hand relatively poorly differentiated, showing extensive mucous production and a considerable signet ring-cell component (Fig. 1A, 1). However, in other areas, the process was relatively well differentiated and consisted of well-formed glandular structures lined by tumor cells with columnar- and goblet-cell features (Fig. 1A, 2). The stromal infiltrate (Fig. 1A, 3) contained histiocytes, lymphocytes and numerous plasma cells that were further characterised by IHC. They consisted of a polyclonal mixture of $\mathrm{IgG}, \mathrm{IgA}$ and $\mathrm{IgM}$ containing cells that expressed both isotypes of light chains ( $K$ and $\lambda$ ). There was a slight preponderance of IgA positive cells (data not shown). Tumor 
stage was pT3N2M0 with 8 lymphnode metastases (Fig. 1B). The presence of lymphocytic infiltrates in tumors from various sites is considered a good prognostic factor and can be correlated to a less advanced stage of disease and increased recurrence-free survival [25, 26]. Therefore, the presence of lymphocytic infiltrate probably indicates an active ongoing immune response to the autologous tumor in that patient and this prompted the selection of this tumor for the construction of phage antibody repertoires.

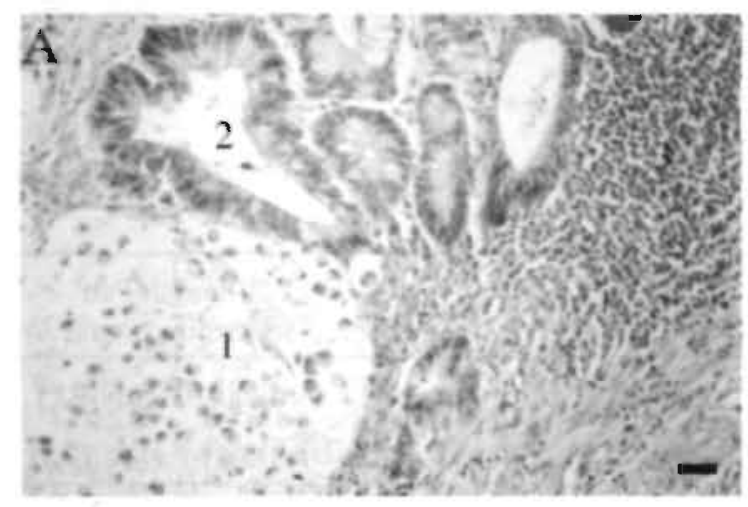

\section{Figure 1}

Morphology (HE staining) of the primary colorectal carcinoma and

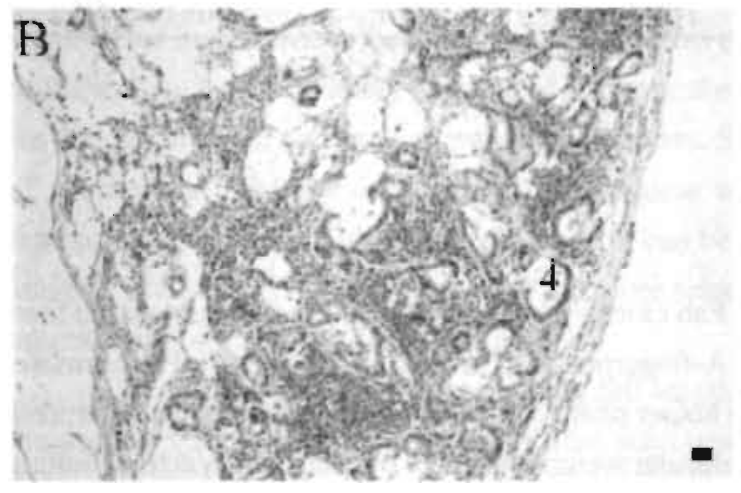
bymph node used for the construction of 'immune' phage anibody reperioires.

A: primary tumor of the selected patient containing various differentiation patterns: (i) a signet ring-cell/mucinous component; (2) a welldifferentiated component and (3) a heavy lymphocytic infiltrate (bar: $10 \mu \mathrm{m}$ ). B: pericolic lymph node containing (4) tumor metastasis (bar: $10 \mu \mathrm{m}$ ).

For the construction of phage antibody repertoires, total RNA was extracted from either two lymph nodes (LN) draining the tumor, or from part of the tumor itself (TIL). Immunoglobulin genes were then amplified by means of RT-PCR and Fab phage antibody repertoires were made in a two-step cloning procedure, analogous to the procedure described by de Haard et al. [12]. However, the order of cloning heavy- and light chain genes was reversed: complete light chain genes (VLCL) were cloned as ApaLI - AscI restriction fragments in the heavy chain-containing 'single domain' VH repertoires. Since these two restriction sites are only present in 2 out of 51 functional VH segments (http://www.mrc-cpe.cam.ac.uk/imt-doc/restricted 
/RESTRICTION.html), this strategy largely avoids restriction-biases of the libraries. To be able to discriminate between those antibodies that had arisen from a secondary immune response in vivo and that had thus undergone an isotype class-switch to IgG and antibodies of different isotype, we constructed repertoires in which either $\mathrm{CHI}(\gamma 1)$ isotype-specific priming or random priming (RP) was used for cDNA synthesis and subsequent amplification of VH genes. This resulted in two different LN-derived Fab repertoires (called 'RP' and 'IgG' hereafter). For the construction of the TIL-derived library, only random priming (RP) was used. The total size (diversity) of single-domain and full-length Fab repertoires is listed in Table 1.

\section{Table 1}

Size/diversity (in total numbers of CFU containing insert) of single-domain and full-length Fab 'immune ' phage antibody repertoires

\begin{tabular}{|c|c|c|c|c|c|}
\hline $\begin{array}{l}\text { V-gene } \\
\text { source }\end{array}$ & $\begin{array}{l}\text { VH (RP)! } \\
\text { library }\end{array}$ & $\begin{array}{l}\mathrm{VH}(\mathrm{IgG})^{2} \\
\text { library }\end{array}$ & VkCk library & $\mathrm{V} \lambda C \lambda$ library & $\begin{array}{l}\text { Full-length Fab } \\
\text { repertoire ( } \mathrm{K} \text { and } \lambda \text { ) }\end{array}$ \\
\hline \multirow[t]{2}{*}{$\mathrm{LN}^{*}$} & $1.5 \times 10^{8}$ & n.r. & $2.5 \times 10^{8}$ & $1.3 \times 10^{8}$ & $6.88 \times 10^{8}(\mathrm{LN}-\mathrm{RP})$ \\
\hline & n.r. & $6.0 \times 10^{7}$ & $2.5 \times 10^{8}$ & $1.3 \times 10^{8}$ & $2.88 \times 10^{8}(\mathrm{LN}-\mathrm{IgG})$ \\
\hline THL** & $5.4 \times 10^{7}$ & n.r. & $1.2 \times 10^{8}$ & $1.7 \times 10^{6}$ & $6.80 \times 10^{8}(\mathrm{TIL})$ \\
\hline
\end{tabular}

* Lymph Node

* Tumor Infiltrating Lymphocytes

obtained from Ramdom Primed (RP) cDNA

? obtained from $\mathrm{CHI}(\gamma 1$ : IgG)-primed cDNA

n.r. not relevant

Ten randomly picked, full-length. Fab clones from both LN-derived libraries were then shown to be all different as judged by DNA-fingerprinting (as described by [10]). Furthermore, these clones were rescued separately with helper phage M13K07 and were all shown to express Ig heavy- and light chain of the correct molecular weight on phage by means of Western blotting (data not shown).

\section{Selection of immune phage antibody repertoires on purified TT antigen}

To determine whether the immune system of the selected patient had previously been exposed to a 'model' antigen, his serum was tested for the presence of circulating antibodies directed to tetanus toxoid (TT) by means of ELISA. Both serum of the patient and control serum of a healthy donor showed strong immunoreactivity towards TT (Fig. 2). 


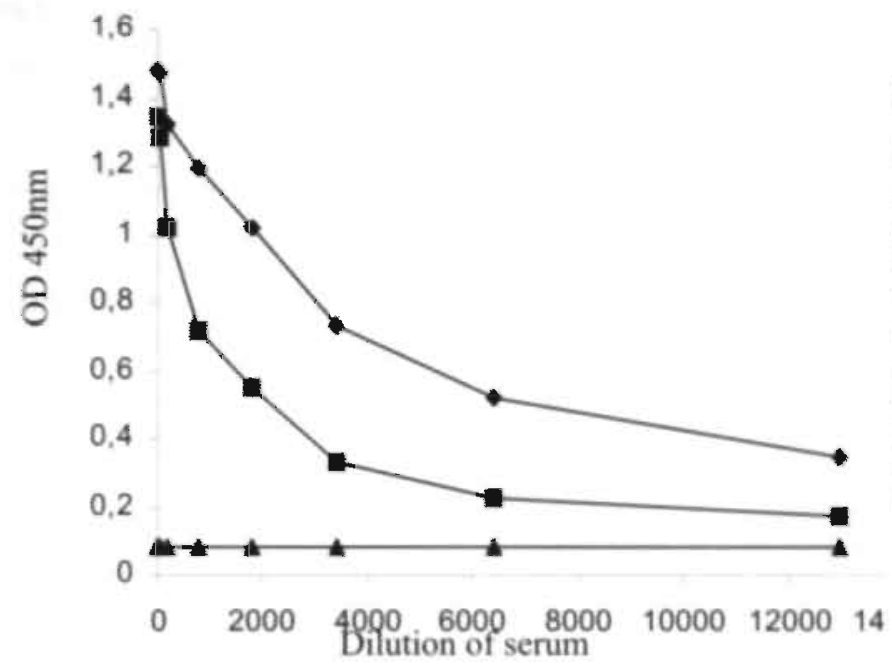

Figure 2

Serological analysis of circulating $\lg G$ antibodies in serum.

Serum of the patient studied was tested on the TT antigen ( $\bullet$ ) and compared to control serum (E) of a healthy donor and to a negative control (no primary antibody: A). Optical density (OD) at $450 \mathrm{~nm}$ was read as function of the dilution of the sera.

$I_{5_{0}}$ values (defined as the dilution at which the ELISA signal dropped to $50 \%$ of the maximum value) for the sera were 1:3200 for the serum of the patient and 1:800 for the control serum. This indicates that the immune system of this patient had previously mounted a response to the antigen (most probably because of immunization), which made this antigen a good target for validation of the constructed immune repertoires. Since memory B-cells generated as a result of an immune response are expected to frequent secondary lymphoid tissue, the antibody repertoires constructed from the pericolic LNs can be expected to contain antibodies to the TT antigen. The LN-derived libraries were therefore selected on purified TT antigen; the input and output titers of phage are listed in Table 2.

The percentage of clones containing full-length Fab insert increased to almost $100 \%$ after the second selection round, indicating that selection enriched phage specifically binding to antigen. From both libraries, numerous specific antibodies could be obtained, as determined by ELISA. (in a frequency of $13 / 45$ tested for the VH(RP) library and 18/45 tested for the VH(IgG) repertoire). Ten randomly picked positive clones (five from each repertoire) were then BstNIfingerprinted and shown to consist of seven different antibodies ( 4 for the VH(RP) repertoire and 3 for the $\mathrm{VH}(\mathrm{IgG})$ library), proving that a diverse set of antibodies was selected. The V-genes of these anti-TT antibodies were sequenced and shown to originate from different germline segments of different $\mathrm{V}$-gene families: VH genes were derived from the VH1 and VH4 (RP) or $\mathrm{VH} 1$ only (IgG) family; light chain genes originated from the $\mathrm{V} \kappa \mathrm{I}$ and $\mathrm{V} \kappa I I I(R P)$ or $\mathrm{V} \lambda \mathrm{I}$ and VкIII (IgG) subgroups. 
Table 2

Characteristics of phage antibody selections using the $L N$-derived (RP and IgG) repertoires on purified Tetanus Toxoïd

\begin{tabular}{|c|c|c|c|c|c|c|c|}
\hline Library & $\begin{array}{l}\text { Selection } \\
\text { round }\end{array}$ & $\begin{array}{l}{[\mathrm{Ag}]^{*}} \\
(\mu \mathrm{g} / \mathrm{ml})\end{array}$ & $\begin{array}{l}\text { Input titer } \\
\text { i }(\mathrm{CFU})^{* *}\end{array}$ & $\begin{array}{l}\text { Output titer } \\
\text { o (CFU) }\end{array}$ & Ratio $0 / \mathbf{i}$ & $\begin{array}{l}\text { Enrichment } \\
\text { factor**** }\end{array}$ & $\begin{array}{l}\% \text { full: } \\
\text { length } \\
\text { clones }\end{array}$ \\
\hline RP & 1 & 10 & $3.0 \times 10^{13}$ & $7.2 \times 10^{5}$ & $2.4 \times 10^{-5}$ & n.r. & 22.2 \\
\hline RP & 2 & 5 & $2.6 \times 10^{13}$ & $5.1 \times 10^{7}$ & $2.0 \times 10^{-6}$ & $82 x$ & 100 \\
\hline $\operatorname{IgG}$ & 1 & 10 & $3.0 \times 10^{13}$ & $6.0 \times 10^{4}$ & $2.0 \times 10^{-9}$ & n.r. & 7.7 \\
\hline $\lg G$ & 2 & 5 & $2.4 \times 10^{13}$ & $1.7 \times 10^{8}$ & $7.2 \times 10^{-6}$ & $3404 x$ & 100 \\
\hline
\end{tabular}

* concentration of antigen used for coating of immunotubes

** titers are given as total amount of colony forming units (CFU)

$* * *$ enrichment factor was defined as (ratio $0 / \mathbf{i}$ E2) / (ratio o/i E1)

As has been observed previously [27], light chain promiscuity was seen for two of the antibodies selected from the $\operatorname{lgGi}$ repertoire, where the same $\mathrm{VH}$ segment was found in combination with two different VL genes. The frequency of somatic mutation in the V-genes of these selected antibodies (as determined by alignment of the sequences to their closest germ lin $\mathrm{e}$ match) was high: overall, 21.8 mutations were found in the selected VH genes, of which 15 caused an amino acid change in the expressed protein. In VL-genes this frequency was, on average, 7.3 mutations of which 4.4 caused an amino acid change.

\section{Selection of phage antibodies on colorectal cancer cell line $\mathrm{CaCo} 2$}

To screen the constructed immune phage antibody repertoires for the presence of antibodies to the tumor, the primary CRC of the selected patient would have been the first choice as 'antigen' target for phage selection. However, due to limitations in the quantity and qualit $y$ of the patient-derived tumor material and to the technical requirements for phage selection, w e chose to use an unlimited, but surrogate source of tumor antigens, i.e. the $\mathrm{CRC}$ cell line $\mathrm{CaCo} 2$. The patient-derived repertoires were selected on $\mathrm{CaCo} 2$ using conditions that were previously described for selections on whole, live cells [23]. The phage titers as well as the percentage of clones with complete Fab insert increased markedly after the third and fourth round of selection , again indicating successful selection of phage antibodies (Table 3). After three and four rounds of selection, individual antibody clones were DNA-(BstNI-) fingerprinted and clones having a distinct fingerprint pattern were tested for their reactivity towards allogeneic primary colorecta 1 cancer tissue in IHC. 
Evidence for a bias towands intracellular antigens in the local humoral anti-tumour immune response of a colorectal cancer patient revealed by phage display
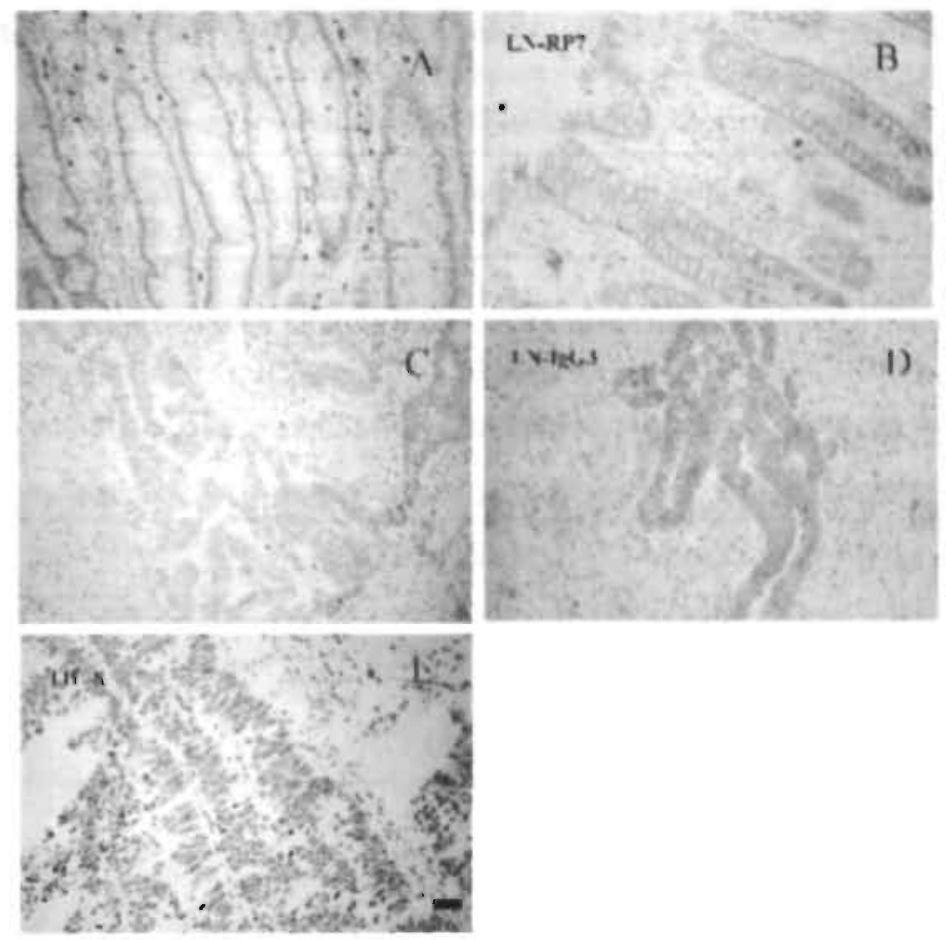

\section{Figure 3}

Immunohistochemical anabsis of normal colonic cpithelium.

$(\mathrm{A}+\mathrm{B})$ and primary $\mathrm{CRC}(\mathrm{C}$. E), using antibodies selected from the LN- and TIL. derived immune libraries. A: negative control ( $\theta$ ); B: clone LN-RP7; C: negative control (e); D: clone LN-IgG3; E:

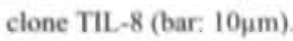

Surprisingly, all different clones that were selected from the LN-derived immune libraries (15 different antibodies on the basis of fingerprint patterns: 6 for the RP library and 9 for the IgG repertoire) were reactive in IHC towards allogeneic primary colorectal carcinoma (examples ar e shown in Fig. 3). All clones selected from the se libraries were epithelial celi-specific but none distinguished CRC from normal colonic epithelium (Fig. 3B and 3D). The observed stainin g pattern was always cytoplasmic. Strikingly, none of the antibodies recognised the $\mathrm{CaCo} 2$ cell line in flow cytometric analysis (shown for LN-RP7 in Fig. 4), meaning that the antigens recognised were all intracellularly expressed. The TIL-derived repertoire yielded only one predominant clon $\mathrm{e}$ (TIL-8) after three selection rounds; this clone also was reactive in IHC and showed pronounce d nuclear staining that was not restricted to epithelial cells (Fig. 3E). Like all antibodies s elected from the $\mathrm{LN}$-derived libraries, this clone did not stain whole, live $\mathrm{CaCo} 2$ cells in flow cytometri c analysis (data not shown). The VH genes of 4 different antibodies selected from both $\mathrm{LN}$-derive $\mathrm{d}$ repertoires and of the antibody isolated from the TIL-derived library were sequenced and show $\mathrm{n}$ to be derived from the three largest VH families: the VH1 and VH4 subgroups for the LN derived antibodies and VH3 subgroup for the TIL-derived antibody. 
Table 3

Characteristics of phage antibody selections using the $L N$-derived (RP and $\operatorname{IgG}$ ) and TIL-derived repertoires on $\mathrm{CRC}$ cell line $\mathrm{CaCo} 2$

\begin{tabular}{lcccccc}
\hline Library & $\begin{array}{c}\text { Selection } \\
\text { round }\end{array}$ & $\begin{array}{c}\text { Input titer } \\
\mathbf{i}(\mathrm{CFU})^{*}\end{array}$ & $\begin{array}{l}\text { Output titer } \\
\mathbf{0}(\mathrm{CFU})\end{array}$ & Ratio o/i & $\begin{array}{c}\text { Enrichment } \\
\text { factor** }\end{array}$ & $\begin{array}{c}\text { \% full-length } \\
\text { clones }\end{array}$ \\
\hline LN-RP & 1 & $3.5 \times 10^{13}$ & $4.4 \times 10^{7}$ & $1.24 \times 10^{-6}$ & n.r. & 22.2 \\
& 2 & $1.6 \times 10^{13}$ & $9.6 \times 10^{6}$ & $6.19 \times 10^{-7}$ & none & 33.3 \\
& 3 & $9.0 \times 10^{12}$ & $2.4 \times 10^{9}$ & $2.67 \times 10^{-4}$ & $430.8 \times$ & 100 \\
\hline LN-IgG & 1 & $2.8 \times 10^{13}$ & $4.8 \times 10^{7}$ & $1.71 \times 10^{-6}$ & n.r. & 7.7 \\
& 2 & $1.5 \times 10^{13}$ & $1.7 \times 10^{7}$ & $1.14 \times 10^{-6}$ & none & 23 \\
& 3 & $1.3 \times 10^{13}$ & $1.7 \times 10^{9}$ & $1.37 \times 10^{-4}$ & $120 \times$ & 93.8 \\
& 4 & $3.7 \times 10^{13}$ & $8.1 \times 10^{10}$ & $2.19 \times 10^{-3}$ & $15.98 \times$ & n.d. \\
\hline TIL & 1 & $1.3 \times 10^{13}$ & $4.4 \times 10^{6}$ & $3.40 \times 10^{7}$ & n.r. & 52.2. \\
& 2 & $3.0 \times 10^{13}$ & $1.5 \times 10^{7}$ & $5.00 \times 10^{-7}$ & $1.47 \times$ & 80 \\
& 3 & $2.8 \times 10^{13}$ & $4.8 \times 10^{7}$ & $1.70 \times 10^{-6}$ & $3.4 \times$ & 86.7 \\
& 4 & $2.2 \times 10^{13}$ & $2.0 \times 10^{8}$ & $9.10 \times 10^{-6}$ & $5.3 \times$ & 86.7 \\
\hline
\end{tabular}

* thers are given as total amount of CFU

** enrichment was defined as fratio $0 / \mathbf{i} \mathrm{E}(\mathrm{n}+1) /($ ratio $0 / \mathbf{i} \mathrm{En})$

it.r. not relevant

n.d, not determined

Furthermore, these selected VH genes contained somatic mutations; on average, 12. mutation s were found in the LN-IgG derived VH-genes, of which 8.8 caused an amino acid change in the protein. Surprisingly, this frequency was higher for the clones selected from the LN-RP library: 24.7 mutations per VH-gene, of which 17 caused an amino acid difference. The VH gene of the Til-derived antibody contained 12 mutations, of which 8 resulted in an amino acid difference.

To compare the specificities selected from the constructed 'immune' libraries with thos e of clones selected from a phage antibody library made from non-immune V-gene sources, a non immune repertoire [11] was used in parallel for selection on the $\mathrm{CaCo} 2$ cell line. Selections using this scFv library yielded 17 different antibodies that recognised patient-derived primary CRC in IHC. Within this group, two specificities could be distinguished: (1) 5 antibodies recognised pan- 
Evidence for a bias towards intracellular antigens in the local humoral anti-tumour immune response of a colorectal cancer patient revealed by phage display

cell markers common to different cell types and (2) 12 antibodies recognised epithelial cell restricted antigens (examples of these are shown in Fig. 4). The latter group of antibodies did no t discriminate between malignant $\mathrm{CRC}$ and normal colonic epithelium (Fig. 4B and 4D). However, 3 out of 5 antibodies tested did stain whole, live $\mathrm{CaCo} 2$ cells in flow cytometric analysis (shown for ces31 in Fig. 5), showing that most of the antigens recognised were expressed on the cell surface of $\mathrm{CaCo} 2$ cells. In addition, this confirms the possible selection of antibodies to intracellular targets. Finally, 6 different antibodies were selected that did recognise cell-surfac e antigens on the $\mathrm{CaCo} 2$ cell line (shown for clone ces 9 in Fig. 5) but that did not show an $y$ reactivity in IHC towards patient-derived tumor material (data not shown).
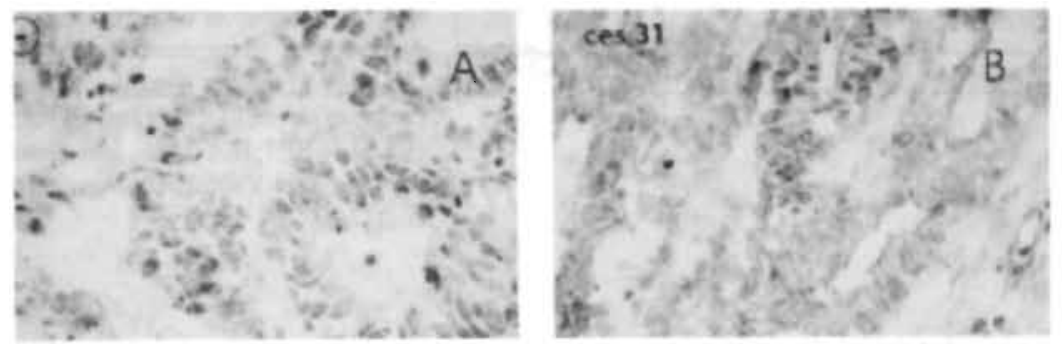

Figure 4

Immunohistoch emical analysis of primary CRC using antibodies selected from the non-immune
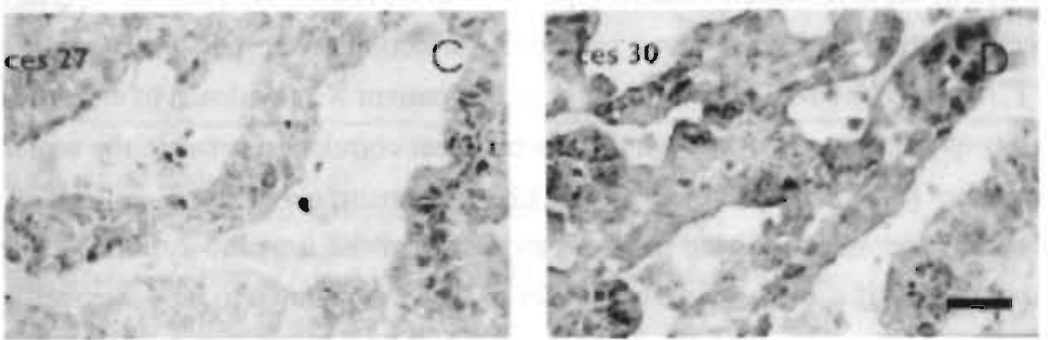
scFv library.

A: negative control (ө); B: clone ces31; C: clone ces27; D: clone ces30 (bar: $10 \mu \mathrm{m})$.

\section{Discussion}

In this report, we describe for the first time the analysis of phage antibody repertoire s made from different, CRC patient-derived, immune V-gene sources, to study the local humora I immune response to the tumor. Human 'immune' Fab libraries were made from the tumor draining lymph nodes and lymphocytes infiltrating the tumor; this tumor was an adenocarcinoma selected on the basis of a high level of lymphocyte infiltration. Two of the immune libraries were first validated by the successful isolation of antibodies to the 'model' antigen tetanus toxoid. Upon selection of the immune libraries on the $\mathrm{CRC}$ cell line $\mathrm{CaCo}$, a striking panel of specificities was obtained: only antibodies to intracellular target antigens were selected. However, parallel selections using a non-immune library yielded many different antibodies tha $t$ recognised cell-surface structures on $\mathrm{CaCo} 2$. 
These results point towards in vivo tolerance mechanisms that bias the specificity of a loca I humoral immune response towards intracellular targets.
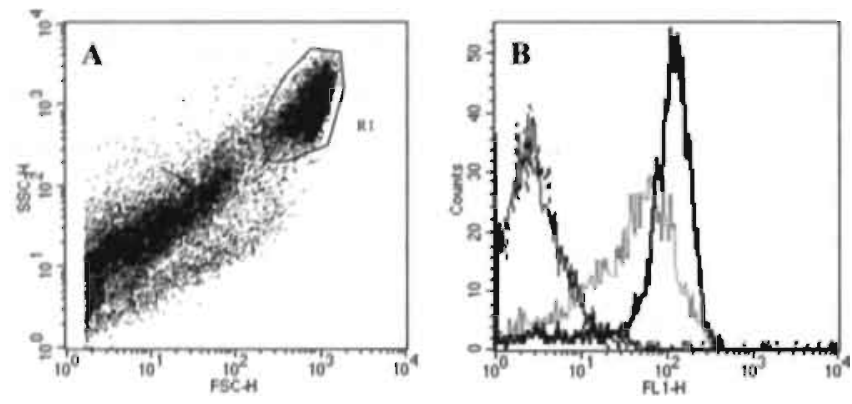

\section{Figure 5}

Analysis of phage antibody binding to $\mathrm{CaCo} 2$ cells by means of flow cytometry.

A: dot-plot showing forward scatter (FCS-H) versus sideward scatter (SSC-H) of $\mathrm{CaCo} 2$ cells; the gate selecting whole, live cells is indicated (RI). B: number of cells (events) as function of fluorescence intensity (FL L-H). Thin line: negative control (an antibody to TT); thin striped line: clone LN-RP7; thin dotted line: clone scFv ces9; thick solid line: clone scFv ces31.

To validate two of the constructed immune repertoires as representative pools of V-gene s that had been selected during in vivo immune responses, selections were performed on the 'model' antigen TT, of which the serum antibody titer of this patient was evidence of an activ e or previous immune response (Fig. 2). Although there is no linear correlation between the seru $\mathrm{m}$ titer of anti-TT antibodies and the frequency of circula ting IgG positive memory B-cells [28], the presence of a serum titer does indicate previous exposure of the immune system to th $\mathrm{e}$ antigen. Several antigen-specific antibodies were retrieved that were shown to be somaticall y mutated. Random mutations in a V-gene are estimated to result in a ratio of replacement ( $R$ ) versus silent (S) mutations of 1.5 for framework (FR-) regions and of 2.9 for complementarity-determining regions (CDRs) [29,30]. Higher R:S ratios for the CDRs indicate that the antibody has been positively selected for binding to antigen. The R:S ratio for the CDRs were very high for selected VH segments, but did not exceed the 'background' value of 2.9 for VL segments (Table 4). This indicates that at least the VH genes had been selected during an in vivo response, in which they were mutated and subsequently selected for their increased affinity for the antigen. Indeed, measurement of the kinetics of binding of one of the anti-TT antibodies selected from the IgG repertoire by surface plasmon resonance (SPR) [31] analysis using a BIAcore 2000, revealed an off-rate of $4.5 \times 10^{-4} \mathrm{~s}^{-1}$, which is typical for high affinity antibodie s generated after a secondary immune response. These data validate the constructed immun e repertoires as a source of antibodies that have arisen from local in vivo immune responses. 
Evidence for a bias towards intracellular antigens in the local humoral anti-tumour immune response of a colorectal cancer patient revealed by phage display

\section{Table 4}

Ratios of replacement $(R)$ to silent (S) mutations in CDR-and framework (FR), regions of $V$ genes of selected antibodies directed to the TT antigen and to CRC cell line CaCo2

\begin{tabular}{lccccc}
\hline $\begin{array}{l}\text { Library } \\
\text { source }\end{array}$ & Antigen & V-gene & $\begin{array}{c}\text { Number of V- } \\
\text { genes sequenced }\end{array}$ & R:S (CDR) & R:S (FR) \\
\hline LN-IgG* & TT & VH & 2 & 17 & 1 \\
& & VL & 3 & 2.2 & 0.6 \\
LN-RP** & TT & VH & 4 & 4.8 & 1.3 \\
& & VL & 4 & 1.8 & 2.3 \\
\hline LN-IgG & CaCo2 & VH & 4 & 3.5 & 2.3 \\
& & VL & n.d. & n.d. & n.d. \\
LN-RP & $\mathrm{CaCo2}$ & VH & 4 & 5.2 & 1.2 \\
& & VL & n.d. & n.d. & n.d. \\
\hline TIL*** & \multirow{2}{*}{$\mathrm{CaCo2}$} & VH & I & 1 & 2.3 \\
& & VL & n.d. & n.d. & n.d. \\
\hline
\end{tabular}

n.d. not determined.

- Lymph Node-derived, IgG-primed repertoire

* Lymph Node-derived, Random-Primed repertoire

*** Tumor infiltrating lymphocytes-derived (random-primed) repertoire

From all three immune phage antibody repertoires ( $\mathrm{LN}$ - and TIL-derived), only antibodie s that recognise intracellular (cytoplasmic or nuclear) targets were selected (Fig. 3 and 5), despite the use of whole, live cells in the selection procedure. We have previously determined the integrity (and viability) of $\mathrm{CaCo} 2$ cells before and after one round of selection (with 12 washes) to be $90 \%$ and $70 \%$ respectively [23]. Thus, the cell surface remains largely intact during the whole procedure. Indeed, after selection of the non-immune library, many different $\mathrm{CaCo} 2 \mathrm{cell}$ binding antibodies were retrieved (Fig. 4 and 5). However, a small amount of intracellular protein is liberated during the selection procedure, which also serves as 'antigen' in the selection. For this reason, antibodies directed to cytoplasmic and nuclear antigens were retrieved from the immune libraries. The lack of retrievall of antibodies that react with the cell-surface therefor $\mathrm{e}$ strongly argues for a bias in the specificities present in the immune repertoires and thus in the local in vivo antibody response of this CRC patient. To further confirm this bias toward $\mathrm{s}$ 
intacellular target antigens, selections were performed on the tumor antigen epithelial cel I adhesion molecule (Ep-CAM), which is known to mount a humoral immune response in approximately $15 \%$ of $\mathrm{CRC}$ patients [32]. No specific phage antibodies could be retrieved after four rounds of selection on purified, recombinant antigen (data not shown). In addition, serological analysis of the patient's serum neither revealed any immunoreactivity towards the EpCAM antigen (data not shown).

The VH genes of a subset of anti CRC antibodies selected from the 'immune' repertoires were sequenced and shown to be somatically mutated; the R:S ratios for CDRs and FRs of these antibodies are listed in Table 4. Although the R:S ratio of CDRs of VH genes isolated from the $\mathrm{LN}$-IgG repertoire indicates that they did undergo somati c mutation, the ratio is far lower than that observed for the anti-TT antibodies (Table 4). This may indicate that the B-cells from whic $h$ these anti-CRC antibodies are derived were hampered in their development to plasma- or memory cells through the lack of T-cell help or through a tolerance mechanism, e.g. by encountering soluble antigen (reviewed in [33, 34]). The VH genes of anti-CRC antibodie s isolated from the LN-RP library were also somatically hypermutated (as indicated by the R: S. ratio of CDRs: Table 4), to a similar levell as the genes of the anti-TT antibodies selected from this repertoire. This indicates the presence of somatically hypermutated antibodies of non-IgG isotype. Indeed, immunohistochemical analysis revealed that in the lymph nodes draining the tumor, B-cells secreting antibodies of the IgA isotype were abundantly present (data not shown). This result is not surprising, since the presence in CRC patients of circulating $\lg \mathrm{A}$ antibodie s directed to intracellular antigens has already been described [35]. Although the number of antibodies retrieved from the TIL-derived repertoire is very limited, it is striking that the VH of selected clone TIL- 8 has an R:S ratio of the CDRs that is lower than the 'random' threshold og 2.9 This more 'naive' pattern of mutation may be caused by a lack of local T-cell help. Thes e data indicate that the B-cell from which this antibody is derived probably is not part of the memory pool of $\mathbf{B}$-cells.

Differences between the LN-derived RP and IgG repertoires were observed in the pane I of antibodies selected on both the 'model' antigen $\mathrm{TT}$ and on the $\mathrm{CaCo} 2$ cell line. The pattern of somatic mutation observed in the VH genes of anti-TT antibodies selected from the $\mathrm{Ig} \mathrm{G}$ repertoire suggests that these genes are probably derived from the memory pool of B-cells , whereas the VH genes of antibodies selected from the RP repertoire had a more "naive " (IgM-like) pattern of mutation [29,30] (Table 4). Interestingly, although both repertoires yielde d antibodies reactive with patient-derived primary CRC, the panel of selected antibodies wa s completely different (as judged by DNA fingerprint analysis (data not shown) and sequencing of the selected V-genes). Theoretically, the same antibodies found in the IgG repertoire shoul d also be present in the RP library, in which all different antibody isotypes should be represented. 
However, many parameters (including mRNA levels, number of B-cells and efficiency of V-gen e amplification) affect the contents of these two (RP and IgG) random combinatorial phag e antibody libraries, which may explain the retrieval of a different panel of antib odies from both repertoires.

One possible disadvantage of the combinatorial phage antibody approach is that the original pairing between VH and VL in antibodies is disrupted. This disrupts the origina I specificity of the antibody and may also create new specificities. However, if the antibody repertoire is sufficiently large, the original combinations of $\mathrm{V}$-genes should also be present. The

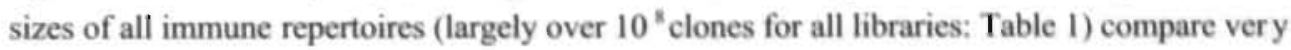
well to those of immune repertoires that have been described $[5,9,36]$. However, since the exact number of B-lymphocytes present in the tissues used for construction of the immune repertoire s is unknown, the possibility remains that certain original specificities were not represented in the immune libraries.

The analysis of autoreactive antibodies and of the tumor antigens they recognise ha s recently been performed by means of the SEREX technology, a serological analysis of the humoral immune response in cancer patients [37]. Using this technique, both cytoplasmic and nuclear $[38,39]$ antigens have been identified as immunogenic targets. We show that in the CR C patient studied, such antibodies are being produced by the B-cells present in LNs draining the tumor and in the tumor itself and that most of these antibodies are somatically hypermutated . However, by using this $\mathrm{V}$-gene cloning procedure, we are likely to select antibody genes derived both from memory B-cells and from plasma cells, which m ay not always contribute equally to the serum titer of anti-tumor antibodies [28]. Therefore, it remains to be seen whether the intraceliular antigens recognised by our phage antibodies are identical to the antigens described for the SEREX procedure [38]. Our data do not rule out the existence of humoral responses to certain cell-surface antigens, as has been reported by others $[32,40,41]$, but they do show tha there is a large bias towards intracellular $[4,35,42,43]$ targets. It remains to be determine $d$ whether such epithelial cell-specific, somatically hypernutated antibodies are also found in other CRC patients.

As has been observed before for auto-antibodies directed to the p53 proto-oncogene [ 44 , 45], the selected antibodies presented here are directed to the native antigen that is also expresse d in non-malignant tissue (Fig. 3). Such a non-specific humoral immune response may be only a consequence of the breakdown of immune tolerance checkpoints in the patient. However, it wil I be interesting to study the possible biological significance of the presence of the B-cells that produce the selected antibodies and the role of these antibodies in tumor eradication or tumo $r$ escape from immune surveillance.

We conclude that the combinatorial phage antibody approach is a rapid and valid way to 
study local humoral immune responses to defined and unknown target antigens in CRC patients . Such studies will aid in an understanding of the immune response to the autologous tumor i $n$ CRC patients, which will eventually lead to improvements in immunotherapy of minima I residual disease.

\section{References}

I. Shiku H, Takahashi T, Resnick LA, Oettgen HF, Old LJ (1977) Cell surface antigens of human malignant melanoma. III. Recognition of autoantibodies with unusua 1 characteristics. J. Exp. Med. 145: 784-789

2. Garrett TJ, Takahashi T, Clarkson BD, Old LJ (1977) Detection of antibody to autologous human leukemia cells by immune adherence assays. Proc. Natl. Acad. Sci. U. S. A. 74: 4587-4590

3. Lubin R, Schlichtholz B, Bengoufa D, Zalcman G, Tredaniel J, Hirsch A, de Fromentel CC, Preudhomme C, Fenaux P, Fournier G, et al. (1993) Analysis of p53 antibodies in patients with various cancers define B-cell epitopes of human p53: distribution on primary structure and exposure on protein surface. Cancer Res. 53: 5872-5876

4. Imai H, Furuta K, Landberg G, Kiyosawa K, Liu LF, Tan EM (1995) Autoantibody to DNA topoisomerase II in primary liver cancer. Clin. Cancer Res. 1: 417-424

5. Coomber DW, Hawkins NJ, Clark MA, Ward RL (1999) Generation of anti-p53 Fa b fragments from individuals with colorectal cancer using phage display. J. Immunol. 163: 2276-2283

6. Tureci O, Sahin U, Pfreundschuh M (1997) Serological analysis of human tumo r antigens: molecular definition and implications. Mol. Med. Today 3: 342-349

7. McCafferty J, Griffiths AD, Winter G, Chiswell DJ (1990) Phage antibodies: filamentou s phage displaying antibody variable domains. Nature 348: 552-554

8. Clackson T, Hoogenboom HR, Griffiths AD, Winter G (1991) Making antibod y fragments using phage display libraries. Nature 352: 624-628

9. Chester KA, Begent RH, Robson L, Keep P, Pedley RB, Boden JA, Boxer G, Green A, Winter G, Cochet O, et al. (1994) Phage libraries for generation of clinically usefu I antibodies. The Lancet 343: 455-456

10. Marks JD, Hoogenboom HR, Bonnert TP, McCafferty J, Griffiths AD, Winter G (1991) By-passing Immunization; Human Antibodies from V-gene Libraries Displayed on Phage. J. Mol. Biol. 222: 581-597

11. Vaughan TJ, Williams AJ, Pritchard K, Osbourn JK, Pope AR, Earnshaw JC, McCaffert y J, Hodits RA, Wilton J, Johnson KS (1996) Human Antibodies with Sub-nanomola r Affinities Isolated from a Large Non-immunized Phage Display Library. Nat. Biotechnol. 14: $309-314$

12. de Haard HJ, van Neer N, Reurs A, Hufton SE, Roovers RC, Henderikx P, de Bruïne AP, Arends J-W, Hoogenboom HR (1999) A large non-immunized human Fab fragmen t phage library that permits rapid isolation and kinetic analysis of high affinity antibodies. J. Biol. Chem. 274: 18218-18230

13. Nissim A, Hoogenboom HR, Tomlinson IM, Flyn G, Midgley C, Lane D, Winter G 
(1994) Antibody fragments from a 'single pot' phage display library as immunochemica I reagents. EMBO J. 13:692-698

14. Griffiths AD, Williams SC, Hartley O, Tomlinson IM, Waterhouse P, Crosby WL, Kontermann RE, Jones PT, Low NM, John Allison T, Prospero TD, Hoogenboom HR, Nissim A, Cox JPL, Harrison J, Zaccolo M, Gherardi E, Winter G (1994) Isolation of high affinity human antibodies directly from large synthetic repertoires. EMBO J. 13: 3245-3260

15. Clark MA, Hawkins NJ, Papaioannou A, Fiddes RJ, Ward RL (1997) Isolation of human anti c-erbB-2 Fabs from a lymph node-derived phage display library. Clin. Exp. Immunol. 109: $166-174$

16. de Haard HJ, Kazemier B, Oudshoom P, Boender P, van Gemen B, Koolen MJ, van der Groen G, Hoogenboom HR, Arends JW (1998) Selection of human anti-human immunodeficiency virus type 1 envelope single-chain antibodies from a peripheral bloo d cell-based phage repertoire, J. Gen. Virol. 79: 2883-2894

17. Yip YL, Hawkins NJ, Clark MA, Ward RL (1997) Evaluation of different lymphoi d tissue sources for the construction of human immunoglobulin gene libraries. Immunotechnology 3: 195-203

18. Zhang H, Lake DF, Barbuto JA, Bernstein RM, Grimes WJ, Hersh EM (1995) A huma n monoclonal antimelanoma single-chain Fv antibody derived from tumor-infiltrating lymphocytes. Cancer Res. 55: 3584-3591

19. Sambrook T, Fritsch EF, Maniatis T (1989) eds. Molecular Cloning: A Laboratory Manual. Cold Spring Harbor Laboratory Press, Cold Spring Harbour, p

20. Dower WJ, Miller JF, Ragsdale CW (1988) High efficiency transformation of E. coli by high voltage electroporation. Nucleic Acids Res. 16: 6127-6!45

21. Hoogenboom HR, Griffiths AD, Johnson KS, Chiswell DJ, Hudson P, Winter G (1991) Multi-subunit proteins on the surface of filamentous phage: methodologies for displaying antibody (Fab) heavy and light chains. Nucleic Acids Res. 19: 4133-4137

22. Roovers RC, Henderikx P, Helfrich W, van der Linden E, Reurs A, de Bruine AP. Arends JW, de Leij L. Hoogenboom HR (1998) High-affinity recombinant phage antibodies to the pan-carcinoma marker epithelial glycoprotein-2 for fumour targeting. Br. J. Cancer $78: 1407-1416$

23. Mutuberria R, Hoogenboom HR, van der Linden E, de Bruïne AP, Roovers RC (1999) Model systems to study the parameters determining the success of phage antibody selections on complex antigens. J. Immunol. Methods 231: 65-81

24. Sanger F, Nicklen S, Coulson AR (1977) DNA sequencing with chain-terminating inhibitors, Proc. Natl. Acad. Sci. U. S. A. 74: 5463-5467

25. Di Giorgio A, Botti C, Tocchi A, Mingazzini P, Flammia M (1992) The influence of tumor lymphocytic infiltration on long term survival of surgically treated colorecta I cancer patients. Int. Surg. 77: 256-260

26. Aaltomaa S, Lipponen P, Eskelinen M, Kosma VM, Marin S, Alhava E, Syrjanen K (1992) Lymphocyte infiltrates as a prognostic variable in female breast cancer. Eur. $J$. Cancer 28A: $859-864$

27. Persson MA, Caothien RH, Burton DR (1991) Generation of diverse high-affinity hurnan monoclonal antibodies by repertoire cloning. Proc. Natl. Acad. Sci. U. S. A. 88: 2432- 
2436

28. Leyendeckers H, Odendahl M, Lohndorf A, Irsch J, Spangfort M, Miltenyi S, Hunzelmann N, Assenmacher M, Radbruch A, Schmitz J (1999) Correlation analysi s between frequencies of circulating antigen-specific IgG-bearing memory $\mathrm{B}$ cells an $\mathrm{d}$ serum titers of antigen-specific İG. Eur. J. Immunol. 29: 1406-1417

29. Shlomchik MJ, Marshak-Rothstein A, Wolfowicz CB, Rothstein TL, Weigert MG (1987) The role of clonal selection and somatic mutation in autoimmunity. Nature 328: 805-811

30. Apel M, Berek C (1990) Somatic mutations in antibodies expressed by germinal centr e B cells early after primary immunization. Int. Immunol. 2: 813-819

31. Jonsson U, Fagerstam L, Ivarsson B, Johnsson B, Karlsson R, Lundh K, Lofas S, Persson B, Roos H, Ronnberg I, et al. (1991) Real-time biospecific interaction analysis usin $\mathrm{g}$ surface plasmon resonance and a sensor chip technology. BioTechniques 11: 620-627

32. Mosolits S, Harmenberg U, Ruden U, Ohman L, Nilsson B, Wahren B, Fagerberg J, Mellstedt H (1999) Autoantibodies against the tumour-associated antigen GA733-2 i n patients with colorectal carcinoma. Cancer Immunol. Immunother 47: 315-320

33. Nossal GI ( 1994) Negative selection of lymphocytes. Cell 76: 229-239

34. Pulendran B, van Driel R, Nossal GJ (1997) Immunological tolerance in germina I centres. Immunol. Today 18: 27-32

35. Takahashi M, Chen W, Byrd DR, Disis ML, Huseby ES, Qin H, McCahill L, Nelson H, Shimada H, Okuno K, Yasutomi M, Peace DJ, Cheever MA (1995) Antibody to ra s proteins in patients with colon cancer. Clin. Cancer Res. 1: 1071-1077

36. Cai X, Garen A (1995) Anti-melanoma antibodies from melanoma patients immunize d with genetically modified autologous tumor cells: Selection of specific antibodies fro $\mathrm{m}$ single-chain Fv fusion phage libraries. Proc. Natl. Acad. Sci. U. S. A. 92: 6537-6541

37. Sahin U, Tureci O, Schmitt H, Cochlovius B, Johannes T, Schmits R, Stenner F, Luo G, Schobert I, Pfreundschuh M (1995) Human neoplasms elicit multiple specific immune responses in the autologous host. Proc. Natl. Acad. Sci. U. S. A. 92: 11810-11813

38. Scanlan MJ, Gordan JD, Williamson B, Stockert E, Bander NH, Jongeneel V, Gure AO, Jager D, Jager E, Knuth A, Chen YT, Olá LJ (1999) Antigens recognized by autologous antibody in patients with renal-cell carcinoma. Int. J. Cancer 83: 456-464

39. Gure AO, Stockert E, Scanlan MJ, Keresztes RS, Jager D, Altorki NK, Old LJ, Chen YT (2000) Serological identification of embryonic neural proteins as highly immunogenic tumor antigens in small cell lung cancer. Proc, Natl. Acad. Sci. U. S. A. 97: 4198-4203

40. Disis ML, Pupa SM, Gralow JR, Dittadi R, Menard S, Cheever MA (1997) High-tite r HER-2/neu protein-specific antibody can be detected in patients with early-stage breast cancer. J. Clin. Oncol. 15: 3363-3367

41. Albanopoulos K, Armakolas A, Konstadoulakis MM, Leandros E, Tsiobanou E, Katsaragakis S, Alexiou D, Androulakis G (2000) Prognostic significance of circulatin g antibodies against carcinoembryonic antigen (anti-CEA) in patients with colon cancer. Am. J. Gastroenterol. 95: 1056-1061

42. Hammel P, Boissier B, Chaumette MT, Piedbois P, Rotman N, Kouyoumdjian JC, Lubin R, Delchier JC, Soussi T (1997) Detection and monitoring of serum p53 antibodies in patients with colorectal cancer. Gut 40:356-361

43. Stockert E, Jager E, Chen YT, Scanlan MJ, Gout I, Karbach J, Arand M, Knuth A, O Id LJ (1998) A survey of the humoral immune response of cancer patients to a panel of 
Evidence for a bias towards intracellular antigens in the local humoral anti-tumour immune response of a colorectal cancer patient revealed by phage display

human tumor antigens. J. Exp. Med. 187: 1349-1354

44. Schlichtholz B, Tredaniel J, Lubin R, Zalcman G, Hirsch A, Soussi T (1994) Analyses of p53 antibodies in sera of patients with lung carcinoma define immunodominan t regions in the p53 protein. Br.J. Cancer 69: 809-816

45. Schlichtholz B, Legros Y, Gillet D, Gaillard C, Marty M, Lane D, Calvo F, Soussi T (1992) The immune response to p53 in breast cancer patients is directed agains t immunodominant epitopes unrelated to the mutational hot spot. Cancer Res. 52: 63806384 


\title{
Chapter 10
}

\author{
Epilegue
}

Rob C. Roovers 


\section{Epilogue}

Since the proof of principle of the phage display technique, described in 1985 by George Smith [1] for small peptides and in 1990 by John McCafferty and coworkers for antibody molecules [2], the technique has evolved into an extensive area of research and it is used in a variety of formats for a range of applications (reviewed in chapter 2 of this thesis). In this thesis, the technique was used to obtain human antibodies to a known tumour antigen (chapters 3 to 6) and to identify (possibly) new antigens expressed in colorectal carcinoma (chapters 7 to 9). To this aim, large, non-immunised phage antibody repertoires as well as repertoires made from patient-derived lymphoid tissues were used to obtain recombinant antibody fragments that recognise antigens expressed in CRC. In addition, subsequent $\mathrm{V}$-gene engineering was used to optimise their format for use in cancer targeting.

The first part of the work involved the isolation and development of fully human antibodies to the Ep-CAM antigen. In chapter 2 and 3, antibody phage display was used to isolate the $\mathrm{V}$-genes of a high affinity murine antibody to the Ep-CAM antigen; these genes were subsequently engineered into multivalent molecules. Since increased affinity has been reported to improve tumour targeting [3], we first performed a systematic analysis of several wellcharacterised antibodies to select the antibody with most favourable kinetics of antigen-binding. The subsequent cloning of the V-genes encoding the selected antibody then provided the building blocks for the engineering of this antibody into multivalent formats (chapter three). This approach indeed resulted in multivalent species of the cloned antibody and the multivalent formats were shown to have an increased apparent affinity in surface plasmon resonance (SPR) analysis, caused by avidity. Whether these smail bi- and trivalent species are sufficiently large and will have enough flexibility to cross-link adjacent receptors on the same cell surface has still to be determined. The relative structural rigidity of e.g. diabodies versus intact IgG [4, 5]may hamper simultaneous binding of the two antigen binding sites to two antigen molecules. In an in vivo setting, therefore, the avidity effect of multivalent scFv may not consist of simultaneous binding of two (or more) antigen binding sites, but of quick rebinding of one arm when the other has dissociated from antigen. Thus, this effect will be highly dependent on the concentration of antigen at the cell surface. In addition, the structural architecture and particular the motility of the antigen in the cell membrane will affect the avidity effect of scFv multimers. The gain in tumour targeting efficiency is therefore also dependent on the target antigen. However, since the Ep-CAM antigen has been shown to be expressed in high copy numbers at the cell surface of CRC, the effect of multivalency on the tumour targeting properties of anti-Ep-CAM antibodies is expected to be large and the in vivo performance of multivalent antibody formats to be 
outstanding. High concentrations of circulating antigen have been reported to negatively influence the imaging of solid tumours [6]. The Ep-CAM antigen, however, is not shed into the circulation, which further increases its potency as tumour target for radio-immuno imaging. Multivalent Fv's lack antibody Fe regions and are therefore expected to have less background binding to Fc-receptor expressing blood cells. In addition, their in vivo pharmacokinetic behaviour is suitable for rapid (1-2 days) imaging of patients [7, 8]. When equipped with the appropriate peptide tags for direct isotope labelling [9-11], these engineered molecules may form a new and promising generation of tumour imaging reagents. Indeed, recombinant phage antibodies directed to CEA have been successfully used in radio-immuno guided surgery and imaging $[12,13]$ of CRC.

In chapter 4 we describe the successful humanisation of the MOC-31 anti-Ep-CAM antibody described in chapters two and three through a phage display procedure termed "guided selection" [14]. This procedure has been used to develop the first phage antibody (an anti-TNFantibody [14]) to enter a phase III clinical trial. Recently, the technique has been successfully used for the humanisation of a murine antibody targeting the CD30 receptor [15], which is expressed on Hodgkin-Reed Sternberg cells in Hodgkin's lymphoma. Preservation of the exact epitope specificity present in the original murine antibody was crucial in this case, since the antibody inhibited shedding of the CD30 receptor. The original murine anti Ep-CAM antibody and its derived human counterpart described in chapters 2 and 4 compete for binding to the EpCAM antigen, which indicates that they recognise overlapping, if not identical epitopes on the antigen. In addition, their kinetics of antigen binding are very similar. Interestingly, however, their mode of interaction with the antigen most probably is completely different, as determined by molecular modelling of the antibody combining site. Whether these differences in interaction between the original murine and its derived human antibody and the antigen have any influence on their tumour targeting potential remains to be seen (see below).

Chapter 5 describes one of the few fully human antibodies to the Ep-CAM antigen that recognises an epitope outside of the "cluster 2" epitope [16], which is targeted by most of the murine hybridomas described to date. This antibody was isolated from a large, non-immunised scFy phage antibody repertoire. The targeting of a different epitope on this antigen offers exciting possibilities for the engineering of antibody-based targeting molecules. "Chelating" antibodies [17] may be synthesised that combine specificities for both epitopes on the same antigen in one molecule and the effect of this bivalency on their in vivo targeting potential may be assessed. As has already been shown in literature and is also described in chapter 5 of this thesis, large improvements of the apparent affinities of antibodies may be achieved by increasing their valency through antibody engineering, which may lead to improvements in the in vivobehaviour of the antibody being studied $[7,18]$. We have set out to test the selected anti-Ep-CAM antibody 
for its targeting capacity in an in vivo model for tumour targeting using athymic (nude) mouse xenografted with the human CRC cell line LS174T. However, radio-active labelling of the recombinant scFv with either ${ }^{125} \mathrm{I}$ (targeting tyrosine residues) or ${ }^{99 \mathrm{~m}} \mathrm{Tc}$ using HYNIC (via lysine residues) resulted in a lack of immunoreactivity of the labelled protein. These resuits indicate that direct isotope labelling strategies using genetic tags [9-11] may be necessary to preserve antibody-binding capacity. These and similar studies are in progress and planned. Thus, antibody phage display, together with protein (antibody-) engineering provides an excellent tool for a systematic study of the effect of size, valency, charge and exact epitope specificity on the tumour targeting properties of antibodies. In addition, it permits the generation and subsequent testing of cocktails of antibodies directed to either different epitopes on the same tumour antigen, or directed to different antigens (or even a combination of these), which may lead to important improvements in antibody-based immunotherapy. We envisage that such studies will provide further insight in the many parameters that determine the in vivobehaviour of antibody molecules and will therefore aid in the development of antibody-based targeting molecules and immunotherapeutic strategies.

There is still a lack of understanding of the mode of action of the low affinity anti-EpCAM antibody "Panorex" that has been successfully used in the clinic [19, 20]. In this respect, the recent report of the absence of a correlation between the presence of HAMA and an anti idiotype response in patients treated with Panorex and their clinical response [21] is illustrative. Clinical trials using high affinity antibodies to the Ep-CAM antigen have been aborted because of the toxicity observed in the patients treated [22]. This indicates that high affinity antibodies to the Ep-CAM antigen may not be suitable to directly deliver toxic signals to antigen positive cells. However, their value for the visualisation of antigen-positive metastases [23] is undisputed. An increase of the specificity of the Ep-CAM targeting approach may be achieved by means of adenoviral vectors that deliver toxic genes to the tumour under the control of tumour-specific promotors [24]. Such strategies are expected to markedly increase the therapeutic window of antibodies targeting this antigen.

One aspect of targeting the Ep-CAM antigen that has been given surprisingly little attention until now, is the effect of antibody-targeting on the biological function of the protein. The Ep-CAM antigen has been shown to function as a homophilic cell adhesion molecule [25] and to cross-talk with the cadherin-based intercellular junctions ( [26]; for review, see [27]). However, the signal transduction cascade responsible for this effect has not yet been unravelled. The Trop 2 antigen is encoded by the GA733-I gene, which has probably arisen by retroposition of the GA733-2 gene encoding Ep-CAM [28]. Although this slightly homologous antigen (Trop2 and Ep-CAM share 49\% of amino acid homology [29]) has been shown to influence intracellular calcium levels [30], similar effects for Ep-CAM have not yet been shown. Furthermore, the 
effect of antibody (e.g. Panorex)-binding on the biological properties of Ep-CAM are also unknown. If antibody binding to the antigen would result in an intracellular signalling event that restores the cadherin-based intercellular junctions, this would increase the strength of intercellular contacts and decrease metastasis. Such receptor-modulating or antagonistic antibodies may deliver a signal to the tumour that augments the anti-fumour effect of antibody targeting alone, like is the case for the apoptosis-inducing targeting of the CD20 antigen in nonHodgkin's lymphoma.

The second part of the work involved the identification of possibly novel antigens expressed in CRC using a phage antibody display approach. The idea behind this approach is the following: by using non-immunised phage antibody repertoires or libraries made from patientderived material for the selection of antibodies reactive with colon tumours, antibodies may be identified that discriminate between tumour and non-umour, or between metastasis and primary tumour. Thus, tumour antigens may be identified by means of the antibodies that recognise them. Furthermore, this strategy simultaneously provides fully human antibodies to the respective antigen together with their encoding V-genes, which may form useful building blocks for the engineering and development of antibody-based targeting molecules.

In this respect, several aspects of the technology should be considered. First, the choice of the antigen source used for selection is not obvious and several (dis)advantages are inherent to different formats of "antigen". Two important parameters dictate this choice of antigen source and thereby also of the selection procedure used: On the one hand, the whole selection procedure should be efficient in the selection of binding (specific) phage over non-binding phage; on the other hand, the antigen source used should as closely as possible mimic the in vivo antigen expression profile of the tumour. The model systems that we have set up io study the selection of phage antibodies on such complex antigen mixtures (described in chapter 6 ) show that there are large differences in the efficiency of phage antibody selection on different complex antigen sources. However, the selection protocol giving the highest enrichment of specific over nonspecific phage, i.e. selection on whole, live cells using a CRC cell line, proved not to be optimai with regard to its antigenic expression profile. As shown in chapter 8 , selections on this cell line using a non-immunised phage antibody repertoire also resulted in clones that recognised antigens that were unique to the cell line and that were not expressed in patient-derived tumours. Similar results have been obtained by others in our department with selections on lymphoid celi lines (Petrarca et al., unpublished results). As described in chapter 7, the use of patient-derived tumour material for selection was able to circumvent the selection of antibodies to epitopes unique for a cell line. This method was successful in the selection of antibody clones that react with a broad range of colon tumours and also with other epithelial-derived carcinomas. Two antibodies 
broadly reacted with epithelial-derived tumours and with a restricted set of nomal tissues and one antibody stained stroma and stromal cells in CRC only. Since the latter antibody only reacted with a very restricted panel of norma! tissues, it may be a potential tumour-stroma antigen useful for targeting, analogous to the ED-B domain of fibronectin [31, 32].

In the latter strategy, the retrieval procedure used to isolate tumour cells from patientderived tissue caused modification of cell-surface antigens and this, in turn, caused the selection of antibodies that recognised modified instead of native antigens. Whether the exact epitope recognised by the selected antibodies is composed of a partially unfolded protein, or is formed by a portion of a cell-surface receptor that normally interacts with (an) other protein(s) could not be assessed yet. This lack of immunoreactivity towards the native antigen seriously hampered the characterisation of the selected antibodies and thereby the identification of the target antigens. Whether the target antigens have any value for immunopathological diagnosis of CRC remains to be determined. However, this may be limited because of their expression pattern in normal lissues. It will be interesting to study any possible correlation between different histological parameters of colorectal tumours (grade, stage, differentiation) and the expression pattern of these antigens.

As described in chapter 7 and 8 of this thesis, direct selection of phage antibody libraries on tumour material is not likely to lead to the identification of clones that truly discriminate between CRC and normal colon. To direct the selection more towards tumour-specific epitopes, subtraction and/or depletion strategies should be used to delete cross-reactive clones from the pool of selected phage. We have developed and performed depletion strategies using normal colonic crypts isolated from normal colon epithelium before selecting on patient-derived tumour cells. After three rounds of selection, this resulted in a very different set of selected antibodies compared with selections without depletion, but none of these were reactive in immunohistochemistry on CRC. Since theoretical calculations lead us to believe that subtraction and depletion methods will work most efficiently for antigens that are expressed at high levels, these results indicate that tumour specific epitopes are not likely to be abundant. Even more careful design of such selections using patient material may thus result in the identification of more tumour-specific antigens. In addition, selection and screening of phage antibodies not for binding, but for a differential biological effect on tumour versus normal cells may be an exciting and promising approach in the identification of antibody-based cancer immunotherapeutics. These selection strategies may well require an engineered, multivalent antibody format, since it has been shown that homodimers of whole IgG are far more potent in delivering an apoptosisinducing signal to cells than $\operatorname{IgG}[33]$.

Another aspect of the phage technology crucial for the outcome of selection is the size 
and quality of the phage antibody repertoire and especially the source of V-genes from which the repertoire was made. Chapter 8 shows that the antibody specificities selected from libraries made from different, $\mathrm{CRC}$ patient-derived material were all reactive with allogeneic tumour and were all directed to intracellular antigens. Surprisingly, none of the selected clones recognised an antigen unique to the cell line used for selection. This shows that the B-cells from which the Vgenes used for the construction of the "immune" phage antibody repertoires were derived and therefore the humoral immune response in the patient studied was heavily biased towards intracellular antigens. Although these intracellular targets will not provide new handles for immunotargeting purposes, identification of the antigens may offer insight into the immunogenicity of CRC in the patient studied. Such studies may eventually lead to improvements in the design and generation of tumour vaccines.

Using the phage display technology, the quest for novel tumour antigens remains a laborious and technically challenging task. Recently, different genetic approaches have been described that allow a simultaneous study of the expression of a range of genes [34-38] and thereby also the identification of genes that are associated with malignancy or metastatic spread of cancer. Although the latter will not necessarily identify genes that may be used as target for immunotherapeutic intervention (e.g. cell-surface expressed molecules), the wealth of information becoming available will certainly lead to a better understanding of the genetic changes underlying the basis of malignancy. Since the phage display system is amenable to automation, large numbers of simultaneous selections and high throughput screening of selected populations has become possible. Therefore, we envisage that the phage antibody display procedure will be an invaluable tool in target validation and in "proteomics", the study of protein expression and biological function of the very many unknown genes that are now being identified.

\section{Acknowledgements}

The isotope labelling studies of the VEL-2 scFv were conducted by Dr. O. Boerman and Ing. C. Frielink at the Dept. Nuclear Medicine, University Hospital Nijmegen, Nijmegen, the Netherlands. At this place, I would like to thank them for their collaboration.

\section{References}

1. Smith GP (1985) Filamentous fusion phage: novel expression vectors that display cloned antigens on the virion surface. Science 228: 1315-1317 
2. McCafferty J, Griffiths AD, Winter G, Chiswell DJ (1990) Phage antibodies: filamentous phage displaying antibody variable domains. Nature 348: 552-554

3. Adams GP, Schier R, Marshal! K, Wolf EJ, McCall AM, Marks JD, Weiner LM (1998) Increased affinity leads to improved selective tumor delivery of single-chain Fv antibodies. Cancer Res. 58: 485-490

4. Perisic O, Webb PA, Holliger P, Winter G, Williams RL (1994) Crystal structure of a diabody, a bivalent antibody fragment. Structure 2: 1217-1226

5. Lawrence LJ, Kortt AA, lliades P, Tulloch PA, Hudson PJ (1998) Orientation of antigen binding sites in dimeric and trimeric single chain Fv antibody fragments. FEBS Lett. $\mathbf{4 2 5}$ : $479-484$

6. Davies Q, Perkins AC, Frier M, Watson S, Lalani E, Symonds EM (1997) The effect of circulating antigen on the biodistribution of the engineered human antibody hCTM01 in a nude mice model. Eur. J. Nucl. Med. 24: 206-209

7. Adams GP, MeCartney JE, Tai MS, Oppermann H, Huston JS, Stafford WF 3d, Bookman MA, Fand I, Houston LL, Weiner LM (1993) Highly specific in vivo tumor targeting by monovalent and divalent forms of 74IF8 anti-c-erbB-2 single-chain Fv. Cancer Res. 53: 4026-4034

8. Wu AM, Chen W, Raubitschek A, Williams LE, Neummaier M, Fischer R, Hu S-Z, Odom-Maryon T, Wong JYC, Shively JE (1996) Tumor localization of anti-CEA singlechain Fvs: improved targetting by non-covalent dimers. Immunotechnology 2: 21-36

9. Liberatore M, Neri D, Neri G, Pini A, lurilli AP, Ponzo F, Spampinato G, Padula F, Pala A, Colella A.C (1995) Efficient one-step direct labelling of recombinant antibodies with iechnetium-99m. Eur. J. Nucl. Med. 22: 1326-1329

10. Neri D, Petrul H, Winter G, Light Y, Marais R, Britton KE, Creighton AM (1996) Radioactive labeling of recombinant antibody fragments by phosphorylation using human casein kinase II and [gamma-32P]-ATP. Biotechnology 14: 485-490

11. Waibel R, Alberto R, Willuda J, Finnern R, Schibli R, Stichelberger A, Egli A, Abram U, Mach JP, Pluckthun A, Schubiger PA (1999) Stable one-step technetium-99m labeling of His-tagged recombinant proteins with a novel Tc(1)-carbonyl complex [see comments]. Nat. Biotechnol. 17: 897-901

12. Begent RiHJ, Verhaar MJ, Chester KA, Casey JL, Green AJ, Napier MP, Hope-Stone LD, Cushen N. Keep PA, Johnson CJ, Hawkins RE, Hilson AJW, Robson L (1996) Clinical evidence of efficient tumor targeting based on single-chain Fv antibody selected from a combinatorial library. Nat. Med. 2: 979-984

13. Mayer A, Tsiompanou E, O'Malley D, Boxer GM, Bhatia J, Flynn AA, Chester KA, Davidson BR, Lewis AA, Winslet MC, Dhillon AP, Hilson AJ, Begent RH (2000) Radioimmunoguided surgery in colorectal cancer using a genetically engineered antiCEA single-chain Fv antibody [In Process Citation]. Clin. Cancer Res. 6: 1711-1719

14. Jespers LS, Roberts A, Mahler SM, Winter G, Hoogenboom HR (1994) Guiding the selection of human antibodies from phage display repertoires to a single epitope of an antigen. Biotechnology 12: 899-903

15. Klimka A, Matthey B, Roovers RC, Barth S, Arends JW, Engert A, Hoogenboom HR (2000) Human anti-CD30 recombinant antibodies by guided phage antibody selection using cell panning. Br. J. Cancer 83: 252-260

16. De Leij L. Helfrich W, Stein R, Jules Mattes M (1994) SCLC-cluster-2 antibodies detect 
the pancarcinoma/epithelial glycoprotein EGP-2. Int. J. Cancer Supplement 8: 60-63

17. Neri D, Momo M, Prospero T, Winter G (1995) High-affinity antigen binding by chelating recombinant antibodies (CRAbs). J. Mol. Biol. 246: 367-373

18. Tai MS, MeCartney JE, Adams GP, Jin D, Hudziak RM, Oppermann H, Laminet AA, Bookman MA, Wolf EJ, Liu S, Stafford III WF, Fand I, Houston LL, Weiner LM, Huston JS (1995) Targeting c-erbB-2 expressing tumors using single-chain Fv monomers and dimers. Cancer Res. 55: 5983s-5989s

19. Riethmüller G, Schneider-Gädicke E, Schlimok G, Schmiegel G, Raab R, Höffken K, Gruber R, Pichlmaier H, Hirche H, Pichlmayer R, Buggisch P, Witte J (1994) Randomized trial of monoclonal antibody for adjuvant therapy of resected Dukes' C colorectal carcinoma. The Lancet 343: 1177-1183

20. Riethmüller G, Holz E, Schlimok G, Schmiegel W, Raab R, Hoffken K, Gruber R, Funke I, Pichlmaier H, Hirche H, Buggisch P, Witte J, Pichlmayr R (1998) Monoclonall antibody therapy for resected Dukes' C colorectal cancer: seven-year outcome of a multicenter randomized trial. J. Clin. Oncol. 16: 1788-1794

21. Gruber R, van Haarlem LJ, Warnaar SO, Holz E, Riethmuller G (2000) The human antimouse immunoglobulin response and the anti-idiotypic network have no influence on clinical outcome in patients with minimal residual colorectal cancer treated with monoclonal antibody CO17-IA. Cancer Res. 60: 1921-1926

22. Knox SJ, Goris ML, Tempero M, Weiden. PL, Gentner L, Breitz. H, Adams GP, Axworthy D, Gaffigan S, Bryan K, Fisher DR, Colcher D, Horak ID, Weiner LM (2000) Phase II trial of yttrium-90-DOTA-biotin pretargeted by NR-LU-10 antibody/streptavidin in patients with metastatic colon cancer [In Process Citation]. Clin. Cancer Res. 6: 406414

23. Kosterink JG, de-Jonge MW, Smit EF, Piers DA, Kengen RA, Postmus PE, Shochat D, Groen HJ, The HT, de-Leij L (1995) Pharmacokinetics and scintigraphy of indium-111. DTPA-MOC-31 in small-cell lung carcinoma. J. Nucl. Med. 36: 2356-2362

24. Vile R (2000) Cancer gene therapy-new approaches to tumour cell killing. J. Gene Med. 2: $141-143$

25. Litvinov SV, Velders MP, Bakker HA, Fleuren GJ, Wamaar SO (1994) Ep-CAM: a human epithelial antigen is a homophilic cell-cell adhesion molecule. J. Cell Biol. 125 : $437-446$

26. Litvinov SV, Balzar M, Winter MJ, Bakker HA, Briaire-de Bruijn IH, Prins F, Fleuren GJ, Warnaar SO (1997) Epithelial cell adhesion molecule (Ep-CAM) modulates cell-cell interactions mediated by classic cadherins. J. Cell Biol, 139: 1337-1348

27. Balzar M, Winter MJ, de Boer CJ, Litvinov SV (1999) The biology of the 17-1 A antigen. (Ep-CAM). J. Mol. Med. 77: 699-712

28. Linnenbach AJ, Seng BA, Wu S, Robbins S, Scollon M, Pyrc JJ, Druck T, Huebner K (1993) Retroposition in a family of carcinoma-associated antigen genes. Mol. Cell. Biol. 13: $1507-1515$

29. Linnenbach AJ, Wojcierowski J, Wu SA, Pyrc JJ, Ross AH, Dietzschold B, Speicher D, Koprowski H (1989) Sequence investigation of the major gastrointestinal tumorassociated antigen gene family, GA733. Proc. NatI. Acad. Sci. U. S. A.86: 27-3 I

30. Ripani E, Sacchetti A, Corda D, Alberti S (1998) Human Trop-2 is a tumor-associated calcium signal transducer. Int. J. Cancer 76: 671-676 
31. Carnemolla B, Neri D, Castellani P, Leprini A, Neri G, Pini A, Winter G, Zardi L (1996) Phage antibodies with pan-species recognition of the oncofoetal angiogenesis marker fibronectin ED-B domain. Int. J. Cancer 68: 397-405

32. Neri D, Carnemolla B, Nissim A, Leprini A, Querze G, Balza E, Pini A, Tarli L, Halin C, Neri P, Zardi L, Winter G (1997) Targeting by affinity-matured recombinant antibody fragments of an angiogenesis associated fibronectin isoform. Nat. Biotechnol. 15: 12711275

33. Ghetie MA, Podar EM, Ilgen A, Gordon BE, Uhr JW, Vitetta ES (1997) Homodimerization of tumor-reactive monoclonal antibodies markedly increases their ability to induce growth arrest or apoptosis of tumor cells. Proc. Natl. Acad. Sci. U. S. A 94: 7509-7514

34. Veleulescu VE, Zhang L, Vogelstein B, Kinzler KW (1995) Serial analysis of gene expression. Science 270: 484-487

35. Zhang L, Zhou W, Velculescu VE, Kem SE, Hruban RH, Hamilton SR, Vogelstein B, Kinzler KW (1997) Gene expression profiles in normal and cancer cells. Science 276: 1268.1272

36. Lal A, Lash AE, Altschul SF, Velculescu V, Zhang L, McLendon RE, Marra MA, Prange C, Morin PJ, Polyak K, Papadopoulos N, Vogelstein B, Kinzler KW, Strausberg RL, Riggins GJ (1999) A public database for gene expression in human cancers. Cancer Res. 59: $5403-5407$

37. Hufton SE, Moerkerk PT, Brandwijk R, de Bruïne AP, Arends JW, Hoogenboom HR (1999) A profile of differentially expressed genes in primary colorectal cancer using suppression subtractive hybridization. FEBS Lett. 463: 77-82

38. Yang GP, Ross DT, Kuang WW, Brown PO, Weigel RJ (1999) Combining SSH and cDNA microarrays for rapid identification of differentially expressed genes. Nucleic Acids Res. 27: 1517-1523 


\section{Summary}

The work described in this thesis focuses on two goals in the field of tumour immunology / immunotherapy of human cancer. The selection, engineering and development of antibodies to the known colon tumour antigen Ep-CAM are described in the first chapters and the selection and characterisation of antibodies to possibly novel tumour antigens in the last chapters of this thesis.

Chapter one introduces the concept of tumour targeting and immunotherapy of human cancer using antibodies. Since the idea of the "magic bullet", originally introduced by Paul Ehrlich, immunotherapy of cancer based on antibodies directed to tumour-associated antigens has progressed tremendously. This is evidenced by the recent FDA-approval of several antibodybased drugs for the treatment of e.g. lymphoma and breast carcinoma. This chapter describes the different antibody formats used for tumour targeting, the various strategies that have been used, the various problems associated with these strategies and recent advances made by means of molecular engineering techniques, notably the phage display technology.

Chapter two gives a detailed overview of the phage display technology and its applications. If first describes the basic concept of linking genotype and phenotype of antibodies in a bacteriophage display system. The genes encoding antibodies are cloned into the phage genome as a fusion to one of the coat proteins, thereby providing a means of selecting those genes that code for antibodies with the desired antigen-specificity. The various possible selection strategies are described, as well as the many different screening methods used to identify clones with the desired characteristics.

Chapter three describes a systematic comparison of the antigen-binding kinetics of five different murine whole antibodies directed to the colon tumour associated antigen Ep-CAM and the subsequent cloning of the genes of those antibodies with most favourable kinetics. The genes encoding these antibodies were formatted as single-chain Fv ( $\mathrm{scFv}$ ), expressed in bacteria and further characterised with respect to their specificity and affinity for the Ep-CAM antigen.

Chapter four reviews the design and synthesis of multimeric antibody fragments by shortening the peptide linker between VH and VL in a scFv. By truncating the linker sequence separating VH from VL, intra-chain pairing of the domains is prevented and inter-chain pairing is favoured. This results in bi- tri- and tetravalent antibody fragments, depending on the linker length and orientation of VH and VL in the scFv module. These multivalent fragments have distinct advantages over monovalent scFv molecules in cancer targeting applications.

Chapter five describes the humanisation of the murine anti Ep-CAM antibody of which the cloning is described in chapter one by a procedure termed 'guided selection'. Using a phage display strategy, the genes encoding the VH and VL domains of the murine antibody were. subsequently replaced by libraries of respectively human VH and VL genes. After each round of 'chain shuffling', selection on antigen was used to obtain those human genes that encoded antigen-binding antibodies. The murine antibody and its human equivalent were shown to have 
the same epitope-specificity and comparable antigen-binding kinetics. However, structural modeling revealed that the molecular interactions of both antibodies with the Ep-CAM antigen differed significantly.

Chapter six reports the direct selection of completely human antibodies to the Ep-CAM antigen from a large, non-immunised human phage antibody repertoire. Two antibodies were identified that specifically reacted with recombinant antigen; however, one of the antibodies showed cross-reactivity with antigens expressed in tumour stroma. Using antibody engineering, the Ep-CAM specific antibody was then converted to the so-called 'minibody' format, which is more suitable for in vivotargeting applications. This bivalent antibody consinuct was then shown to have an increased affinity for the antigen, caused by the presence of the two antigen binding sites in the same molecule.

In chapter seven, a model study examining the parameters important for successful phage antibody selection on complex antigens is described. Two phage antibodies, directed to the EpCAM antigen and to the endothelial marker E-selectin, were used in these models. Mixing specific phage with non-specific, non-binding phage that conferred a different antibiotic resistance gene to the bacterial host permitted the calculation of enrichment of specific over nonspecific phage after one round of selection. Selection on a variety of complex antigen sources such as cell-surfaces, tissue cryosections or on in vivo grown solid tumours revealed that there are iremenuous ditierences in seiection efficacy, depending on the selection method used. This study has implications for the design of phage selections on these complex antigen mixtures, notably aimed at the identification of possibly novel antigens expressed on colorectal caner.

Chapter eight reports the selection of antibodies directed to antigens expressed in colorectal carcinoma using a large, non-immunised phage antibody repertoire and patient-derived tumour material as 'antigen'. Three different antibodies were selected that each recognised antigens expressed in a number of colon tumours of different patients. These antigens were expressed in only a limited number of normal, adult tissues and can thus be categorised as tumour-associated antigens.

Chapter nine describes a case study of the humoral immune response in a colorectal cancer patient using a phage display approach. "Immune" phage antibody repertoires were constructed from the lymph nodes draining a colorectal tumour and of the lymphocytes infiltrating that (same) tumour. These repertoires were then compared with a large, nonimmunised repertoire for the selection of antibodies reactive with colorectal tumours. Using a colon cell line as 'antigen', all antibodies selected from the immune repertoires reacted with patient-derived allogeneic tumour material. However, all antibodies reacted with intracellular antigens, whereas selections using the non-immunised repertoire readily yielded antibodies reactive with antigens expressed on the cell surface. Thus, the humoral immune response in the patient studies was heavily biased towards intracellular target antigens.

Chapter ten finally discusses the results obtained in the various studies. 


\section{Samenvatting}

Het onderzock dat beschreven staat in dit proefschrift richt zich op twee doelstellingen binnen het vakgebied tumor-immunologie / immuuntherapic van kanker. De selectic, het 'engineeren' en de ontwikkeling van antistoffen gericht tegen het belende tumor-antigeen EpCAM ('Epithelial cell adhesion molecule") staan beschreven in de eerste hoofdstukken van het proefserif, terwijl de laatste hoofdstukken gericht zijn op de selectie en karakterisatie van antistoffen gericht tegen mogelik nicuwe tumor-antigenen.

Hoofdstuk 1 introduceert het concept van 'Tumor targeting' en immuuntherapie van kanker met behulp var antistoffen. Sinds het idee van de 'magische kogel' werd geintroduceerd door Paul Ehrlich heef immuntherapie van kanker een stomachtige ontwikkeling doorgemaakt. Dit werd recentelik nog onderstreept door de goedkeuring van een aantal antlichaam-gebaseerde drugs voor de behandeling van kanker door de FDA. Dit hoofdstuk beschrijt de verschillende formaten van antistoffen die zijn gebraikt voor fumor-targeting, de verschillende strategiên en de problemen imherent aan deze methoden en de recente vooruitgang die met behulp van moleculaire 'engineering' technicken is geboekt, m.n. door het gebruik van de faag-display technologie.

Hoof̂astuk 2 geeft een gedetailleerd overzicht van de faag-display technologie en van de verschillende toepassingen van de techniek. Het beschrijft eerst het principe van de koppeling van genotype en fenotype van een antistof in een bacteriofaag systeem. De genen die coderen voor antistoffen worden gekloneerd in het genoom van een bacerifaag als fusie aan een van de mantel-eiwitten van de faag. Hierdoor ontstaat de mogelijkheid om die genen te selecteren die coderen voor antistoffen met de gewenste antigeen-specificiteit. De verschillende mogelijke selectie-strategiën worden beschreven, naast het sçala aan scrẹ̦ings-methoden dat wordt gebruikt om clones met de gewenste karakteristieken te identificeren.

Hoofdstuk 3 beschrijft een systematische vergelijking van de antieen-bindings kinetiek van vijf verschillende muize-antistoffen gericht tegen het colon tumor-antigeen Ep-CAM en de klonering van de genen van de antistoffen met beste kinetische eigenschappen. De coderende genen van deze antistofen werden her-formatteerd als enkele-keten antistof-fragmenten (scFv), in bacteriën tot expressie gebracht en verder gekarakteriseerd wat betreft hun specificiteit en affinitiet voor het Ep-CAM antigeen.

Hoofdstuk 4 geeft een overzicht van het ontwerp en de synthese van multimere antistoffragmenten door inkorting van de peptide linker tussen VH en VL in een scFv. Door het verkorten van de linker sequentie die VH en VL van elkaar scheidt wordt intra-moleculaire paring van $\mathrm{VH}$ en VL voorkomen en inter-moleculaire paring bevorderd. Dit resulteert in bi-, trien tetravalente antistof-fragmenten, afhankelijk van de lengte van de linker en de orientatie van $\mathrm{VH}$ en VL in de scFv-cassette. Deze multimere fragmenten hebben verschillende voordelen ten opzichte van monomere fragmenten voor het gebruik in tumor-targeting. 
Hoodstuk 5 beschrijft de humanisering van de muize-antistof gericht tegen het Ep-CAM tumor-antigen waarvan de klonering beschreven staat in hoofdstuk drie met behulp van de 'geleide-selectie' techniek. Met behulp van een faag-display procedure werden de genen die de $\mathrm{VH}$ en VL domeinen van de muize-antistof coderen na elkaar vervangen door een bank van humane VH en VL domeinen respectievelijk. Na iedere ronde van 'keten-verwisseling' werden door middel van selectie op het antigeen die humane genen verkregen die codeerden voor antistoffen die bonden aan het antigeen. Van de originele muize- en afgeleide humane antistof werd aangetoond dat ze dezelfde epitoop-specificteit hadden en een vergelijkbare antigeenbindings kinetiek. Echter, moleculaire model structuur-analyse liet zien dat de moleculaire interacties van beide antistoffen met het Ep-CAM antigeen sterk van elkaar verschilden.

Hoofdstuk 6 beschrijft de directe selectie van compleet humane antistoffen gericht tegen het p-CAM tumor antigeen uit een grote, niet-geïmmuniseerde faag antistof bibliotheek.. Twee antistoffen werden geïdentificeerd die specifiek met het recombinante antigeen reageerden; echter, een van deze antilichamen kruis-reageerde met antigenen die tot expressie kwamen in tumor stroma. Met behulp van antilichaam 'engineering' technieken werd het Ep-CAM specifieke antilichaam omgebouwd tot het zogeheten 'minibody' formaat, dat zeer geschikt is voor gebruik in in vivo toepassingen in tumor-targeting. Van dit bivalent antilichaam construct werd vervolgens aangetoond dat het een verhoogde affiniteit had voor het antigeen, veroorzaakt door de aanwezigheid van twee antigeen bindingsplaatsen in een en hetzelfde molecuul.

In hoofdstuk 7 wordt een model studie beschreven naar de parameters die een succesvolle selectie van faag-antistoffen op complexe antigenen mogelijk maken. Twee faag-antilichamen, gericht tegen het Ep-CAM antigen en tegen de endotheel-cel merker E-selectine, werden gebruikt in deze modellen. Door het mengen van specifieke fagen met niet-specifieke die een andere antibioticum-resistentie aan de bacterie geven was het mogelijk om de verrijking van specifiekeover niet-specifieke fagen te berekenen na een (1) selectie ronde. Selectie op een scala aan comlexe antigenen, zoals de oppervlakte van cellen, vriescoupes van weefsel of in vivo groeiende solide tumoren liet zien dat er grote verschillen bestaan in de selectie efficientie, afhankelijk van de gebruikte selectie methode. Deze stude heeft consequenties voor het ontwerp van faag (antistof-) selecties op deze complexe antigeen-mengsels, met name gericht op de identificatie van mogelijk nieuwe tumor antigenen op colorectaal carcinoom.

Hoofdstuk acht beschrijft de selectie van antistoffen gericht tegen antigenen die tot expressie komen op colorectale tumoren, gebruik makende van een grote, niet-geïmmuniseerde faag antistof bibliotheek en patient-afgeleid tumor materiaal als 'antigeen'. Drie verschillende antistoffen werden geselecteerd die ieder antigenen herkenden die op een scala aan colon tumoren tot expressie kwamen. Van de antigenen, werd aangetoond dat ze selectief in een aantal normale weefsels voorkwamen; deze antigenen kunnen daarom worden gecategoriseerd als 'tumor-geacssocieerd'.

Hoofdstuk negen beschrijft een studie van de humorale immuun respons in een patient 
met colorectaal carcinoom, gebruik makende van de faag-display technologie. 'Geïmmuniseerde' faag antistof banken werden geconstrueerd van de tumor-drainerende lymfeklieren en van de tumor-infiltrerende lymfocyten van de patient. Deze faag bibliotheken werden vervolgens vergeleken met een grote, niet-geïmmuniseerde faag antistof bank met betrekking tot de selectie van antistoffen die reageerden met colon tumoren. Gebruik makende van een colon cel-lijn als 'antigen' bleek dat alle antistoffen die werden geselecteerd uit de geïmmuniseerde bibliotheken reageerden met patient-afgeleid allogeen tumor materiaal. Echter, alle antistofen reageerden met intracellulaire antigenen, terwijl uit de niet-geïmmuniseerde antistof bank gemakkelijk antistoffen geselecteerd konden worden die antigenen herkenden op de oppervlakte van tumor cellen. De humorale imuun respons in de bestudeerde patient was daarom sterk gericht / beperkt naar intracellulaire antigenen.

Hoofdstuk tien, tenslotte, bediscussieert de resultaten die werden verkregen in de verschillende studies. 


\section{Dankwoord}

Het is een van de laatste stukken van je proefschrift die je schrijft, vaak een van de eersten die mensen lezen en misschien wel een van de moeilijkste om te schrijven: het dankwoord. Natuurlijk is het werk dat beschreven staat in dit proefschrift niet het werk van mij alleen geweest, maar van een hele groep mensen. Ook vanzelfsprekend is dat ik op deze plaats niet iedereen die in meer of mindere mate heeft bijgedragen aan dit proefschrift met naam en toenaam kan noemen. Toch wil ook ik de mensen die het nauwst betrokken zijn geweest bij mijn promotie hier bedanken. In de eerste plaats mijn paranimf, collega en mede-werker Edith. Edith: zonder jouw huilp was het nooit zo'n dik boekje geworden!! Bedankt voor je enorme inzet, maar vooral voor je fantastische collegialiteit en vriendschap, die het samenwerken met jou tot een waar genot hebben gemaakt. Dan natuurlijk mijn begeleiders Jan-Willem, Adriaan en Hennie. Jan-Willem, bedankt voor het vertrouwen in die sollicitant uit Frankrijk, voor het mogelijk maken van mijn promotie en voor alle hülp en adviezen bij het schrijven van mijn proefschrift. Grote Adelaar: bedankt voor de aliijd scherpe blik, de vele uren van discussie en het mee-sturen van mijn onderzoek. Jouw bijdrage was ongemerkt altijd groot! Hennie: als directe begeleider (en soms begelijder), mede-auteur en medestander heb ik heel veel van je geleerd. Ik denk met genoegen terug aan onze samenwerking en ben blij dat ik als eerste AiO voor je mocht komen. werken. Bedankt voor al die begeleiding, wijze lessen en discussies, maar ook voor de prettige en gezellige sfeer waarin we het onderzoek hebben verricht. Mijn (ex-)kamergenoten, vrienden en vriendinnen Birgit (Mother), Esther (Hippie), Sigrid (Tetu), Veerlekind (Belg), Solange (uit vroeger tijden), Han (voisami) en Meindert (amice) wil ik bedanken voor alle grappen, grollen, verhalen, sketches en one-man shows die ik heb gegeven (en waar jullie dus mee opgezadeld werden!!) en die ik van jullie heb mogen ontvangen/meemaken. Bedankt voor alle gezelligheid, maar vooral ook voor de steun in moeilijke tijden.... we houden contact! Ook alle andere (ex-) collega's (Mat, Peter, Simon, Alex, Don, Roel, Barry, Paula, Ivo, Patrick, Louise, Riki, Claudia, Nicole, Hans, Anneke, Cor, Corine, Caroline, René, Twan, Anita, Judy, Ricardo, Rob, Henk en. verder iedereen die ik nog vergeten ben), Bianca en Martijn die bij mij stage hebben gelopen en de mensen van de klinische kant van de Pathologie wil ik bedanken voor de fantastische tijd op de afdeling. Otto Boerman en Cathelijne Frielink uit Nimweghen wil ik bedanken voor hun inzet en voor de prettige samenwerking, al wilden de in vivo (muizen-) experimenten helaas niet erg vlotten! Aneta and Pete: thanks for the nice and successful collaboration on the MOC31 work. I'm looking forward to the publication of our paper! Mensen van het secretariaat (i.h.b. Sherlock) en van de afdeling fotografie (Geert-Jan): bedankt voor alle hulp. RPBS: ook al was Bottom er niet vaak bij, hij heeft er altijd van genoten en de avonden waren gedenkwaardig!! Ries: al bende en blijfde unne levensgrote badaap en moette af en toe unne schup onder oew..... krè̀èen, ik ben vereerd een (foute) vriend zoals jij te hebben!! As-ge moar nie als lievehirsbisje komt tèèdens de promotie!! Blonde Hedonis: we zien elkaar veel te weinig! Amo en Marion: hopelijk komt 
er toch ook snel een vervolg op het "vier over de rooie (piste)".... ik zal het zeker missen!! Als laatste, "but by far not the least', wil ik hier mijn ouders bedanken voor alle steun, liefde en het vertrouwen die ze me altijd gegeven hebben. Moeke: samen komen we d'r wel!!! 'S-pap mocht dit helaas niet meer meemaken, maar toch is hij er nog altijd en zal hij er altijd ook bij blijven....... en we hebben elkaar! Ma vieille: het zit er (eindelijk) op..... Na al die jaren apart nu gelukkig eindelijk tijd voor en met elkaar...... ik geniet er iedere dag weer van!! De woorden van Brel zeggen genoeg........

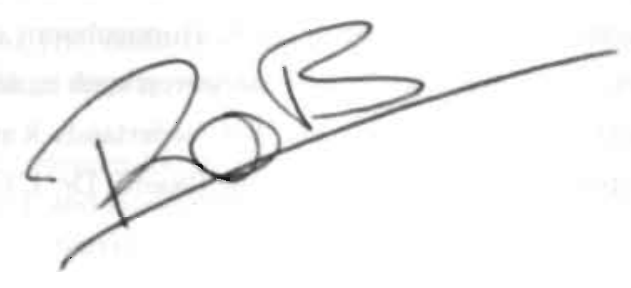




\section{Curriculum Vitae}

De auteur van dit proefschrift werd geboren op 5 september 1971 te Tilburg. Na in 1989 het VWO (gymnasium B) diploma behaald te hebben aan het Mill-Hillcollege te Goirle, werd in datzelfde jaar begonnen aan de studie scheikunde aan de Katholieke Universiteit Nijmegen. In 1991 werd tevens gestart met de studie Frans aan dezelfde universiteit, waarvan het propaedeutisch examen werd behaald in 1992. Na een buitenlandse stage van zeven maanden in Parijs (november 1994 - juni 1995) werd in 1995 het doctoraaldiploma scheikunde behaald. Vanaf juli 1995 tot juli 2000 was de auteur werkzaam als assistent in opleiding ( $\mathrm{AiO}$ ) aan de Universiteit Maastricht, vakgroep Pathologie (hoofd: Prof. dr. J.W. Arends; begeleiders: Dr. Ir. H.R. Hoogenboom en Dr. A.P.de Bruine). Tijdens deze periode werd het onderzoek verricht dat beschreven staat in dit proefsehrift. Vanaf augustus 2000 is de auteur werkzaam als post-doc aan het Nederlands Kanker Instituut (Antoni van Leeuwenhoekhuis te Amsterdam), afdeling Celbiologie (hoofd: Dr. J. Collard). 


\section{List of publications}

Roovers, RC; van der Linden, E; Zijlema, H; de Bruïne, A; Arends, J-W and Hoogenboom, HR (1997) Human phage antibodies to colon tumor antigens from patient-based antibody repertoires. Immunology Letters 56, 191

Helfrich, W; Kroesen, BJ; Roovers, RC; Westers, L; Molema, G; Hoogenboom, HR and de Leij, L (1998): Construction and characterization of a bispecific diabody for retargeting $\mathrm{T}$ cells to human carcinomas. Int. J. Cancer 76(2), 232-239

Hoogenboom, HR; de Bruïne, AP; Hufton, SE; Hoet, RM; Arends, JW and Roovers, RC (1998): Antibody phage display technology and its applications. Immunotechnology4(1), 1-20

Roovers, RC; Henderikx, P; Helfrich, W; van der Linden, E; Reurs, A; de Bruine, AP; Arends, J-W; de Leij, L and Hoogenboom, HR (1998): High-affinity recombinant phage antibodies to the pan-carcinoma marker epithelial glycoprotein-2 for tumour targeting. $\mathrm{Br}$. J. Cancer 78(11), 1407 . 1416

Klimka, A; Barth, S; Matthey, B; Roovers, RC; Lemke, H; Hansen, H; Arends, J-W; Diehl, V; Hoogenboom, HR and Engert, A (1999): An anti-CD30 single-chain Fv selected by phage display ans fused to Pseudomonas exotoxin A (Ki-4(scFv)-ETA') is a potent immunotoxin against a Hodgekin-derived cell line. Br. J. Cancer 80(8), 1214-1222

de Haard, HJ; van Neer, N; Reurs, A; Hufton, SE; Roovers, RC; Henderikx, P; de Bruïne, AP; Arends, J-W and Hoogenboom, HR (1999): A large non-immunized human Fab fragment phage library that permits rapid isolation and kinetic analysis of high affinity antibodies. J. Biol. Chem. 274(26), 18218-18230

Mutuberria, R; Hoogenboom, HR; van der Linden, E; de Bruïne, AP and Roovers, RC (1999): Model systems to study the parameters determining the success of phage antibody selections on complex antigens. J. Immunol. Methods 231 (1-2), 65-81

Beiboer, SHW; Reurs, A; Roovers, RC; Arends, J-W; Whitelegg, NR; Rees, AR and Hoogenboom, HR (2000): Guided Selection of a Pan-Carcinoma Specific Antibody Reveals Similar Binding Characteristics yet Structural Divergence between the original Murine Antibody and its Human Equivalent. J. Mol. Biol. 296 (3), 833-849

Klimka, A: Matthey, B; Roovers, RC; Barth, S; Arends, J-W; Engert, A and Hoogenboom, HR (2000): Human anti-CD30 recombinant antibodies by guided phage antibody selection using cell panning. Br. J. Cancer 83(2), 252-260

Todorovska, A; Roovers, RC; Dolezal, O; Kortt, AA; Hoogenboom, HR and Hudson, PJ (2000): Design and application of Diabodies, Triabodies and Tetrabodies for Cancer Targeting. J. Immunol. Methods in press 
Roovers, RC; van der Linden, E; de Bruïne, AP; Arends, J-W and Hoogenboom, HR (2000): In vitro characterisation of a monovalent and bivalent form of a fully human anti Ep-CAM phage antibody. Cancer Immunol. Immunother, Accepted for publication

Roovers, RC; van der Linden, E; de Bruïne, AP; Arends, J-W and Hoogenboom, HR (2000): Identification of colon tumour-associated antigens by phage antibody selections an primary colorecial carcinoma. Submitted for publication

Roovers, RC; van der Linden, E; Zijlema, H; de Brüne, AP; Arends, J-W and Hoogenboom, HR (2000): Evidence for a bias towards intracellular antigens in the local humoral anti-tumor immune response of a colorectal cancer patient revealed by phage display. Submitted for publication 



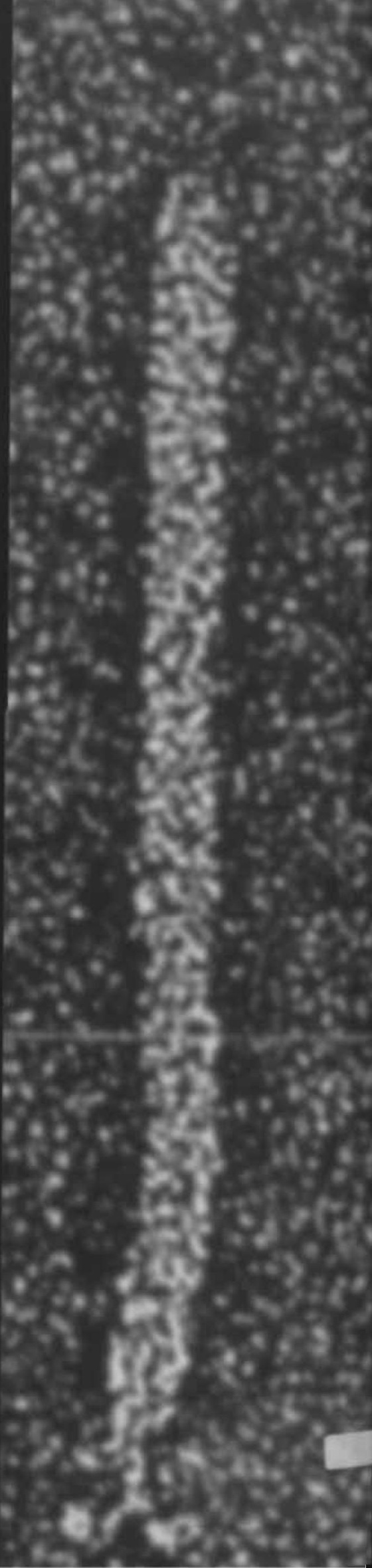

